DOE/ER-0099

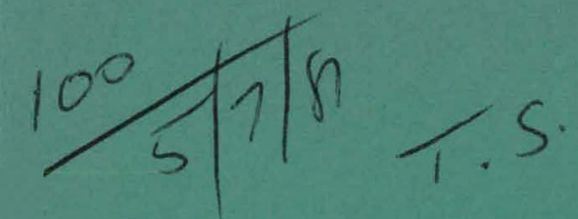

Or. 2611

\title{
An Assessment of the Satellite Power System and Six Alternative Technologies
}

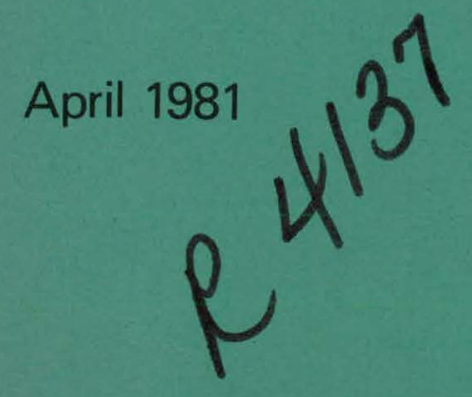

MASTER

Prepared for:

U.S. Department of Energy

Office of Energy Research

Solar Power Satellite Project Division

Under Contract No. 31-109-ENG-38

DOE/NASA

Satellite Power System

Concept Development

and

Evaluation Program 


\section{DISCLAIMER}

This report was prepared as an account of work sponsored by an agency of the United States Government. Neither the United States Government nor any agency Thereof, nor any of their employees, makes any warranty, express or implied, or assumes any legal liability or responsibility for the accuracy, completeness, or usefulness of any information, apparatus, product, or process disclosed, or represents that its use would not infringe privately owned rights. Reference herein to any specific commercial product, process, or service by trade name, trademark, manufacturer, or otherwise does not necessarily constitute or imply its endorsement, recommendation, or favoring by the United States Government or any agency thereof. The views and opinions of authors expressed herein do not necessarily state or reflect those of the United States Government or any agency thereof. 


\section{DISCLAIMER}

Portions of this document may be illegible in electronic image products. Images are produced from the best available original document. 


\section{NOTICE}

This report was prepared as an account of work sponsored by the United States Government. Neither the United States nor the United States Department of Energy, nor any of their employees, makes any warranty, express or implied, or assumes any legal liability or responsibility for the accuracy, completeness, or usefulness of any information, apparatus, product, or process disclosed, or represents that its use would not infringe privately owned rights. Reference herein to any specific commercial product, process, or service by trade name, mark, manufacturer, or otherwise, does not necessarily constitute or imply its endorsement, recommendation, or favoring by the United States Government or any agency thereof. The views and opinions of authors expressed herein do not necessarily state or reflect those of the United States Government or any agency thereof.

Avallable from:

National Technical Information Service (NIIS)

National Tectinical Information

5285 Port Royal Rosd

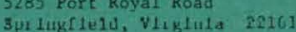

$\begin{array}{lll}\text { Price: } & \text { Printed Copy: } & \$ 18.50 \\ & \text { Microfiche: } & \$ 4.00\end{array}$ 


\section{An Assessment of the Satellite Power System and Six Alternative Technologies}

April 1981

Prepared by:

T. Wolsko, R. Whitfield, M. Samsa, L S. Habegger,

E. Levine and E. Tanzman

Argonne National Laboratory

Argonne, IL 60439

Under Contract No. 31-109-ENG-38

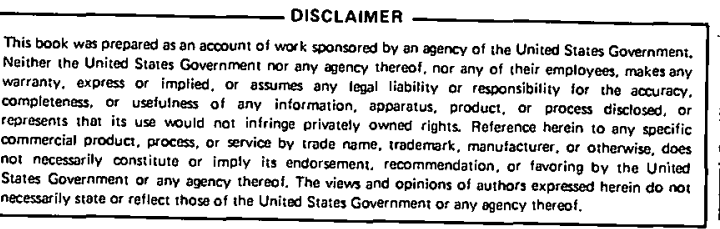

This book was prepared as an account of work sponsored by an agency of the United States Government. .

Prepared for:

U.S. Department of Energy

Office of Energy Research

Solar Power Satellite Project Division

Washington, D.C. 20585

DOE/NASA

Satellite Power System

Concept Development

and

Evaluation Program 


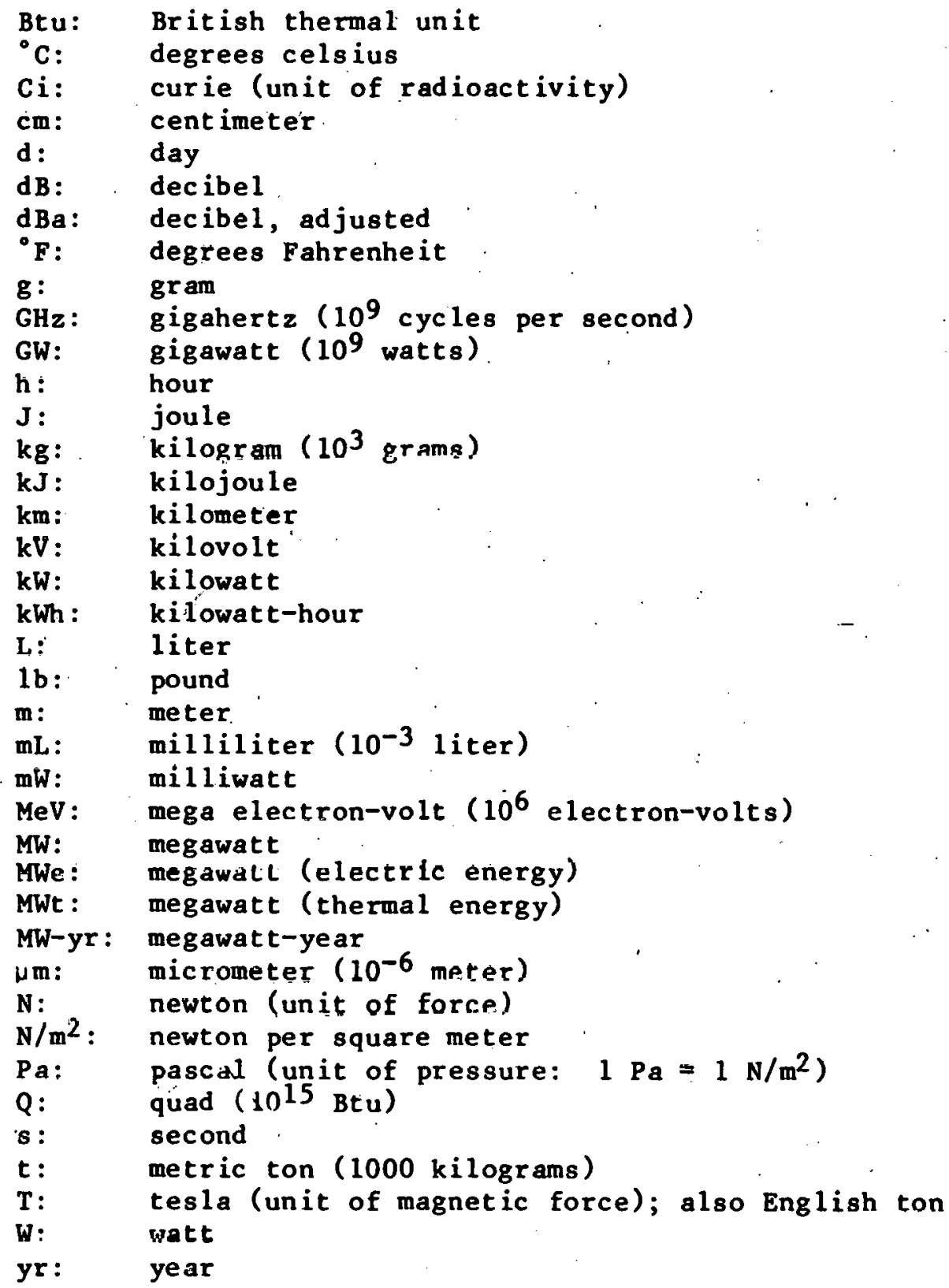


CONTENTS

EXECUTIVE SUMMARY . . . . . . . . . . . . . . . . . . . . . . . $x i$

REFERENCES FOR EXECUTIVE SUMMARY. . . . . . . . . . . . . . . . . . . xXXIV

1 INTRODUCTION . . . . . . . . . . . . . . . . . . . . . . . . . 1

1.1 Background. . . . . . . . . . . . . . . . . . . . . . . . . . 1

1.2 Objective and Approach. . . . . . . . . . . . . . . . . . . . 1

2 ASSESSMENT FRAMEWORK . . . . . . . . . . . . . . . . . . . . . . . . 4

2.1 Overview. . . . . . . . . . . . . . . . . . . . 4

2.2 Comparat ive Issuess. . . . . . . . . . . . . . . . . . . . 4

2.3 Selection of Energy Alternatives. . . . . . . . . . . . . 6

2.4 Characterization of Energy Systems. . . . . . . . . . . . . . . . 7

2.5 Side-by-Side Analysis of Energy Systems . . . . . . . . . . . . . 7

2.6 Alternative Futures Analys is. . . . . . . . . . . . . . . . . 9

2.7 Assessment Integration/Aggregation Techniques . . . . . . . . . . 10

3 ChaRACTERIZATIONS OF THE SPS AND ALTERNATIVE TECHNOLOGIES. . . . . . . 11

3.1 Selection of Alternative Technologies . . . . . . . . . . . . . . 11

3.2 Brief Technical Description of Alternative Generation Systems . . 14

3.2.1 Satellite Power System . . . . . . . . . . . . . . 14

3.2.2 Central-Station Terrestrial Photovoltaic System. . . . . . 21

3.2.3 Conventional Coal-Fired Power Plant. . . . . . . . . . . 22

3.2.4 Coal-Gasification/Combined-Cyc le Power Plant . . . . . . . 26

3.2.5 Light Water Reactor Power Plant. . . . . . . . . . . . . 30

3.2.6 Liquid-Metal, Fast-Breeder Reactor . . . . . . . . . . 32

3.2.7 Fusion . . . . . . . . . . . . . . . . . . 37

3.3 Cost Characterizations. . . . . . . . . . . . . . . . . 41

3.3.1 Satellite Power System . . . . . . . . . . . . . . 42

3.3.2 Conventional Coal-Fired Power Plant with Advanced
Flue Gas Desulfurization ................... 45

3.3.3 Combined-Cycle Power Plant with Low-Btu Gasifiers. . . . . 46

3.3.4 Light Water Reactor. . . . . . . . . . . . . . . . . . 46

3.3.5 Liquid-Metal, Fast-Breeder Reactor . . . . . . . . . . 47

3.3.6 Fusion Reactor . . . . . . . . . . . . . . . . . . . 47

3.3.7 Central-Station Terrestrial Photovoltaic . . . . . . . 48

4 Comparative analysis . . . . . . . . . . . . . . . . . . . . . 49

4.1 Assumptions and Alternative Futures Scenarios . . . . . . . . . 49

4.1.1 Assumptions of the Comparative Analysis. . . . . . . . . 49

4.1.2 Alternative Futures Scenarios. . . . . . . . . . . . . 51

4.2 Cost and Performance. . . . . . . . . . . . . . . . . . 68

4.2.1 Introduction ..................... . . 68

4.2.2 Uncertainty in Capital Cost Ranges for SPS

and Alternatives . . . . . . . . . . . . . . . . 69

4.2.3 Fuel Price Projections . . . . . . . . . . . . . . 72 
CONTENTS (Cont'd)

4.2.4 Cost Comparisons. . . . . . . . . . . . . . . . . . 74

4.2.5 Cost Sensitivity Analysis . . . . . . . . . . . . . 79

4.2.6 Comparative Cost Uncertainty. . . . . . . . . . . 87

4.3 Health and Safety .. . . . . . . . . . . . . . . . . . . . . 94

4.3.1 Introduction. . . . . . . . . . . . . . . . . . 94

4.3.2 Methodology .. . . . . . . . . . . . . . . . 94

4.3.3 Discussion of Results . . . . . . . . . . . . . . 97

4.4 Environmental Welfare Effects . . . . . . . . . . . . . . . 112

4.4.1 Introduction. . . . . . . . . . . . . . . . . 112

$4,4,2$ Comparative Impacts .................... . . 113

4.4.3 Generation of Air Pollution . . . . . . . . . . . . . . 121

4.4.4 Cilmatic Changes Due to Air Pollution. . . . . . . . . . 123

4.4.5 Thermal Discharges and Resulting Climal ic Change. . . . 114

4.4.6 Water Pollution. . . . . . . . . . . . . . . . . 125

4.4.7 : Water Use Changes . . . . . . . . . . . . . . . . 125

4.4.8. Generation of Solid Waste. . . . . . . . . . . . . 126

4.4.9 Land Use Changes. . . . . . . . . . . . . . . . . . 127

4.4.10 Noise Generation. . . . . . . . . . . . . . . . . . . . 127

4.4.11, Electromagnet ic Disturbances. . . . . . . . . . . . . . . 128

4.4.12 Radioactive Emissions . . . . . . . . . . . . . . . . . 128

4.4.13 Microwave Radiation . . . . . . . . . . . . . . . . 129

4.4.14 Aesthetic Disturbances. . . . . . . . . . . . . . . . 129

4.5 Resources . . . . . . . . . . . . . . . . . . . . 129

4.5 .1 Land. . . . . . . . . . . . . . . . . . 130

4.5.2 Materials .................... 137

4.5.3 Energy. . . . . .. . . . . . . . . . . . 137

4.5 .4 Water... . . . . . . . . . . . . . . 142

4.5 .5 Labor . . . . . . . . . . . . . . . . . . 144

4.6 Macroeconomic and Socioeconomic Issues. . . . . . . . . . . . . 146

4.6.1 Introduction. . . . . . . . . . . . . . . . . . 146

4.6.2 Macroeconomic Analysis. . . . . . . . . . ... . 147

4.6.3 Socioeconomic Comparisons . . . . . . . . . . . . . 157

4.7 Institutional Issues. . . . . . . . . . . . . . . . . . 158

4.7.1 Introduction. . . . . . . . . . . . . . . . . . . 158

4.7.2 Snmparison of Preeent Reginintory Scliumus. . . . . . . . 159

4.7.3 Regulatory Trends . . . . . . . . . . . . . 167

4.7.4 Summary ....................... 168

5 ASSESSMENT CONCLUSIONS . . . . . . . . . . . . . . . . . . . 169

5.1 Introduction. . . . . . . . . . . . . . . . . . . . . 169

5.2 Side-by-Side Conclusions. . . . . . . . . . . . . . . . . . 169

5.3 Alternative Futures Conclusions of the Comparative Assessment . . 177

5.4 Concluding Remarks. . . . . . . . . . . . . . . . . . 182

REFERENCES. . . . . . . . . . . . . . . . . . . . . 183 
FIGURES

1 Fuel Price Projections for Different Scenarios. . . . . . . . . . . xviii

2 Development Costs of the SPS. . . . . . . . . . . . . . . . . xix

3 Total Quantified Construction and O\&M Fatalities per 1000 MW-yr . . xx

4 Alternative Futures Analys is of Land Requirements . . . . . . . . . xxii

5 Alternative Futures Analysis of Annual Water Consumption for Baseload Electricity Generation . . . . . . . . . . . . . . . . xxiii

2.1 Analys is Sequence for Comparative Assessment. . . . . . . . . . 5

2.2 Comparative Assessment Classification System. . . . . . . . . . . . 6

3.1 Satellite Power System Concept. . . . . . . . . . . . . . . . . . . 16

3.2 SPS Satellite Configurations. . . . . . . . . . . . . . . 17

3.3 SPS Efficiency Chain, GaAlAs and Si . . . . . . .

3.4 Efficiency Chain of the Central-Station Photovoltaic System . . . . 21

3.5 Generation of $1250 \mathrm{MW}$, High-Sulfur Coal, Wellman-Lord Process . . . 23

3.6 Wellman-Lord Process. . . . . . . . . . . . . . . . . . . 25

3.7 1250-MW Coal-Gasification/Combined-Cycle System . . . . . . . . . 27

3.8 Summary of Emissions from a 1250-MW, Low-Btu Gasifier, Combined-Cyc le Plant. . . . . . . . . . . . . . . . . . . 29

3.9. Simplified LWR Flow Diagram..................... 31

3.10 1250-MW Liquid-Metal, Fast-Breeder Reactor. . . . . . . . . . . 34

3.11 Configurations of Pool- and Loop-type Primary Coolant Systems . . . 35

3.12 Schematic of NUWMAK Fusion Power Plant. . . . . . . . . . . . . . . 38

3.13 Schematic of NUWMAK Load-Leveling System. . . . . . . . . . . . . . 39

3.14 Tritium Effluent System Design. . . . . . . . . . . . . . . . 40

3.15 Development Costs of the SPS. . . . . . . . . . . . . . . . . . . . 43

4.1 U.S. Energy Output Ratios, 1929-1974, and Base Projections to 2025. 52

4.2 Simplified Macroeconomic Model of the Interaction between Energy and the Economy. . . . . . . . . . . . . . . . . . . . . 53

4.3 Ratio of Gross Energy/GNP, in $10^{3} \mathrm{Btu} / 1971$ \$ . . . . . . . . . . . 57

4.4 Supply-Demand Patterns for Various Scenarios in the Year 2000. . . 58

4.5 Supply-Demand Patterns for Various Scenarios in the Year 2025 . . 59

4.6 Electrification as a Percentage of Net Energy Use:

Three Scenarios . . . . . . . . . . . . . . . . . . . . . . 60

4.7 Delivered $0 i 1$ Prices. . . . . . . . . . . . . . . . . . 61

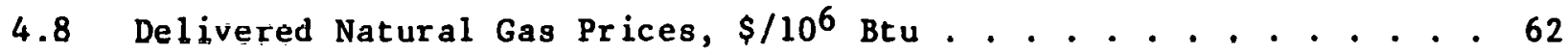

4.9 . Delivered Coal Prices, $\$ / 10^{6}$ Btu. . . . . . . . . . . . . . 63 


\section{FIGURES (Cont'd)}

4.10 Electricity Prices, $\$ / 10^{6}$ Btu . . . . . . . . . . . . . . . . . . . 64

4.11 Cost and Performance Evaluation Framework . . . . . . . . . . . . . 69

4.12 Fuel Price Projections for Different Scenarios. . . . . . . . . . . 76

$4.13 \mathrm{U}_{3} \mathrm{O}_{8}$ Prices for Constrained and Unconstrained Scenarios . . . . . 77

4.14 Typical Patterns of Costs and Revenue Requirements. . . . . . . . 78

4.15 Levelized Energy Cost Ranges for Scenario UH. . . . . . . . . . . . 81

4.16 Levelized Energy Cost Ranges for Scenario UI. . . . . . . . . . . . 82

4.17 Levelized Energy Cost Ranges for Scenario CI. . . . . . . . . . . 83

4.18 Total Fnergy Costs as a Function of Capacily. . . . . . . . . . . . 84

4.19 Effect of Changes in Financial Aseumptions on Relative

4.20 Comparison of Coal and SPS Energy Costs with Fixed
Parameters and Inputs. . . . . . . . . . . . . . . . . . . . . 87

4.21 Coal Prices . . . . . . . . . . . . . . . . . . . . . . . 88

4.22 Real Coal Price Increases... . . . . . . . . . . . . . . . 90

4.23 Distributions of Levelized Fuel Cost and Levelized
Capital Charge of a Coal Plant.

4.24 Typical Cost Distribution for Advanced Technolngies . . . . . . . 91

4.25 Distributions of the Sum of Cost Elements . . . . . . . . . . . . . 92

4.26 Probability Curves of SPS Costs Equalling Coal Costs. . . . . . . 93

4.27 Components of Comprehensive Health and Safety Impact Analysis . . 95

4.28 Procedure for Computation of Occupational Impacts of Direct and Indirect Construction and Component Production. . . . . . . . . 96

4.29 Direct and Indirect Occupational Fatalities from Unit
Facility Component Production . . . . . . . . . . . . . . . . 100

4.30 Total Occupational Fatalities in Construction Phase of
System with 1000 MW Average Generation. . . . . . . . . . . . . . 100

4.31 Total Quantified Construction and O\&M Fatalities per $1000 \mathrm{MW}-\mathrm{yr}$. . 101

4.32 Annual Occupational Fatalities from Construction and O\&M Baseload Scenarios with and without SPS . . . . . . . . . . . . 111

4.33 Pathway of Energy Activities, Impacts, and Effects. . . . . . . . 114

4.34 Land Requirements for Scenario CI, without SPS. . . . . . . . . . . 133

4.35 Land Requirements for Scenario CI, with SPS . . . . . . . . . . . 133

4.36 Land Requirements for Scenario UI, without SPS. . . . . . . . . . . 134

4.37 Land Requirements for Scenario UI, with SPS . . . . . . . . . . . . 134

4.38 Land Requirements for Scenario UH, without SPS. . . . . . . . . . 135 
FIGURES (Cont'd)

4.39 Land Requirements for Scenario UH, with SPS . . . . . . . . . . . 135

4.40 Alternative Futures Analys is of Land Requirements . . . . . . . . . 136

4.41 Schematic of Energy Balance . . . . . . . . . . . . . . . . . 139

4.42 Alternative Futures Analys is of Annual Water Consumption

for Baseload Electricity Generation . . . . . . . . . . . . . . . 143

4.43 O\&M and Fuel Cycle Labor Requirements . . . . . . . . . . . . . . 146

4.44 Coal Demand and Supply, Scenario CI . . . . . . . . . . . . . 150

4.45 Coal Demand and Supply, Scenario UI . . . . . . . . . . . . . . 150

4.46 Coal Demand and Supply, Scenario UH . . . . . . . . . . . . . . 151

4.47 Changes in Annual Energy Expenditures with and without

SPS in 2025, as a Function of SPS Energy Price. . . . . . . . . . . 153

4.48 Changes in Energy Expenditures for 2000-2030. . . . . . . . . . . . 154

\section{TABLES}

1 Developmental Status of the Technologies Selected for Comparison. : xiii

2 Major Characteristics of Alternative Central-Station Technologies . xv

3 . Capital Cost Ranges for Technical and Regulatory Uncertainty. . . . xvii

4 Levelized Energy Cost Ranges for Scenario CI. . . . . . . . . . . . xviii

5. Net Decrease in Annual Energy Expenditures Due to the SPS . . . . . xxiv

6 Cost and Performance: Key Issues, Uncertainties, and

Comparative Conclusions . . . . . . . . . . . . . . . . . xxv

7. Health and Safety: Key Issues, Uncertainties, and

Comparat ive Conclusions . . . . . . . . . . . . . . . . . . . . xxvi

8 Environmental Welfare: Key Issues, Uncertainties, and

Comparative Conclusions . . . . . . . . . . . . . . . . . . . . . xxvii

9 Resources: Key Issues, Uncertainties, and Comparative Conclusions.xxviii

10 Economic/Societal Issues: Key Issues, Uncertainties, and Comparative Conclusions . . . . . . . . . . . . . . . . . . . xxix

11 Institutional Issues: Key Issues, Uncertainties, and Comparative Conclusions . . . . . . . . . . . . . . . . . . . . xxx

12 Energy Supply Options . . . . . . . . . . . . . . . . . . . . . xxxi

13 Evaluation of Energy Supply Options s1-s3 for Demand Scenario UH - Unconstrained, High Demand. . . . . . . . . . . . . . xxxii

14 Evaluation of Energy Supply Options S4-S6 for Demand Scenari, CI - Constrained, Intermediate Demand. . . . . . . . . . .xxxiii

2.1 Candidate Alternative Technologies. . . . . . . . . . . . . 8 
3. 1 Technologies Considered in Initial Screening. . . . . . . . . . . . 12

3.2 Quantitiative Screening of Energy Systems . . . . . . . . . . . . 13

3.3 Characterization Parameters for Plant Site and Fuel Cycle ..... 15

3.4 SPS Cell and Planform Power Characteristics . . . . . . . . . . . . 19

3.5 Air Pollutants from a 1250-MW Coal Facility . . . . . . . . . . . 26

3.6 Solid and Sludge Wastes from a 1250-MW Coal Facility; $70 \%$ Capacity Factor . . . . . . . . . . . . . . . . . . . 26

3.7 Postulated Radionuclide Releases, 1250-MW LMFBR Power Plant at $70 \%$ Capacity Factor. . . . . . . . . . . . . . . . . 36

3.8 LMFBR Wastewater Effluents at Nominal Operation . . . . . . . . 37

3.9 Capital Requirements of the SPS, 1978 Dollars $x 10^{6}$........ . 1,

3.10 Operations and Maintenance Costs of the SPS . . . . . . . . . . . . 45

4.1 RFF Model Assumptions about Population, Labor Force; Productivity and GNP, 1975-2025 . . . . . . . . . . . . . . . . . . 54

4.2 Constrainèd Energy Supplies for Future Scenarios. . . . . . . . . 55

4.3 Assumed Long-Run Costs per Million Btu. . . . . . . . . . . . . . . 56

4.4 Nuclear Fuel Prices for Future Scenarios. . . . . . . . . . . . . 65

4.5 Electrical Generation in Comparative Scenarios and

4.6 Total Installed and New-Construction Baseload Capacity
for Six Comparative Assessment Scenarios. . . . . . . . 66

4.7 Energy System Deployment for Scenario UH with and withnut SPS . . . .66

4.8 Energy System Deployment for Scenario UI with and withnut SPS . . . 67

4.9 Energy System Deployment for Scenario CI with and without SPS . . . 67

4.10 Capital Cost Uncertainty Factors for Alternative Technologies . . . 71

4.i1 Capital Cost Ranges for Technical and Regulatory Uncertainty . . . 73

4.12 Fuel Cost Projections: Delivered Prices for Three Scenarios, 1980 to 2020 . . . . . . . . . . . . . . . . . . . . . 75

4.13 Base Capital Structure and Kconnmic Assumptions. . . . . . . . . . 79

4.14 Levelized 2000-2030 Cost of Electricity from SPS and Alternat ive Technologies. . . . . . . . . . . . . . . . . 80

4.15 Effect of Reduced SPS Implementation Rate on Costs: Nominal Average Unit Costs. . . . . . . . . . . . . . . . . . 85

4.16 Uncertainty Index for Health and Safety Issues. . . . . . . . . . . 97

4.17 Categorization of Health and Safety Issues. . . . . . . . . . . . . 98

4.18 Summary of Quantified Average Fatalities per Year per 1000 MW Generation, 30-Year Plant Lifetime. . . . . . . . . . . . . 99 
4.19 Summary of Health and Safety Issues for Nuclear Fission Reactors. . 102

4.20 Summary of Health and Safety Issues for Combined-Cycle Coal System. 104

4.21 Summary of Health and Safety Issues for Central-Station Terrestrial Photovoltaic Power System . . . . . . . . . . . 105

4.22 Summary of Health and Safety Issues for Satellite Power System. . . 106

4.23 Summary of Health and Safety Issues for the Fusion Power System . . 108

4.24 Summary of Potentially Major but Unquantified Issues. . . . . . . . 110

4.25 Scenario Baseload Capacities and Electrical Generation. . . . . . 112

4.26 Welfare Effects of a Conventional Coal Fuel Cycle . . . . . . . . 115

4.27 Welfare Effects of a Light Water Reactor Fuel Cycle . . . . . . . 116

4.28 Welfare Effects of a Coal-Gasification/Combined-Cycle Fuel Cycle. . 117

4.29 Welfare Effects of a Liquid-Metal, Fast-Breeder Reactor Fuel Cycle. 118

4.30 Welfare Effects of a Terrestrial Photovoltaic Fuel Cycle. . . . . 119

4.31 Welfare Effects of a Satellite Power System Fuel Cycle. . . . . . 120

4.32 Welfare Effects of a Fusion Fuel Cycle. . . . . . . . . . . . . 121

4.33 Potential Severity of and Status of knowledge about Key Environmental Welfare Issues. . . . . . . . . . . . . . . . . 122

4.34 Side-by-Side Comparative Assessments: Resources. . . . . . . . . 131

4.35 Land Requirements, by Technology, in $\mathrm{km}^{2}$ per GW of Installed Capacity. . . . . . . . . . . . . . . . . . . . . 132

4.36 Land Requirements per Unit Energy Output. . . . . . . . . . . . . . 132

4.37 Potential Materials Problems, by Technology, for Three Screening Criteria. . . . . . . . . . . . . . . . . 138

4.38 Summary of Energy Balance Data. . . . . . . . . . . . . . . . . 141

4.39 Water Consumption Data for Energy Systems, $10^{6} \mathrm{~m}^{3} / \mathrm{GW} / \mathrm{yr}$. . . . . 143

4.40 Labor Requirements for Specific Plant Designs . . . . . . . . . . . 145

4.41 Normalized Labor Requirements . . . . . . . . . . . . . . . . 145

4.42 Baseline Energy/Economic Data . . . . . . . . . . . . . . . . . . 149

4.43 Energy Use and Prices for 2025 without SPS. . . . . . . . . . . . 149

4.44 Baseload and SPS Deployment Data. . . . . . . . . . . . . . 151

4.45 Energy Use and Prices for 2025 with SPS Deployment at $60 \mathrm{mills} / \mathrm{kWh} .152$

4.46 Energy Expenditures with SPS at $60 \mathrm{mills} / \mathrm{kWh}$ and without SPS for the Year 2025 . . . . . . . . . . . . . . . . . . 152

4.47 Energy Technology Labor Requirements. . . . . . . . . . . . . . . 157

4.48 Justifications fur Regulating Coal Technologics at Each Level of Government . . . . . . . . . . . . . . . . . . 161 
TABLES (Cont'd)

4.49. Justifications for Regulating Light Water or Breeder

Reactors at Each Level of Government. . . . . . . . . . . . . . . . 162

4.. 50 Justifications for Regulating Terrestrial Photovoltaics at Each Level of Government . . . . . . . . . . . . . . . . . . 163

4.51 Justifications for Regulating SPS at Each Level of Government . . 164

4.52 Comparative Cost Estimates for Federal Regulations of Coal and Light Water Reactor Electricity Production Systems. . . . . . . 166

5.1 Cost and Performance: Key Issues, Uncertainties, and Comparative Cunclusions . . . . . . . . . . . . . . . . 170

5.2 Health and Safety: Key Issues, Uncertainties, and Comparat ive Conclusions . . . . . . . . . . . . . . . . 171

5.3 Environmental Welfare: Key Issues, Uncertainties, and Comparat ive Conclusions . . . . . . . . . . . . . . . . . 172

5.4 Resources: Key Issues, Uncertainties, and Comparative Conclusions. 173

5.5 Economic/Societal Issues: Key Issues, Uncertainties, and Comparative Conclusions . . . . . . . . . . . . . . . . . . . . . . 174

5.6 Institutional Issues: Key Issues, Uncertainties, and Comparat ive Conclusions . . . . . . . . . . . . . . . . 175

5.7 Energy Supply options . . . . . . . . . . . . . . . . . . 179

5.8 Evaluation of Energy Supply. Options S1-S3 for Demand Scenario UH - Unconstrained, High Demand. . . . . . . . . . . . . . 180

5.9 Evaluation of Energy Supply. Options S4-S6 for Demand Scenario CI - Constrained, Intermediate Demand . . . . . . . . . . . 181 
The SPS Concept Development and Evaluation Program (CDEP) ${ }^{1}$ was estab1 ished by the Department of Energy (DOE) and the National Aeronautics and Space Administration (NASA) to generate information by which a rational decision could be made regarding the direction of the Satellite Power System (SPS) program after fiscal 1980. The four functional areas within the joint DOE/NASA CDEP are as follows :

- Systems Definition: development of the SPS reference system design.

- Environmental Assessment: evaluation of potential environmental effects of SPS.

- Societal Assessment: evaluation of potential societal effects of SPS.

- Comparative Assessment: development of a comparative data base on the SPS and $s$ ix other energy technologies.

The results of the first three activities are inputs to the comparative assessment process as well as independent program assessments.

This report concerns the comparative assessment portion of the CDEP. The objective of the comparative assessment is to develop an initial understanding of the SPS with respect to a limited set of energy alternatives. This is consistent with the overall CDEP objective, that is, to determine whether or not the SPS concept is sufficiently attractive (presenting no insurmountable barriers) to receive further research investment.

In all comparative assessments it is vital that the assumptions, uncertainties, and significant differences between the systems being compared are clearly and objectively presented. Otherwise, the comparison may prove useless for making meaningful decisions. The key assumptions and ground rules made in this report are as follows:

1. The baseload electric generation technologies are projected to be on 1 ine in the year 2000, with an approximate availability date of 1990 . Further, the R\&D base and the infrastructure are assumed to be in place when required.

2. All data are traceable to publicly available information.

3. Each Lechuology is treated as an indcpendent variable. For example, if coal costs go up or down, the costs of Lhe ither technologies arc aooumed not to change for the same reasons.

4. When no historical data or basic reports were available, the analysts have specified the conditions they have chosen and presented their rationales for doing so. In cases where the chosen conditions have favored or disfavored a technology, the analysts have stated the bias. 
The SPS, fusion, and central-station terrestrial photovoltaics technologies have received less engineering design and $R \& D$ than the other technologies examined in this assessment. Therefore, they are subject to larger uncertainty as well as greater optimism. Furthermore, the life cycle costs of these three technologies are reduced, since the R\&D and infrastructure costs are not addressed explicitly, in keeping with the second part of the first as sumption.

The third assumption tends to exaggerate cost overlap, but taking correlated characteristics into account was not feasible in this study except in a theoretical way. The choices made under the fourth assumption tend to favor the two solar technologies and fusion.

The intent of the data derived under these assumptions is to compare SPS to each of the other six technologies, or to subsets of the six, or to all six technologies together. The limitations resulting from the assumptions preclude other comparisons. Within these assumptions and ground rules, the six limited but representative energy technologies were sclected, characterized, and documented. I'hese data were normalized to unit bases, such as dollars per megawatt or environmental residuals per megawatt, and alternative futures were compared (i.e., possible technology mixes, supply and demand cases, and resultant environmental, resource,.. and cost uncertainties).

The technology alternatives selected for comparison with the SPS were limited to the following:

- Improved conventional coal technology

- Light water reactor (LWR)

- Coal gasification/combined cycle (CG/CC)

- Liquid-metal, fast-breeder reactor (LMFBR)

- Central station, terrestrial photovoltaic (TPV)

- Fusion (magnetically confined)

These selections were considered to be the most representative set of year2000 energy technologies for comparison to the SPS reference system. It should be noted that the selections were not made by DOE, but by the Concept Development and Evaluation Program.

A six-step comparative methodology is described briefly in this report and more thoroughly in a companion report. 2 This assessment included only five of the six steps (i.e., selection of alternatives, issue selection, system characterizations, side-by-side analysis, and alternative futures analys is).

This assessment represents an update of the preliminary side-by-side comparative assessment ${ }^{3}$ and has added an alternative futures analysis. The update includes changes in the technology descriptions as well as improvements in the comparative analyses.

Included in this document are a brief description of the comparative methodology, brief characterizations of the alternative technologies, 
side-by-side comparisons in selected issue areas, alternative futures analysis for three different scenarios and most issues, and conclusions on the comparative viability of the SPS technology.

The issue areas used for comparisons were (1) cost and performance, (2) health and safety, (3) environmental welfare, (4) resources, (5) macroeconomic and socioeconomic, and (6) institutional. The comparisons were performed for technologies that are at different stages of development -current, near-term, and advanced -- and which therefore have different degrees of information available (e.g., actual vs. projected construction data). Table 1 lists experience and uncertainty levels for the technologies evaluated in this assessment. Capital cost uncertainty factors and cost uncertainty issues are also listed. These cost uncertainty factors were developed on the basis of existing relevant documentation and on the judgments of the assessment participants.

As stated earlier, the information presented and developed in these comparisons has been derived from published research and information found in the literature for the various technologies. However, in some instances, data have not been available from such sources, and it has been necessary to develop these data either through analysis or on the basis of engineering judgment. In these instances, the rationales are explained and the inherent uncertainties duly noted.

Table 1 Developmental Status of the Technologies Selected for Comparison

\begin{tabular}{|c|c|c|c|}
\hline Technology & $\begin{array}{c}\text { Units } \\
\text { in } \\
\text { Operation }\end{array}$ & $\begin{array}{c}\text { Capital Cost } \\
\text { Uncertainty } \\
\text { Rating }\end{array}$ & $\begin{array}{c}\text { Cost } \\
\text { Uncertainty } \\
\text { Issues }\end{array}$ \\
\hline $\begin{array}{l}\text { Conventional } \\
\text { Coal }\end{array}$ & 100 & 2 & Fuel, $\mathrm{ECT}^{\mathrm{a}}$ \\
\hline LWR & 50 & 2 & Fue 1, ECT \\
\hline $\mathrm{CG} / \mathrm{CC}$ & 5 & 3 & Fue 1 \\
\hline LMFBR & 5 & 3 & Fue 1, ECT \\
\hline TPV & 0 & 4 & $\begin{array}{l}\text { Materials, cell } \\
\text { efficiency }\end{array}$ \\
\hline SPS & 0 & $4-5$ & $\begin{array}{l}\text { Materials, ECT, } \\
\text { Space Transport, } \\
\text { and Construction } \\
\text { O\&M }\end{array}$ \\
\hline Fusion & 0 & $4-5$ & $\begin{array}{l}\text { Materials, Con- } \\
\text { tainment Design, } \\
\text { ECT }\end{array}$ \\
\hline
\end{tabular}

afC.T - Environmental Control Technology. 
Cost and performance characterization data for the alternative technologies are presented briefly in Sec. 3 and form the basis for the comparisons that are reported in Sec. 4. Cost data for the SPS were obtained from NASA-sponsored Boeing and Rockwell systems design efforts. Cost estimates for the alternative technologies were developed from reference design reports.

\section{ALTERNATIVE TECHNOLOGY CHARACTERIZATIONS}

Six alternative technologies were selected for comparison with the SPS; their major characteristics are displayed in Table 2. The general approach was to review a broad segment of the recent technical literature concerned with the characteristics of the individual technologies and their accompanying fuel cycles. This data base of information was then synthesized into the alternative technology reference characterizations by adapting the data inco internally consistent energy and materials balances for each of the systems. Where appropriate, a nominal generating capacity nf 1250 MWe was selected for the reference technologies. Only the terrestrial photovoltaic and fusion systems differ from this nominal capacity due to special considerations unique to each system.

An integral part of the energy and materials balances was the determination of natural resource requirements such as land, water, fuels, and other raw materials, and the determination of environmental residuals including air-borne emissions, liquid effluents, and solid and radioactive wastes. These parameters have been estimated for the main plant site and for major elements of the respective fuel cycles.

The final step in the characterization procedure was to estimate the capital construction costs, labor requirements, and annual nonfuel operation and maintenance (O\&M) costs for each alternative reference system. Detailed lists of equipment, materials, and site labor requirements from the Energy Economic Data Base (EEDB) and other major references were used as the basis for estimating the direct and indirect capital construction costs and construction labor requirements for many of the systems. For technologies not included in the EEDB, similar data from other major references was used. All costs are presented in 1978 dollars.

Direct capital costs include the costs of all materials, components, structures, and direct labor necessary for construction of the reference facility at the plant site. Indirect costs include temporary site construction facilities, payroll insurance and taxes, and othcr conatruction serviceo. Excluded are items sensitive to the particular policies of individual utilities, including owner's costs, fees and permits, interest on construction funds, contingency funds, and price escalation during construction.

Nonfuel O\&M costs were derived on the basis of labur requirements, disposal and materials handling costs, and other factors applicable to the respective technologies. Decommissioning costs for each of the nuclear systems are also included. Fuel costs for each of the systems are scenariodependent and will be estimated as part of the subsequent cost and performance analys is. 
Table 2 Major Characteristics of Alternative Central station Technologies*

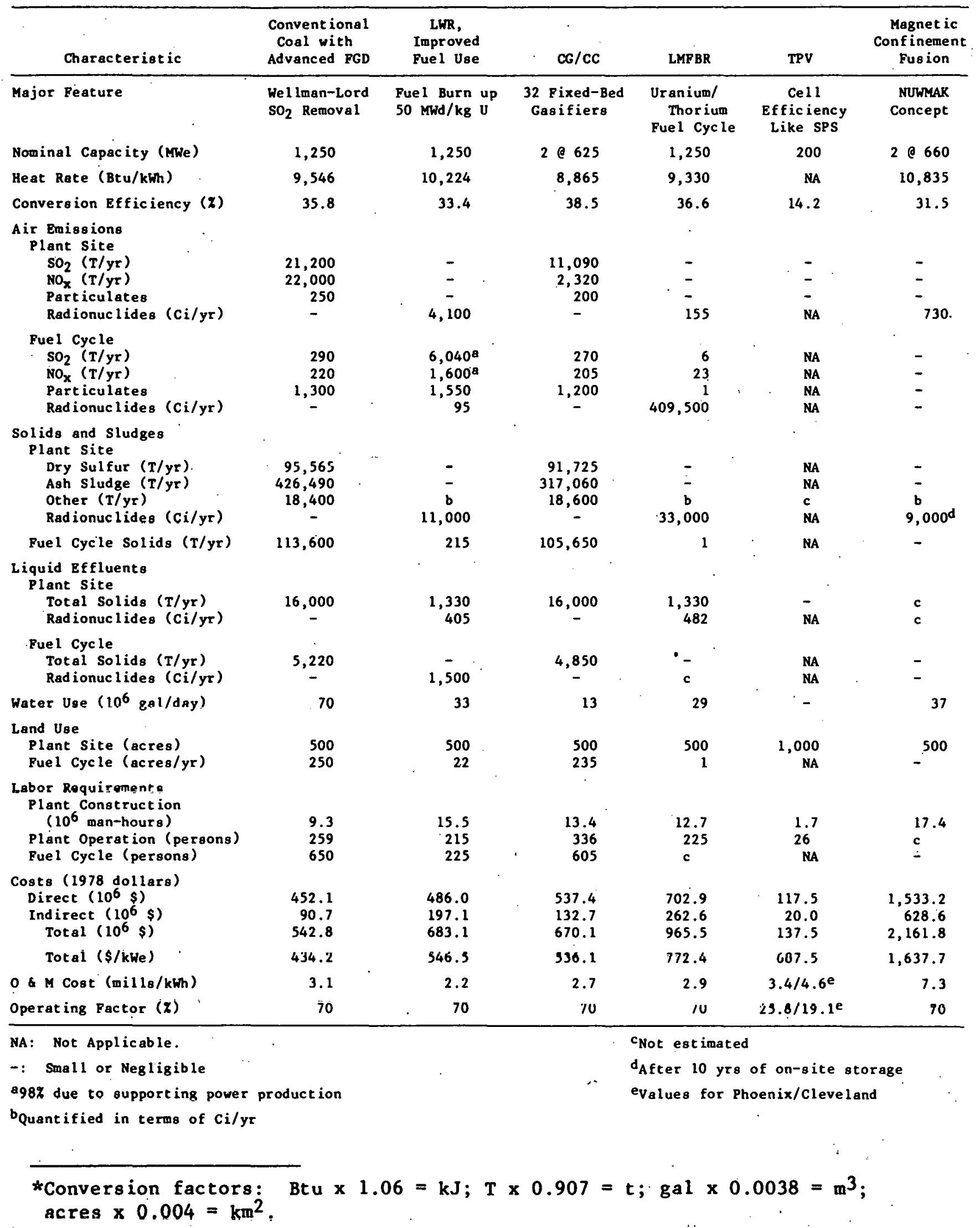




\section{ALTERNATIVE FUTURES SCENARIOS}

Since the objective of this comparative assessment is to compare technologies projected for the post-2000 era, a great number of assumptions are required. Most of these assumptions are highly uncertain and interdependent so that a single consistent set may not present the decision maker with an adequate comparative perspective of the future. The alternative futur"s analys is was chosen as a means of providing a broader perspective of key pameters that may describe the future. The assumptions underlying the alternative futures analysis constitute a set of energy supply/demand futures or scenarios.

Six scenarios were created from a consistent economic model so that interdependencies between económic assumptions were preserved. Scenarios, were selected as a means of exploring and analyzing, not predicting, the economic energy future. The scenarios were selected to represent a plausible future world, and no probabilities were assigned to any of them. Scenarios were selected to provide a comparative perspective on the ncgative and positive aspects of demand and mixes of supply technologies in the post-2000 era.

A model developed by Resources for the Future, Inc. (RFF) 4 was selected for this assessment on the basis of several selection criteria -- sectoral detail, endogenous treatment of both capital investment and final demand, and transferable experience in the form of existing model runs covering the desired time frame, 2000-2030.

One GNP trajectory was selected for all scenarios. For simplicity, three alternative price elasticities of aggregate demand for energy were considered, viz.,

H: High energy intensiveness, corresponding to low ejasticity $(-0.25)$;

I: Intermediate energy intonsivenoco, corrcaponding to intermediate elasticity $(-0.4$ for residential and housing demand, -0.7 for industry, 0 for feedstocks);

$\mathrm{L}$ : Low energy intensiveness, corresponding to high elasticity $(-0.75)$.

Regarding constraints, two cases were selected:

$\mathrm{U}$ : Unconstrained supply of coal and nuclear power;

G: Constrainet supply, due to hoalth, safety, environmental, and other limitations on the rate of supply increase.

The three price elasticities and two different constraints resulted in the development of six scenarios. Each of these scenarios resulted in different supply-demand patterns and different fuel (i.e., coal and nuclear) price trajectories. Three of these six scenarios [i.e., unconstrained high energy (UH), unconstrained intermediate energy intensity (UI), and constrained intermediate energy intensity (CI)] were selected for the alternative futures comparisons. 


\section{COST AND PERFORMANCE}

Table 3 shows the nominal capital costs and capital cost uncertainty factors that were developed for the SPS and the six alternative technologies. The following three factors were considered to include the major capital cost uncertainties and were used to derive the capital cost uncertainty ratios shown in Table 3 .

1. Uncertainty about future costs of materials, supplies, and labor necessary to construct powerplant facilities;

2. Uncertainty about the future requirements and associated costs of environmental and safety equipment; and

3. Uncertainty about the capability of technologies to perform as conceptualized.

The analysis of the alternative energy supply/demand scenarios resulted in the range of fuel prices shown in Fig. 1. The range of coal prices seems to bracket forecasts made by others, and the light water reactor fuel price is similar to that in other projections.

The capital cost ranges and scenario-dependent fuel prices were used to calculate levelized energy cost ranges for each technology. Table 4 shows the levelized energy cost ranges for the SPS and the six alternatives for scenario CI (constrained coal and nuclear, intermediate energy demand). Similar energy cost ranges were calculated for other scenarios with similar cost ranges. These cost ranges were developed with independent reference costs so that the degree of overlap between coal and nuclear technologies and the SPS systems is not as large as shown in Table 4, because there is probably some correlation between the SPS cost base and coal/nuclear data bases that are not accounted for in these calculations.

Table 3 Capital Cost Ranges for Technical and Regulatory. Uncertainty $(\$ / \mathrm{kW})$

\begin{tabular}{|c|c|c|c|c|c|c|c|}
\hline Costs & Coal & LWR & $\mathrm{CG} / \mathrm{CC}$ & LMFBR & TPV & Fusion & SPS \\
\hline 1978 Costs (Nominal) & 549 & 712 & 690 & 1037 & 844 & 2378 & $3340 / 3079$ \\
\hline \multicolumn{8}{|l|}{2000 Costs } \\
\hline $\begin{array}{l}\text { Low } \\
\text { Nominal } \\
\text { High }\end{array}$ & $\begin{array}{r}647 \\
762 \\
1605\end{array}$ & $\begin{array}{r}886 \\
1100 \\
2566\end{array}$ & $\begin{array}{r}813 \\
957 \\
2623\end{array}$ & $\begin{array}{l}1291 \\
1603 \\
5048\end{array}$ & $\begin{array}{r}731 \\
1057 \\
4229\end{array}$ & $\begin{array}{c}2378 \\
3677 \\
?\end{array}$ & $\begin{array}{c}3139 / 287.4 \\
3646 / 3362 \\
16,698 / \\
15,398\end{array}$ \\
\hline \multicolumn{8}{|l|}{ Cost Ratios: } \\
\hline $\begin{array}{l}2000 \text { Low } / 1978 \text { Nominal } \\
2000 \mathrm{Nominal} / 2000 \text { Low } \\
2000 \mathrm{High} / 2000 \text { Nominal }\end{array}$ & $\begin{array}{l}1.18 \\
1.18 \\
2.11\end{array}$ & $\begin{array}{l}1.24 \\
1.24 \\
2.33\end{array}$ & $\begin{array}{l}1.18 \\
1.18 \\
2.74\end{array}$ & $\begin{array}{l}1.24 \\
1.25 \\
3.14\end{array}$ & $\begin{array}{l}0.87 \\
1.45 \\
4.00\end{array}$ & $\begin{array}{c}1.00 \\
1.55 \\
?\end{array}$ & $\begin{array}{l}0.94 / 0.94 \\
1.16 / 1.16 \\
4.58 / 4.58\end{array}$ \\
\hline
\end{tabular}


Table 4 Levelized Energy Cost Ranges for Scenario $\mathrm{CI}^{\mathrm{a}}$

\begin{tabular}{|c|c|c|c|}
\hline \multirow[b]{2}{*}{ Technology } & \multicolumn{3}{|c|}{ Cost, (1978) mills $/ \mathrm{kWh}$} \\
\hline & Low & Nominal & High \\
\hline SPS & & & \\
\hline $\begin{array}{l}\text { Si } \\
\text { GaAlAs }\end{array}$ & $\begin{array}{l}45: 6 \\
42.3\end{array}$ & $\begin{array}{l}52.1 \\
48.5\end{array}$ & $\begin{array}{l}218.1 \\
201.7\end{array}$ \\
\hline $\begin{array}{l}\text { Coal } \\
\text { Conventional, High-S } \\
\text { CG/CC }\end{array}$ & - & $\therefore \quad \begin{array}{r}41.1 \\
\therefore \quad 42.0\end{array}$ & $\begin{array}{l}54.8 \\
69.0\end{array}$ \\
\hline $\begin{array}{l}\text { Nuc lear } \\
\text { LWR } \\
\text { LMFBR }\end{array}$ & - & $\begin{array}{r}30,0 \\
35,1\end{array}$ & $\begin{array}{l}53.8 \\
90.9\end{array}$ \\
\hline TPV & 36.6 & 51.4 & $\cdot 195.7$ \\
\hline Fusion (NUWMAK)b & - & 74.0 & - \\
\hline
\end{tabular}

${ }^{\text {Th }}$ is constrained scenario represents continuation and augmentation of current regulatory trends concerning emissions, health, and safety. The price elasticity of energy demand is assumed to be moderate (intermediate), which is considered the most likely situation if constraints are maintained.

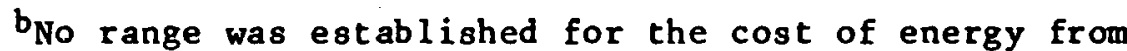
fusinn.

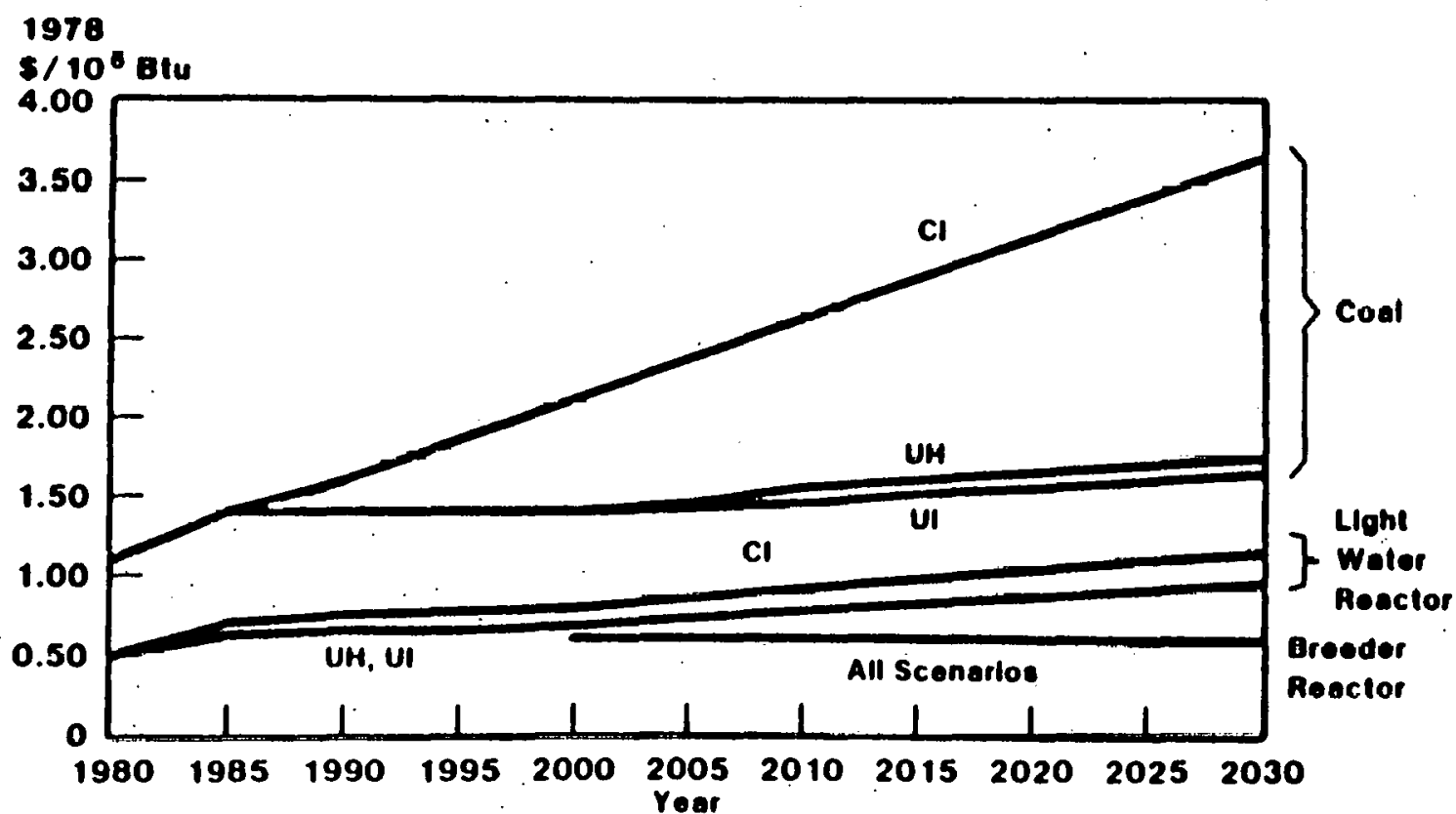

Fig. 1 Fuel Price Projections for Different Scenarios 


\section{DEVELOPMENT COSTS}

Boeing ${ }^{5}$ estimated development costs on the basis of the reference system scenario, which predicates a 20-year development schedule and a 30-year deployment schedule (for 60 5-GW satellites). These costs amount to $\$ 100-110$ billion and are broken down as follows (Fig. 2):

- Research costs: mainly ground-based research to address environmental and social issues and alternative systems, resulting in a preferred system;

- Engineering: development and testing of prototype subsystems, resulting in specifications for demonstration units and production facilities;

- Demonstration: flight tests of a 100-200 MW unit integrated with a comercial network;

- Investment: development of industrial infrastructure, e.g., transportation, photovoltaic, and klystron manufacturing facilities.

- Construction and implementation: the first 5-GW SPS unit put into place.

It is important to note that these cost estimates assume that all effort is specific to the SPS. The benefits from generic research or from cost sharing (e.g., industry or other federal program support for photovoltaics manufacturing facilities) have not been considered. Such cost modifications could amount to $50-70 \%$ of the $\$ 102.5$ billion.?

Since comparable cost data for the other six technologies were not available, side-by-side comparisons of costs or of the benefits or disadvantages of public expenditures were not attempted.

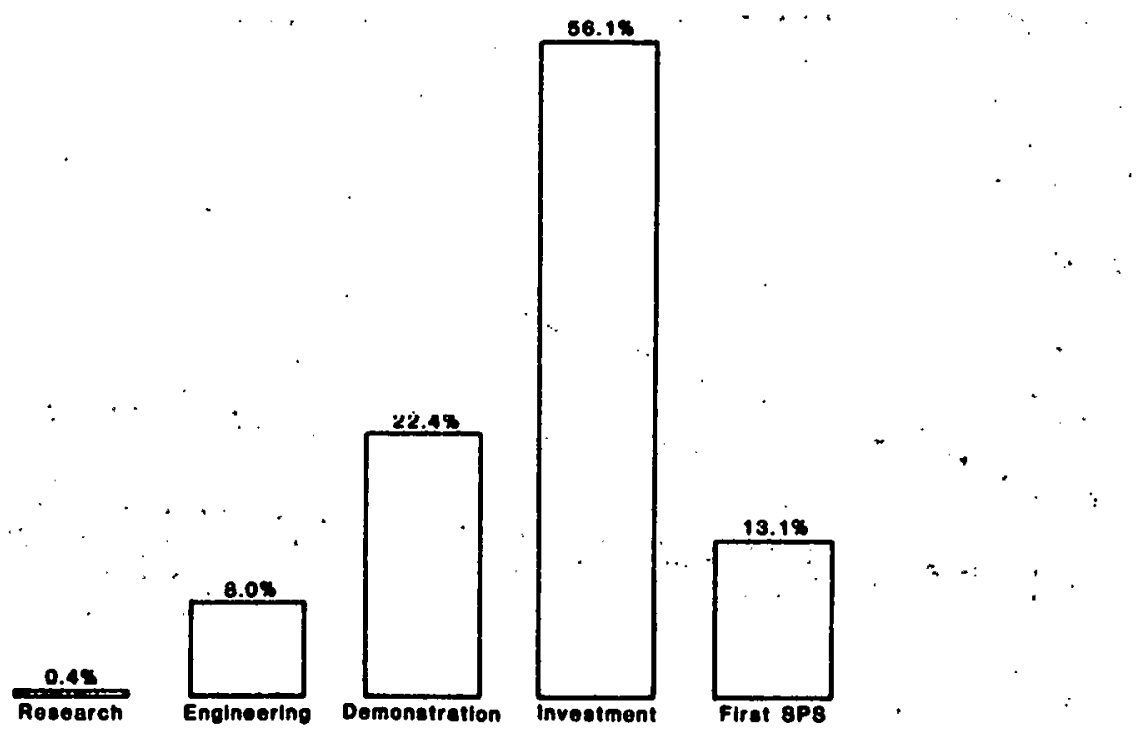

Fig. 2 Development Costs of the SPS

(Source: Ref. 6) 
The comparison of health and safety aspects of advanced and current technologies is not possible on the basis of total quantified $r$ isk because of the uncertainties and unquantifiable impacts for all the technologies, even current coal and nuclear technologies. The health and safety issues can best be summarized as follows:

- All the technologies will have distinct health and safety impacts.

- It is difficult to quantify and assess the low-level and delayed impacts of all the technologies.

Assessing the health and safety risks required three major tasks: detailed characterization of each phase of the fuel cycle; analysis of the magnitude of risk associated with each identified issue; and accumulation of risks by technology, risk category, and generation scenario. Each segment of the energy cycle was considered, including component fabrication, plant construction, fuel extraction and processing, operation and maintenance, and waste disposal. In addition, an uncertainty index was assigned to each issue to reflect the uncertainty in the magnitude of the impact. Figure 3 shows the total quantified construction and O\&M fatalities per MW/yr for SPS and five alternative technologies.

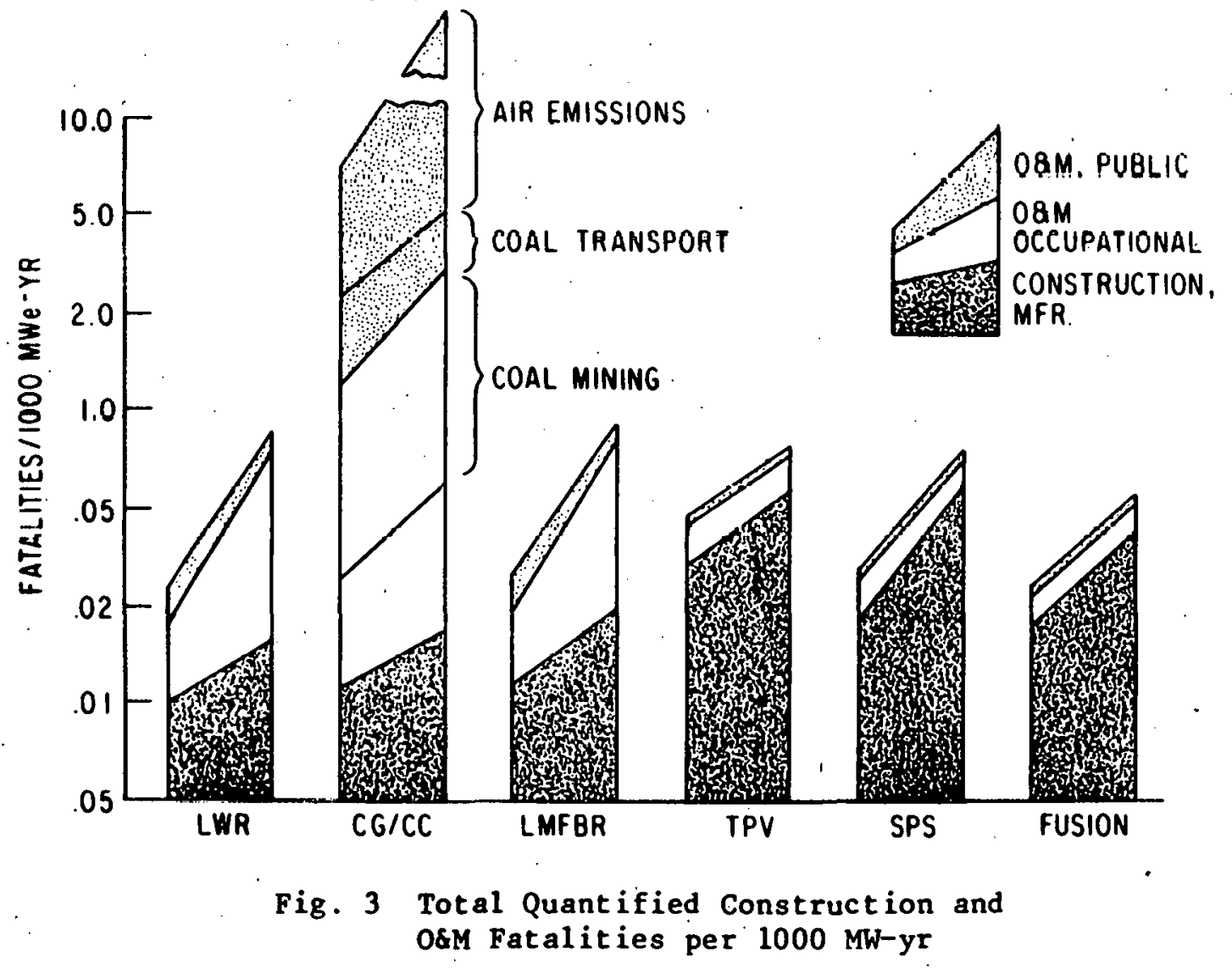


of the various systems considered, the coal technology has the largest overall quantified risk, primarily due to coal extraction, processing and transport, and air-borne emissions, although large uncertainties remain in the actual effect of the air-borne emissions. On the other hand, additional issues that are potentially major but remain largely unquantifiable were not identified for the coal system. Quantified risks from the remaining technologies (fission, fusion, SPS, and centralized terrestrial photovoltaic) are comparable within the range of quantified uncertainty. The occupational risks for component production, both direct and indirect, are a substantial fraction of the total risk, in particular for the advanced, capital-intensive solar and fusion technologies.

\section{ENVIRONMENTAL WELFARE}

Environmental effects not related to health and safety are classified here as environmental welfare effects, e.g., weather modification by carbon dioxide, materials degradation, electromagnetic interference with communications, aesthetics, and noise. Welfare effects were identified at each part of the fuel cycle and were categorized by the environmental impact (e.g., air pollution) that produced the welfare effect (e.g., crop damage). In summary, each technology produces environmental effects that affect society in different ways. With the exception of the $\mathrm{CO}_{2}$ climatic effects from coal combustion, all the technologies appear to be equivalent with regard to environmental welfare problems.

\section{RESOURCES/MACROECONOMIC/INSTITUT IONAL IS SUES}

Three areas important in the comparative assessment of energy technologies are resource requirements, macroeconomic effects, and institutional considerations. The scenarios (alternative energy futures) developed as part of the SPS Concept Development and Evaluation Program were used to provide another perspective on the land and water resources required; macroeconomic results followed from the scenario development activity. The institutional analysis, completed before development of the scenarios, focused on regulatory issues.

Land. requirements were first derived on a normalized basis for each of the energy technologies. The land requirements (in $\mathrm{km}^{2}$ per $1,000 \mathrm{MW}$ of installed capacity) used in this study are: 10 for coal, 3 for light water reactor (LWR), 2 for liquid metal fast breeder reactor (LMFBR), 20 for terrestrial photovoltaic (TPV), 35 for SPS, and 2 for fusion. These amounts include (where appropriate) land requirements for resource and fuel extraction, processing, the power plant site itself, and waste disposal. Transmission requirements are not included because they have been shown to be about the same for all technologies, particularly in view of studies indicating that 60 SPS rectennas $c$ an be sited within 300 miles of a load center. Scenariodriven results shown in Fig. 4 for the 1980 to 2030 time period indicate that total land use (excluding transmission) increases 0-500\% without SPS and $100-900 \%$ with SPS, whereas electrical energy demand increases $75-850 \%$ by the year 2030. The land required by SPS alone in the year 2030 is 2-6 times the total land in use for electrical generation in the United States today. The availability of additional land for power plant sites has not been determined. 


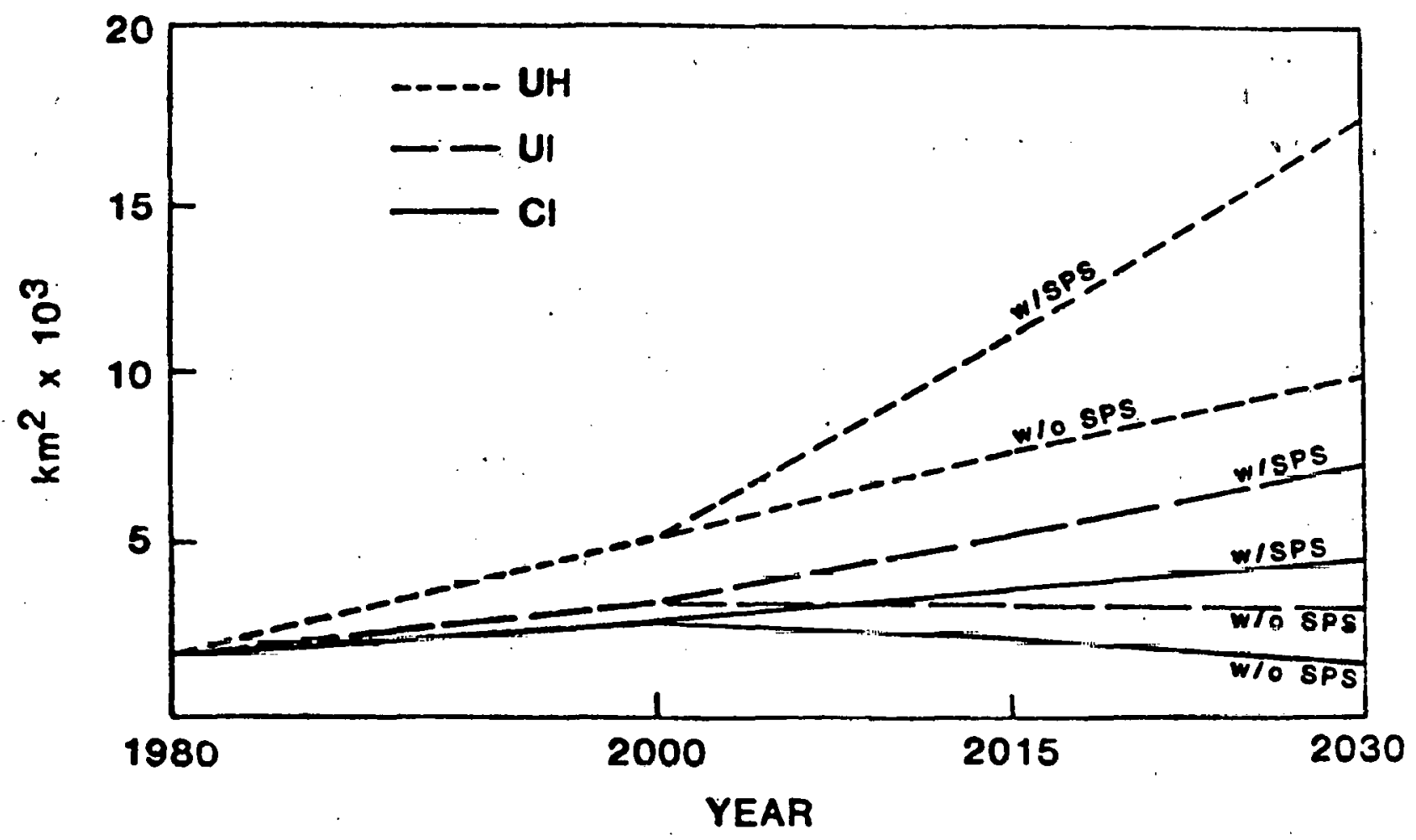

Fig. 4 Alternative Futures Analysis of Land Requirements

The need for large contigious areas, as for SPS rectennas, is a further complicat ing factor.

Water use in $\mathrm{m}^{3} \times 10^{6} / \mathrm{GW} /$ year, is 22 for coal, 60 for LWR, 22 for LMFBR, 12 for fusion and negligible for TPV and SPS. Total water requirements for the three scenarios, with and without SPS, are shown in Fig. 5. Results indicate that deployment of SPS can save large volumes of water; in scenario Cii, sps 8 aves an amount equal to $40 \%$ of the total used in 1980 for baseload electrical generation by coal and nuclear; in scenario UH, the saving is $170 \%$ of today's total.

Due to large uncertainties in determining the resource/reserve 1 evels for both the United States and the world, the analysis of materials problems was less quantitative than the land and water analyses. A screening methodology included a reliance on imports as a criterion as well as availability and total demand comviderations. These screening facturs identifled gallium as being a material of serious concern. Gallium is used extensively in the GaAlAs solar. cell option for SPS. Also of serious concern is tungsten, which is used both in SPS and cosl technologies.

Net energy analysis shows that the payback period for most of the technologies studied is small (less than 1.5 years). The payback periods for the SPS GaAlAs option, coal, and the nuclear options are about one year, and those for the SPS Si option and TPV (silicon cells) are about 6 and 20 years, respectively. Thus, the GaAlAs design affords SPS with an option that compares favorably with conventional technologies on a net energy basis. 


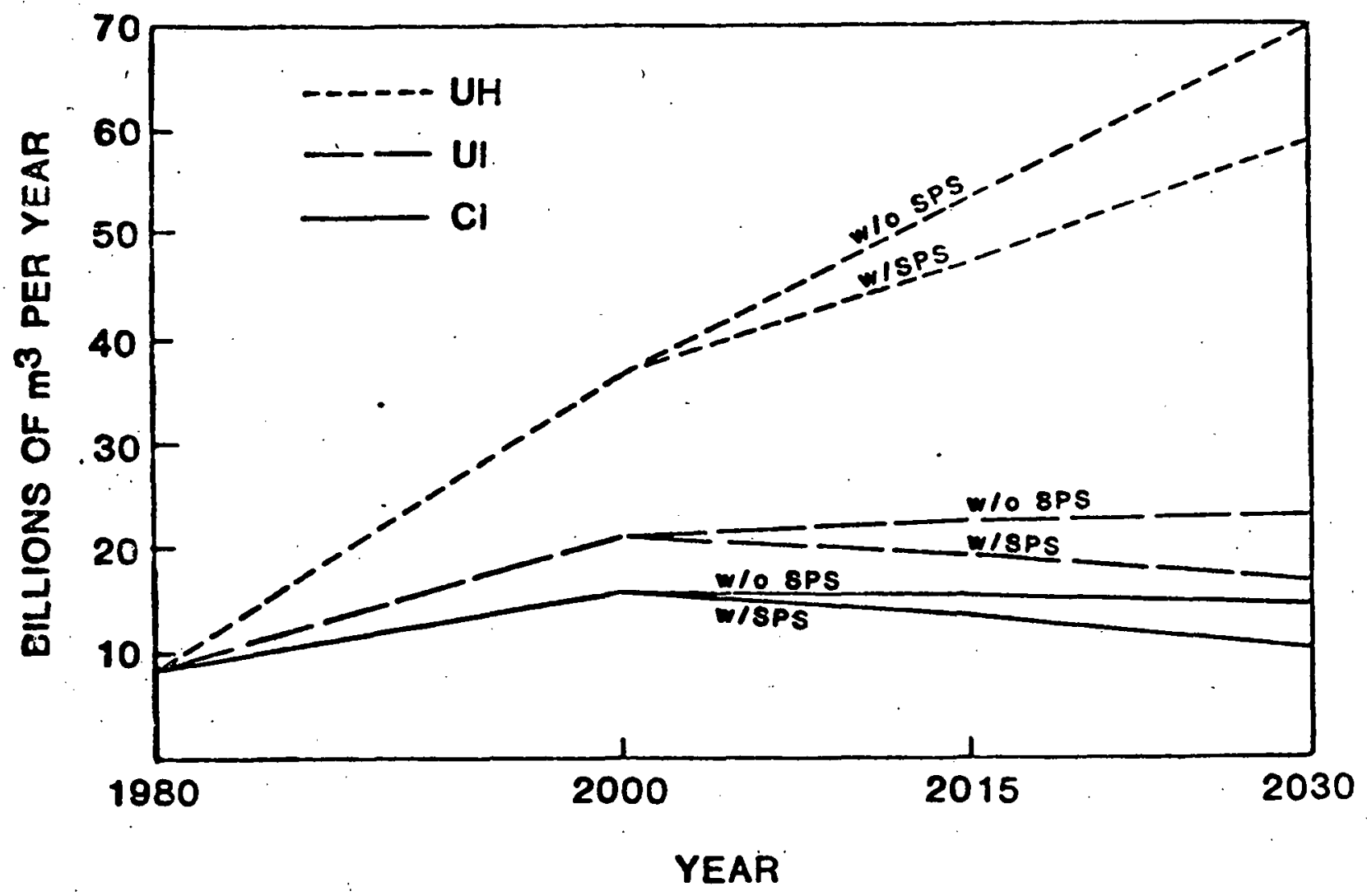

Fig. 5 Alternative Futures Analysis of Annual Water Consumption for Baseload Electricity Generation

Macroeconomic analyses included the calculation of changes in GNP for - the year 2000 and, in qualitative terms, the effect on inflation due to deployment of the SPS. Using a target GNP of $\$ 3.7$ trillion (all figures in 1978 dollars) for the year 2000 , deployment of $10 \mathrm{GW}$ of SPS power will require $\$ 20$ to $\$ 50$ billion of excess investment compared to the least expensive option (coal). This is 10 to $15 \%$ of $\$ 200$ billion, the amount available for financing economic growth of about $2.3 \%$ per annum. Compounded to the year 2030 , such a reduction would result in a $\$ 200$ to $\$ 500$ billion reduction in the target GNP of $\$ \bar{t}$ trillion.

If uranium and coal fuel supplies are much more contrained than presently envisioned, then deployment of SPS would reduce consumption of these scarce items and possibly reduce their prices. This could in turn reduce total energy expenditures, as indicated in Table 5. For the UH and UI scenarios, SPS energy costs of about 40-50 mills/kWh would result in a breakeven from the point of view of total energy expenditures.

The institutional analysis focused on the regulatory aspects of electricity generation by coal, nuclear, and the SPS. The technologies were characterized relative to one another, and justifications for regulation, the level of governmental responsibility, and the cost of regulation were considered. Studies estimate that the annual cost of regulating the nuclear industry is about $\$ 6$ billion, versus about $\$ 3.4$ billion for coal. In view of the changing regulacory enviroment (e.g., the decentralization movement and the growth. of power on the local leve1),. SPS regulatory costs may look more like nuclear regulatory costs than coal regulatory costs. Regulatory costs 
Table 5 Net Change in Annual Energy Expenditures

Due to the SPS $\left(1978 \$ \times 10^{9}\right)$

\begin{tabular}{|c|c|c|c|c|c|c|}
\hline \multirow[b]{3}{*}{ Year } & \multicolumn{6}{|c|}{ Scenario (mills $/ \mathrm{kWh})$} \\
\hline & \multicolumn{2}{|c|}{ UH } & \multicolumn{2}{|c|}{ UI } & \multicolumn{2}{|c|}{ CI } \\
\hline & 60 & 120 & 60 & 120 & 60 & 120 \\
\hline 2015 & 8 & 79 & 4 & 34 & -12 & 11 \\
\hline 2025 & 14 & 132 & 6 & 56 & -20 & 19 \\
\hline 2030 & 16 & 158 & 8 & 67 & -25 & 23 \\
\hline
\end{tabular}

for SPS could be significant compared to SPS investment costs, particularly in a low deployment rate $(3.3 \mathrm{GW} / \mathrm{yr})$ scenario.

\section{CONCLUSIONS}

This comparative assessment analyzed each technology issue by issue (side-by-side analysis); and then evaluated the technologies, given different post-2000 economic climates and the economic trajectories that would lead to those climates (alternative futures analysis). Conclusions were formed separately for these two types of analyses and are summarized in the following tables. Tables 6 to 11 summarize the comparison among the seven technologies issue-by-issue. Comparisons are described in terms of key issues, uncertainty about the understanding of those issues and a concluding comparative statement that cuts across all technologies for that issue area.

Table 12 describes the six mixes of technologies that werp analyzer in terms of meeting the energy demand for two different scenarios (i.e., IIH and CI). Tables 13 and 14 summarize comparative conclusions about mixes of technologies from an energy supply/demand perspective. In these tables, the comparative analyses are described briefly, issue by issue, for each of the energy supply alternatives. 
Table 6 Cost and Performance: Key Issues, Uncertainties, and Comparative Conclusions

\begin{tabular}{|c|c|c|c|}
\hline System & Key Issues & Uncertainties & Comparative Conclusions \\
\hline $\begin{array}{l}\text { Coal } \\
\text { (Conventional, } \\
\text { CG/CC) }\end{array}$ & $\begin{array}{l}\text { Capital cost expected } \\
\text { to escalate only slightly } \\
\text { but coal price would raise } \\
\text { energy price substantially. }\end{array}$ & $\begin{array}{l}\text { Coal price uncertain but } \\
\text { dependent on amount of } \\
\text { demand and environmental } \\
\text { regulations. }\end{array}$ & $\begin{array}{l}\text { SPS is economically competitive } \\
\text { with coal and nuclear if fuel } \\
\text { prices rise sharply and environ- } \\
\text { mental regulations raise the } \\
\text { capital cost of these techno- }\end{array}$ \\
\hline $\begin{array}{l}\text { Nuclear } \\
\text { (LWR, } \\
\text { LMFBR) }\end{array}$ & $\begin{array}{l}\text { Capital cost will probably } \\
\text { escalate due to environ- } \\
\text { mental and safety regula- } \\
\text { tions. Uranium prices } \\
\text { expected to increase. }\end{array}$ & $\begin{array}{l}\text { Capital cost increases } \\
\text { are uncertain. }\end{array}$ & $\begin{array}{l}\text { logies. However, if the regula- } \\
\text { tory climate is severe for coal } \\
\text { and nuclear it may also affect } \\
\text { SPS. The probability that SPS } \\
\text { will be cost competitive with } \\
\text { coal is very small until well } \\
\text { after } 2000 \text {. }\end{array}$ \\
\hline TPV & $\begin{array}{l}\text { Costs depend strongly on } \\
\text { cell production cost. }\end{array}$ & $\begin{array}{l}\text { Large improvements } \\
\text { required in cell cost. }\end{array}$ & $\begin{array}{l}\text { SPS has approximately the same } \\
\text { cost range as TPV and fusion, } \\
\text { but the range is very large and }\end{array}$ \\
\hline
\end{tabular}


Table 7 Health and Safety: Key Issues, Uncertainties, and Comparative Conclusions

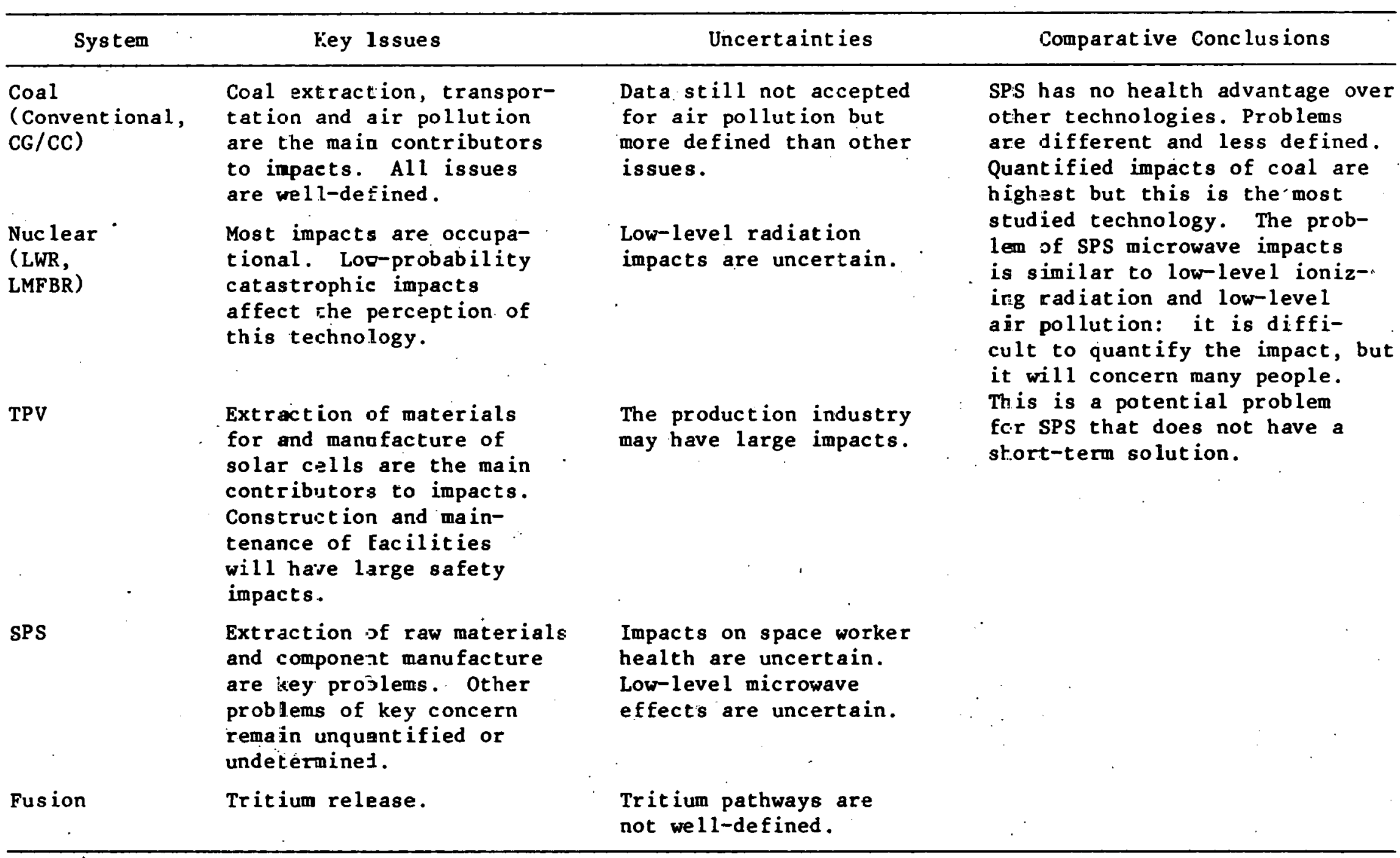


Table 3 Environmental Welfare: Key Issues, Uncertainties, and Comparative Conclusions

\begin{tabular}{|c|c|c|c|}
\hline Sy,s tem & Key Issues & Uncertainties & Comparative Conclusions- \\
\hline $\begin{array}{l}\text { Coal } \\
\text { (Conventional, } \\
\text { CG/CC) }\end{array}$ & $\begin{array}{l}\mathrm{CO}_{2} \text { climate impacts } \\
\text { dominate the issues. }\end{array}$ & $\mathrm{CO}_{2}$ uncertainty. & $\begin{array}{l}\text { Each technology has a different } \\
\text { set of environmental welfare } \\
\text { problems. The } \mathrm{CO}_{2} \text { problem has } \\
\text { the greatest catastrophic poten- } \\
\text { tial, but } \mathrm{CO}_{2} \text { from electricity }\end{array}$ \\
\hline $\begin{array}{l}\text { Nuc lear } \\
\text { (LWR, } \\
\text { LMFBR) }\end{array}$ & $\begin{array}{l}\text { Radiation waste disposal. } \\
\text { Safeguards problems. }\end{array}$ & $\begin{array}{l}\text { Waste disposal tech- } \\
\text { nology performance is } \\
\text { unproven. }\end{array}$ & $\begin{array}{l}\text { production is only a small part } \\
\text { of the overall problem. Micro- } \\
\text { wave problems will not be solved } \\
\text { for many years, possibly not } \\
\text { unt il after a system is built } \\
\text { and operated. }\end{array}$ \\
\hline TPV & $\begin{array}{l}\text { Mo significant environ- } \\
\text { mental welfare issues were } \\
\text { identified. }\end{array}$ & & \\
\hline Fusion & $\begin{array}{l}\text { No significant issues } \\
\text { were identified because } \\
\text { the technology is not } \\
\text { completely defined. }\end{array}$ & & . \\
\hline
\end{tabular}


Table 9 Resources: Key Issues, Uncertainties, and Comparative Conclusions

\begin{tabular}{|c|c|c|c|}
\hline System & Key Issues & Uncertainties & Comparative Conclusions \\
\hline $\begin{array}{l}\text { Coal } \\
\text { (Conventional, } \\
\text { CG/CC) }\end{array}$ & $\begin{array}{l}\text { Water contamination } \\
\text { is the only issue. }\end{array}$ & No large uncertainties. & $\begin{array}{l}\text { Large contiguous land consump- } \\
\text { tion is the biggest resource } \\
\text { issue for SPS. No other resource } \\
\text { problem is as important with the } \\
\text { possijle exception of uranium }\end{array}$ \\
\hline $\begin{array}{l}\text { Nuc lear } \\
\text { (LWR, } \\
\text { LMFBR) }\end{array}$ & $\begin{array}{l}\text { Uranium suppiy could be } \\
\text { limited after } 2000 .\end{array}$ & $\begin{array}{l}\text { Uranium supply is } \\
\text { uncertain for LWR. }\end{array}$ & fuel supplies for the LWRs. \\
\hline TPV & $\begin{array}{l}\text { Large land areas are } \\
\text { required. Energy fayback } \\
\text { is } 100 .\end{array}$ & $\begin{array}{l}\text { Energy intensity of } \\
\text { cell production is } \\
\text { uncertain. }\end{array}$ & \\
\hline SPS & $\begin{array}{l}\text { Large contiguous land } \\
\text { use. Some materialls } \\
\text { problems. } \\
\qquad\end{array}$ & $\begin{array}{l}\text { Microwave health and } \\
\text { safety regulations may } \\
\text { require an even larger } \\
\text { buffer zone - even more } \\
\text { total land. }\end{array}$ & $\because$ \\
\hline
\end{tabular}


Table 10 Economic/Societal Issues: Key Issues, Uncertainties, and Comparative Conclusions

\begin{tabular}{|c|c|c|c|}
\hline $\begin{array}{l}\text { Coal } \\
\text { (Conventional, } \\
\text { CG/CC) }\end{array}$ & $\begin{array}{l}\text { Regional economic im- } \\
\text { pacts are a problem } \\
\text { in the West, but have. } \\
\text { been well-studied. }\end{array}$ & $\cdot$ & $\begin{array}{l}\text { Because it is a new technology. } \\
\text { entailing many new industries, } \\
\text { SPS would require a large invest- } \\
\text { ment in the infrastructure. This, } \\
\text { coupled with the capital inten- }\end{array}$ \\
\hline $\begin{array}{l}\text { Nuc lear } \\
\text { (LWR, } \\
\text { LMF BR) }\end{array}$ & $\begin{array}{l}\text { Possible opposition to wide } \\
\text { deployment of nuclear tech- } \\
\text { nology by some sectors of } \\
\text { the public. }\end{array}$ & & $\begin{array}{l}\text { siveness of the technology, would } \\
\text { mean that SPS could have the } \\
\text { largest effect on the GNP and the } \\
\text { economy. Regional impacts of } \\
\text { implementing nuclear technology }\end{array}$ \\
\hline TPV & $\begin{array}{l}\text { Regional implemencation } \\
\text { expected. Large capital } \\
\text { requirements. }\end{array}$ & $\begin{array}{l}\text { Industrial infra- } \\
\text { structure not described. }\end{array}$ & $\begin{array}{l}\text { (fission, fusion) are less signi- } \\
\text { ficant than those of other tech- } \\
\text { nologies. }\end{array}$ \\
\hline SPS & $\begin{array}{l}\text { Capital cost and infra- } \\
\text { structure investments } \\
\text { could affect GNP. } \\
\text { Regional effects are } \\
\text { likely. Possible public } \\
\text { opposition. }\end{array}$ & ". & \\
\hline Fusion & $\begin{array}{l}\text { No estimates of infra- } \\
\text { structure and R\&D costs. }\end{array}$ & & . \\
\hline
\end{tabular}


Table 11 Institutional Issues: Key Issues, Uncertainties, and Coxparative Conclusions

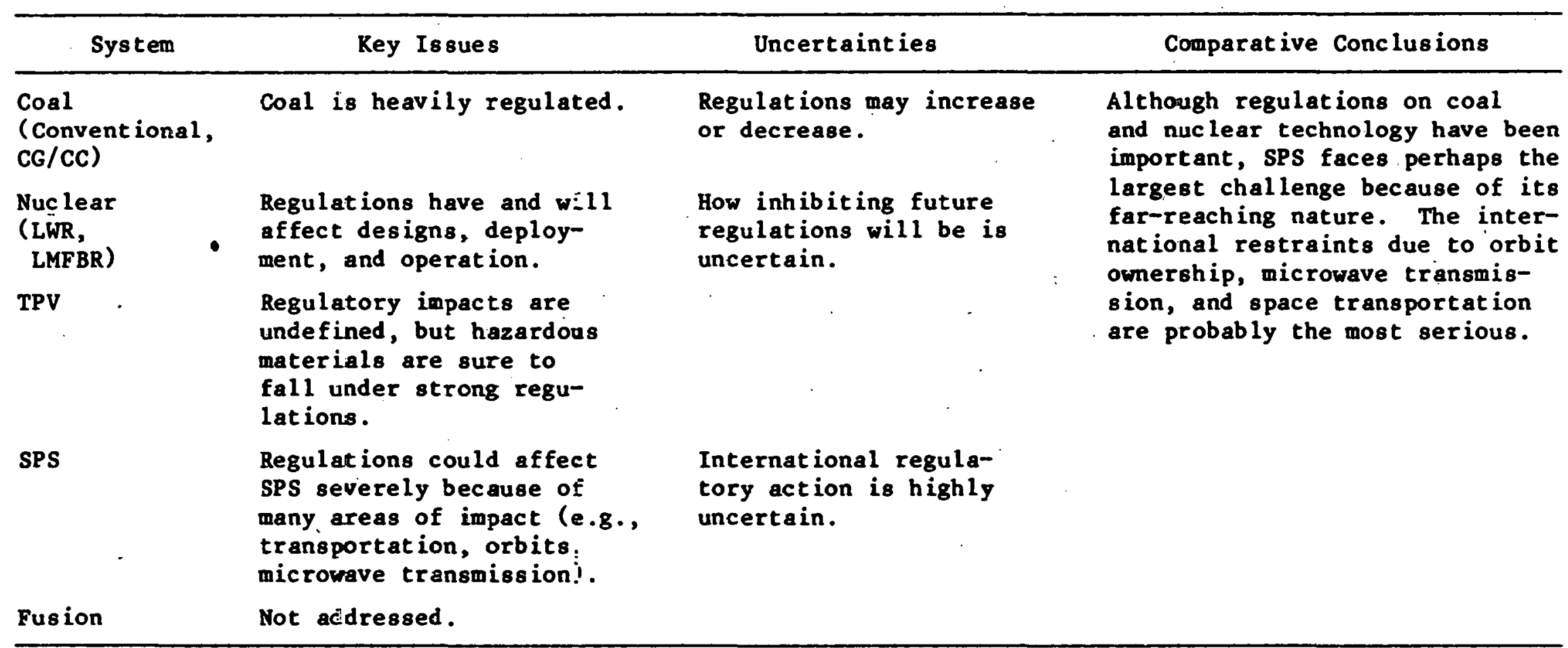


Table 12 Energy Supply Options

\begin{tabular}{|c|c|c|}
\hline & Supply Option & Description \\
\hline S1 & Convent ional & $\begin{array}{l}\text { Conventional coal combustion and combined-cycle } \\
\text { plants and nuclear LWRs with advancement to LMFBRs } \\
\text { make up this supply option. Coal and uranium } \\
\text { would be continually used in conventional systems } \\
\text { until they are replaced by improved systems, e.g., } \\
\text { combined-cycle coal gasification and the LMFBR. }\end{array}$ \\
\hline s2 & $\begin{array}{l}\text { Conventional fuel } \\
\text { utilization plus SPS }\end{array}$ & $\begin{array}{l}\text { This supply option includes the use of coal, with } \\
\text { nuclear only in the form of the LWR, replaced } \\
\text { by the SPS when fuel prices for uranium either } \\
\text { rise too high or the resource is depleted. }\end{array}$ \\
\hline s3 & $\begin{array}{l}\text { Conventional fuel } \\
\text { sources plus fusion }\end{array}$ & $\begin{array}{l}\text { This option utilizes coal, with nuclear in the } \\
\text { form of both the LWR and LMFBR, and replaces these } \\
\text { systems with fusion. If fusion is not available } \\
\text { when the LWR fuels are running low, the LMFBR } \\
\text { would be utilized until fusion technology is } \\
\text { available. }\end{array}$ \\
\hline S4 & $\begin{array}{l}\text { This is the same as } \\
\text { Supply Option } 1 .\end{array}$ & \\
\hline s5 & $\begin{array}{l}\text { Conventional systems } \\
\text { plus. SPS. }\end{array}$ & Same. as Supply Option 2 . \\
\hline s6 & $\begin{array}{l}\text { Conventional systems } \\
\text { plus fusion }\end{array}$ & $\begin{array}{l}\text { In this case since the energy demand is expected } \\
\text { to be low, only nuclear.LWRs would be used until } \\
\text { fusion would be available. Since the energy } \\
\text { demand is low, it is expected that the uranium } \\
\text { fuel would last until fusion technology could be } \\
\text { applied. }\end{array}$ \\
\hline
\end{tabular}


Table 13 Evaluation of Energy Supply Options S1-S3 for Demand Scenario UH - Unconstrained, High Demand

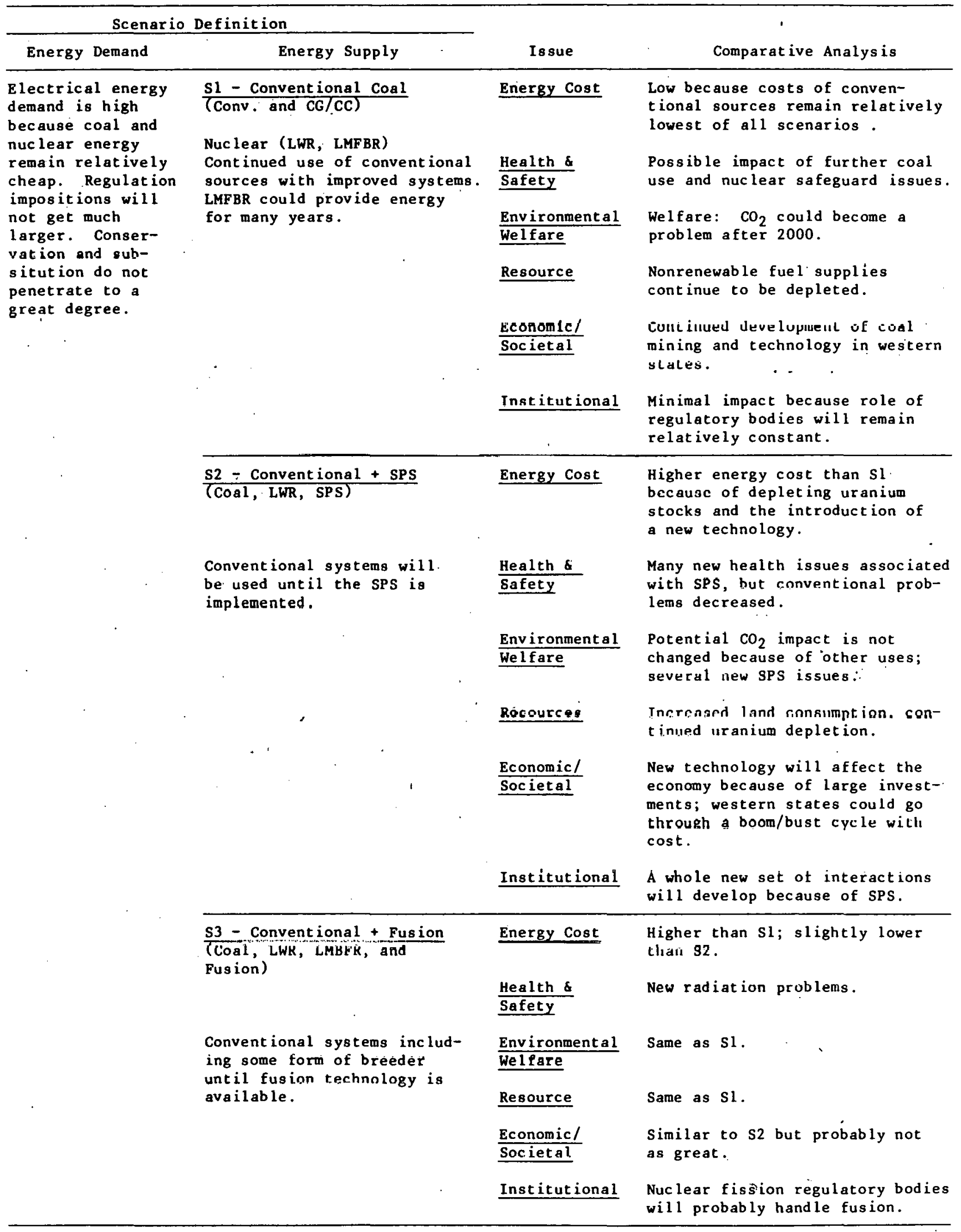


Table 14 Evaluation of Energy Supply Options S4-S6 for Demand

Scenario CI - Constrained, Intermediate Demand

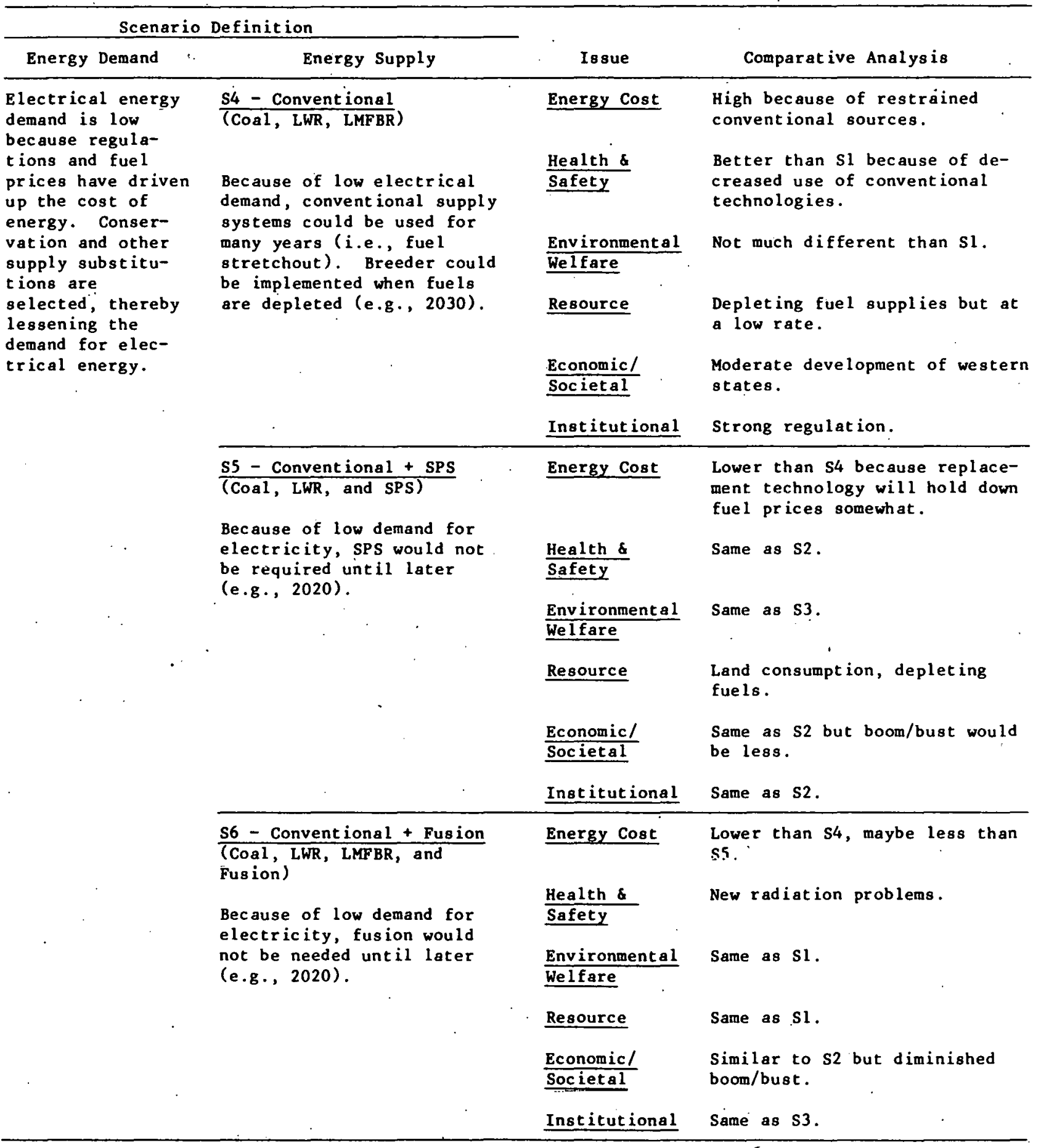


1. SPS CDEP Reference System Report; U.S. Department of Energy and NASA, DOE/ER-0023 (Oct. 1978).

2. Wolsko, T., et al., A Methodology for the Comparative Assessment of the Satellite Power System (SPS) and Alternative Technologies, Argonne National Laboratory Report for U.S. Department of Energy, DOE/ER-0051 (Jan. 1980).

3. Wolsko, T., et al., A Preliminary Assessment of the Satellite Power System (SPS) and Six Other Technologies, Argonne National Laboratory Report ANL/AA-20 (April 1980).

4. Ridker, R., and $W$. Watson, l'o Choose a Future, Johns Hopkins Press for Resources for the Future, Inc. (in press).

5. Solar. Power Satellite System Definition Study, Executive Summary, Boeing Aerospace Corporation, D180-25969-1 (June 1980).

6. Piland, R.o., Reference System Characterization and Cost Overview, DOE/ NASA Program Review (April 1980).

7. Woodcock, G.R., Solar Power Satellites and the Evolution of Space Technology, presented at the 1980 Meeting and Technical Display of the American Institute of Aeronautics and Astronautics, Baltimore, Md. (May 1980). 


\section{INTRÖUUČ́TION}

\subsection{BACKGROUND}

The SPS Concept Development and Evaluation Program (CDEP) ${ }^{1}$ was estab1 ished by the Department of Energy and the National Aeronautics and Space Administration to generate information from which a rational decision could be made regarding the direction of the Satellite Power System (SPS) Program after fiscal 1980. The comparative assessment program is one of four functional areas within the joint DOE/NASA CDEP. The other CDEP functional areas are:

- Systems definition: reference system design, alternative and advanced concept design, and critical supporting studies.

- Environmental assessment: evaluation of human health and safety, ecological, atmospheric, and electromagnetic interference issues pertaining to microwave transmission, power-line transmission, transportation activities, construction, and operation of the SPS.

- Societal assessment: evaluation of international issues, institutional issues (e.g., utility interfacing), resource issues, and public outreach.

The results of these three activities are inputs to the comparative assessment process as well as to program assessments. These four areas form the basis for the CDEP assessment of the technical possibility, economic viability, and environmental and social acceptability of the SPS concept.

\subsection{OBJECTIVE AND APPROACH}

The objective of the assessment is to provide an initial, traceable and consistent comparison of the SPS and selected current, near-term, and advanced energy technologies. To achieve this objective, the comparative assessment was divided into four parts:

1. Energy alternatives characterization: terrestrial alternatives were selected, and their cost, performance, and environmental and societal attributes were specified for use in the comparison with the SPS in the post-2000 era.

2. Methods: the framework for comparisons was established.

3. Evaluation: the SPS was compared with alternative systems in terms of key issues such as 1 ife-cycle cost and environmental impacts.

4. Management and integration: the results of the assess- ments were assembled and integrated into a consistent comparative assessment. 
Data on alternative technologies were sought from previous research and from other comparisons, and data on the SPS developed by other parts of the program were evaluated and used for the comparative assessment. Traceable data were gathered on alternative technologies, evaluated, and normalized to some consistent power or energy level and then synthesized into a format convenient for comparison.

A comparative assessment such as this cannot proceed without a large number of initial assumptions. Furthermore, a group of technologies that is representative, for which data exist, and of a size reasonable for study must be selected from a larger set. These assumptions and technologies were selected on the basis of an objective selection procedure and the subjective judgments of the assessors and their program staff. The documentation of this assessment was prepared to provide the reader who strongly objects to some assumptions or data with ample information for reanalysis of the comparison with other data or assumptions. However, the many assumptions and data selections supporting this report were made carefully and thoughtfully.

This fillal comparative assessment is a revision and expansion of a preliminary assessment and represents a culmination of the CDEP program in this area. Some of the information from the preliminary assessment has not changed either because it represented the best comparative information available on a particular issue or because the issue was not considered as important as others and was therefore de-emphasized. The goal of the pre1 iminary assessment was to gather some initial comparative information on a limited set of technologies. The objective of the present assessment-is-to finalize these comparisons on all key issues on the basis of state-of-the-art knowledge and to point out data deficiencies that affect the conclusions, as well as to add comparisons based on alternative. future scenarios.

The preliminary assessment ${ }^{2}$ evaluated six centralized baseload technologies: conventional coal; light water reactor (LWR); coal gasification/ combined cycle (CG/CC); liquid-metal, fast-breeder reactor (LMFBR); centralstation, terrestrial photovoltaic (TPV); the satellite power system (SPS); and fusion. For the final comparative assessment, some minor modifications were introduced into this group of technologies; most notably, an improved emission control system for the conventional coal technology and an improved fuel utilization cycle for the LWR were assumed.

The technologies compared with the SPS in this assessment vary in their stages of development and, therefore, in their degree of definition. This variability was handled by qualifying the data wherever possible: for example, a technological uncertainty factor was applied to data used in the cost and pertormance comparisons.

The assessment framework or methodology is described briefly in this report and in more detail in a companion report. 3 This assessment follows the structure of the first five steps of the methodnlngy, hut the sixth (integration/aggregation techniques) was not carried out. Instead of a formalized procedure for reducing the comparative information to a specific, condensed format for decision-making, the information is presented in its entirety; it was assumed that decision makers would use their own procedures for summarizing and evaluating the information. 
I

A11 issues included in the methodology taxonomy are addressed in this assessment. The side-by-side assessment reported here is a normalized comparison ( $i . e$., per unit of energy output, such as per megawatt year) based on assumptions about the economic conditions in the beginning of the 21 st century. This alternative-futures comparison defines plausible economic and energy futures and makes comparisons on the basis of the energy and economic climate pertinent to these futures.

Reported in this document are a brief description of the comparative methodology; brief characterizations of the alternative technologies; side-by-side comparison, by issue; alternative futures comparison, by issue; and conclusions about the assessment. 


\section{ASSESSMENT FRAMEWORK}

\subsection{OVERVIEW}

This section describes a framework for comparing the SPS with various projected alternative energy sources on the basis of technical possibility, economic viability, and social and environmental acceptability. A more detailed description of the approach and method used in the assessment is contained in the methodology report for the comparative assessment. 3

The analysis in the comparative methodology is composed of the following steps (Fig. 2.1):

1. Comparative issues selection and organization. Key issues from the deployment of the SPS and the alternative systéms are selected and organized into an appropriate taxonomy.

2. Energy alternatives selection. Alternatives similar in utility to SPS are selected. Many possible issues and alternatives are examined, and these selections provide. an initial focus for the remaining steps in the comparative assessment.

3. Energy system characterization. The energy system characterization provides reference data on technology costs and performance, resource use, and environmental residuals.

4. Side-by-side analysis of energy systems. Side-by-side analysis normalizes the energy output from each system to allow comparison of alternative technology impacts.

5. Alternative futures analysis. The alternative futures analys is incorporates the results of the side-by-side impact analys is into future energy supply/demand and state-of-the world scenarios that are not forecasts but are designed to examine specific issues and potential problems over a range of possible futures.

6. Development and application of integration/aggregation techniques. The development of formal techniques for integrating and aggregating the large amounts of data and information provided by the analys is will aid the dccision maker in formulating SPS proyram recommendations.

Only the first five steps have been carried out in this comparative assessment. The following sections describe each of these six steps of the comparative assessment framework in more detail.

\subsection{COMPARATIVE ISSUES}

The selection of issues for the comparative assessment must be guided by the idea that not only should the issues structure be general enough to 


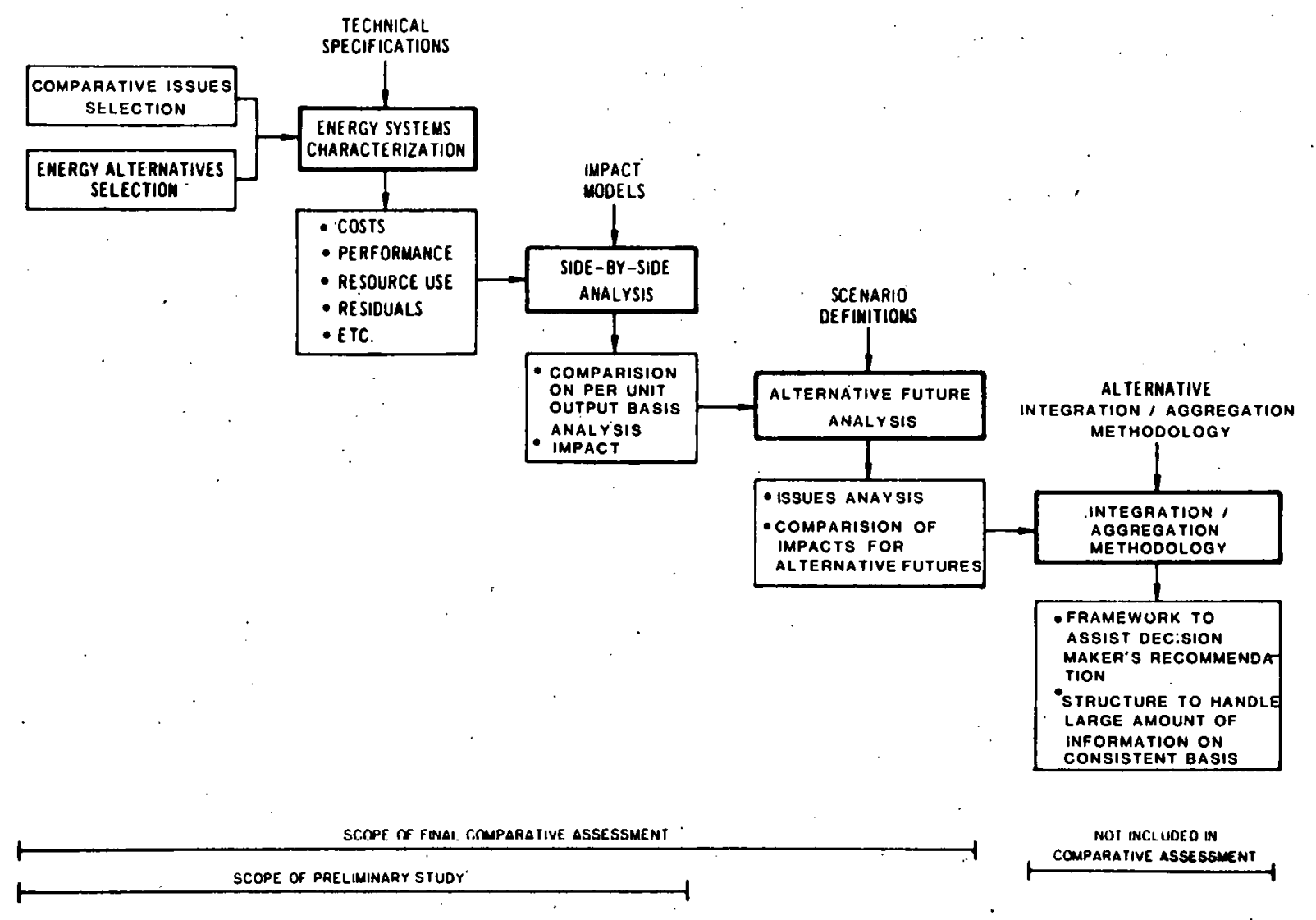

Fig. 2.1. Analys is Sequence for Comparative Assessment

accommodate different impacts that result from the alternative technologies, but it should also be specific enough so that comparisons betwèn technologies are feasible and commensurate.

The classification system for the comparative assessment is shown in Fig. 2.2. The major issue categories are cost and performance, environmental, economic and societal, resource, and institutional.

In the cost and performance category, the life-cycle cost and system performance are compared. The R\&D cost comparison between technologies was not considered because of the inability to develop an acceptable methodology or accurate data. Life-cycle cost includes development, construction, operation, maintenance, and decommissioning. Reliability is an example of an important system performance issue. The costs being compared are projected, and it is important to specify the uncertainty in these projections so that conclusions can be drawn in perspective.

Environmental issues are divided into two subcategories: health and safety issues and welfare issues. Health and safety is subdivided into public and occupational issues. In this context, health refers to chronic impacts (e.g., respiratory illness), whereas safety refers to the effects of accidents such as launch malfunctions, spills,., and unexpected releases of hazardous pollutants. Welfare impacts are those that result from disruptions of the physical environment, such as damage to buildings from air pollution, degradation of radio-frequency communication due to 


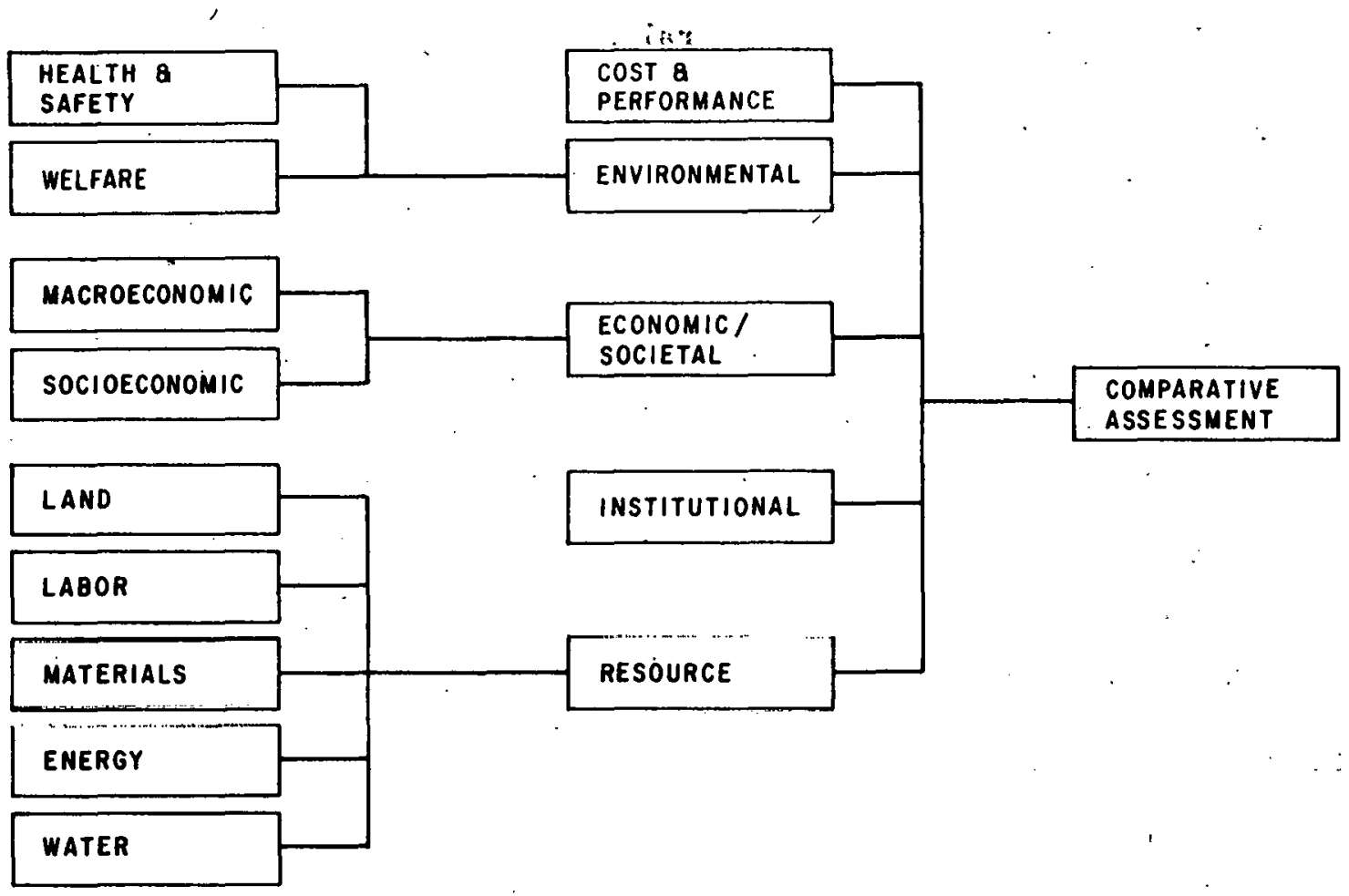

Fig. 2.2. Comparative Assessment Classification System

microwave interference, and changes in land value because of deployment of an energy technology.

The economic and societal category is divided into two parts: macroeconomic and socioeconomic. The macroeconomic issues deal with national and regional macroeconomic impacts (e.g., trade, GNP, capital availability, and employment). Socioeconomic issues concern the monetary impact and social stresses on the localities where power systems are sited.

Institutional comparisons deal with the effects of existing and potential institutions on the deployment of a technology (regulatory impacts). International institutional issues are addressed in terms of their regulatory impact on energy' systems. The resource category includes five subcategories: land, labor, materials, energy, and water. Here, key concerns include resource limits, production 1 imits, dependence on foreign resources, and need for new skilled labor.

\subsection{SELECTION OF ENERGY ALTERNATIVES}

The technologies initially considered for comparison with the SPS listed in Table 2.1 include six fossil. options, ten nuclear technologies (including two fusion options), five solar technologies, and three geothermal technologies. The 1 ist was narrowed to six technologies according to the following criteria:

- Technical data must be available in sufficient detail to allow adequate technical characterization and comparison. 
- The candidates must be central-station, baseload technologies.

- The technology should be available for commercial application by year 2000 .

- Include improved current baseload technologies.

- Include representative advanced technologies currently being engineered.

- Include alternative (nonspace) applications of photovoltaic solar energy technology.

- Include alternatives that show potential as long-term energy sources after 2000 .

- Fuel must be available for a long period (e.g., 20002050).

The energy alternatives selected were conventional coal with stack scrubber, coal gasification/combined cycle, the light water reactor, the liquid-metal breeder reactor, fusion, and the photovoltaic solar central station. Missing from this list are wind, biomass, decentralized solar (e.g., space heating and cooling, process heating and cooling, water heating; and photovoltaics for electrical energy production), and OTEC. These technologies were not included in the $f$ inal $l$ ist because they are not large centralstation-baseload options or they have only regional application.

\subsection{CHARACTERIZATION OF ENERGY SYSTEMS}

Following the selection of energy alternatives and the preliminary selection of comparative issues, the reference energy systems were defined and described, and data on cost, performance, and environmental impact were collected from published sources for issue comparisons.

The ground rules for this data collection included the following:

- Characterizations should use readily available information.

- Characterizations should be performed and documented by persons who are knowledgeable about alternative technologies and DOE programs.

- Each technology characterization should be internally consistent.

- The set of characteristics should be consistent enough, overall, to facilitate comparisons with the SPS concept.

- There should be enough information to allow adequate evaluation of issues (failing this criterion, a candidate technology may have to be dropped).

\subsection{SIDE-BY-SIDE ANALYSIS OF ENERGY SYSTEMS}

The objective of the side-by-side analysis is to compare the alternatives on the basis of single units normalized to the same power level, using a 
Table 2.1 Candidate Altërnative Technologies

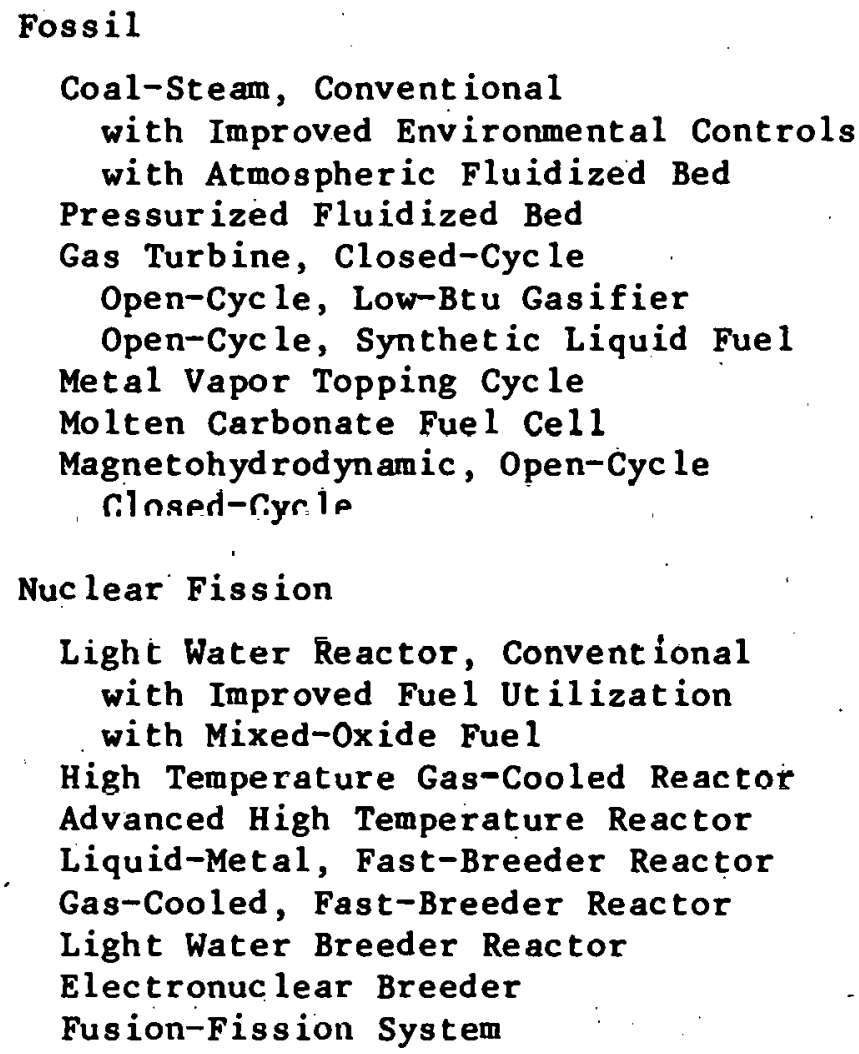

Fusion

Magnetic Confinement

Inertial Confinement

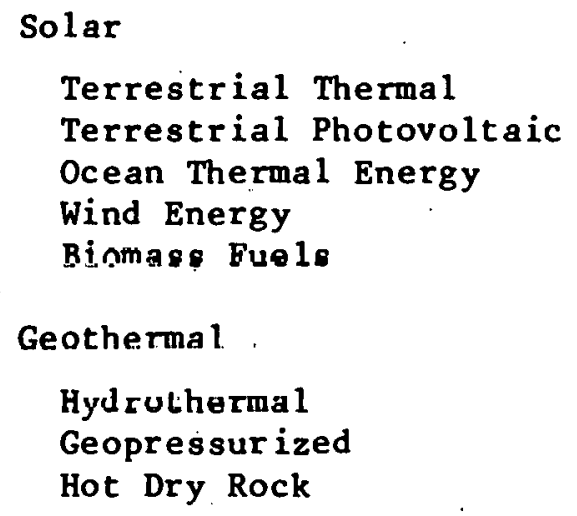


consistent set of ground rules for all units. This was the first analytical step of the comparative assessment, and it entailed listing information (some detailed, some summary) for each of the energy systems. Information categories cover the technical, economic, environmental, and societal issues mentioned earlier.

Two important functions of the side-by-side analysis are: (1) providing the decision maker and analyst with a normalized comparison, * and (2) functioning as an intermediate step between the technology characterizations and the alternative futures analysis.

\subsection{ALTERNATIVE FUTURES ANALYSIS}

The alternative futures analysis compared alternative energy-supply systems (i.e., alternative mixes of coal, nuclear, and SPS technologies) under different. levels of energy demand (i.e., alternative supply-demand patterns). This analysis addressed synergistic impacts or those that result from aggregation of single-plant effects. An integral part of the analysis was the creation of scenarios (e.g., statements about future supply, demand, lifestyle, resources, and regulation) to serve as inputs to other analyses.

The primary objective of the alternative futures analyses was to provide a comparison of the impacts of alternative technologies under several different assumptions of future conditions.

The following criteria were considered in the choice of scenarios that drive the alternative futures:

- A limited number of scenarios should be used, and they should be credible and representative;

- They must illustrate a suitably large range of alternative policies, and economic and social conditions (or at least those of major concern or interest);

- They must not produce a flood of data that would tend to overwhelm analysts and the decision-making process;

- They should highlight or identify major categories of issues for further analysis; and

- Uncertainty should be included in a consistent and efficient manner, conveying useful information to the decision maker.

*The term "normalized comparison" simply means that quantifiable impacts are expressed in amount of impact per unit output of electrical energy, e.g., per megawatt-year (MW-yr). Thus, a 5-MW system that provides. energy continuously for one year and expels 1,000 tons of pollutants to the environment in the process will be characterized by the normalized amount of 200 $(=1,000 \div 5)$ tons of pollutant per MW-yr of electrical energy; similarly, a 1 MW plant that operates for half a year and produces 50 tons of pollutants is assigned the normalized amount of $100(=50 \div 1 / 2)$ tons of pollutants per MW-yr. 
Although a scenario must be plausible, it does not necessarily have a probability of occurrence associated with it, but instead addresses key issues and, perhaps, reveals other problems that result from specific future models.

\subsection{ASSESSMENT INTEGRATION/AGGREGATION TECHNIQUES}

The objective of integration/aggregation techniques is to analyze and focus the data assembled for the comparison of SPS with terrestrial technologies. A further objective is to begin reducing the complexity of the decision-making problem (which is aggravated by the large amounts of supporting data for each technology) by using techniques such as formal incorporation of preferences.

There are a number of criteria for deciding the appropriate level at which to carry out such integration/aggregation techniques. These include:

- The number of measurement categories desired;

- The number of alternatives desired;

- The manner in which views of priorities are determined, represented, and incorporated into the decision-making process;

- The use of uncertainty;

- The degree of inclusion of interactions between variables and priorities; and

- The suitability of the aggregated information for describing dynamic and time-varying conditions.

The degree of appropriateness of any of these criteria is determined by the degree of quantification of variables and effects that is achievable. Cost-risk-benefit analysis, total social cost, minimum energy cost with environmental constraints, and decision analysis are some of the techniques that may be considered. These approaches are formalized techniques that require value judgments. Since these value judgments would mainly be those of the analysts, it was decided to present the comparative information in its entirety and permit the reader to use his or her own values for arriving at any aggregate evaluation. 
This section contains brief descriptions of each of the technologies considered. More detailed characterizations are contained in the SPS CDEP Reference System Report ${ }^{1}$ and in the alternative technology characterization reports. 4,5 The objective of the technology characterizations was to collect and develop a consistent and traceable set of characterization parameters for the SPS and other possible post-2000 baseload systems. The characterizations represent "first-order" characteristics that define systems in sufficient detail for the cost and environmental analyses.

\subsection{SELECTION OF ALTERNATIVE TECHNOLOGIES}

The preliminary list of 29 technologies (Table 3.1 ) was initially screened according to two sets of criteria. The 1 ist was reduced to a subset of systems that were then further screened by more restrictive criteria to a final subset of alternatives. Decentralized technologies were excluded from the comparative assessment, since the focus was on baseload alternatives to SPS. A more detailed description of the technology screening and selection process is presented in another report. 6

Initial screening was both qualitative and quantitative. The qualitative screening procedure included the following criteria for selection of an initial and representative subset of candidate electrical power generation systems :

A. The initial set should include improved conventional systems (e.g., coal and LWR systems).

B. It should represent the following classes of advanced systems :

1. Advanced coal combustion and synfuels,

2. Solar,

3. Fission,

4. Fusion, and

5. Geothermal.

C. It should include the principal energy systems most suitable for large, central-station baseload generation within each class of inexhaustible energy sources.

D. It should reflect the consensus about which candidates are most likely to be viable in the year 2000 .

A group of qualified energy technology researchers was asked to judge the candidate technologies according to the listed criteria, and their choices of the most viable candidate technologies for the year 2000 constituted the qualitative screening selections.

The quantitative screening technique explicitly considered five major technology factors and numerous subfactors (Table 3.2). The following criteria were used in the final alternative technology eelection: 
Table 3.1 Technologies Considered in Initial screening

\begin{tabular}{|c|c|c|}
\hline $\begin{array}{l}\text { Energy } \\
\text { Source }\end{array}$ & $\begin{array}{l}\text { Conventional } \\
\text { Sys tems }\end{array}$ & New Systems \\
\hline \multicolumn{3}{|c|}{ Exhaustible Resource Technologies } \\
\hline Coal & $\begin{array}{l}\text { Coal-steam plants } \\
\text { with flue-gas } \\
\text { desulfurization }\end{array}$ & $\begin{array}{l}\text { - Coal-steam plants with improved environ- } \\
\text { mental controls } \\
\text { - Atmospheric fluidized-bed combustion } \\
\text { (AFBC) } \\
\text { - Pressurized fluidized-bed combustion } \\
\text { (PFBC) } \\
\text { - Low-Btu gasifier/open cycle gas turbine; } \\
\text { combilled cyele } \\
\text { - Closed cycle gas turbine } \\
\text { - Metal vapor topping cycle } \\
\text { - Open cycle magnetohydrodynamics (MHD) } \\
\text { - Closed cycle magnetohydrodynamics } \\
\text { - Molten carbonate fuel cell with gasifier } \\
\text { (MCFC) } \\
\text { - Synthetic fuels for advanced power. } \\
\text { cycles. }\end{array}$ \\
\hline Fission & $\begin{array}{l}\text { Light water reactors } \\
\text { with once-through } \\
\text { fuel cycle }\end{array}$ & $\begin{array}{l}\text { - Light water reactors (LWR) with improved } \\
\text { fuel utilization efficiency } \\
\text { - Light water reactors with mixed oxide } \\
\text { fuels } \\
\text { - High temperature gas-cooled reactors } \\
\text { - Advanced high temperature reactors }\end{array}$ \\
\hline Geothermal & Dry steam & $\begin{array}{l}\text { - Liquid-dominated hydrothermal } \\
\text { - Geopressure }\end{array}$ \\
\hline enewable o: & Essentially Inexh & le Resource Technologies \\
\hline Solar & $\begin{array}{l}\text { Hydroelectric } \\
\text { Wood-fired steam }\end{array}$ & $\begin{array}{l}\text { - Solar thermal electric with storage } \\
\text { - Solar photovoltaic with storage } \\
\text { - Ocean thermal energy conversion } \\
\text { - Wind energy conversion with storage } \\
\text { - Biomass fueled (other than wood-fired } \\
\text { steam) }\end{array}$ \\
\hline Fission & & $\begin{array}{l}\text { - Liquid-metal, fast-breeder reactor } \\
\text { (LMFBR) } \\
\text { - Gas-cooled, fast-breeder reactor... } \\
\text { - Light water breeder reactor } \\
\text { - Electronuclear breeder } \\
\text { - Fusion-fission systems }\end{array}$ \\
\hline Fusion & & $\begin{array}{l}\text { - Magnetic confinement fusion } \\
\text { - Inertial confinement fusion }\end{array}$ \\
\hline Geothermal & & - Hot dry rock (HDR) \\
\hline
\end{tabular}


1. Technical data must be available in sufficient detail to allow adequate technical characterization and comparison.

2. The candidates must be central-station, baseload technologies.

3. The technology should be available for commercial applica$t$ ion by the year 2000 .

4. Include improved current baseload technologies.

5. Include representative advanced technologies currently being engineered.

6. Include alternative (non-space) applications of photovoltaic solar energy technology.

7. Include alternatives that show potential as long-term energy sources after 2000.

8. Fuel must be available for a long period (e.g., 20002050).

The details of the qualitative and quantitative screening procedures are reported in a supporting document. 6

Table 3.2 Quantitative Screening of Energy Systems

\begin{tabular}{ll}
\hline \multicolumn{1}{c}{ Factors } & \multicolumn{1}{c}{ Subfactors } \\
\hline Technology Availability & Technology Feasibility \\
& Fuel or Energy Resource Availability \\
Regional Limitations & Status of Development \\
Economic Attractiveness & RD\&D Costs \\
& Capital and o\&M Costs \\
& Fuel Costs \\
& Plant Availability and Reliability \\
& Utility Compatibility \\
& Air and Water Pollutants \\
Environmental Impacts & Land Use or Disturbance \\
& Public Health and Safety \\
& Reversible vs. Irreversible Impacts \\
& Energy, Materials \\
Critical Resource Requirements & Land, Water \\
& Capital, Manpower \\
& Economic \\
Socioeconomic Impacts & Industrial Infrastructure \\
& Social \\
& International \\
\hline
\end{tabular}


The light water reactor ( $L W R$ ) and coal technologies best satisfy the applicable criteria and thus were included in the final list of technologies to be compared with the SPS. Only one technology, terrestrial photovoltaics (TPV), meets the special criterion (No. 6) established to provide for a direct comparison of photovoltaics in space and terrestrial applications.

The combined-cycle system had the highest rating of the three advanced coal systems and thus was selected for the comparative assessment.

The liquid-metal, fast-breeder reactor (LMFBR), although controversial, has great potential, is close to demonstration, and has received worldwide backing; it was thus included in the comparative assessment.

Fusion is a technology of high scientific interest and potential. Therefore, it was selected to fill a position as a baseload alternative, even though DOE's Fusion Review Panel has stated that a date for a commercially competitive prototype reactor cannot now be established.

\subsection{BRIEF TECHNICAL DESCRIPTION OF ALTERNATIVE GENERATION SYSTEMS}

The characteristics of each of the alternative generation systems have been derived primarily through a synthesis of data and information obtained from available technical literature. The best self-contained system characterizations available in single documents were chosen as primary data sources. Where deficiencies were noted, available supplemental material was obtained or input from reviewers was solicited.

In most cases, the available data are for nominal systems that differ in some respects from the reference alternatives chosen for comparison. Usually, these differences are a result of varying assumptions about system generating capacity, cooling type, or, in some cases, even the site or fuel characteristics. Thus, in some cases, the reference characterizations required engineering judgment to adjust data to the system capacities and basic assumptions being used. : The subsequent analyses are generally not sensitive to small variations in the system parameters derived in this fashion. However, the analysis is broad enough to allow reasonable conclusions to be drawn.

The parameters addressed in the system characterizations include those that relate to the physical system design and operating fartors, capital and operating costs, reliability and availability, resource requirements, and environmental residuals. Table 3.3 briefly summarizes the characterization parameters for the technologies. Studies conducted by $\mathrm{TRW}^{4}$ and United Engineers and Constructors ${ }^{5}$ provide the basis for the non-SPS technical, environmental, and cost characterizations summarized in the following sections of this chapter.

\subsubsection{Satellite Power System}

The satellite power system characterization is based on data available in the SPS CDEP Reference System Report, 1 supplemented by additional studies 
Table 3.3 Characterization Parameters for Plant Site and Fuel Cycle

Physical System Characteristics

- Plant Configuration

- The rmodynamic Cycle Characteristics

- Capacity Factor

- Environmental Controls

- Mass \& Energy Balances

Environmental Residuals

- Air-Borne Emissions

- Liquid Effluents

- Solid Wastes

- Radionuclides

- Waste Heat
Capital and Operating Costs

- Construction Schedule

- Construction Cash Flow

- Direct and Indirect Capital Cost

- O\&M Costs

- Decommissioning Costs

Natural and Human

Resource Requirements

- Fuel Use

- Water Use

- Land Use

- Construction Labor

- Operating Labor

performed for NASA by Boeing ${ }^{7}$ and Rockwel1.8 The satellite power system consists of three basic elements: the first two, in geosynchronous orbit at $36,000 \mathrm{~km}$, are the solar collector, which receives energy from the sun and converts it to electrical energy, and a microwave antenna, which transmits that energy to the third element, an earth-based rectifying antenna (rectenna). The reference system is sized for $5 \mathrm{GW}$ of DC power output to a conventional utility grid. The satellite has one end-mounted antenna, as illustrated in Fig. 3.1.

The satellite consists of a planar solar array structure of graphite composite material. Two conversion options (Fig. 3.2) are presently being considered: one is the use of single-crystal gallium aluminum arsenide (GaAlAs) solar cells with a concentration ratio of 2 ; the other is the use of single-crystal silicon ( $\mathrm{Si}$ ) solar cells with no concentration.

The size of the solar array is dictated primarily by the efficiency chain of the various elements in the system. Figure 3.3 shows the end-to-end efficiency chain for the GaAlAs and silicon cell options. The satellite is designed to provide $5 \mathrm{GW}$ of DC power to the utility busbar, and with an overall efficiency of approximately $7 \%$, it is necessary to size the solar arrays so that approximately $70 \mathrm{GW}$ of solar energy will be intercepted. The efficiency assumed is the minimum efficiency, including the worstcase summer solstice factor $(0.9675)$, the seasonal variation $(0.91)$, and the end-of-1ife (30-year) solar cell efficiency (assuming annealing in the silicon case). For the GaAlAs case, the end-of-life (30-year) concentrator reflectivity is 0.83 . Since only half of the intercepted solar energy is reflected by the concentrators, the equivalent 1 ifetime average efficiency is 0.915 .

The GaAlAs option is a five-trough configuration with a solar blanket area of $26.52 \mathrm{~km}^{2}$, a reflector area of $53.04 \mathrm{~km}^{2}$, and an overall planform area of $55.13 \mathrm{~km}^{2}$. The silicon option has the solar blanket with no concentration, resulting in a blanket area of $52.34 \mathrm{~km}^{2}$ and a planform area of $54.08 \mathrm{~km}^{2}$. Table 3.4 lists the cell and planform power characteristics for each cell type. 


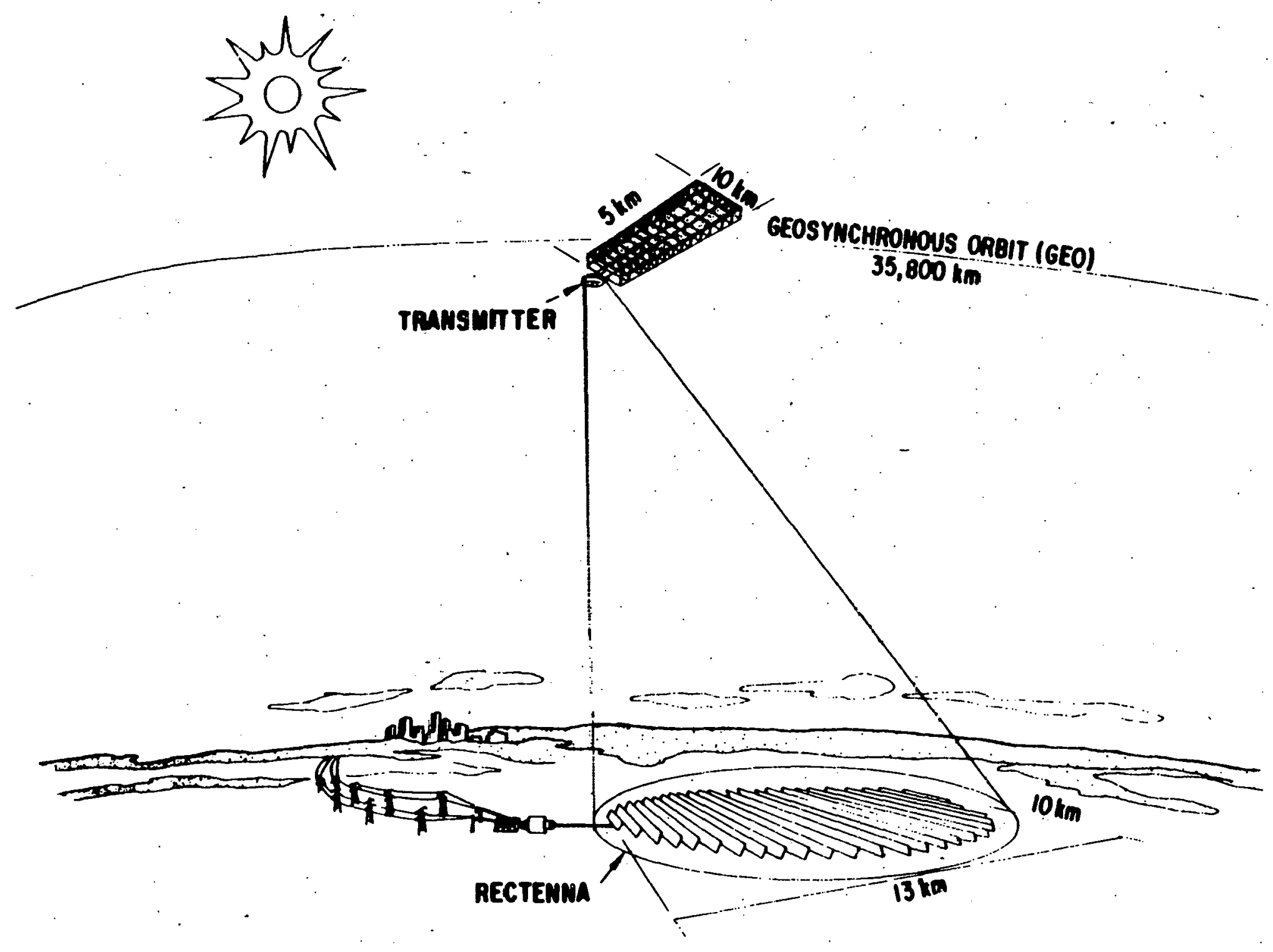

Fig. 3.1 Satellite Power System Concept (Source: Ref. 1) 
SILICON CR $=1$

BLANKET AREA $=52.34 \mathrm{~km}^{2}$

PLANFORM AREA $=54.08 \mathrm{~km}^{2}$
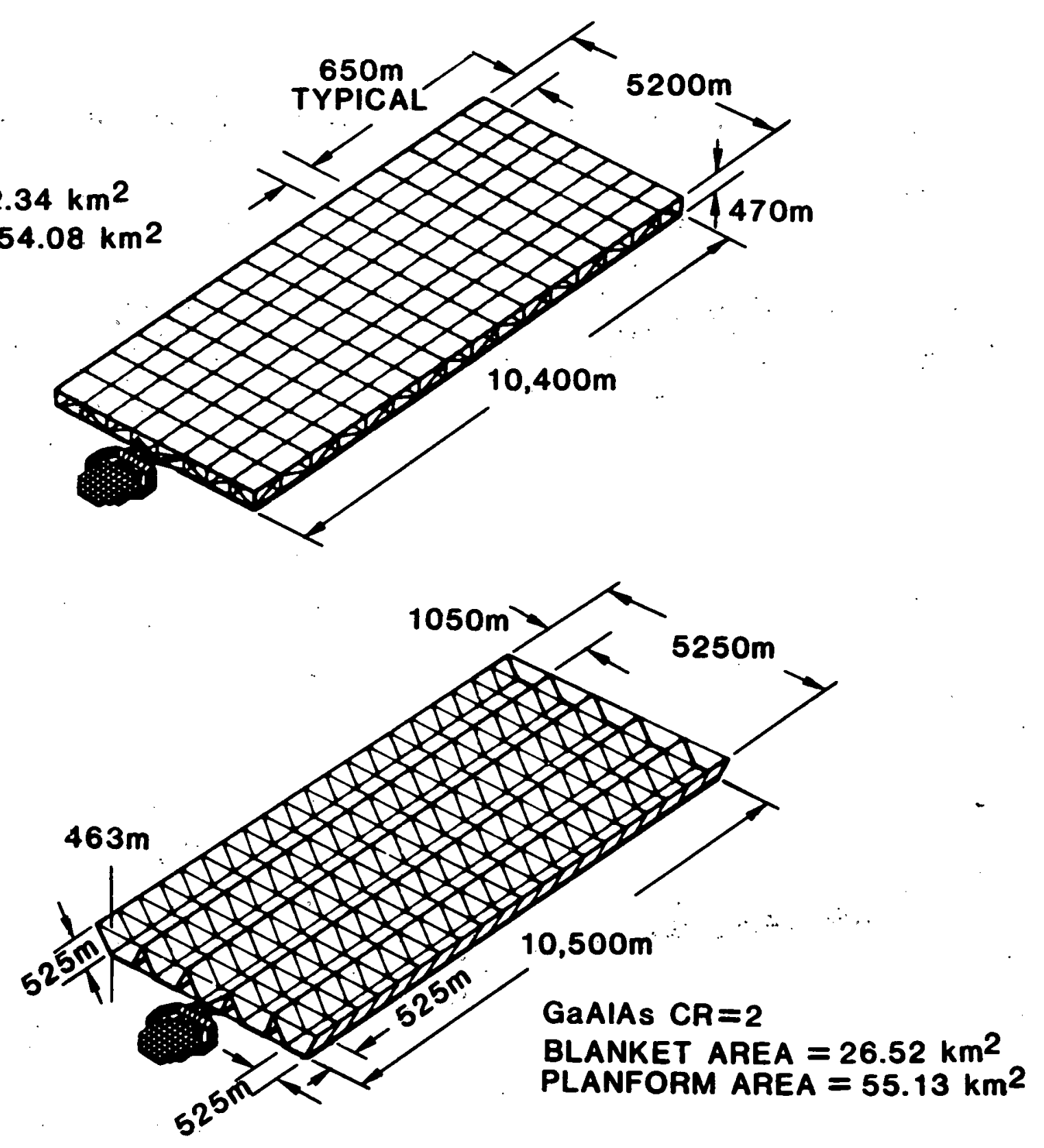

Fig: 3.2 SPS Satellite Configurations (Source: Ref. 1) 


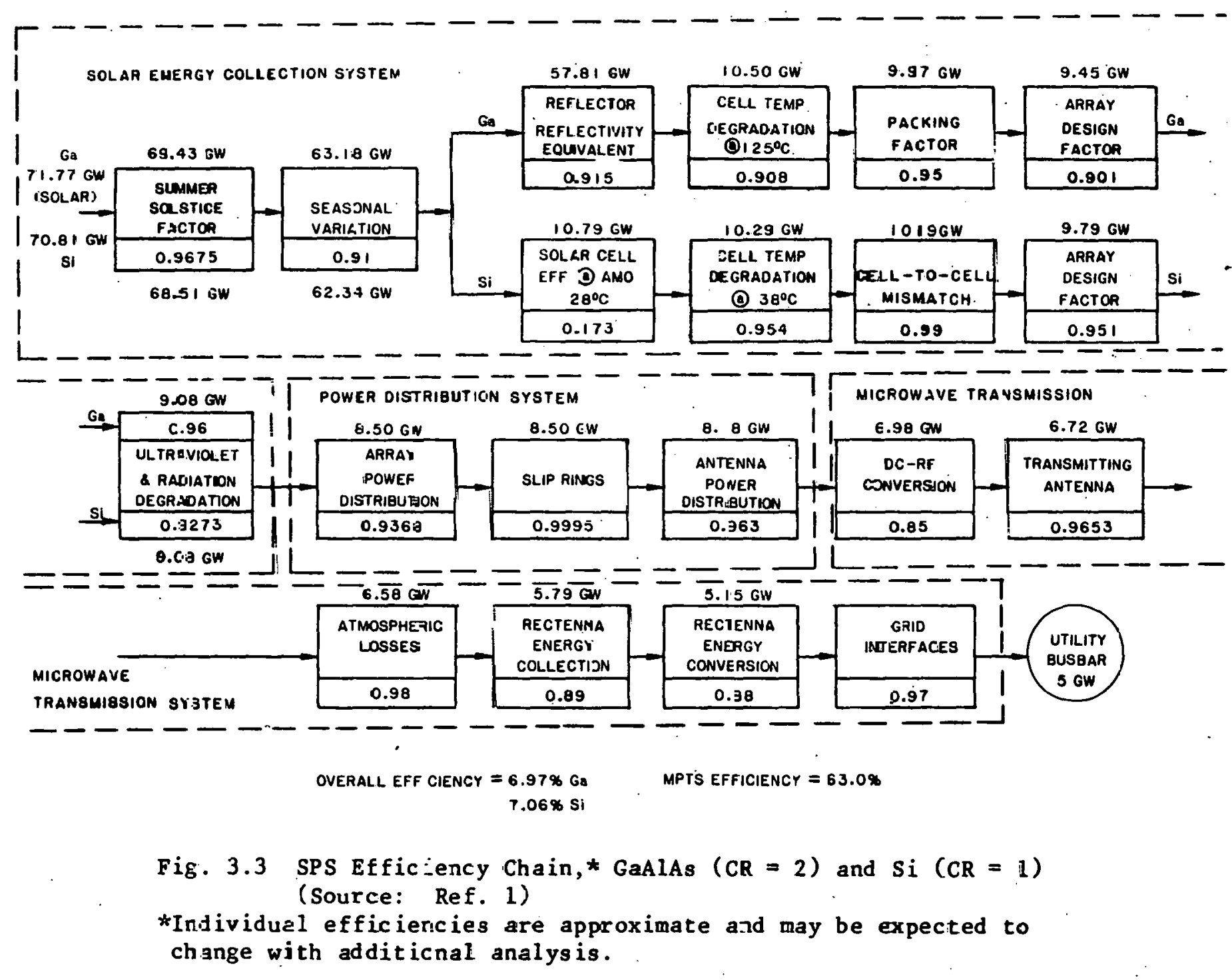


Table 3.4 SPS Cell and Planform Power Characteristics

\begin{tabular}{lcc}
\hline \multicolumn{1}{c}{ Cell Type } & GaAlAs & Silicon \\
\hline Concentration ratio & 2 & 1 \\
Solar power available & $1,353 \mathrm{~W} / \mathrm{m}^{2}$ & $1,353 \mathrm{~W} / \mathrm{m}^{2}$ \\
Solar power on cell at maximum off-sun pointing & $2,414 \mathrm{~W} / \mathrm{m}^{2}$ & $1,190 \mathrm{~W} / \mathrm{m}^{2}$ \\
Cell conversion efficiency at $28^{\circ} \mathrm{C}$ AMO (in vacuum) & $20 \%$ & $17.33 \%$ \\
Blanket power output & & $186 \mathrm{~W} / \mathrm{m}^{2}$ \\
Beginning of life & $380 \mathrm{~W} / \mathrm{m}^{2}$ & $149 \mathrm{~W} / \mathrm{m}^{2}$ \\
End of life & $370 \mathrm{~W} / \mathrm{m}^{2}$ & $186 \mathrm{~W} / \mathrm{m}^{2}$ \\
Planform power output & & $149 \mathrm{~W} / \mathrm{m}^{2}$ \\
Beginning of life & $185 \mathrm{~W} / \mathrm{m}^{2}$ & $171 \mathrm{~W} / \mathrm{m}^{2}$ \\
End of life & &
\end{tabular}

Source: Ref. 1 .

The end-mounted microwave antenna is a phased-array transmitter of $1-\mathrm{km}$ diameter. The phase control system utilizes an active, retrodirective array with a pilot beam reference for phase conjugation. Klystrons are used as the baseline power amplifier with slotted waveguides as the radiating element. The ground rectenna has subarray panels with an active element area of 78.5 $\mathrm{km}^{2}$. At $35^{\circ}$ latitude, the total rectenna area, including the buffer zone, would be $149 \mathrm{~km}^{2}$.

The construction of the satellite in geosynchronous orbit (GEO) is estimated to require six months. The initial estimates of construction crew size are 555 for the silicon option $[480$ in GEO and 75 in low earth orbit (LEO)] and 715 for the GaAlAs option (680 in GEO and 35 in LEO).

The transportation system assumed for the NASA contractor reference system consists of four major components: the heavy-lift launch vehicle (HLLV), the cargo orbit-transfer vehicle (COTV), the personnel launch vehicle (PLV), and the personnel orbit-transfer vehicle (POTV). The HLLV is a twostage, vertical launch, winged, horizontal landing, reusable vehicle with a 424-metric ton payload to low earth orbit. The Kennedy Space Center was chosen as the reference earth launch site. The COTV is an independent, reusable, electric engine-powered vehicle, which transports cargo from the HLLV delivery site in low earth orbit to the geosynchronous earth orbit. For the GaAlAs option, the COTV is powered by GaAlAs solar cells, whereas a silicon solar cell power supply is assumed for the silicon option.

Personnel for the orbital construction and support functions are transported to LEO by the PLV, which is a modified space shuttle orbiter with a passenger module. The POTV, a two-stage, reusable, chemical-fuel vehicle, is used to transfer personnel from LEO to GEO and vice versa. Additionally, a LEO operations base would be constructed and used for temporary storage of supplies and propellant. 
Power conversion equipment converts the direct current (DC) power from the collectors into high density microwave (RF) power; the microwave antenna transmits it to the ground-based rectifying antenna, called the rectenna. The microwave antenna is a phased-array transmitter of $1-\mathrm{km}$ diameter and contains 7,220 subarrays or power modules. The antenna transmits $6.85 \mathrm{GW}$ of power at $2.45 \mathrm{GHz}$.

The subarrays are arranged to provide a 10-dB Gaussian power distribu$t$ ion across the array surface. The power density varies from $22.14 \mathrm{~kW} / \mathrm{m}^{2} \mathrm{at}$ the center module to $2.45 \mathrm{~kW} / \mathrm{m}^{2}$ at the outer edge. At the earth's surface, the power is $23 \mathrm{~mW} / \mathrm{cm}^{2}$ at the rectenna center and $0.08 \mathrm{~mW} / \mathrm{cm}^{2}$ in the first s ide lobe.

Each subarray covers 108 square meters and contains from 4 to 50 klystrons, depending on the power output of the subarray, Each klystron converts DC to $70 \mathrm{~kW}$ of RF. An alternative concept desriper in the :SPS CDEP Reference System Report would use a 50-kW klystron tube that would result in the use of 6 to 50 tubes per subarray (Ref. 1; p. 30). The subarray radiates power through slotted waveguides on the surface. Electronic phasing equipment in each subarray processes a beam-phasing signal from the ground and focuses the microwave beam. Waste heat is dissipated by radiation. The subarray also includes power distribution and conditioning equipment, waveguides, amplifiers, and frequency-control electronics.

The rectenna consists of a dipole network and diode rectifiers, which receive and rectify the microwave power; a power distribution and conditioning system, which collects and delivers the rectified DC power to the utility interface; and the structure that provides support to the dipole rectenna panels and components of the distribution system. The support structure also provides a ground plane for the microwave power.

At $35^{\circ}$ latitude, the rectenna area of $10 \mathrm{~km}$ by $13 \mathrm{~km}$ contains 814 rows of rectenna panels tilted $40^{\circ}$ from the horizontal, providing an active intercept area of $78.5 \mathrm{~km}^{2}$. A total of 436,805 panels will be assembled on site and erected. In order to minimize electrical wiring from the rectenna panel area, two electrical switchyards will be employed, each with its own converter and relay building. The rectenna site, including auxiliary buildings and the buffer zone, has been estimated to be an elliptical plot $12 \mathrm{~km}$ by $15.8 \mathrm{~km}$, with a total area of $149 \mathrm{~km}^{2}$.

The configuration of the ground-based rectenna, which receives and rectifies the downlink power beam, has half-wave dipoles feeding schottky barrier diodes. Two-stage, low-paos filtera between the dipoles and diodes suppress harmonic generation and provide impedance matching. The'rectenna is a series of serrated panels perpendicular to the incident beam, rather than a continuous structure. Each panel has a steel-mesh ground plane with $75-80 \%$ optical transparency. This mesh is mounted on a steel framing structure, supported by steel columns in concrete footings. Aluminum conductors are used for the electrical power collection system. 


\subsubsection{Central-Station Terrestrial Photovoltaic System}

The reference terrestrial photovoltaic (TPV) alternative is a 200-MW system in which silicon cells are mounted in fixed-tilt, flat-plate arrays, in eight 25-MW modular components. The reference system, which does not include storage, is based primarily on designs published in a 1978 EPRI study. 9 That study defined the cost and performance goals for utility photovoltaic conversion devices and assessed the effects of photovoltaic generation on electric utility systems.

The reference TPV system is assumed to have a silicon-cell efficiency equal to that of the SPS silicon cell, or $19 \%$. (A cell efficiency of $12 \%$ was assumed in the EPRI study.) This modified assumption alters the EPRI design, in that it reduces by approximately $37 \%$ the number of solar cells required to generate 200 MW. Figure 3.4 shows the energy efficiency chain for this system.

Eight 25-MW modules of photovoltaic arrays are connected radially to a 34.5-kV switchyard, which, in turn, supplies the transmission grid through a step-up transformer. Each module contains $48.9 \times 10^{6}$ cells measuring $6 \mathrm{~cm} \times 6$ $\mathrm{cm}$. Each module is composed of the solar array field and its connecting DC cables and main bus, the DC-to-AC converter station, and the AC medium-voltage connection to the $34.5-\mathrm{kV}$ switchyard. Within each module, the photovoltaic cells are connected in series and parallel to provide as high a voltage as

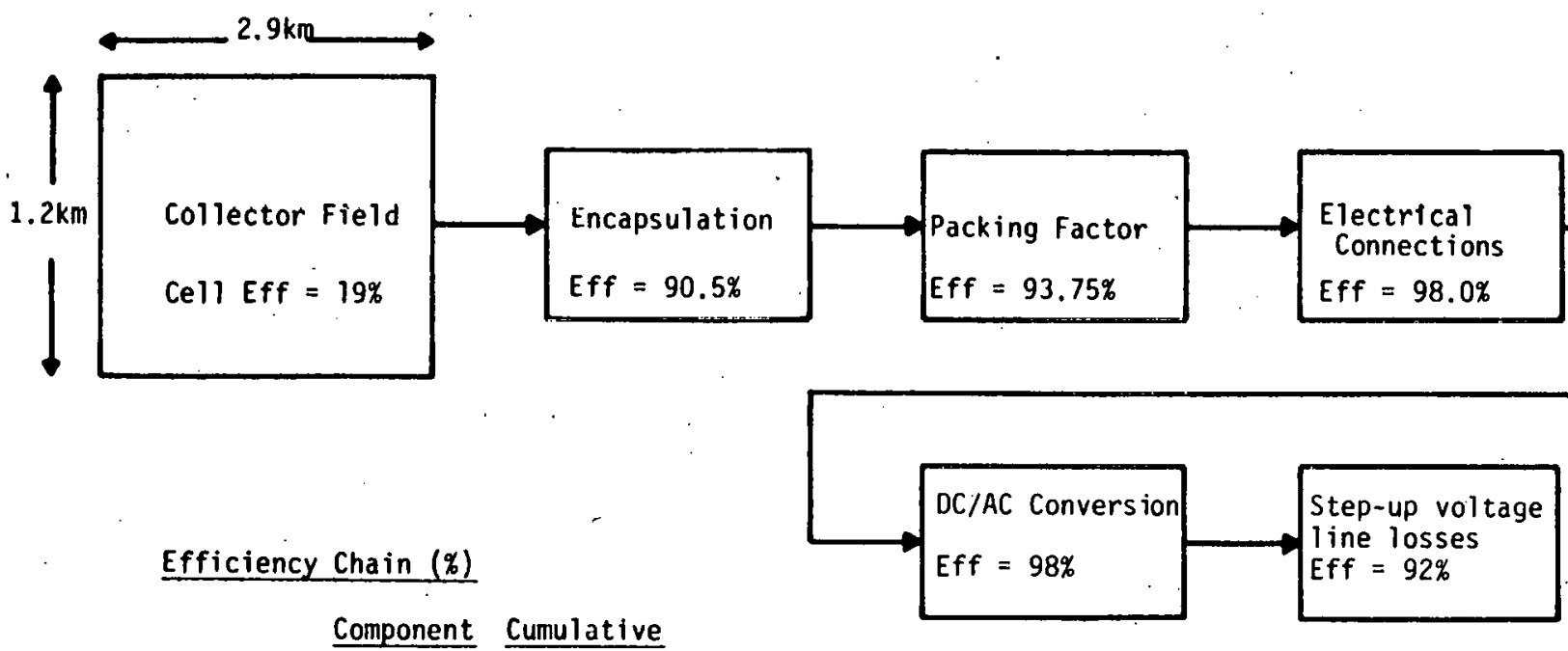

$\begin{array}{lll}\text { Solar Cell. } & 19.00 & 19.00 \\ \text { Encapsulation } & 90.50 & 17.20 \\ \text { Packing Factor } & 93.95 & 16.12 \\ \text { Connections. } & 98.00 & 15.80 \\ \text { DC/AC Converter } & 92.00 & 15.53 \\ \begin{array}{c}\text { Step-up volt/line } \\ \quad \text { losses. }\end{array} & 98.00 & 14.24\end{array}$

Fig. 3.4 Efficiency Chain of the Central-Station Photovoltaic System 
practical. This produces improved inverter efficiency and minimizes DC cable losses. The arrangement is such that $\pm 5,200 \mathrm{~V} \mathrm{DC}$ and 2,438 V AC are provided at the inverter input.

The plant capacity factor can be highly variable, since it is critically dependent on the plant's geographic location. Capacity factors have been estimated to. range from nearly $25.8 \%$ in the Phoenix area to just under $18 \%$ in Boston. The Phoenix site was chosen for this analys is.

The reference system is designed to occupy a $4-\mathrm{km}^{2}$ (1000-acre) site, which houses the solar arrays, switch gear, transformer station, and personnel buildings. Excluding periodic maintenance crews, the staff requirement is about 26 persons.

Environmental residuals from the plant site should he minimal under normal operating conditions. No gaseous emissions should result from the normal operation of the system, and any waste heat should be removed from the arrays by natural convection. Small amounts of waste and garbage would be generated by personnel on site and small amounts of combustion products would be produced by on-site maintenance vehicles. An unquantified but small amount of runoff would result from cleaning of the solar arrays. Some environmental residuals would be generated as a result of the cell manufacturing process, but these effects have not yet been characterized.

\subsubsection{Conventional Coal-Fired Power Plant}

The reference, high-sulfur coal-combustion system is a single-unit facility. The steam plant uses a cross-compound turbine generator with two parallel shafts and has a net plant capacity of $1250 \mathrm{MW}$. The basic steam cycle is modeled after a 1232-MW concept designed by United Engineers and Constructors (UE\&C), as described in their report "Commercial Electric Power Cost Studies."10 The UE\&C design utilizes a conventional lime flue-gas desulfurization system for stack gas cleaning and a mechanical draft cooling tower for removing condensate heat.

The characterization represents high-sulfur coal-combustion technology and $\mathrm{SO}_{2}$ removal as projected to be available in 2000. The plant capacity factor is assumed to be $70 \%$. It is also assumed that all of the plant's stack gases are processed to remove $90 \%$ of the $\mathrm{SO}_{2}$ (recent EPA regulations). Thus the reference high-sulfur coal facility for the year 2000 is assumed to use a Wellman-Lord $\mathrm{SO}_{2}$ removal system. The Wellman-Lord process has recently been demonstrated by the EPA, 11 and it is expected that this or a similar technology will be the preferred option in the year 2000. The Wellman-Lord system reduces the area of land required, but the processing of all stack gases decreases the net plant efficiency. Therefore, the plant capital cost is higher than that for the UE\&C design. 10 These factors have been fully accounted for in the characterization.

Figure 3.5. is a simplified schematic of the functional plant components. The combustion boiler produces steam at $26.5 \times 10^{6} \mathrm{~N} / \mathrm{m}^{2}(3845 \mathrm{psi})$ and $543^{\circ} \mathrm{C}\left(1010^{\circ} \mathrm{F}\right)$. Turbine power is produced with throttle stean of $24.2 \mathrm{x}$ $10^{6} \mathrm{~N} / \mathrm{m}^{2}(3515 \mathrm{psi})$ at $540^{\circ} \mathrm{C}\left(1000^{\circ} \mathrm{F}\right)$ for the high pressure turbine and steam at $4.1 \mathrm{~N} / \mathrm{m}^{2}(600 \mathrm{psi})$ at $540^{\circ} \mathrm{C}$ for the intermediate pressure turbine. 


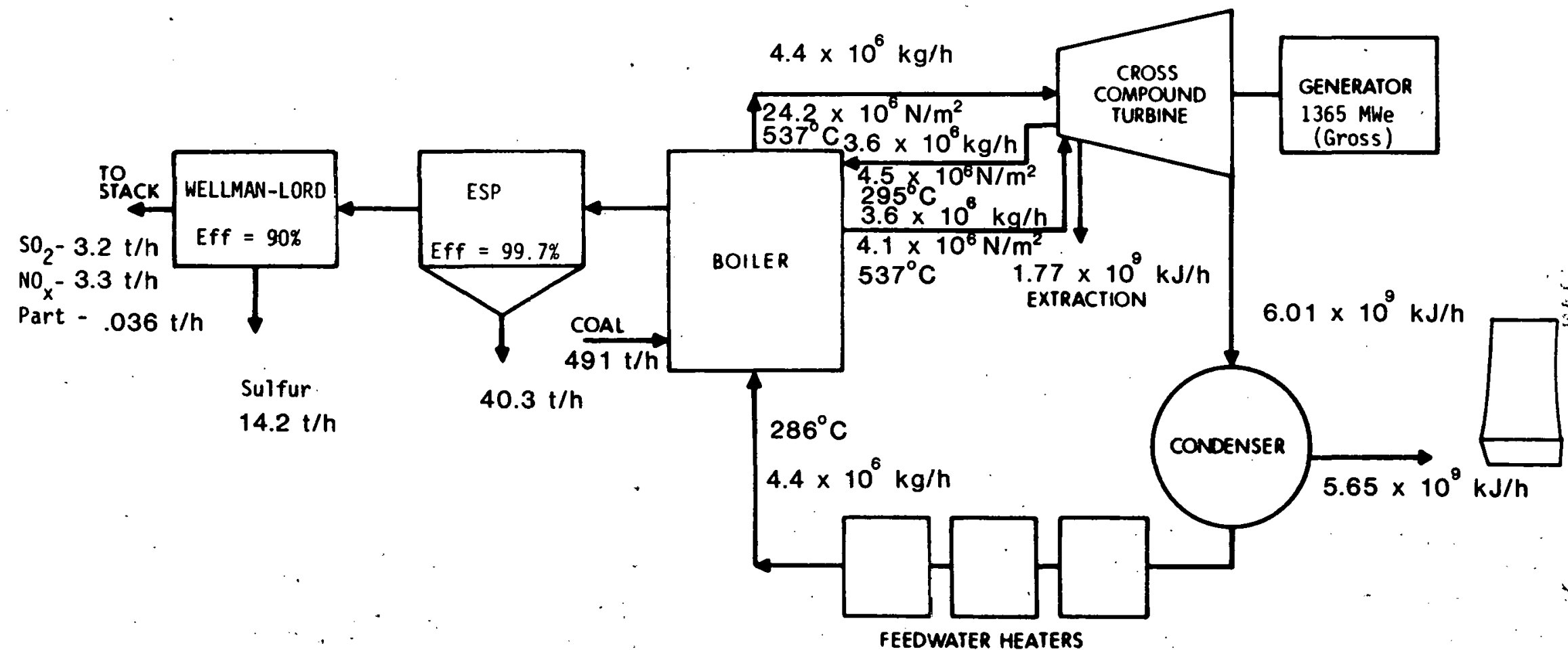

Gross Generation 1365 MWe

Aux Use.. $\quad 115$ MWe

Net Generátion. 1250 MWe

Fig. 3:5 Generation of 1250 MW, High-Sulfur Coal, Wellman-Lord Process 
Figure 3.5 illustrates the generation of a net capacity of 1250 MW with an assumed capacity factor of $70 \%$, from typical eastern high-sulfur. bituminous coal. The amount of pulverized coal yielding $10.1 \times 10^{3} \mathrm{~kJ}$ is required to generate one $\mathrm{kWh}$ of net output; this corresponds to a net plant efficiency of $35.75 \%$. The coal characteristics assume a higher heating value of $25.6 \mathrm{x}$ $10^{3} \mathrm{~kJ} / \mathrm{kg}$ of coal on an as-received basis. At this rate, an average of 8245 metric tons $(t)$ of coal would be needed at the site each day. Because coal storage requirements are estimated at full capacity factor, a 3-day live storage stock pile would contain $35.3 \times 10^{3} \mathrm{t}$ of coal, and a 57-day reserve storage would contain $67.2 \times 10^{4} \mathrm{t}$ of coal. A $9.1-\mathrm{m}-\mathrm{h}$ igh active storage and a $15.24-\mathrm{m}$-high reserve storage pile results in a site area of $56 \times 10^{3} \mathrm{~m}^{2}$ devoted to coal storage:

other fuel in the form of natural gas is aloo required for reducing sulfur dioxide $\left(\mathrm{SO}_{2}\right)$ from the Wellman-Lord scrubber system (Fig. 3.6$)$ to elemental sulfur. This process requires about $148 \times 10^{6} \mathrm{~kJ} / \mathrm{h}$ of natural gas at full plant capacity or, at $70 \%$ capacity and $34 \times 10^{3} \mathrm{~kJ} / \mathrm{m}^{3}$ of gas, about $2.7 \times 10^{6} \mathrm{~m}^{3}$ of natural gas per year.

The design has hot electrostatic precipitators sized for the removal of 99.7\% of the flyash particulates emitted from the combustion furnace boiler. Auxiliary electric power of $13.9 \mathrm{MW}$ is required for effective operation of the electrostatic precipitators. 12,13

The combustion of $4.9 \times 10^{5} \mathrm{~kg} / \mathrm{h}$ of coal with an ash content of $10.29 \%$ by weight produces $40 \times 10^{3} \mathrm{~kg} / \mathrm{h}$ of flyash, assuming an $80 \% \mathrm{flyash} / 20 \%$ bottom ash proportion. (About $10^{4} \mathrm{~kg} / \mathrm{h}$ of bottom ash would be produced.) Removal of $99.7 \%$ of this flyash leaves $120 \mathrm{~kg} / \mathrm{h}$ of flyash to be sent downstream for further processing in the Wellman-Lord $\mathrm{SO}_{2}$ removal system.

The sludge wastes from the electrostatic precipitators and bottom ash total $63,120 \mathrm{~kg} / \mathrm{h}$ for the $1250 \mathrm{MW}$ reference coal facility at $100 \%$ capacity.

Downstream from the electrostatic precipitators is the Wellman-Lord flue-gas desulfurization system. This system uses a regenerable process in which $\mathrm{SO}_{2}$ is removed from flue gases with a sodium sulfite scrubbing solution. The concentrated $\mathrm{SO}_{2}$ stream that is produced $c$ an be processed into elemental sulfur or sulfuric acid, both of which are marketable industrial products.

The Wellman-Lord process consists of the four basic steps shown schematically in Fig. 3.6. These steps are (1) flue gas pretreatment, (2) $\mathrm{SO}_{2}$ absorption, (3) purge treatment, and (4) sodium sulfite regeneration. A fifth step, the processing of $\mathrm{SO}_{7}$ into marketable sulfur by-products, is not part of the Wellman-Lord process, but is generally associated with Wellman-Lord installations.

Tables 3.5 and 3.6 show the air pollutants and solid waste products emitted by this 1250 MW facility.

The normal construction period would take a total of seven years. Two years would be taken up for site selection, design, and preparation, and five years for on-site construction. Operation of the plant would require a staff of 259 . 


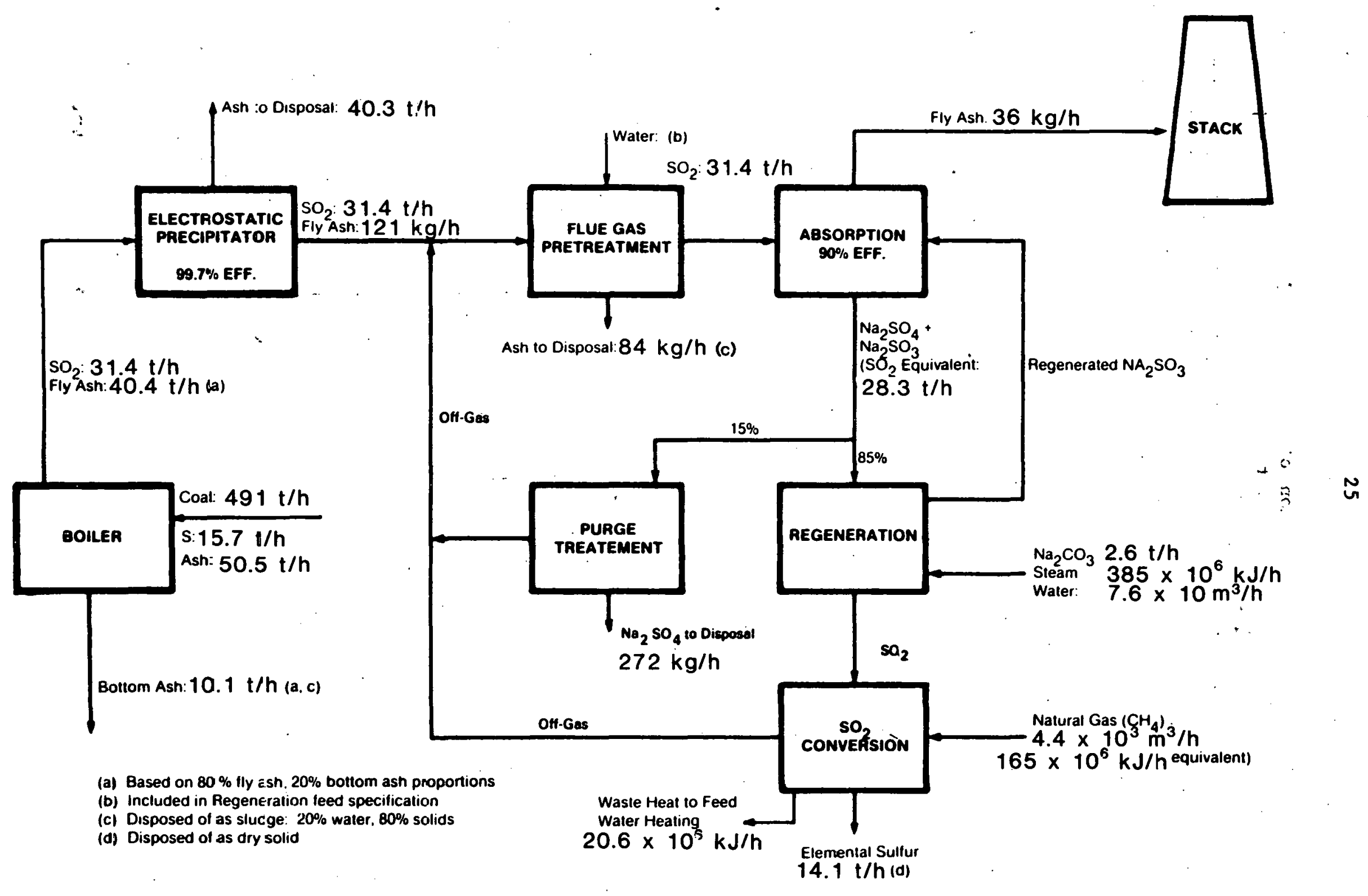

Fig. 3.6 Wellman-Lord Process (Adapted from Ref. 5) 
Table 3.5 Air Pollutants from a 1250-MW Coal Facility

\begin{tabular}{|c|c|c|c|c|c|c|}
\hline \multirow[b]{2}{*}{ Pollut ant } & \multicolumn{2}{|c|}{$100 \%$ Capacity } & \multirow{2}{*}{$\frac{y \text { Factor }}{t}$} & \multicolumn{2}{|c|}{$70 \%$ Capacity } & \multirow{2}{*}{$\frac{\text { Factor }}{\mathrm{kg} / 10^{6} \mathrm{~kJ}}$} \\
\hline & & $g / h$ & & $\mathrm{~kg} / \mathrm{h}$ & $\mathrm{t}$ & \\
\hline $\mathrm{SO}_{2}$ & & 136 & 27,605 & 2203 & 19,323 & 0.26 \\
\hline Particulates & & 36 & 318 & 25 & 223 & 0.003 \\
\hline $\mathrm{NO}_{\mathbf{x}}$ & & 254 & 28,537 & 2278 & 19,978 & 0.27 \\
\hline
\end{tabular}

Table 3.6 Solid and Sludge Wastes from a 1250-MW

Coal Facility. $70 \%$ Capacity Factor

\begin{tabular}{|c|c|c|c|c|}
\hline \multirow[b]{2}{*}{ Solid Waste } & \multicolumn{3}{|c|}{$\begin{array}{c}\text { Accumulation Rates at } 70 \% \\
\text { Capacicy Factor }\end{array}$} & \multirow{2}{*}{$\frac{\text { Laud ALea }}{10^{3} \mathrm{~m}^{2}}$} \\
\hline & $\mathrm{kg} / \mathrm{h}$ & $t / y r$ & $10^{3} \mathrm{~m}^{3} / \mathrm{yr}$ & \\
\hline Elemental Sulfurb & 9,917 & 86,964 & 44 & 190 \\
\hline Ash Sludge & 44,260 & 388,105 & 269 & 1,145 \\
\hline $\begin{array}{l}\text { Sodium Sulfite/ } \\
\text { Sodium Sulfate }\end{array}$ & 2,909 & 16,744 & 8.6 & 40.5 \\
\hline Total & - & - & - & $1,375.5$ \\
\hline
\end{tabular}

assumes 8-m disposal depth typical of current practices.

${ }^{b_{D}}$ isposal density $=1953 \mathrm{~kg} / \mathrm{m}^{3}$.

${ }^{8} 80 \%$ ash, $20 \%$ water, density $=1440 \mathrm{~kg} / \mathrm{m}^{3}$. Solids content is $40,100 \mathrm{~kg} / \mathrm{h}$ from bottom ash, and $85 \mathrm{~kg}$ from Wel Iman-Lord pretreatment.

\subsubsection{Coal-Gasification/Combined-Cycle Power Plant}

The coal-gasification/combined-cycle plant is an integrated system whose primary components are a gasifier, an open-cycle gas turbine, and a Rankine bottoming cycle. The basic plant is modeled after a 579-MW plant described in the ECAS study; 14 the design was augmented with information from the EPRI Preliminary Design study. 15 The plant design was scaled to $1250 \mathrm{MW}$ net plant output ( 2 units at $625 \mathrm{MW}$ each).

The reference facility is fired with eastern high-sulfur bituminous coal with heat content of $25,646 \mathrm{~kJ} / \mathrm{kg}(11,026 \mathrm{Btu} / \mathrm{lb})$. The overall net plant efficiency, which accounts for in-plant auxiliary steam and electrical consumption, is $38.5 \%$. Figure 3.7 displays the major pieces of plant equipment in a simplified cycle schematic and energy flow diagram of the reference design . 


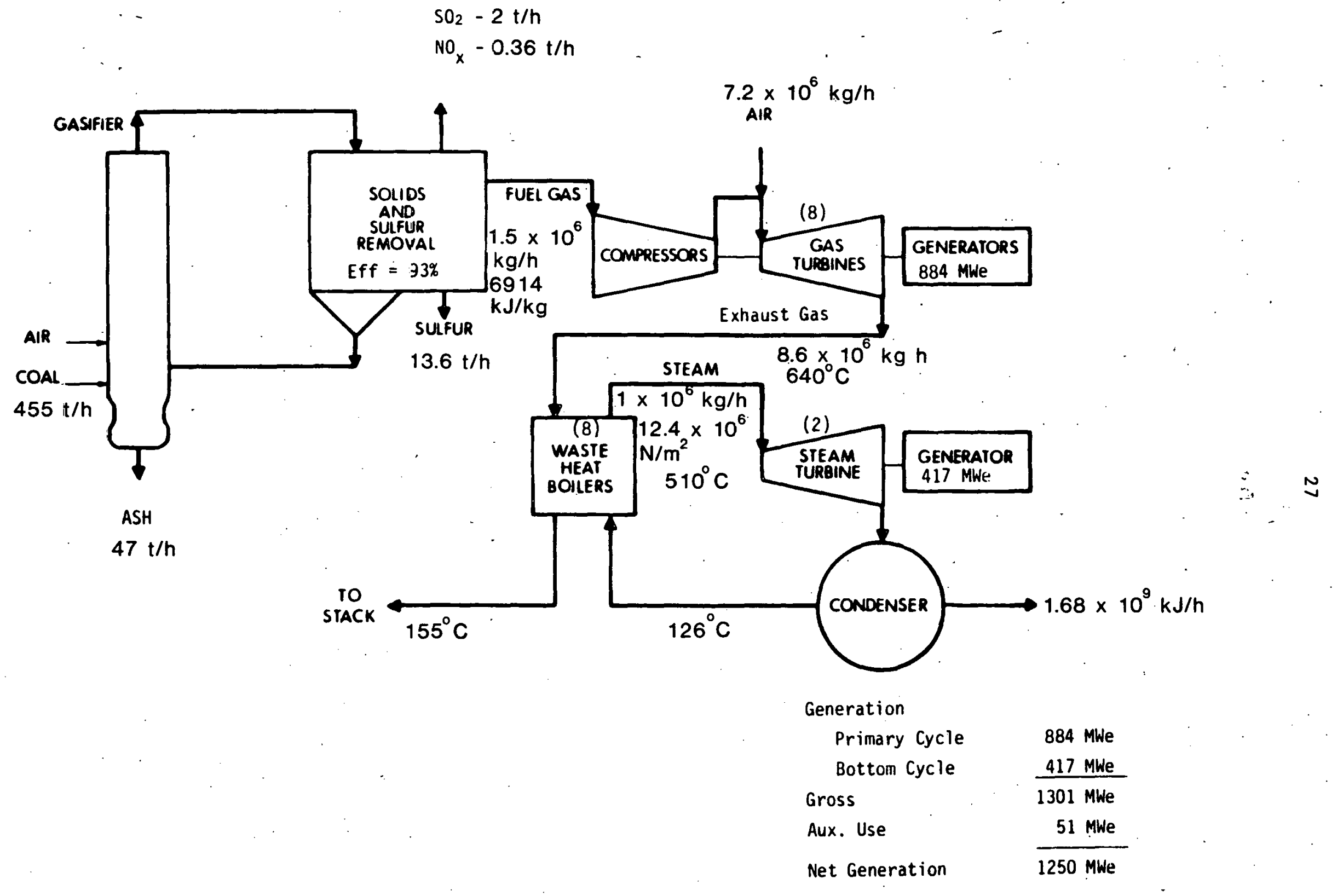

Fig. 3.7 1250 MW Coal-Gasification/Combined-Cycle System 
The prime cycle consists of eight air-cooled gas turbine generator units, with a $12: 1$ compressor pressure ratio and $1315^{\circ} \mathrm{C}$ firing temperature (that is, the temperature at the inlet of the first-stage rotor). The prime cycle generates two-thirds of the total electrical power output. The gas turbine exhaust temperature is $640^{\circ} \mathrm{C}$.

The bottoming cycle includes eight heat-recovery steam generators (HRSG) and two steam turbines. The HRSGs extract thermal energy from the gas turbine exhaust stream. The steam is supplied to steam-turbine generators, which contribute about one-third of the total power output. At full capacity, coal feed is required at a rate of $455 \mathrm{t} / \mathrm{h}$ or $2.8 \times 10^{6} \mathrm{t} / \mathrm{yr}$ at $70 \%$ capacity factor. At this rate, an average of $7650 \mathrm{t}$ of coal would be required at the site each day; as coal storage requirements are estimated at full capacity factor, a 3-day live storage stock pile would contain 22,950 of coal, and a 57-day reserve storage would contain 435,000 t of coal.

The average slurage density of urflicy coal in live storage is 700 $\mathrm{kg} / \mathrm{m}^{3}$ and reserve storage density averages $865 \mathrm{~kg} / \mathrm{m}^{3}$. The assumption of $9.15-$ $\mathrm{m}$-high active storage and $15.25-\mathrm{m}-\mathrm{high}$ reserve storage yields an area of about $36 \times 10^{3} \mathrm{~m}^{2}$ devoted to coal storage and handling.

Figure 3.8 depicts. the major environmental pollutants that arise from the impurities in the fuel and water used by the plant. The major impurities in the fuel are the sulfur and nitrogen compounds and incombustible ash. In the gasification step, almost all of the ash is separated from the coal, so it does not show up as a potential air pollutant. Similarly, about $93 \%$ of the sulfur is removed from the process stream by the combined Alkazid-claus process. Another $1.3 \%$ is disposed of in the scrubber sludge from the wet limestone scrubber. The remaining sulfur appears as $\mathrm{SO}_{2}$ in the stack gas from the various plant flues and exhausts. $\mathrm{NO}_{2}$ control is effected by removing most of the $\mathrm{NH}_{3}$ from the fuel gas streams before combustion.

Water used for plant cooling is also a source of environmental pollu$t$ ion. As the water is evaporated, concentrations of dissolved solids increase. This brackish "blowdown" water must be specially handled, tn avnid pollution of local water systems.

The cleanup system must remove enough sulfur as elemental sulfur so that the sum of the $\mathrm{SO}_{2}$ emitted from incinerator flues and the $\mathrm{SO}_{2}$ emitted from the power plant flues will be no greater than allowed by EPA standards. The carbonyl sulfide (COS) formed in the gasifier and entering with the raw gas is almost completely hydrolyzed to hydrogen sulfide ( $\mathrm{H}_{2} \mathrm{~S}$ ) before entering the Alkazid plant. Five percent of the $\mathrm{H}_{2} \mathrm{~S}$ removed by the Alkazid plant will not be converted to elemental sulfur in the claus plant. The tail gas is treated in the Wellman-Lord plant, which allows $90 \%$ of the sulfur to be recycled back to the claus process. The Alkazid plant removes $95 \%$ of the $\mathrm{H}_{2} \mathrm{~S}$ entering with the raw gas. Only $5.6 \%$ of the total sulfur is emitted to the atmosphere as $\mathrm{SO}_{2}$.

Nitrous oxides are formed by combustion of ammonia, and to a 1 imited extent by oxidation of $\mathrm{N}_{2}$ gas diluent. To meet the emission standards, 0.14 $\mathrm{kg}$ of $\mathrm{NO}_{2}$ may be emitted to the atmosphere per million $\mathrm{kJ}$ of gaseous fuel. 




Fig. 3.8 Summary of Emissions from a 1250-MW, Low-Btu Gasifier, Combined-Cycle Plant 
In the "cleanup system, foul water condenses from the gas during dewatering. A foul process water enters with oil and phenol from the gasifier washer-coolers. These foul waters contain dissolved $\mathrm{H}_{2} \mathrm{~S}, \mathrm{NH}_{3}, \mathrm{CO}_{2}$, and phenols. The water separated from the oil and phenol is returned to the washer-coolers where some additional makeup water is located. This makeup water evaporates and enters the cleanup systems with the saturated gas.

The construction period for a large coal-fired electric generation facility of the type characterized here would take a total of seven years. This includes a two-year period of fairly low level of effort for site selec$t$ ion, design and preparation, and a five-year period of actual on-site construction. During the on-site construction period, an estimated 8.1 million person-hours of direct craft labor would be required. The operating personnel requirement ( 336 persons) for this plant were estimated from experience with conventional plants.

\subsubsection{Light Water Reactor Power Plant}

The reference light water reactor (LWR) power plant $16-20$ is a 1250-MW single-unit facility consisting of a pressurized water reactor supplying superheated steam to a conventional turbine generator. Condenser cooling is accomplished with a cooling tower.

The reference reactor as shown schematically in Fig. 3.9 was scaled up to 3750 MWt from a basic Westinghouse 3450-MWt design. At the present $t$ ime, nuclear fuel is being discharged from reactors after an average burnup of $25,000$ to 30,000 megawatt days per metric ton of fuel ( $M W-d / t)$. LWR technology has a goal2l of achieving $50,000 \mathrm{MW}-\mathrm{d} / \mathrm{t}$, and therefore this value was assumed to be achieved by the year 2000 for the purpose of this characterization.

The nuclear steam supply system (NSSS) consists of a light-watermoderated nuclear reactor having a reactor core containing low-enriched uranium oxide fuel, approximately $4.15 \% \mathrm{U}-235$, in approximately 193 fuel assemblies. Loaded in the core are $98,000 \mathrm{~kg}$ of fuel. The core is refueled by replacing approximately one-third of the total set. of fuel elements at roughly one-year intervals. The spent fuel is stored on, site in a special fuel handing building. This building is also a repository for fresh fuel prior to its insertion in the core.

The NSSS produces approximately. 3750 MWt at nominal. full power. The power generation system consists of the reactor core and vessel, its associated pressurizer, and four primary reactor coolant loops and four steam generators. Primary coolant (water) is heated from $295^{\circ} \mathrm{C}$ to $330^{\circ} \mathrm{C}$ by the nuclear reaction taking place in the core. The nominal coolant pressure is $15.5 \times 10^{6} \mathrm{~Pa}$ (or $\mathrm{N} / \mathrm{m}^{2}$ ). The high pressure is maintained in the primary system by a pressurizer to prevent boiling in the core. This hot water is then passed through the steam generators (u-tube heat exchangers) where water on the secondary side of the heat exchanger is heated to produce steam. Water on the primary side of the steam generator is returned to the core to be reheated to $330^{\circ} \mathrm{C}$. Steam produced on the secondary side of the steam generator passes through the turbine generator power-conversion system. The turbine generators, at nominal rated power, produce $1250 \mathrm{MW}$. The condensate from the 


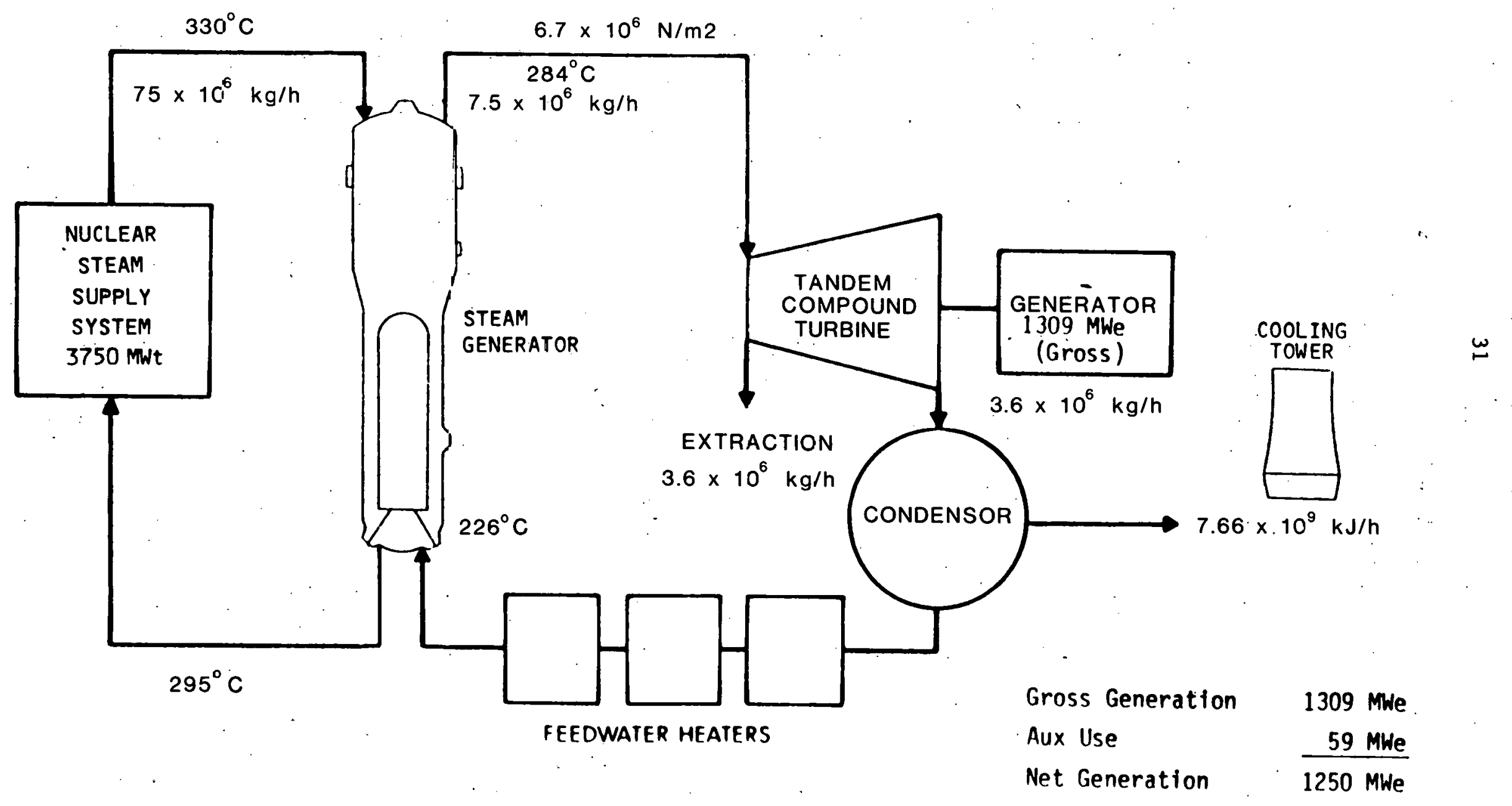

Fig. 3.9 Simplified LWR Flow Diagram 
turbine is returned by the steam generator feedwater pumps. The reactor is equipped with residual-heat removal systems. The condensers are designed to condense the outlet steam from the low pressure turbine and the exhaust steam from the auxiliary turbine drive of the feedwater pump at $500 \mathrm{~Pa}$, by dissipating the heat to three mechanical-draft wet cooling towers. The three main mechanical-draft wet cooling towers are each sized for one-third of the requirements. Each tower is designed to cool $13.6 \mathrm{~m}^{3} / \mathrm{s}$ of water from $48^{\circ} \mathrm{C}$ to $33^{\circ} \mathrm{C}$ when operating at a wet bulb temperature of $23^{\circ} \mathrm{C}$. Each tower employs a reinforced concrete-filled structure combined with components for water distribution, fill splash service, support system, drift eliminators, louvers, and fan deck.

Radioactive contaminants can come from the fuel itself or from (1) impurities in the fuel cladding, (2) activated wear products, or (3) other sources. Because several systems are contaminated, normal maintenance, operations, and leaks will lead to release of some of these elemento. The mechanisms of release of these radioactive elements are primarily leakage through the building ventilation systems and dissolution in liquid effluents. Areas that have the potential for contamination are ventilated through high efficiency particulate filters, which remove more than $99.9 \%$ of the particles larger than $0.3 \mu \mathrm{m}$. Potentially contaminated liquid effluents are monitored or processed to remove radioactive elements by filtration and ion exchange. In each case, not all of the radioactive elements can be prevented from entering the biosphere. Consequently, radioactive elements are emitted to the biosphere by the LWR, * within the limits prescribed by the EPA and enforced by the NRC.

Water consumption results primarily from cooling tower evaporative losses and cooling tower blowdown $(1.42 \mathrm{~m} 3 / \mathrm{s}$ at full power). The largest consumers of water are the mechanical-draft cooling towers (about $1 \mathrm{~m}^{3} / \mathrm{s}$ ).

The primary sources of liquid effluents from a LWR facility include the cooling tower blowdown stream and process water effluent. No radioactive wastes are discharged in effluent streams. These waste streams, which are processed to remove radionuclides, are then discharged under controlled conditions.* Cooling tower blowdown does not contain any radionuclide contamination but does contain chemicals added for control of corrosion and biological growth.

\subsubsection{Liquid-Metal, Fast-Breeder Reactor}

The LMHBK plant reference design' is a 3400-MWt loop-type, sodiumcooled fast-breeder reactor plant with a nominal electrical rating of $1250 \mathrm{MW}$.

*Airborne radionuclides: total noble gases, $3 \times 10^{3} \mathrm{Ci} / \mathrm{yr}$; iodine, $13.1 \mathrm{x}$ $10^{-2} \mathrm{Ci} / \mathrm{yr} ; \mathrm{Mn}, \mathrm{Fe}, \mathrm{Co}, \mathrm{Sr}, \mathrm{Cs}, 4.1 \times 10^{-2} \mathrm{Ci} / \mathrm{yr}$.

HrWasle-water effluents at ' $70 \%$ capacity factor: total suspended solids, $0.94 \mathrm{t} / \mathrm{d}$; total dissolved solids, $2.35 \mathrm{t} / \mathrm{d}$; organics, $210 \mathrm{~kg} / \mathrm{d}$.

tThe plant design was developed by United Engineers and Constructors for the Department of Energy in the Energy Economic Data Base (EEDB) program as described in Ref. 22. Additional input was derived from Ref. 23. 
The plant area will be about 70 acres, including the reactor building, switchyard, parking lot, access roads, and wet cooling towers. As a minimum, a buffering area of 400 acres is needed. Thus with other physical facilities, a total area of 1000 to 1200 acres is needed. The 1000-MWe LMFBR design (about 2500 MWt) was scaled up to 1250 MWe because the cost estimate is also based on this plant and major equipment.

The LMFBR primary system consists of a liquid sodium-cooled nuclear reactor having a reactor core containing low-enriched (about 11-15\%) uranium and plutonium oxides in approximately 400 fuel-and-blanket assemblies. The core is refueled by replacing approximately one-third of the assemblies after achieving a 53,000 MW-d/t average burnup. Both the new and spent reactor fuels are intensely radioactive and must be stored in heavily shielded areas.

The reactor produces approximately 3417 MWt at nominal full power. The LMFBR heat transport system removes the heat generated by the reactor. core and converts it to the rotational mechanical energy required by the generator to produce electric power. The overall system consists of a radioactive primary coolant (liquid sodium) system, a nonradioactive secondary coolant (also liquid sodium) system, a steam generation system, and a steam plant system, the latter including the turbine that delivers the required mechanical energy to the electrical generator. A simplified system diagram is given in Fig. 3.10.

The primary coolant system consists of several redundant circulating loops that conduct sodium from the core exit plenum of the reactor vessel and circulate it through intermediate heat exchangers. Here, the heat is transferred to the sodium of the secondary coolant system. The primary sodium then returns to the reactor vessel. In the secondary system, secondary sodium is heated in the intermediate heat exchangers and is circulated to the steam generation system. There are four parallel primary loops and four secondary loops, one serving each primary loop.

Two basic arrangements for the primary coolant system have been proposed: the pool-type and the loop-type configurations. These are depicted schematically in Fig. 3.11. In the pool-type configuration, the reactor, intermediate heat exchangers, primary pump, and interconnecting piping are all immersed in a large primary tank filled with sodium. During operation, sodium is drawn from the bulk content of the tank by the primary pumps and is forced through the reactor. Then, the sodium flows by gravity through the intermediate heat exchangers and discharges back to the bulk sodium in the primary tank. The driving force for the intermediate heat exchanger flow is the difference between the level of sodium over the reactor and that in the remainder of the primary tanks. With this configuration, the primary tank with its cover and the tubes and tube sheets of the intermediate heat exchangers constitute the primary coolant system boundary.

In the loop-type configuration, the primary pumps and the intermediate heat exchangers are located outside the reactor vessel. Either hot-leg or cold-leg pumps could be used in the primary system. The primary loop piping is elevated, and guard vessels are provided around the pump, intermediate heat exchanger, and reactor vessel so that leaks in the primary.piping or these components cannot cause the sodium level in the reactor to drop below the minimum safe level. The loop nozzles would be covered, and continuous 


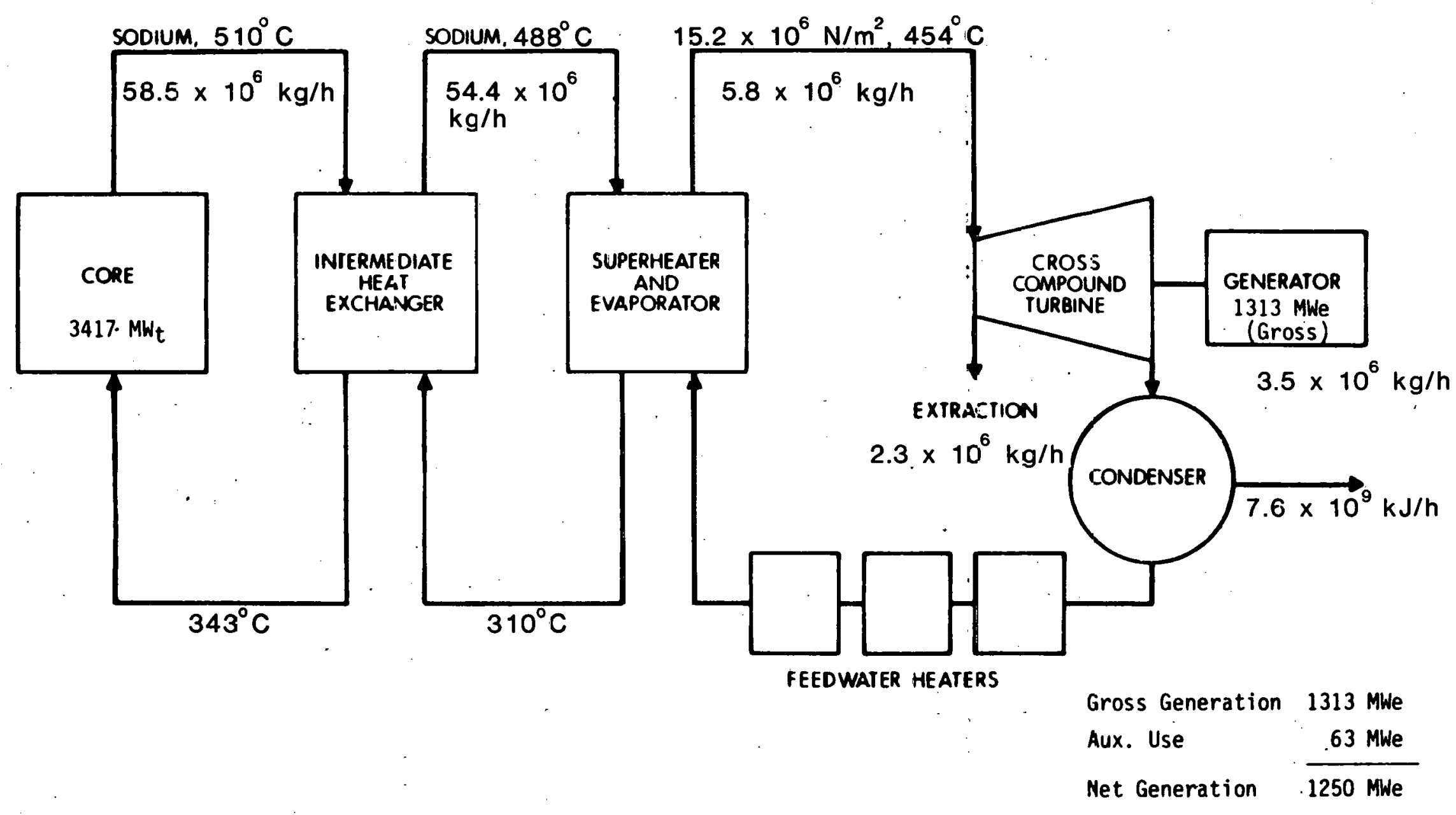

Fig. 3.10 1250 MW Liquid-Metal, Fast-Breeder Reactor 
POOL
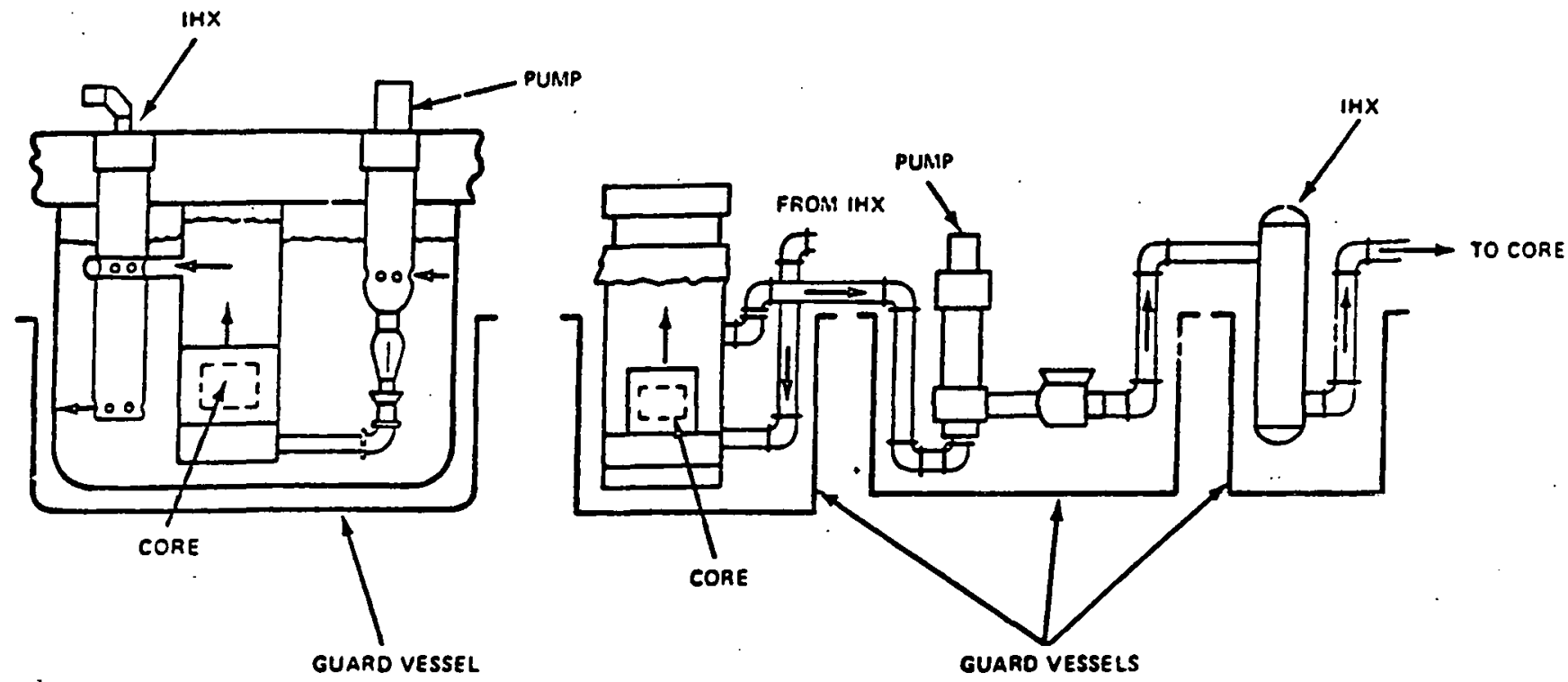

Fig. 3.11 Configurations of Pool- and Loop-type Primary Coolant Systems

heat removal by sodium circulating through the loops could be permitted. The LMFBR characterized in this section is a loop-type plant.

The primary sodium system is designed to operate at a lower pressure than the secondary sýstem. Thus, should a leak develop in an intermediate heat exchanger between these two systems, sodium would flow from the nonradioactive secondary system into the radioactive primary system. Finally, even though such leakage would not result in a radiological problem in the secondary system, the intermediate heat exchangers are designed to facilitate removal or replacement of faulty tubco.

The overall steam cycle is expected to be similar to that of modern fossil-fired, steam-electric power plants. The turbine design assumed in this study is a set of tandem compound turbines like those used in fossil-fuel plants.

Barriers to release of fission products are the fuel element cladding, the boundary of the primary coolant system, and the outer reactor containment.

The outer containment consists of a leak-tight cylindrical steel or steel-lined concrete building with a flat bottom and hemispherical or ellipsoidal dome. The containment building houses the reactor and entire primary coolant system, spent fuel handling and storage facilities, and sodium service systems related to the primary system.

The turbine configuration consists of two half-capacity tandem, compound, four-flow machines with $0.85-\mathrm{m}$ last stages designed to operate at $3600 \mathrm{rpm}$. Inlet steam conditions at the high-pressure throttle valves are 
$15.4 \times 10^{6} \mathrm{~Pa}$ and $455^{\circ} \mathrm{C}$. This reactor plant design provides the superheat so the inlet steam is not saturated; its condition resembles that in a fossil-fired power plant.

The condensers are designed to condense the low-pressure turbine outlet steam and exhaust steam from the auxiliary turbine drive of the feedwater pump by dissipating the heat to three mechanical-draft wet cooling towers. Each tower is designed to $\operatorname{coo} 112.3 \mathrm{~m} / \mathrm{s}$ of water from $48^{\circ}$ to $33^{\circ} \mathrm{C}$ when operating at a wet bulb temperature of $23^{\circ} \mathrm{C}$.

Radioactive contaminants come from the fuel itself, impurities in the fuel cladding, activated wear products, or other sources. Because several systems are contaminated, normal maintenance, operations, and leaks will lead to release of some of these elements. The building ventilation systems and processed liquid effluents are the transport mechanisms for release of these radioactive elements. Areas with the potential for contamination are ventilated through high-efficiency particulate filters, which remove more than $99.9 \%$ of the particles greater than $0.3 \mu \mathrm{m}$. Potentially contaminated 1iquid effluents are monitored or processed to remove radioactive elements primarily by filtration and ion exchange. In each case, not all of the radioactive elements can be prevented from entering the biosphere. Table 3.7 shows the estimated airborne radionuclide releases from the reference 1250-MW LMFBR facility. These emissions are within the limits prescribed by the EPA for the LWR.

The aqueous chemical wastes from a nuclear power plant generally enter the environment via the blowdown stream from a closed-cycle cooling system or the circulating cooling water stream from an open-cycle system. The major sources of the waste streams from a nuclear power plant are those originating from the condenser cooling system and the process water system. All other waste streams are minor compared to those. Negligible radioactive effluents will be emitted from an LMFBR plant. A summary of effluents is provided in lable 3.8 .

Solid wastes generated at the reactor will consist typically of filters from the heating and ventilation system, deactivated primary coolant sodium cold traps, analytical laboratory and liquid waste treatment residues, contaminated tools and parts, and waste such as plastic bags, footcovers, paper towels, and protective clothing. These wastes will be compacted and packaged in 55-galion $\left(0.21 \mathrm{~m}^{3}\right)$ sealed drums, then shipped to a low-level waste burial ground. About $0.26 \mathrm{~m}^{3}$ of tritium waste per year, in the form of $\mathrm{Ca}\left(\mathrm{O}^{3} \mathrm{H}\right)_{2}$, will be included in these solid wastes.

About 3117 , curies of betagamma waste and about 30,000 curies of tritium waste will be generated each year.

Table 3.7 Puslulated Radiunuclide Releases, 1250-MW LMFBR Power Plant at $70 \%$ Capacity Factor

\begin{tabular}{lr}
\hline Nuc lide & $\begin{array}{c}\text { Atmospheric Release, } \\
\text { Ci/yr }\end{array}$ \\
\hline $\mathrm{H}-3$ & 65.63 \\
$\mathrm{Ar}-39$ & 87.50 \\
$\mathrm{Kr}-85 \mathrm{~m}$ & 0.33 \\
$\mathrm{Kr}-85$ & 0.44 \\
$\mathrm{Kr}-87$ & 0.44 \\
$\mathrm{Kr}-88$ & 0.54 \\
$\mathrm{Xe}-133$ & 0.03 \\
\hline
\end{tabular}


The 1250-MW LMFBR would reject heat at about $7.5 \times 10^{6} \mathrm{~kJ} / \mathrm{h}$ through the cooling towers. In addition, there will be miscellaneous thermal losses to air (called general plant losses) amounting to less than $1 \%$, a value typical of present-day nuclear facilities. Approximately $2.8 \times 10^{5}$ $\mathrm{m}^{2}$ of 1 and will be required for facilities associated with the LMFBR power plant; namely, the reactor buildings, turbine building, switchyard, parking lot, access roads, and cooling towers. As a minimum, an exclusion area of at least $16 \times 10^{6}$ $\mathrm{m}^{2}$ is needed, and presently most LWR stations are on even larger sites.

Water consumption results primarily from cooling tower evaporative losses, cooling tower blowdown, and general plant uses, totalling $1.28 \mathrm{~m}^{3} / \mathrm{s}$. By far the largest consumers of water are the mechanicaldraft cooling towers, which use approximately $0.88 \mathrm{~m}^{3} / \mathrm{s}$.

\subsubsection{Fusion}

The reference fusion-power plant is based on the NUWMAK power plant design developed by the University of Wisconsin Fusion Engineering Program of the Nuclear. Engineering Department. 24 The NUWMAK power plant produces electricity through a boilingwater reactor power cycle with heat supplied by a Tokamak fusion reactor. One plant produces. $660 \mathrm{MW}$ net, and the power facility characterized here consists of two NUWMAK reactors, producing 1320 MW net power.

The NUWMAK discussed here is a newer and more realistic design than the UWMAK series developed by the University of Wisconsin. The objective of the new treatment was to simplify mechanical design and maintainability. The power density in NUWMAK is increased to about $10 \mathrm{~W} / \mathrm{cm}^{3}$ as compared to 0.5 to $2 \mathrm{~W} / \mathrm{cm}^{3}$ in earlier designs. Figure 3.12 is a schematic of this NUWMAK concept. The reference fusion plant uses deuterium-tritium fuel. During the reactor burn cycle the deuterium (D) and tritium (T) in the toroidal reactor chamber are in a plasma state. When a $D-T$ fusion reaction occurs, a helium-4 nucleus (alpha particle) is formed and a $14-\mathrm{MeV}$ neutron is given off. The high-energy neutrons are absorbed by a blanket that surrounds the fusion reaction chamber. The neutrons heat the blanket, and this heat is then removed from the blanket and used to produce electricity. NUWMAK uses boiling water as a coolant and a conventional boiling-water reactor power cycle to produce electricity.
Table 3.8 LMFBR Wastewater Effluents at Nominal ( $1250 \mathrm{MW}$ ) Operation

\begin{tabular}{lc}
\hline Effluent & Amount \\
\hline Chemical & $t / h$ \\
\hline BOD & 0.000 \\
Chromates & 0.000 \\
Phosphates & 0.007 \\
Boron & 0.051 \\
Acids & 0.013 \\
Organics & 0.011 \\
Ch1orine & 0.004 \\
Radiological & Ci/yr \\
\hline Uranium & neg1. \\
Ra-226 & 0 \\
Th-230 & 0. \\
Th-234 & 0 \\
Co-60 & 0.774 \\
Sr-90 & 0.257 \\
I-131 & 0.01 \\
Cs-134 & 9.38 \\
Cs-137 & 7.97 \\
Ce-144 & 0.030 \\
Pu & 0 \\
Tritium & 350 \\
Ru-106 & 0.014 \\
Other activation and & 70.32 \\
fission products & \\
\hline
\end{tabular}




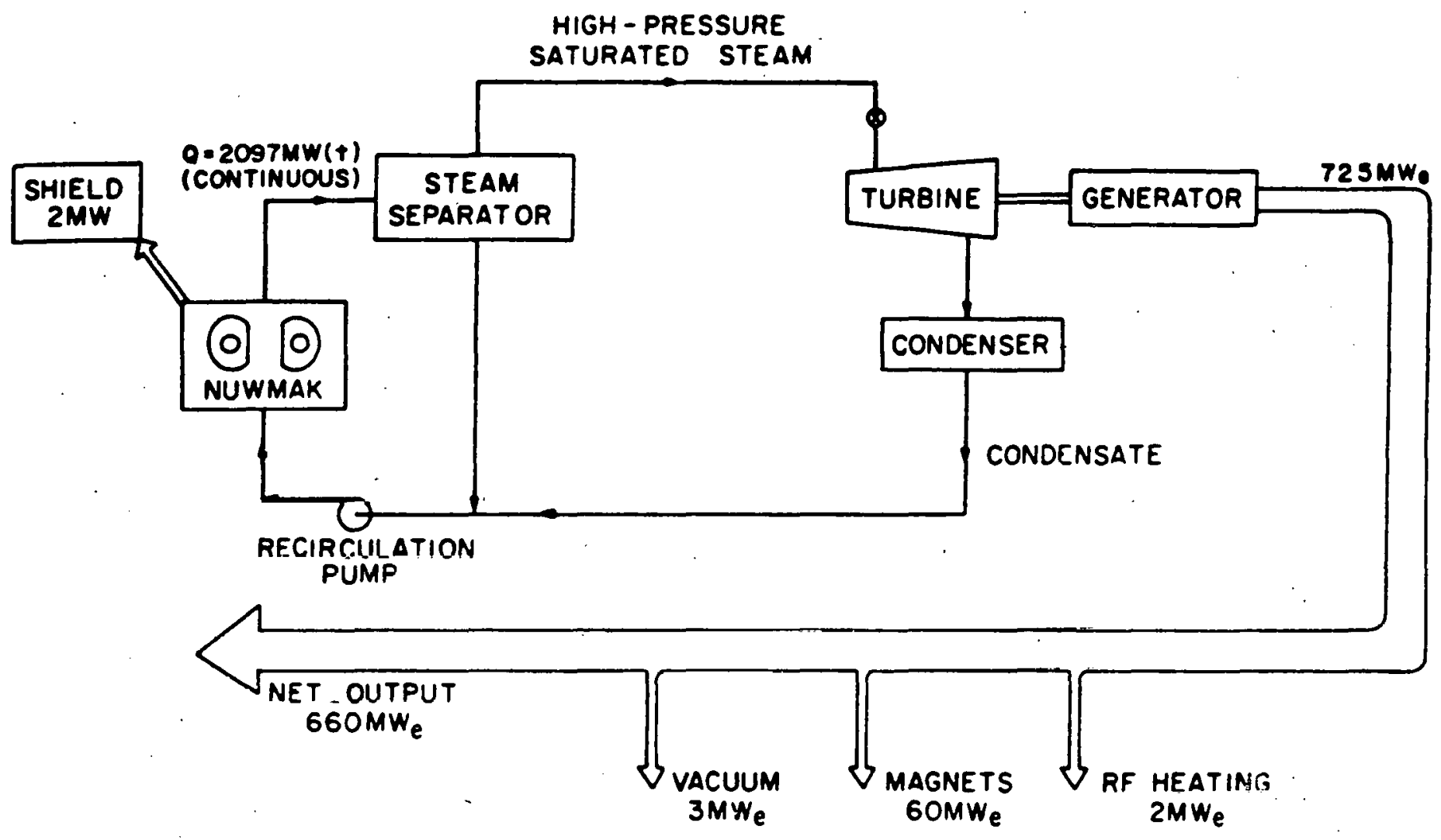

Fig. 3.12 Schematic of NUWMAK Fusion Power Plant

The power flow for one NUWMAK reactor is shown in Fig. 3.12. The gross thermal efficiency is $34.5 \%$. After accounting for auxiliary power requirements of $65 \mathrm{MW}$, of which $60 \mathrm{MW}$ is needed to cool the magnets, the net power output is $660 \mathrm{MW}$ with a net thermal efficiency of $31.5 \%$. Two reactors would have a net output of $1320 \mathrm{MW}$.

The NUWMAK reactors differ from those of previous studies (such as UWMAK) in that no diverter is used. Impurity control (which is needed in order to keep the plasma from cooling) is accomplished instead by gas puffing, which, along with partial pellet fueling, permits operation for approximately 225 seconds with adequate plasma cleanliness. During a burn, neutral deuterium gas is puffed into the plasma approximately every 0.5 seconds. Tritium is introduced in solid pellets, which penetrate only the outer plasma mantle. A sharp temperature profile develops at the plasma edge, which is kept cold both by the gas puffing and by introduction of impurities. However, the step temperature profile prevents impurities from diffusing towards the plasma center. The impurities are neutralized and pumped out through vacuum-pump ports.

The plasma requires a magnetic field of $6.05 \mathrm{~T}$ (tesla) at a major radius of $5.13 \mathrm{~m}$, which means a maximum field of $12 \mathrm{~T}$ at the magnet. To provide the needed access for maintenance and repair, NUWMAK is designed with only eight large superconducting " $D$ "-shaped TF coils and the increased ripple is corrected with 16 saddle-shaped trimming coils. The primary design of the 
TF coil uses NbTi superconductor with subcooled superfluid liquid helium at $1.8 \mathrm{~K}$ and atmospheric pressure. There are four cryogenic vertical field coils inside the TF coils and four superconducting coils at the outside of the TF coils to maintain the elongated plasma. The ohmic heating coils are located inside the central core of the reactor system. Since the magnets require a pulsed power supply, each reactor is supplied with a 2-MWh superconductive energy storage unit.

Since ohmic heating is effective only at relatively low plasma temperatures, auxiliary heating is necessary to raise plasma temperatures to ignition conditions (when fusion reactions will sustain themselves without further heat input). The NUWMAK design employs radio-frequency (RF) supplementary heating in the ion cyclotron range of frequencies in order to ignite the plasma. The design entails launching a fast magnetosonic wave into a 50-50 DT plasma and heating the ions at the second harmonic cyclotron frequency of deuterium.

The NUWMAK reactor operates with a cycle length of 245 seconds: 225 seconds of burn followed by 20 seconds of down time. The heat stored in the blanket material provides energy to the coolant during the down $t$ ime, reducing the cyclic variation from $70 \%$ to $30 \%$ of the maximum energy to the turbines. Since a $30 \%$ variation is still unacceptable, a steam drum is used and the feedwater temperature is adjusted. Figure 3.13 is a schematic of this load-leveling system, with which constant electrical output can be achieved. Simultaneous operation of the two reactors is not necessary for constant electrical output. Two reactors produce 4566 MWt with a net electrical output of $1320 \mathrm{MW}$. Since the burn time is $92 \%$ of the cycle time, the net thermal efficiency is $31.5 \%$.



Fig. 3.13 Schematic of NUWMAK Load-Leveling System 
The total tritium inventory in NUWMAK may amount to more than $10^{10} \mathrm{Ci}$. In order to 1 imit tritium releases from NUWMAK to less than $10 \mathrm{Ci}$ per day, tritium losses must be limited to one part in one hundred million on a daily basis. Essentially perfect containment of tritium depends on clearly identifying possible routes of tritium release. During normal operation, potential sources of tritium loss include the plasma fueling and fuel purification components, energy-storage equipment (both normal and emergency), tritium breeding and extraction system components, and the first wall and blanket coolant. Tritium containment associated with each of these systems is examined in the analysis of a multi-layer containment system.

The three-level containment system (Fig. 3.14) is designed to deal with tritium release under both normal and abnormal conditions. Each level prevents the dilution of released tritium, so that it $c$ an be recovered before permeating to the next barrier. The primary containment oyotcm consists of those pipes and other structural elements that contain tritium or tritiumbearing ialerials.

The secondary containment system consists mainly of a second physical barrier around the primary system components: for example, primary system piping outside the plasma chamber is contained within larger-diameter piping. A slowly flowing inert gas is passed through the annulus and monitored for tritium leakage. Large pieces of equipment requiring maintenance or adjustment are enclosed in glove boxes.

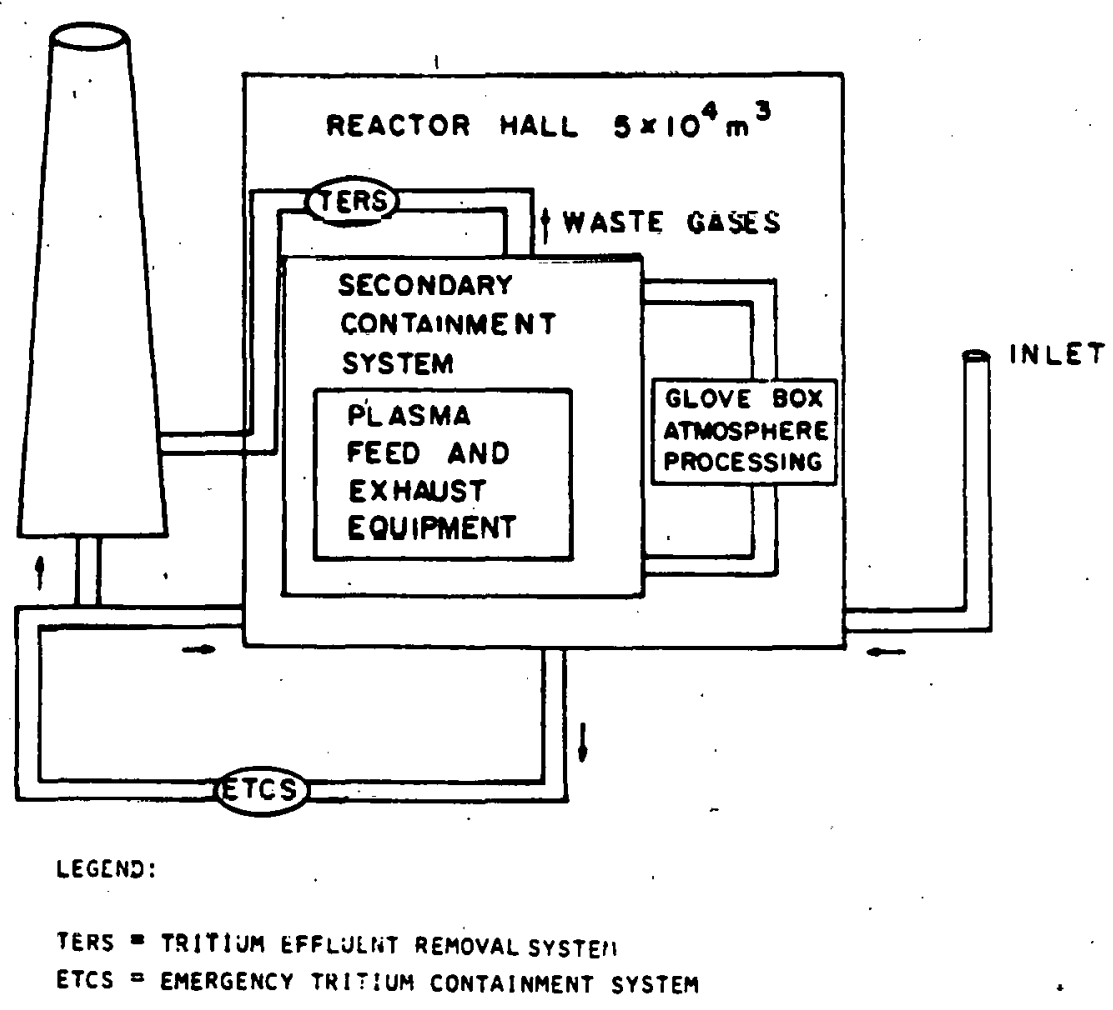

Fig. 3.14 Tritium Effluent System Design 
The tertiary containment system includes the reactor hall, rooms containing tritium processing equipment, the reactor building itself, the tritium effluent removal system (TERS), and the emergency tritium containment system (ETCS). The TERS is designed to operate on routine tritium losses while the ETCS is used only under abnormal conditions.

As with the primary and secondary systems, the reactor building is subdivided to reduce both the extent of loss and the extent of contamination in the event of a leak. Each reactor hall has a volume of $8.7 \times 10^{4} \mathrm{~m}^{3}$ and may be divided radially to provide the least impediment to maintenance operations. The reactor building is maintained at $8.4 \times 10^{3} \mathrm{~Pa}$ during operation, and the pressure can be reduced to $1.3 \times 10^{3} \mathrm{~Pa}$ under emergency conditions.

About $20 \%$ of the building volume atmosphere would be circulated each day, 'from areas of smallest to largest radioactive hazard before leaving through a stack of sufficient height to guarantee proper dispersal of the effluent. Under normal operation, this stack effluent would contain about 1 Ci per day.

The emergency tritium containment system (ETCS) consists of a heated catalyst to oxidize $\mathrm{HT}$ and $\mathrm{T}_{2}$ to $\mathrm{HTO}$ and $\mathrm{T}_{2} \mathrm{O}$, alumina beds presaturated with water at $100 \%$ humidity, and the required air hand ling equipment. The ETCS is used in the event of a simultaneous breakdown of both the primary and secondary systems to rapidly detritiate air from contaminated areas of the reactor building. During cleanup, the inlet dampers of contaminated areas are closed and only a small fraction of fresh air is allowed to circulate to reduce tritium losses from the stack.

One further source of tritium leakage is the boiling water coolant. It has been calculated that the leak rate of tritium into the cooling water will be limited to a few curies per day. In the event that the leak rate increases, it is possible, without much increase in costs, to add equipment for removing tritium (in the range of 0.001 to $10 \mathrm{Ci} / \mathrm{mL}$ ) by combined electrolysiscatalysis or by molecular photo-excitation.

The 14-MeV neutrons from the fusion reaction induce radioactivity in the structure surrounding the plasma. Most of the activity originates in the inner region of the blanket. The blanket should be replaced every two years, and the material processed and stored on the plant site.

\subsection{COST CHARACTERIZATIONS}

A comparative assessment of the electric generation costs for the SPS and alternative technologies requires that the cost components of each system be characterized on a consistent and normalized basis, Unfortunately, technology cost estimates from previous efforts were usually developed under assumptions that differed from study to study, and are inconsistent with the characteristics assumed for the nominal reference systems in this assessment. Thus the remainder of this section quantitatively documents the procedure used to derive a set of consistent capital and operation and maintenance (O\&M) costs for the SPS and alternative technologies. 
Costs from the original data source are displayed for each technology and it is shown how these costs are adjusted to be consistent with the nominal reference system characteristics such as plant capacity and overall efficiency. Where the original data present estimated costs in other than 1978 dollars, these are normalized to 1978 dollars by application of appropriate escalation factors.

The development presented in this section results in baseline point estimates based on the assumption that each technology is constructed to come on line in 1978 and is financed totally in 1978 dollars. This. is the starting point for the analysis presented in the cost and performance comparison, where these 1978 point estimates are adjusted to reflect systems coming on 1 ine in the year 2000. These costs are analyzed in the cost and performance comparison in terms of their potential uncertainties in the $2000 \mathrm{time}$ frame by assigning an upper range to the year-2000 base costs. Subsequent analyoio io then based on these cost ranges.

As previously mentioned, construction costs for each of the nominal reference systems were developed on a consistent basis by adjusting published data to a common set of rules and assumptions. Thus, all costs make similar assumptions about the owner's costs, contingencies, and allowances for funds used during. construction. The primary source of data for the coal and nuclear systems was the Energy Economic Data Base (EEDB)22 compiled and updated for DOE by United Engineers and Constructors. The General Electric study for EPRI ${ }^{8}$ and the SPS concept definition studies $1,7,8$ were used for cost data on the terrestrial photovoltaic system and the SPS, respectively.

In several cases the available cost estimates were for plant sizes and heat rates (efficiencies) different from those selected for the reference technologies. These were adjusted by power factors commonly used in electric utility cost estimation. A construction cost that excludes contingencies, owner's costs, and interest during construction was thus derived. Where costs wert in a differente year's dollars, they were adjusted to 1978 dollars by an appropriate escalation rate; SPS cost estimates\%, given in 1977 dollars were escalated to 1978 dollars using an $8.0 \%$ escalatinn factor.

\subsubsection{Satellite Power System}

Development Costs. Boeing 25 estimated development costs on the basis of the reference system scenario, which predicates a 20-year development schedule and a 30-year deployment schedule (for 60 5-GW satellites). These costs amount tó \$100-110 biliton and are broken down as follows (Fig. 3.15):

- Research costs: mainly ground-based research to address environmental and social issues and alternative systems, resulting in a preferred system;

- Engineering: development and testing of prototype subsystems, resulting in specifications for demonstration units and production facilities;

- Demonstration: flight tests of a 100-200 MW unit integrated with a commercial network; 




Fig. 3.15 Development Costs of the SPS (Source: Ref. 26)

- Investment: development of industrial infrastructure, e.g., transportation, photovoltaic, and klystron manufacturing facilities.

- Construction and implementation: the first 5-GW SPS unit put into place.

It is important to note that these cost estimates assume that all effort is specific to the SPS. The benefits from generic research or from cost sharing (e.g., industry or other federal program support for photovoltaics manufacturing facilities) have not been considered. Such cost modifications could amount to $50-70 \%$ of the $\$ 102.5$ billion. 27

Since comparable cost data for the other six technologies were not available, side-by-side comparisons of costs or of the benefits or disadvantages of public expenditures were not attempted.

The SPS development program would consist of five phases and include basic research, engineering verification, prototype demonstration, investment requirements, and commercial production of the satellites. A cost estimate compilation based on 1977 dollars was presented on February 20, 1980, by R.J. Harron and R.C. Wad le of NASA. 28 The estimates were updated to 1978 dollars by a factor of 1.08 and are shown in Table 3.9. The required investment in facilities to produce satellites and related equipment is unique to this program and will enter into the commercial operation costs as an allocated expense, i.e., depreciation of investment for each satellite. In accordance with the reference accounting method, developing and establishing the space fleet for transport of materials, supplies, and personnel are not considered part of the depreciable satellite investment and, accordingly, have been excluded from capital recovery. The cost estimates of the work breakdown structure include provisions for price escalations and for project management and integration, which are included herein, in addition to the applied contingency and owner's costs added for this review. 
Table 3.9 Capital Requirements of the SPS

$(5000 \mathrm{MW}), 1978$ Dollars $\times 10^{6}$.

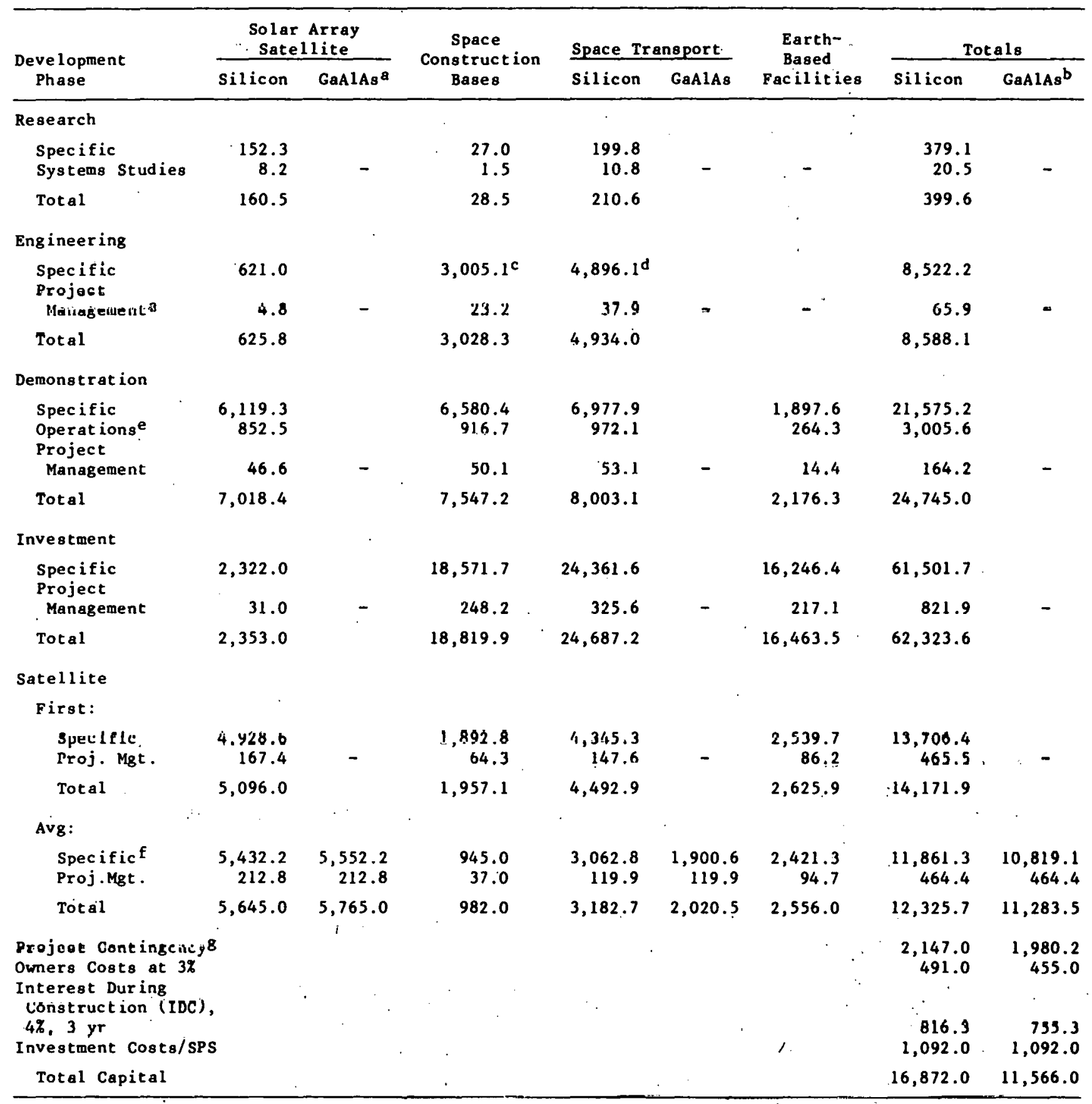

allocated on dollar ratio.

bSPS Ref. System Costs - GaAs Option - Memo 3/3/80, D. Taylor to NASA. Used only chargeo in avg. EPS/ space transport. Assumed investment phase unchanged.

cFull cost of LEO Lab $+0.5 \times$ cost of LEO shuttle flight.

$d_{0.5} \times$ cost of LEO shuttle flight.

eDemonstration period expenditure allocated on dollar ratio.

fVarious segments include "cost growth and escalation" omitted earlier.

$816 \%$ Total $+\$ 1092 \times 10^{6}$ Investment per SPS, net of space transport fleets. 
Table 3.10 Operation and Maintenance Costs of the SPS ( $5000 \mathrm{MW})$

\begin{tabular}{lrr}
\hline Cost Component & $\begin{array}{r}10^{6} \$ \\
(1978)\end{array}$ & $\begin{array}{c}\text { Mills per } \\
\text { kWh }\end{array}$ \\
\hline Maintenance & & \\
$\quad$ Satellite & & \\
$\quad$ Klystron & 10.8 & 0.27 \\
$\quad$ DC-RF Converter & 15.7 & 0.40 \\
$\quad$ Balance & 15.9 & 0.40 \\
$\quad$ Total & 42.4 & 1.07 \\
Transportation & 41.3 & 1.04 \\
$\quad$ Materials Facility & 87.5 & 2.22 \\
$\quad$ Personnel Facility & 128.8 & 3.26 \\
$\quad$ Total & 15.1 & 0.38 \\
Ground Receiving Station & 4.2 & 0.10 \\
Space Construction Bases & 190.5 & 4.81 \\
Cumulative Total & 24.8 & 0.63 \\
Contingency at 13\% & 9.5 & 0.24 \\
Management and Integration at $5 \%$ & 224.8 & 5.68 \\
Grand Total o\&M Costs & & \\
\hline
\end{tabular}

Harron and Wadle also estimated annual operating and maintenance (O\&M) expenses for the space transport, space construction, and repair of the satellites and the ground receiving station. These were not adjusted in any way except for conversion to 1978 dollars (with a multiplier of 1.08). Total annual expenses (shown in Table 3.10) of $\$ 224.8 \times 10^{6} 1978$ dollars are equivalent to an annual charge of $5.7 \mathrm{mills}$ per $\mathrm{kWh}$ of net electrical output.

\subsubsection{Conventional Coa1-Fired Power Plant with Advanced Flue Gas Desulfurization (H-S Coal)}

The capital costs for the reference system were based on EEDB costs, 22 adjusted to reflect a $5.9 \%$ increase in the steam system, insertion of the Wellman-Lord sulfur removal system (and removal of the conventional lime treater), an additional heat exchanger to increase stack gas temperatures, and a larger turbine generator to accomodate higher internal requirements.

Direct and indirect capital costs are estimated at $\$ 452.1$ million and $\$ 90.7$ million (1978 dollars), respectively. A contingency allowance of $7 \%$ is added to account for the conventional nature of the plant. It is anticipated that the owner will spend approximately $9.2 \%$ of the cumulative subtotal on expenses such as consultants, permits, and site selection, and an allowance for funds during construction over the seven-year construction period is 
estimated to total approximately $\$ 52$ million (expressed at "real" rates in January 1978 dollars).

Annual operating and maintenance expenses are estimated to be $\$ 23.5$ million, representing $\$ 5.7 \mathrm{million}$ for the payroll, $\$ 4.8 \mathrm{million}$ for disposal of residues, and $\$ 5.0 \mathrm{million}$ for acid-gas removal supplies. Other components of O\&M are materials, supplies, and interim replacements, which contribute $\$ 7.1$ million, and administrative and general expenses, estimated at $\$ 0.9$ million. Based on an annual plant capacity factor of 0.7 , the annual cash expenditures amount to $3.06 \mathrm{mills}$ per kilowatt hour.

\subsubsection{Combined-Cycle Power Plant with Low-Btu Gasifiers (CG/CC)}

Capital costs and annual expenses were based on a 1975 Energy Conversion Alternatives Study (ECAS) 14 reference plant of 579-MW capacity. As a reference system, the unit was updated to 1978 dollars, general facilities were segregated, and processing segments were exponentially scaled to 625 MW with two units on one site making up the total facility. Appropriate adjustments were made to substitute the reference eastern bituminous coal and more rigorous emission standards. Direct capital costs are $\$ 537.4 \mathrm{million}$.

Indirect capital costs, $\$ 132.7$ million or $24.7 \%$, were derived from data presented on a 630-MW coal gasification facility found in the Energy Economic Data Base (EEDB).22 A comparison was made summarily to validate this match-up by comparing ECAS with EEDB indirect costs for plants with identical capacity (of a different type). The indirect construction costs for the two units total $\$ 132.7$ million, with a breakdown of $60 \%$ for construction service, $22 \%$ for home-office engineering, and $18 \%$ for field engineering.

A construction contingency at $9 \%$ of the cumulative expenditures was added, resulting in installed facilities amounting to $\$ 730.4 \mathrm{million}$ in 1978 dollars. Owners' costs of $\$ 66.5$ million and an Allowance for Equity Funds Used During Construction (AFUDC) over the seven-year construction period of $\$ 65.1 \mathrm{million} y i e l d$ a capital requirement for the $1250-\mathrm{MW}$ CG/CC of $\$ 862$. million, or $\$ 689.60$ per installed kilowatt.

of the estimated operating and maintenance expenses of $\$ 20.66 \mathrm{million}$, materials, supplies, expenses, and interim replacements contribute $47 \%$. The 336-person staff accounts for $\$ 7.4 \mathrm{million}$, and related administrative and general costs are $\$ 1.2 \mathrm{million.}$ Environmental control costs are estimated to be $\$ 2.3 \mathrm{million} / \mathrm{yr}$, principally for disposal of dry solid wastes. The total contribution of environmental control expenditures to energy cost, at the $70 \%$ plant capacity tactor, is 2.70 mills per kilowat hour.

\subsubsection{Light Water Reactor (LWR)}

A 1139-MW system was changed to the reference 1250-MW design by use of conventional capacity-ratio exponential factors used by the electric industry for various segments of the plant. This method yielded an estimate for installed plant cost, in 1978 dollars, of $\$ 485.9$ million. Indirect construction costs for the nuclear plant were estimated to be $\$ 197.1$ million, or some $40.6 \%$ of the installed equipment. These indirect construction costs 
included construction services ( $\$ 75.0 \mathrm{million})$, home-office engineering ( $\$ 91.2$ million), and field engineering ( $\$ 30.8$ million). An allowance for contingent expenditures amounting to $8 \%$ of the cumulative subtotal yields a combined plant investment of $\$ 737.7$ million. Owners' costs of $9.3 \%$ and interest during construction (IDC) computed on a 12-year construction cycle result in overall capital requirements of $\$ 890.2$ million in 1978 dollars.

Annual expenditures for operation and maintenance total $\$ 16.9 \mathrm{million}$, or $2.31 \mathrm{mills}$ per $\mathrm{kWh}$ of net production. Materials, supplies, expenses, and interim replacements contribute $57 \%(1.32 \mathrm{mills})$ to these costs, with staff costs (including administration and general) at 0.83 mills and the balance. accruing to inspection fees, special insurance, and amortized decommissioning expenses.

\subsubsection{Liquid-Metal, Fast-Breeder Reactor (LMFBR)}

The basic plant cost estimate, in 1978 dollars, for a 1390-MW LMFBR unit, which was prepared by. United Engineers and Constructors for the EEDB, 22 was downscaled by the appropriate capacity ratio exponents to the 1250-MW reference size for a total of $\$ 702.9$ million in direct construction costs. Because of safety and inspection requirements, indirect construction costs amount to $\$ 262.6 \mathrm{million}$, for a total facility cost of $\$ 965.5 \mathrm{million}$. A project contingency at $11 \%$ was deemed reasonable for this technology, resulting in a plant investment totalling. $\$ 1071.7$ million in 1979 dollars. Owners' costs over the 12-year construction period are estimated at more than \$93 million, and during the lengthy period, IDC will accumulate to $11.3 \%$ of the cumulative subtotal, even at the reduced "real" cost of utility capital.

Annual non-fuel operating expenses amount to 2.96 mills per annual $\mathrm{kWh}$ of net production, and total $\$ 22.7 \mathrm{million}$. Materials, supplies, expenses, and interim replacements account for $64 \%$; staff, $22 \%$; administrative and general, 9.2\%; and the balance (insurance, inspection fees, and allocated decomissioning expenses), approximately $4.8 \%$.

\subsubsection{Fusion Reactor (NUWMAK)}

The direct capital costs for the magnetically confined fusion facility presented in the NUWMAK report 24 were adjusted to a different average labor rate for consistency with the LWR and LMFBR data. Unlike the procedure in past assessments, in this assessment design allowances for unproven technology appropriate for this system were incorporated in the equipment accounts to eliminate the customary omissions in conceptual design. Direct capital costs for the entire two-unit facility are estimated at $\$ 1.5332$ billion (in 1978 dollars) over the staged construction period of 10 years, which includes eight years per unit with a two-year lag between construction starts. 'Indirect costs for the reference system have been adjusted upward from those contained in the NUWMAK report ( $41 \%$ vs. $35 \%$ ) for consistency with the EEDB boiling water reactor plant, and thus amount to $\$ 628.6$ million. Reflecting the project uncertainties and status of technology development, a project contingency of $18 \%$ is applied to the subtotal for a total plant investment of $\$ 2.551$ billion. The combination of design allowance, increased indirect costs and higher contingency rate may seem to escalate the final cost more than for the other 
technologies, but it is considered prudent for this concept. In any event," the incremental margin would amount to between $15 \%$ and $20 \%$ of the total plant investment, well within cost-estimating accuracy of a novel process. Owners' costs of $9 \%$ and IDC accruals over the 10-year construction period $(\$ 389.2$ million) result in a capital requirement of some $\$ 3.1395$ billion, roughly 2.5 times more expensive than the next most costly terrestrial energy investment, LMF BR.

Annual operating and maintenance expenses for the facility were adjusted, from the basic NUWMAK report, to be $\$ 57.9 \mathrm{million} / \mathrm{yr}$, which includes. a $2 \%$ factor of direct and indirect costs for $0 \& M$ plus scheduled replacements of other plant facilities. Total O\&M costs applied to the energy output amount to $7.29 \mathrm{mills}$ per $\mathrm{kWh}$, adjusted from the reference report to include amortized decommissioning expenses.

\subsubsection{Central-Station Terrestrial Photovoltaic (TPV)}

Direct construction $\operatorname{costs}^{9}$ are estimated to be $\$ 120.1$ mililion ( 1978 dollars), and indirect construction amounts to $\$ 22.4 \mathrm{million}$, for a cumulative total construction cost of $\$ 142.5$ million. Project contingency al lowances $(13.0 \%)$ of $\$ 18.5$ million yield an installed plant cost of $\$ 161.0$ million.

Owners' costs for permits, coordination, consultants, and site selection are estimated at $10.2 \%$ of the installed plant cost, or $\$ 16.4 \mathrm{million}$ in 1978 dollars. The IDC, calculated on a five-year construction period, is $\$ 9.0$ million in real terms, for a capital requirement of $\$ 186.4$ million in 1978 dollars, or $\$ 863.8$ per installed $\mathrm{kW}$.

Operating expenses, in 1978 dollars, are $\$ 1.66$ million per year, including $\$ 561,000$ in payroll and $\$ 762,000$ for the sinking fund accrual of $30 \%$. of the basic facility costs for interim replacements. The total, at an assumed $25 \%$ plant capacity factor, is calculated at $3.5 \mathrm{mills}$ per $\mathrm{kWh}$. 


\subsection{ASSUMPTIONS AND ALTERNATIVE FUTURES SCENARIOS}

\subsubsection{Assumptions of the Comparative Analys is}

Three levels of comparative analysis are described in the assessment framework (Sec. 2) and illustrated in Fig. 2.1. These levels are (1) comparison of characterizations, (2) side-by-side analysis, and (3) alternative futures analysis. In this section, comparisons are made, issue by issue, at each of these levels. Each level of analysis has associated assumptions, and are ordered in a hierachy: therefore, the analysis and assumptions are cumulative as one proceeds from the lowest level (characterization comparison) to the highest level (alternative futures analysis). Before proceeding to the description of these comparative analyses, it is important to delineate the assumptions used here in order to place the comparisons in proper perspective. By assumptions we mean any important information, caveats; or baseline data that affect the analysis.

Many assumptions were made in the course of the comparative analyses, and to describe them all would obscure the comparisons. Therefore, the ones described here are those that most affect the perspective of the analysis. The description of these assumptions is handled sequentially (i.e., as part of the characterization, side-by-side analysis, and alternative futures analys is).

Comparison of Characterizations. These comparisons are made on the basis of the parameters that define a system (e.g., capital cost, O\&M cost, resource consumption, and environmental residuals). Therefore, the characterization comparison is solely dependent on the technology description. For currently utilized technologies (i.e., coal and nuclear fission) most of these parameters are fairly well-defined because advanced technologies represent extrapolations of existing systems. In the case of the newer technologies (i.e., TPV, SPS, fusion), in which similar technology is not in operation, the parameters represent estimates based on design assumptions.

The technologies selected and characterized for these assessments are intended to represent electrical supply systems that could satisfy energy demand in the 2000-2030 era. Some of the advances in design are in limited operation or have been demonstrated, but for others, only design or conceptual information exists. The characterizations were carefully prepared so that the analysis of each technology is internally consistent. For example, the capital cost information presented for a technology includes the cost of environmental control systems, and the assessment of environmental performance is based on the same environmental control systems. The characterizations were developed according to an integrated procedure; therefore, characterization data reported in this assessment may be different from piecemeal information (e.g., capital cost, environmental performance) reported elsewhere. 
Side-By-Side Analysis. The side-by-side analysis uses the characterization information with impact models to determine the impact of a technology, and then normalizes this impact to a unit of net energy output. The determination of impact in most cases requires assumptions about the state of the world (e.g., economic conditions, technology penetration, other environmental pollutants). These assumptions were made in a nonintegrated fashion from issue to issue. For example, in the health and safety analysis certain baseline environmental assumptions were necessary, from wich incremental health impacts from the addition of another power plant could be determined. The results of this type of assessment are generic, not region-specific. The impact models are based on dose-response data derived from experience with existing technology, and the pollution levels they indicate do not necessarily represent projections of what the impact might be from pollution by new technologies. For example, occupational health and safety information was developed from the most representative current technology, in an attempt to predict the levels of occupational health and safety dimpact of the future technologies. The important assumptions (e.g., key economic parameters) that are made in each side-by-side comparative analysis are described in each section.

Alternative Futures Analysis: Since the objective of this comparative assessment is to compare technologies projected for the post-2000 era, a great number of assumptions are required. Most of these assumptions are highly uncertain and interdependent, so that a single consistent set may not present the decision maker with an adequate and consistent comparative perspective of the future. The alternative futures analysis was chosen as a means of providing a broader perspective of the most important parameters that describe the future. These alternative futures perspectives represent an integrated parametric analysis of plausible but unforecastable events, to provide a broader picture of the comparative issues. The assumptions underlying the alternative futures analys is constitute a set of energy supply/demand futures or scenarios.

The alternative futures scenarios describe the level of energy demand and the mix of energy technologies that are used to meet this demand, given a set of assumptions about the U.S. economy. The levels of technology deployment and economic assumptions in each scenario can be used to calculate a comparative assessment. The scope of this assessment is limited to electrical energy and does not describe mixes of nonelertriral onorgy supply.

These scenarios are created from a consistent economic model oo that interdependencies between economic assumptions are preserved. Scenarins were selected as a means of exploring and analyzing, not predicting, the economic energy future. The scenarios were selected to represent a plausible future world, and no probabilities are assigned to any of them. We are not attempting to eliminate uncertainty in our choice of scenarios; in fact, by choosing a range of scenarios we hope to explore the dimensions of uncertainty more fully. Scenarios were selected to provide a comparative perspective on the negative and positive aspects of demand and mixes of supply technologies in the post-2000 era. The remaining part of this section will briefly describe the procedure and the energy supply-demand scenarios used in the alternative futures analysis. A more detailed technical description of these scenarios is found in a separate report. 29 


\subsubsection{Alternative Futures Scenarios}

At a time when petroleum energy prices have increased nearly tenfold in a decade, and analysts have difficulty understanding events that have already occurred, the notion of making energy/economic forecasts well into the 21 st century seems foolhardy.

Given the long-range perspective of the SPS (i.e., not available until year 2000), a 50-year horizon for evaluating alternative major energy technologies (such, as the SPS) is necessary. The key problem is how to reduce the vast number of possible "alternative futures" to a few meaningful alternatives that encompass the range of significant policy variables and unknowns without simply creating confusion. The solution is to focus attention mainly on the factors that may cause energy prices and demands to vary under a given set of economic-demographic assumptions. The underlying economic analysis -- a major research effort in itself -- was borrowed from the work of Ridker and Watson. 30

Most energy/economic analyses begin with some model of the relationship between energy consumption and GNP. The simplest model, found mainly in pre-1973 studies, was based on the observation that GNP and energy demand, $E$, have tended to move closely in tandem in the U.S. for several decades. A simple E/GNP ratio was sometimes assumed. Deeper study of the data revealed a long-term declining trend in this ratio (see Fig. 4.1). This can be interpreted as a result of the economy's shift from energy-intensive primary agriculture and materials and manufacturing industries toward services, which add greatly to the GNP without consuming much energy.

Until 1973, energy prices were declining, on the average, so that demand for energy presumably would have increased if it were not for the structural changes. in the economy mentioned above. After 1973, of course, energy prices rose very sharply. The expected response in a market economy is a further decrease in demand, together with increased supplies. The balancing mechanism is illustrated schematically in Fig. 4.2.

A number of medium- and long-term energy/economic models have an optimizing scheme (usually some mathematical programming algorithm) to project future energy costs for specified levels of demand. This procedure is classified as partial equilibrium insofar as the reverse feedback, i.e., the dependence of GNP on energy prices, is neglected. Examples include the ETA Model; 31 the Nordhaus Model, 32 the Brookhaven BESOM Model, 33 and a dynamic version known as DESOM. 34 All of these models assume that energy prices are bounded by the long-term marginal costs of supply. The independence of GNP and energy-influenced price changes can be a convenient, although rough, approximation if the energy sector is very small (4\%) compared to the rest of the GNP.

The ETA-MACRO 35 model is another kind of general equilibrium model with a more detailed energy sector driven by an aggregated macroeconomic model, which includes a link between economic growth and investment. There are several dynamic, multisector, general equilibrium models in the literature, including Hudson-Jorgenson, 36 PIES, 37 and Gulf-SRI, 38 but they are all necessarily very complex and consequently difficult to use and to explicate. 


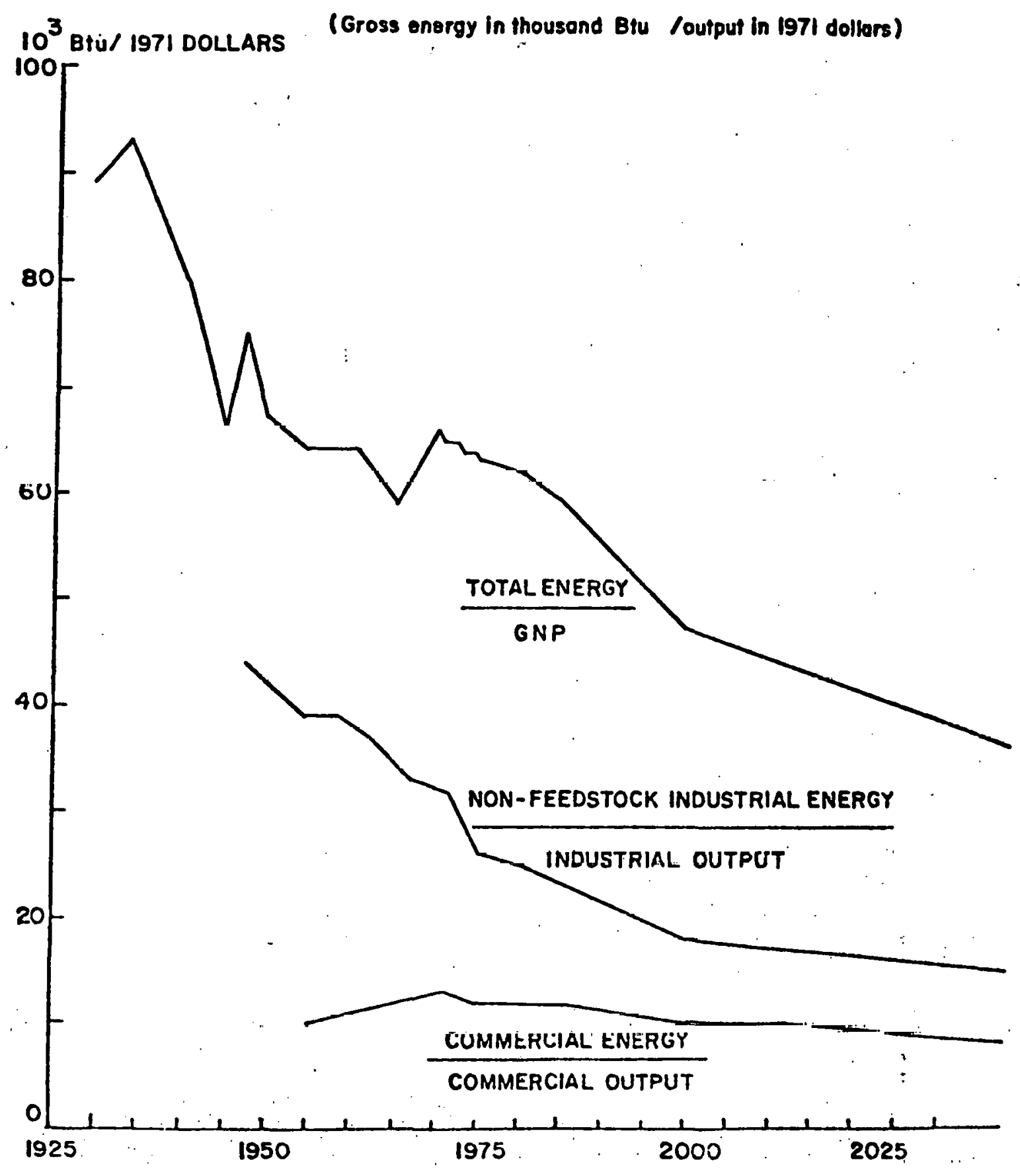

Fig. 4.1 U.S. Energy Output Ratios, 1929-1974, and Base Projections to 2025 


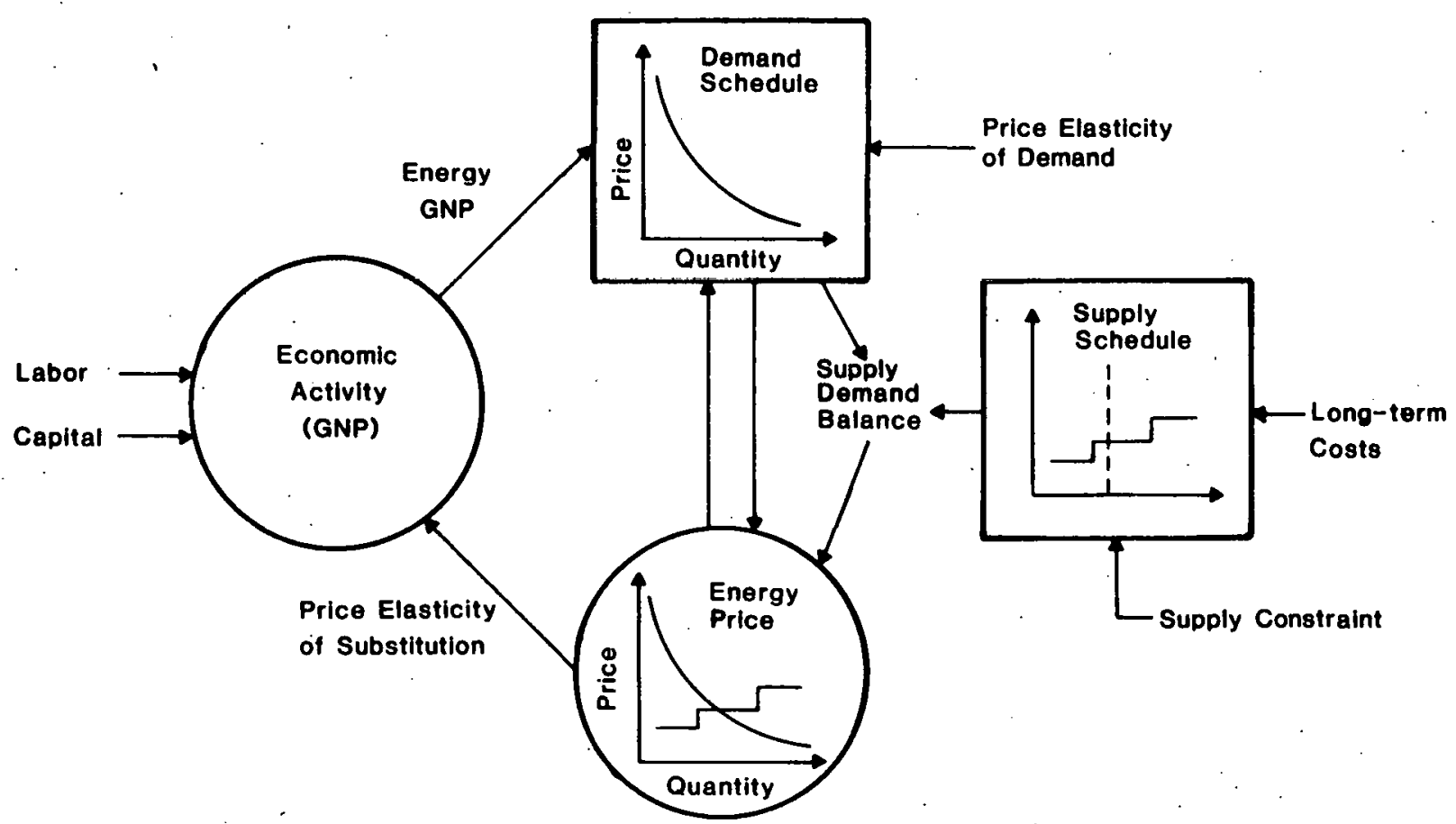

Fig. 4.2 Simplified Macroeconomic Model of the Interaction between Energy and the Economy

Probably the long-term model that is most sophisticated in its treatment of interindustry relationships and capital accumulation is the Resources for the Future (RFF) model, developed by Ridker and Watson, 30 based on a 185-sector dynamic interindustry model.39 The RFF model was selected for this assessment on the basis of several selection criteria -- sectoral detail, endogenous treatment of both capital investment and final demand, and transferable experience in the form of existing model runs covering the desired time frame - 2000-2030.

Table 4.1 provides our assumptions about population, labor force, labor productivity, and GNP in constant (Jan. 1978) dollars. The population figures incorporate a replacement fertility rate of 2.1 children per woman. Although the total fertility rate is currently around 1.9 , there is no basis on which to assume it will remain at this unprecedented leve1. Moreover, immigration -- illegal as well as legal - will probably remain above the 400,000 per year that is incorporated into these projections. The labor numbers, which take into account increased female participation in the labor force, somewhat earlier retirement age, and other trends, are consistent with the population figures. The GNP, derived from projections about the labor force, participation rates, employment rates, changes in working hours per year, and productivity growth rates, increases at an annual rate of $2.8 \%$ between 1980 and 2000 and $2.5 \%$ thereafter. This compares with a rate of $3.1 \%$ per year between 1970 and 1979 and $3.4 \%$ between 1950 and 1970 . The decrease in GNP growth is due in part to declining productivity, attributable to the need to divert capital into the energy sector and energy conservation. clearly, this economic scenario is only one of several self-consistent possibilities. It probably represents an upper limit to GNP growth. 
Table 4.1. RFF Model Assumptions about Population, Labor Force, Productivity, and GNP, 1975-2025

\begin{tabular}{lrrrrrr}
\hline \multicolumn{1}{c}{ Element } & 1975 & 1980 & 1985 & 2000 & 2025 & 2030 \\
\hline Population (millions) & 214 & 225 & 236 & 264 & 304 & 312 \\
Labor force (millions) & 95 & 107 & 111 & 124 & 139 & 142 \\
GNP (billions, 1978 \$) & 1754 & 2108 & 2394 & 3691 & 6449 & 7000 \\
Consumption & 1131 & 1350 & 1451 & 2351 & 4226 & - \\
Investment & 219 & 304 & 435 & 426 & 1011 & - \\
Government & 383 & 403 & 482 & 742 & 1154 & - \\
Exports & 131 & 175 & 196 & 315 & 676 & - \\
Imports & -99 & -152 & -184 & -312 & -643 & - \\
Inventory change & -14 & 11 & 14 & 17 & 27 & - \\
\hline
\end{tabular}

amport requirements are computed explicitly in the RFF model, making due al lowance for the cost of imported energy. Exports are then calculated on the basis of the long-run equilibrium assumption that international currency exchange rates automatically adjust to permit exports to balance imports.

But future energy demand and prices depend not only on GNP but also on other parameters of the economy. The key unknowns are as follows:

- The inherent energy intensiveness of the economy, or (equivalently) the price elasticity of demand;

- The degree of effective constraint on production of coal and nuclear energy that will be imposed for health, safety, and environmental reasons;

- The cost of synthetic fuels from coal and energy from other medium- or long-term technological alternatives, including wind, biomass, passive solar collectors, terrestrial photovoltaic cells, SPS, and fusion.

For simplicity we have considered three alternative price elasticities of aggregate demand for energy, namely:

H: High energy intenoivencos, corregponding th lno elasticity $(-0.25)$.

I: Intermediate energy intensiveness, corresponding to intermediate elasticity $(-0.4$ for residential and housing demand, -0.7 for industry, 0 for feedstocks).

L: Low energy intensiveness, corresponding to high elasticity $(-0.75)$. 
Regarding constraint's, we have selected two cases:

U: Unconstrained supply of coal and nuclear power.

C: Constrained supply, due to health, safety, environmental, and other limitations on the rate of increase of supply.

It is important to note that we have assumed domestic production of petroleum and natural gas, and imports of these fuels, to be strictly limited by geological factors in the first instance and by international political factors in the second. The combined effect of all constraints is shown in Table 4.2.

As regards long-run supply costs, our basic assumptions (Table 4.3 ) are taken from a recent comprehensive appraisal by Resources for the Future.40

Table 4.2 Constrained Energy Supplies (1015. Btu) for Future Scenarios

\begin{tabular}{lrrrrr}
\hline \multicolumn{1}{c}{ Energy Source } & 1980 & 1985 & 2000 & 2025 & 2030 \\
\hline Petroleum & & & & & \\
$\quad$ Domestic production & 20.2 & 16.5 & 11.2 & 6.1 & 5.1 \\
$\quad$ Net Imports & 18.0 & 18.0 & 18.0 & 18.0 & 18.0 \\
$\quad$ Total & 38.2 & 34.5 & 29.2 & 24.1 & 23.1 \\
Natural gas & & & & & \\
$\quad$ Domestic gas & 19.4 & 17.6 & 12.0 & 5.6 & 4.3 \\
Net Imports & 2.3 & 3.0 & 3.0 & 3.0 & 3.0 \\
$\quad$ Total & 21.7 & 20.6 & 15.0 & 8.6 & 7.3 \\
Coal & & & & & \\
$\quad$ nirect & 14.9 & 19.7 & 21.1 & 27.0 & 28.2 \\
Converted & 0 & 0 & 8.5 & 20.8 & 23.0 \\
$\quad$ Total & 14.9 & 19.2 & $29.7 \mathrm{a}$ & $47.8 \mathrm{a}$ & $51.3^{\mathrm{a}}$ \\
Nuc lear & 3.0 & 5.0 & 10.0 & 14.5 & 15.4 \\
Hydro & 3.2 & 3.2 & 3.3 & 3.5 & 3.5 \\
Geothermal & 0 & 0 & 1.0 & 3.0 & 3.5 \\
Solarb & 0 & 0 & 1.1 & 6.1 & 7.5 \\
Shale & 0 & 0 & 5.0 & 18.3 & 21.0 \\
$\quad$ Total Consumption & 81.0 & 82.5 & 94.3 & 126.2 & 136.6 \\
\hline
\end{tabular}

${ }^{a}$ Or other combinations with the same total.

bassive solar collectors or hot water and seasonal space heating in suitable applications. 
Table 4.3. As sumed Long-Run Costs per

Million Btu (1978\$)

\section{Coal gasification \\ $\$ 3.17$ for conversion \\ $+\$ 0.97$ for distribution}

Shale oil

$\$ 4.67$ for extraction

$+\$ 1.90$ for refining and distribution

"Alternatives" (e.g., passive solar, wind, etc.)

$\$ 9.00$ standard case, or

$\$ 4.50$ "decentralized" case, assuming a cost hreak.through

Electricity

$\$ 7.33$ for conversion from coal

$\$ 8.96$ for conversion from nuclear fuel

Source: Ref. 40 .

Note that two price cases for "alternative sources" were considered. The higher $\left(\$ 9 / 10^{6} \mathrm{Btu}\right)$ is consistent with continued dependence on centralized electric or gas utilities. However, the lower-price case $\left(\$ 4.50 / 10^{6} \mathrm{Btu}\right)$ would presumably lead to more decentralized energy. production. Two scenarios of the latter type are con'sidered.

The procedure for quantifying scenarios is outlined briefly as follows. First, from the assumed GNP growth rate and assumed price elasticities of demand, a set of projections of alternative energy (E) to GNP.ratios can be derived, as shown in Fig. 4.3. Detailed demands by each of 185 sectors of the economy are computed from an input-output model for this economic scenario, assuming fixed prices. 30 Next, demands for specific fuel types are generated, and a supply-demand balance is computed for each of six scenarios, representing combinations of the levels of price elasticity and constraints, as follows: $\mathrm{UH}, \mathrm{UI}, \mathrm{UL}, \mathrm{CH}, \mathrm{CI}, \mathrm{CL}$. The supply-demand balances are displayed in Fig. 4.4 (2000) and Fig. 4.5 (2030).

Ihe next step was to calculate the energy prices. (for each primary fuel and for electricity) that would match supply and demand in each year.' Adjustment lags of unknown length make this calculation approximate. The final steps involve recomputation of total demand, by sector, for the revised energy prices; recomputation of total E and E/GNP; and reiteration of the whole sequence until convergence is achieved.

Our baseline scenario is the constrained case with an intermediate value of price elasticity (designated CI). This choice reflects our belief that constraints on production growth are likely to continue, rather than abate; that the intermediate value of elasticity is more likely than either of the extremes; and that the higher cost level $\left(\$ 9.00 / 10^{6} \mathrm{Btu}\right)$ is more realistic for "alternative sources" than the lower cost $(\$ 4.50 / 106 \mathrm{Btu})$. 


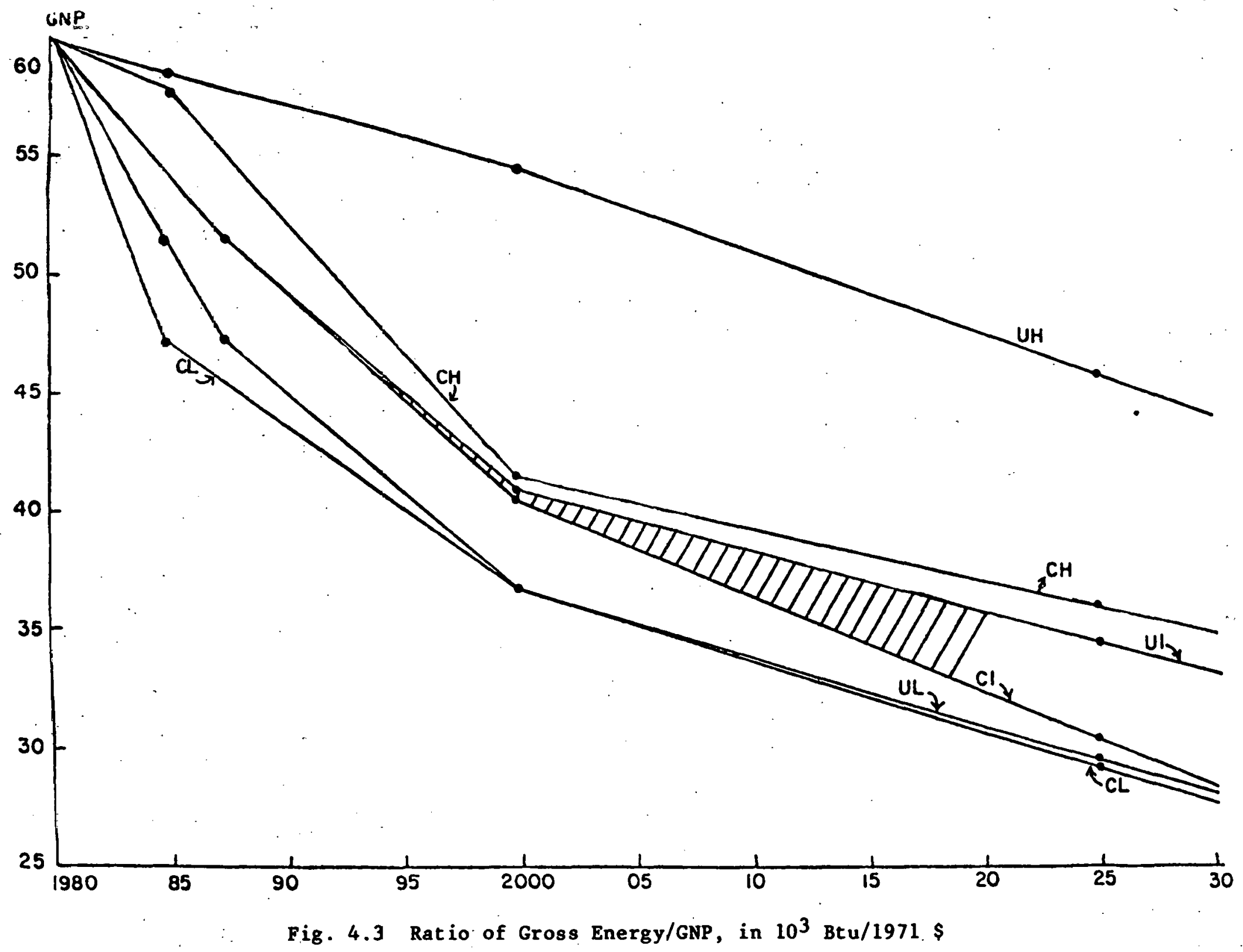




\section{EXCUDING FEED STOCKS}

\section{ENERGYOLMAND EY VARIOUS SECTORS}

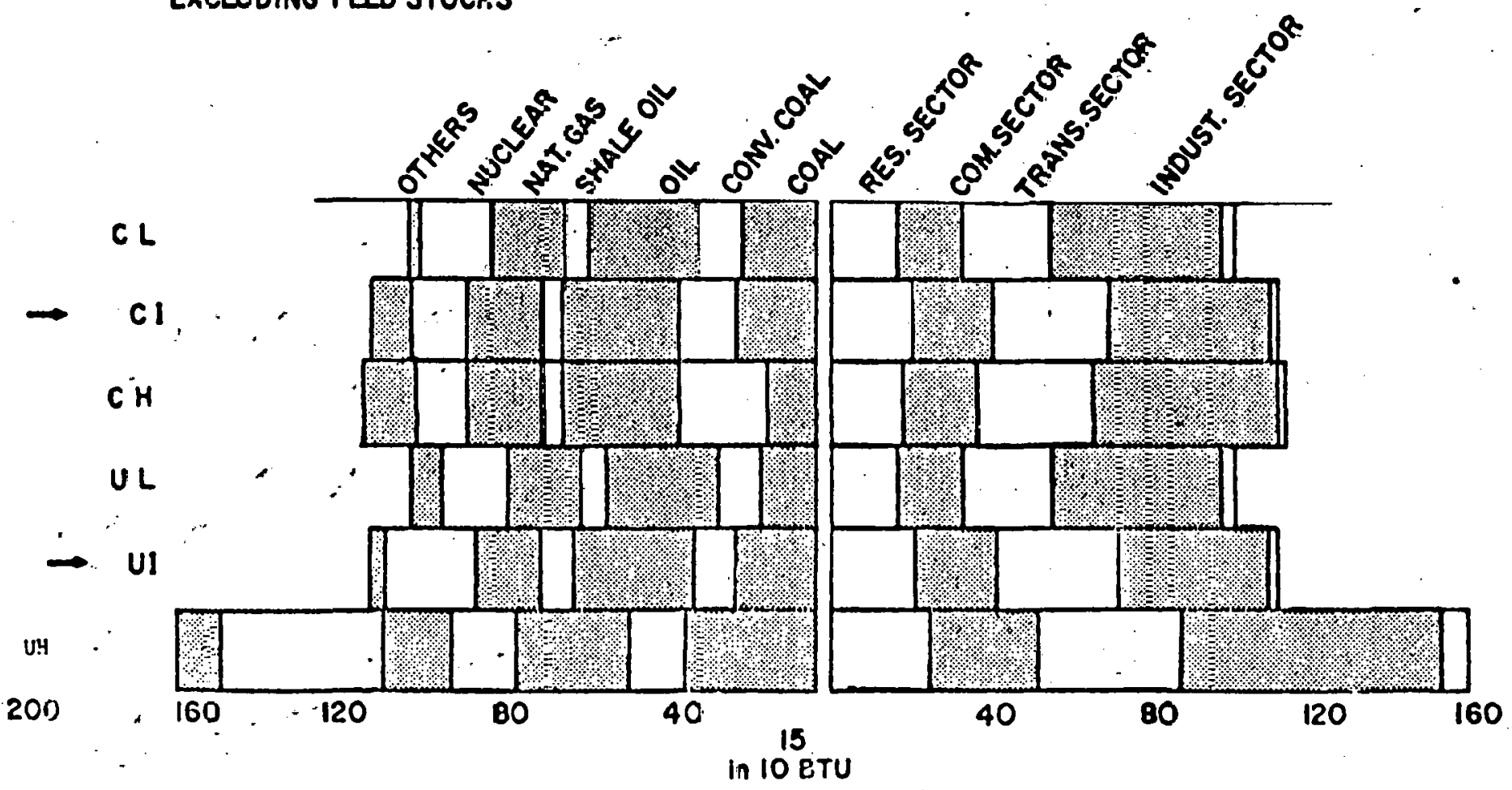

Fig. 2.4 Supply-Demand Patterns for Various Scenarios in the Tear 2000 


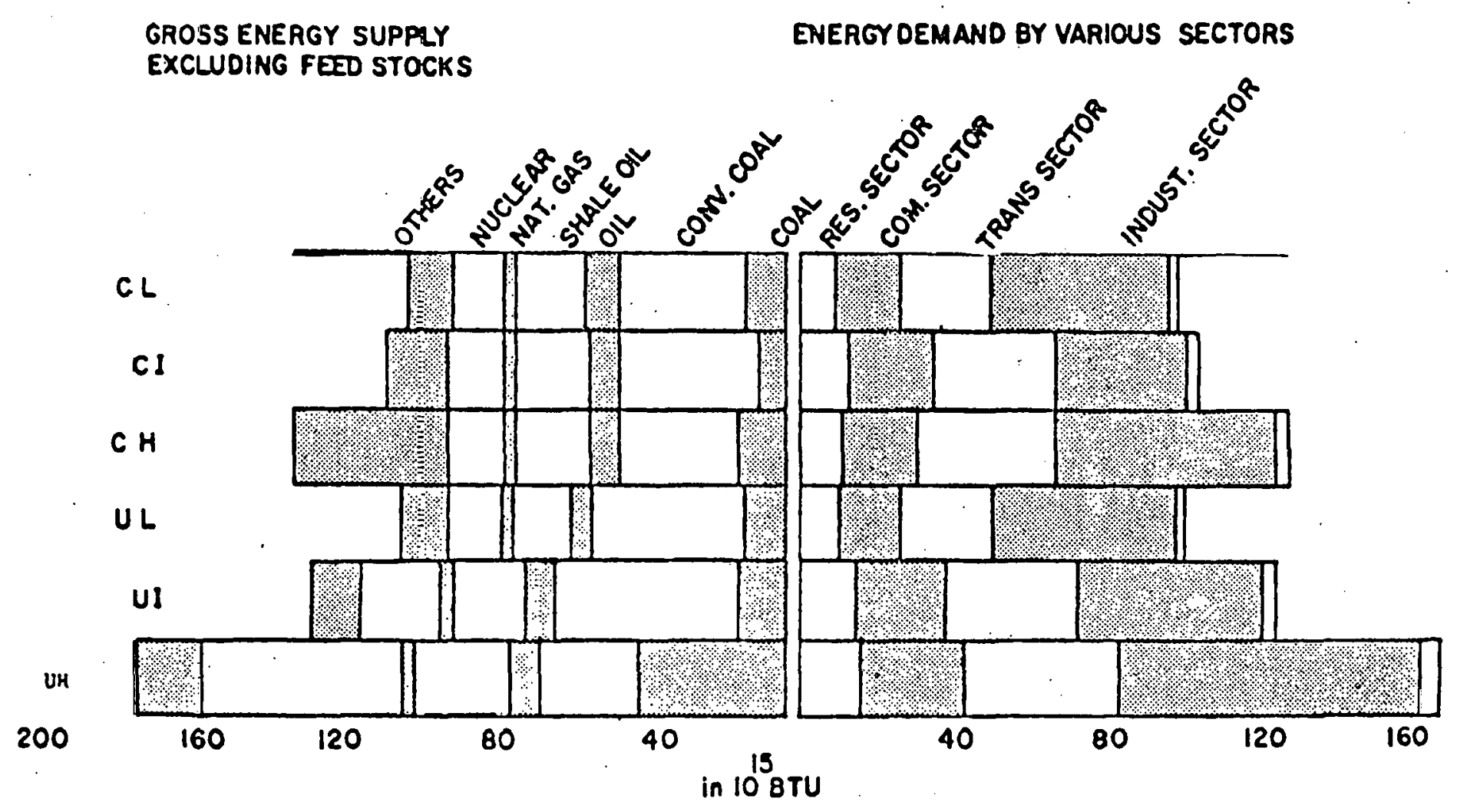

Fig. 4.5 Supply-Demand Patterns for Various Scenarios in the Year 2030 
In only one case -- the unconstrained, high-energy-intensiveness scenario (UH) -- does the economy of 2030 depend on electricity more than it does at present.

In all other cases, the use of electricity can be expected to decline in relative importance, at least after the year 2000 . In Fig. 4.6 electrification is plotted as a percentage of net energy use in the economy, for three representative scenarios.

It is noteworthy that the foregoing results are qualitatively dependent on most of the detailed supply/demand price projections. The calculated supply-demand balances are shown graphically for all scenarios for the years 2000 and 2030 in Figs. 4.4 and 4.5. Price projections for all scenarios are displayed graphically in Figs. 4.7-4.10 for oil, gas, coal, and electricity, respectively. Nuclear fuel prices for light water reactors and LMFBRs are shown in Table 4.4. As expected, energy prices $r$ ise much faster and higher in the 'constrained' scenarios than in the unconstrained cases.

Table 4.5 shows a comparison of the six comparative assessment scenarios and projections updated by the Energy Information Administration.*41 The

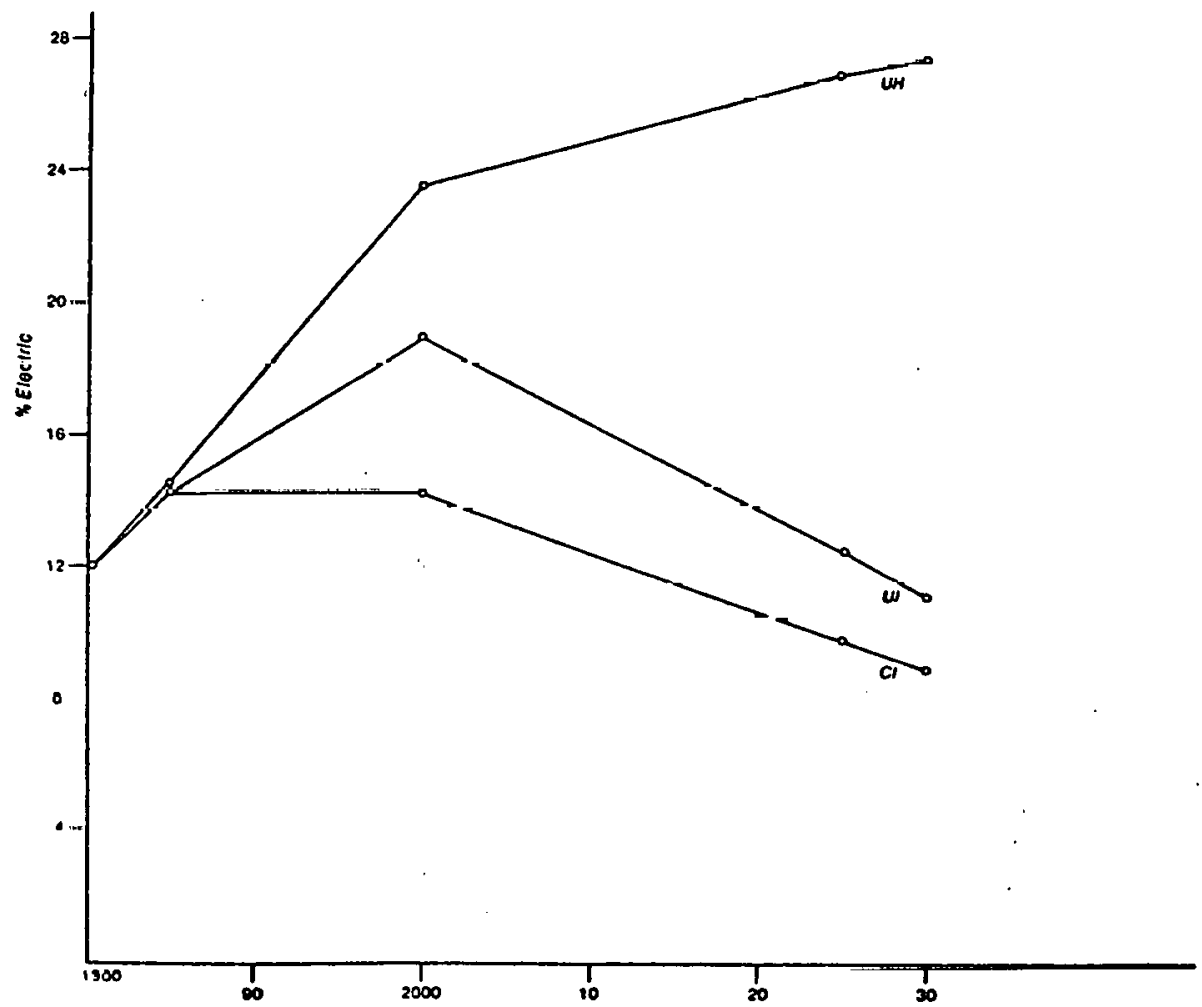

Fig. 4.6. Electrification as a Percentage of Net Energy Use: Three Scenarios

* Supply assumptions and costs for uranium were developed separately but are consistent with the rest of the calculations. 


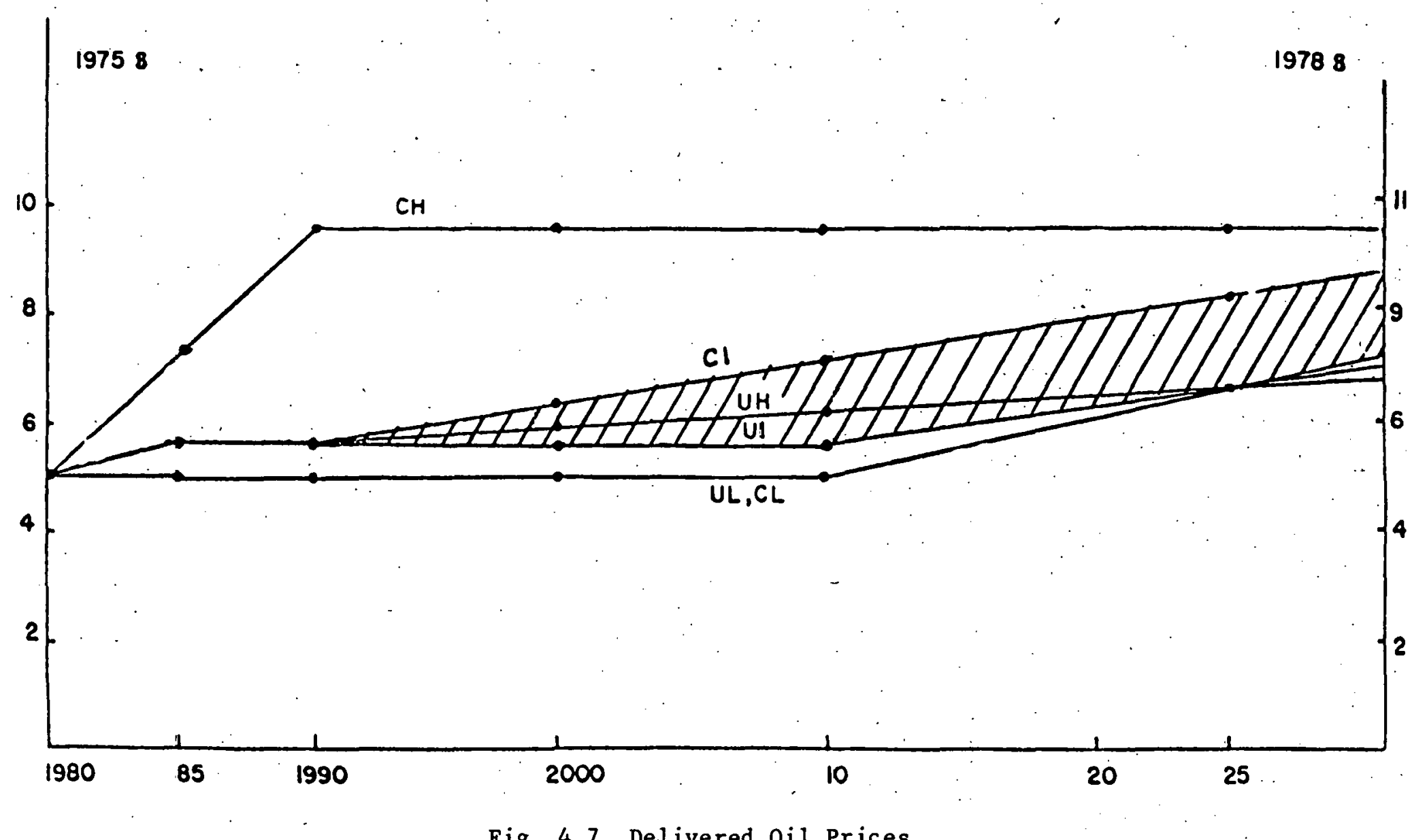




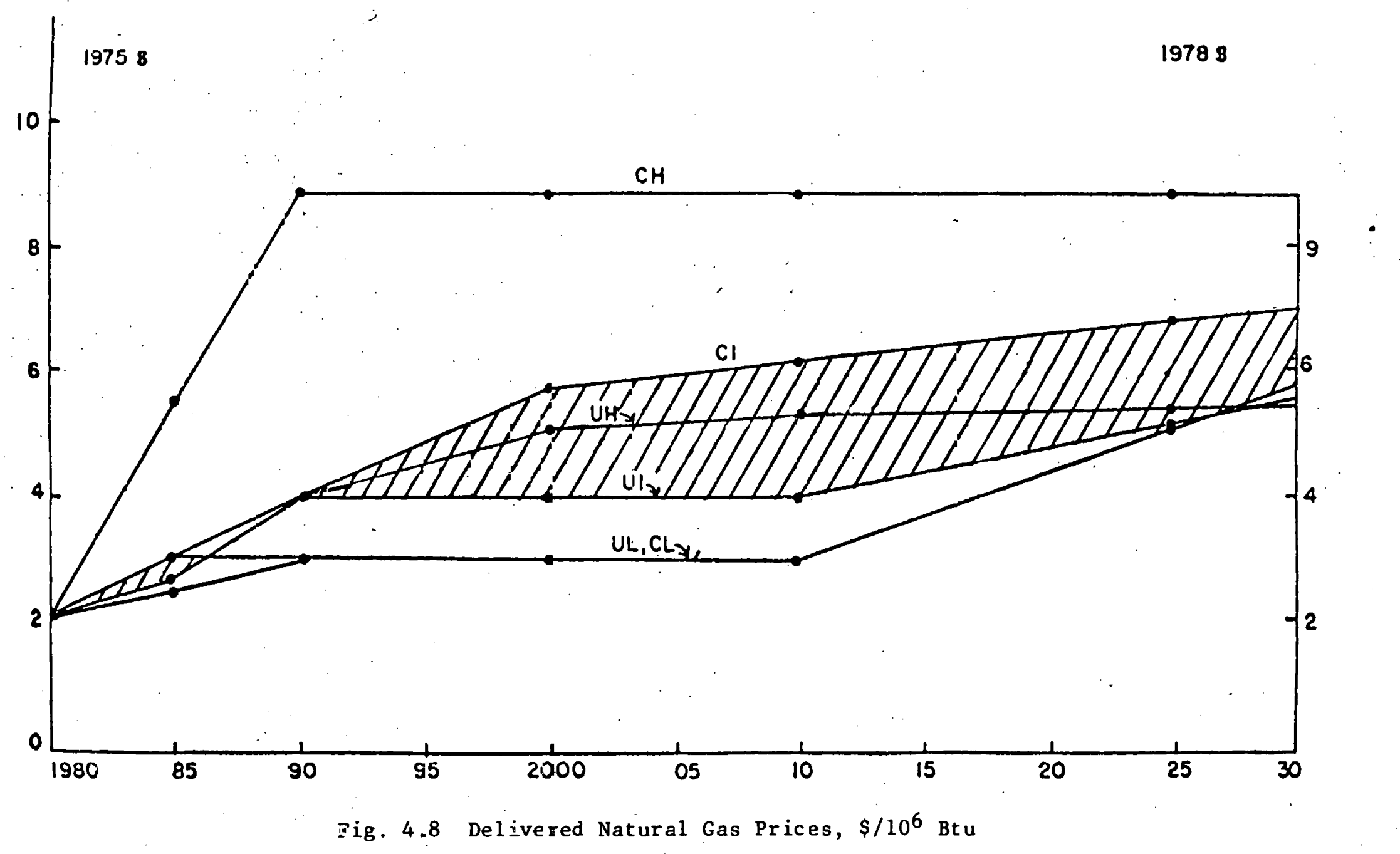




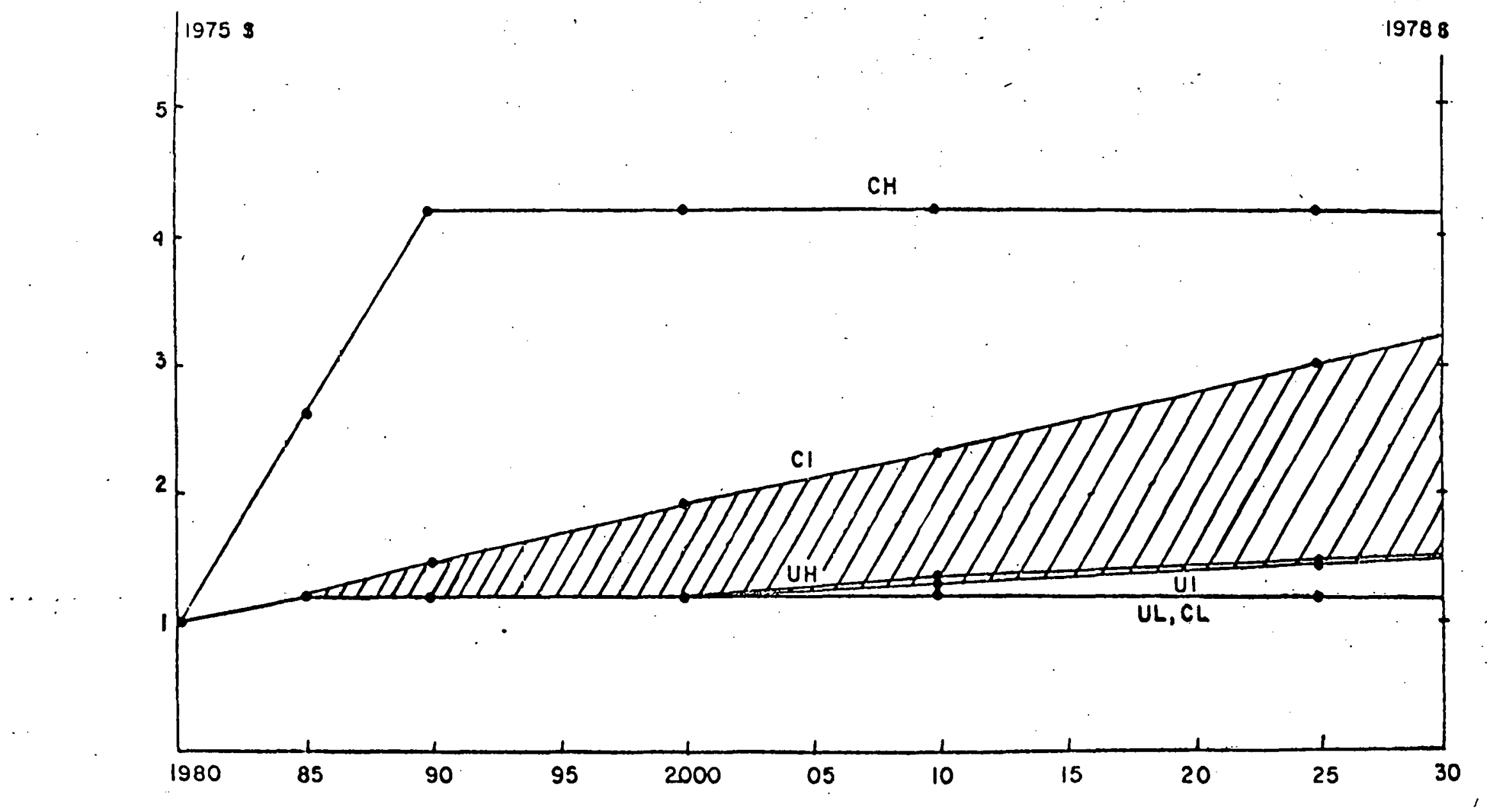

Fig. 4.9 Delivered Coal Prices, $\$ / 10^{6}$ Btu 


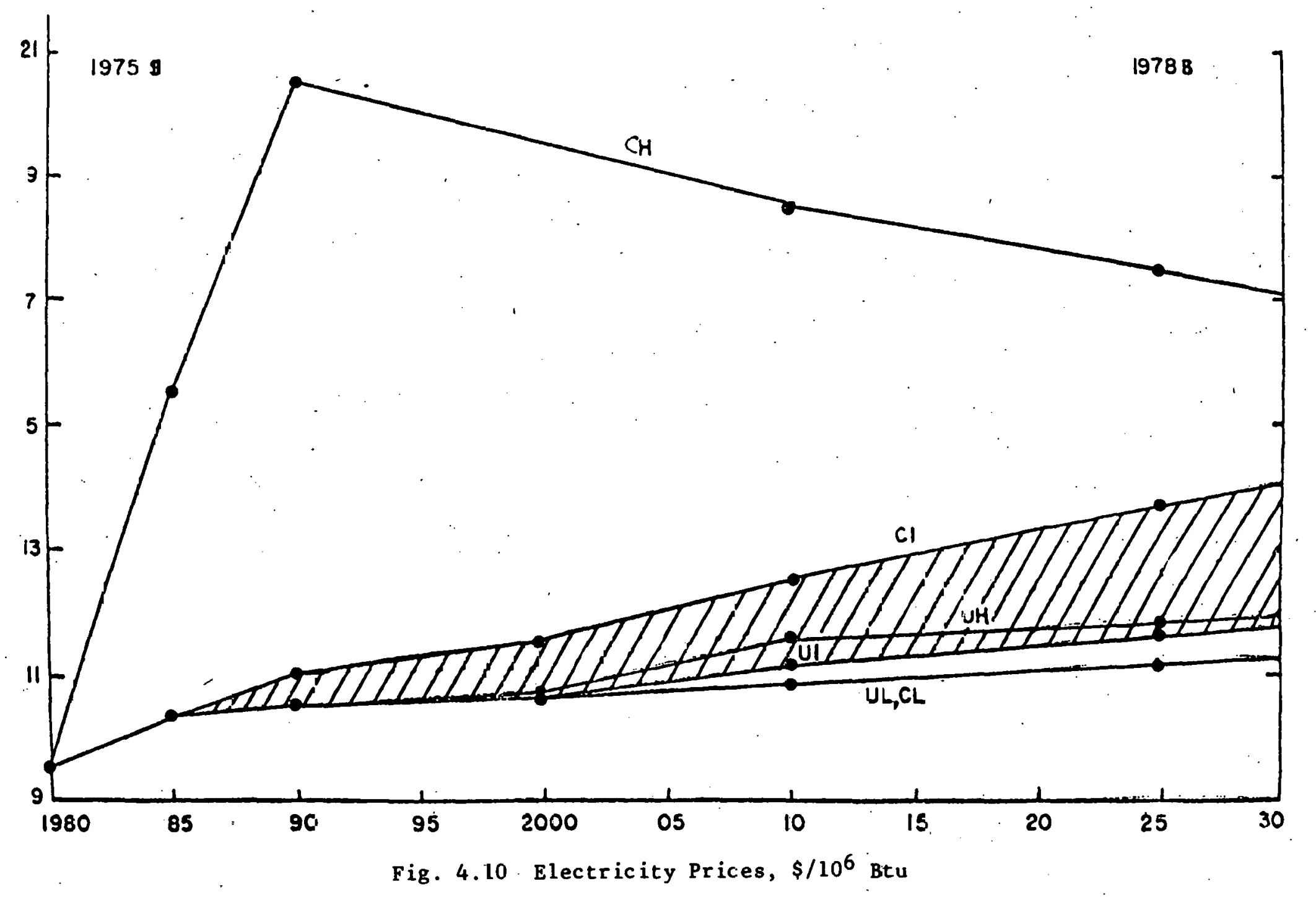


Table 4.4 Nuclear Fuel Prices (1978 $\$ / 10^{6}$ Btu)

for Future Scenarios

\begin{tabular}{lcccc}
\hline & \multicolumn{2}{c}{ Light Water Reactor } & & LMFBR \\
\cline { 2 - 3 } Year & UH, UI, UL & CH, CI, CL & All Scenarios \\
\hline 1980 & 0.62 & 0.62 & Scen \\
1985 & 0.67 & 0.76 & a \\
1990 & 0.71 & 0.81 & a \\
2000 & 0.72 & 0.86 & 0.64 \\
2010 & 0.79 & 0.95 & 0.65 \\
2025 & 0.89 & 1.12 & 0.67 \\
2030 & 0.93 & 1.17 & 0.68 \\
\hline
\end{tabular}

${ }^{a}$ LMFBR introduction assumed between 1990 and 2000.

Table 4.5 Electrical Generation in Comparative Assessment Scenarios and Two Other Projections ( $\left.10^{9} \mathrm{kWh}\right)$

\begin{tabular}{|c|c|c|c|c|c|c|c|c|}
\hline \multirow{2}{*}{$\begin{array}{l}\text { Energy } \\
\text { Source }\end{array}$} & \multirow{2}{*}{$\begin{array}{c}\text { EIA }^{a}(1995) \\
1978 \text { Annual } \\
\text { Report }\end{array}$} & \multirow{2}{*}{$\begin{array}{l}\text { EPRI } I^{b} \\
(2000)\end{array}$} & \multicolumn{6}{|c|}{ Comparat ive Assessment (2000) } \\
\hline & & & UH & UI & UL & CH & CI & CL \\
\hline $\begin{array}{l}\text { Coal } \\
\text { oil }\end{array}$ & $\begin{array}{c}2549-3163 \\
130-85\end{array}$ & $\begin{array}{r}3396 \\
390\end{array}$ & $\begin{array}{r}1922 \\
126\end{array}$ & $\begin{array}{r}1300 \\
126\end{array}$ & $\begin{array}{l}738 \\
126\end{array}$ & $\begin{array}{l}563 \\
126\end{array}$ & $\begin{array}{r}91 \\
126\end{array}$ & $\begin{array}{r}1010 \\
126\end{array}$ \\
\hline Gas & $42-17$ & 0 & 126 & 126 & 126 & 126 & 126 & 126 \\
\hline Nuc lear & $978-1215$ & 2795 & 3010 & 1621 & 1223 & 893 & 970 & 970 \\
\hline Hyd ro & $327-323$ & 395 & 320 & 320 & 320 & 320 & 320 & 320 \\
\hline New & $96-76$ & 164 & 106 & 106 & 106 & 106 & 106 & 106 \\
\hline Total & $4122-4879$ & 7140 & 5610 & 3600 & 2640 & 2134 & 2610 & 2660 \\
\hline
\end{tabular}

asource: $\operatorname{Ref.} 41$.

bsource: Ref. 42 .

comparative assessment scenarios fall within the range of those reported by EIA (with the exception of the nuclear/coal distribution) but lower than the EPRI projections. We do not feel that the comparative assessment scenarios are any better or worse than the EIA or EPRI scenarios, just different. However, we feel that the comparative assessment scenarios are plausible, representative, and useful for alternative future comparisons.

Table 4.6 shows the total installed capacity and new baseload construction for the six scenarios. Since the total capacity and additions were not substantially different for several of the scenarios, only the three most representative scenarios (UH, UI, and CI) were selected for comparative analysis. These cases represent the range of energy growth in the $s$ ix scenarios. Tables 4.7-4.9 report the cumulative capacity for each technology for the three scenarios with and without SPS. These capacity levels will serve as the basis for the comparative analyses reported in subsequent sections of this report. 
Table 4.6 Total Installed and New-Construction Baseload Capacity (1000 MW) for Six Comparative Assessment Scenarios

\begin{tabular}{|c|c|c|c|c|c|c|c|c|c|c|c|c|}
\hline \multirow[b]{2}{*}{ Year } & \multicolumn{2}{|c|}{$\mathrm{UH}$} & \multicolumn{2}{|c|}{ UI } & \multicolumn{2}{|c|}{ UL } & \multicolumn{2}{|c|}{$\mathrm{CH}$} & \multicolumn{2}{|c|}{$\mathrm{CI}$} & \multicolumn{2}{|c|}{$\mathrm{CL}$} \\
\hline & Total & New & Total & New & Total & New & Total & New & Total & New & Total & New \\
\hline 1980 & 202 & 63 & 202 & 63 & 202 & 63 & 202 & 63 & 202 & 63. & 202 & 63 \\
\hline 2000 & 906 & 231 & 536 & 140 & 364 & 91 & 288 & 47 & 402 & 63 & 364 & 91 \\
\hline 2015 & 1344 & 382 & 570 & 114 & 359 & 58 & 385 & 184 & 398 & 100 & 358 & 58 \\
\hline 2030 & 1772 & 417 & 586 & 173 & 335 & 78 & 503 & 80 & 378 & 110 & 335 & 78 \\
\hline
\end{tabular}

Tahle 4.7 Finergy Systom Doploymont (GW of (apacity) for Scenario UH with and without SPS

\begin{tabular}{lrrrr}
\hline & \multicolumn{4}{c}{ Year } \\
\cline { 2 - 5 } Technology & 1980 & 2000 & 2015 & 2030 \\
\hline & \multicolumn{4}{c}{ With SPS } \\
Coal & 155 & 354 & 395 & 460 \\
LWR & 47 & 508 & 546 & 534 \\
LMFBR & 0 & 44 & 175 & 312 \\
TPV & 0 & 0 & 36 & 72 \\
SPS & 0 & 0 & 150 & 300 \\
Fusion & 0 & 0 & 42 & 94 \\
$\quad$ Tnt 11 & 202 & 906 & 1344 & 1772 \\
& & & & \\
& & Without & SPS & \\
Coal & 155 & 354 & 470 & 584 \\
LWR & 47 & 508 & 574 & 628 \\
LMFBR & 0 & 44 & 210 & 375 \\
TPV & 0 & 0 & 36 & 72 \\
SPS & 0 & 0 & 0 & 0 \\
Fusion & 0 & 0 & 54 & 113 \\
$\quad$ Total & 202 & 906 & 1344 & 1772 \\
\hline
\end{tabular}


Table 4.8 Energy System Deployment (GW of (apacity) for Scenario UI with and without SPS

\begin{tabular}{lrrrr}
\hline & \multicolumn{4}{c}{ Year } \\
\cline { 2 - 5 } Technology & 1980 & 2000 & 2015 & 2030 \\
\hline \multicolumn{4}{c}{ With SPS } \\
Coal & 155 & 238 & 166 & 70 \\
LWR & 47 & 263 & 208 & 169 \\
LMFBR & 0 & 34 & 81 & 125 \\
TPV & 0 & 0 & 24 & 48 \\
SPS & 0 & 0 & 75 & 150 \\
Fusion & 0 & 0 & 16 & 24 \\
$\quad$ Total & 202 & 535 & 570 & 586 \\
& & Without & SPS & \\
Coal & & 238 & 181 & 109 \\
LWR & 155 & 263 & 227 & 177 \\
LMFBR & 47 & 34 & 111 & 195 \\
TPV & 0 & 0 & 24 & 48 \\
SPS & 0 & 0 & 0 & 0 \\
Fusion & 0 & 0 & 27 & 57 \\
$\quad$ Total & 202 & 535 & 570 & 586 \\
\hline
\end{tabular}

Table 4.9 Energy System Deployment (GW of Capacity) for Scenario CI with and without SPS

\begin{tabular}{lrrrr}
\hline & \multicolumn{4}{c}{ Year } \\
\cline { 2 - 5 } Technology & 1980 & 2000 & 2015 & 2030 \\
\hline & \multicolumn{4}{c}{ With SPS } \\
Coa1 & 155 & 224 & 121 & 24 \\
LWR & 47 & 157 & 116 & 75 \\
LMFBR & 0 & 22 & 79 & 124 \\
TPV & 0 & 0 & 18 & 36 \\
SPS & 0 & 0 & 50 & 100 \\
Fusion & 0 & 0 & 14 & 19 \\
Total & 202 & 403 & 398 & 378 \\
& & Without & SPS & \\
& & 224 & 135 & 30 \\
Coal & 155 & 24 & 130 & 94 \\
LWR & 47 & 157 & 92 & 169 \\
LMFBR & 0 & 22 & 18 & 36 \\
TPV & 0 & 0 & 0 & 0 \\
SPS & 0 & 0 & 23 & 49 \\
Fusion & 0 & 0 & 398 & 378 \\
$\quad$ Total & 202 & 403 & \\
\hline
\end{tabular}




\subsection{COST AND PERFORMANCE}

\section{4:2.1 Introduction}

The comparison of projected energy costs for alternative technologies is a prime consideration in the selection of programs for further research and development. The basic energy costs of the SPS and other technologies are described in Sec. 3.3. The goal of these cost analyses is to produce an objective comparison using consistent data and assumptions. These comparisons were performed with an internally consistent and traceable data base that was developed for this assessment. In addition, many assumptions were made in performing the cost comparisons reported in this section. Therefore, the absolute numbers reported here are intended only for the present comparison, should not be compared to assessments or energy rost stuntiof raported olcewhere.

Different costing methods, assumptions, or base data could affect the calculations substantially so that comparability to other studies is not possible without a detailed knowledge of technology costing and the differences in assumptions and data that exist between studies. However, the goal of this study was not to produce information that is directly comparable in detail to other studies, but rather to be internally consistent, so that this cost comparison would be useful in decision making concerning the relative economic viability of SPS.

The comparative cost analys is conducted in this assessment was a multistep process. These steps were assembled into an evaluation framework so that the numerous analytical steps could be performed in an orderly progression. Figure 4.11 shows the sequence of steps in the evaluation framework.

The results of four of these steps are discussed in other sections of Lhis repurt: the SPS and the six alternative technologies are characterized in Sec.. 3; the cost characterization, which includes capital and operation and maintenance data, is described in Sec. 3.3; and the alternative future energy supply-demand scenarios, which include SPS implementation rates, are described in detail in Sec. 4.1.

The next section of this report (Sec, 4.2.2) will begin with a descrip$t$ ion of the cost uncertainty that exists in the base data that is reported in Sec. 3.3 for all of the technologies. The uncertainty in fuel price projections that resulted from the alternative futures scenarios will be reported in Sec. 4.2.3. Section 4.2 .4 contains comparative cost information standarized to levelized annual costs for all technologies. The comparative cost information described in Sec. 4.2.4 was subjected to sensitivity analyses, which are discussed in Sec. 4.2.5. Finally; an uncertainty analys is of the comparative costing approach was conducted, and this analys is and its implicatinns for any future comparisons are discussed in Sec. 4.2.6. This cost comparison section ends with some summary statements regarding the status and conclusions of the analys is. 


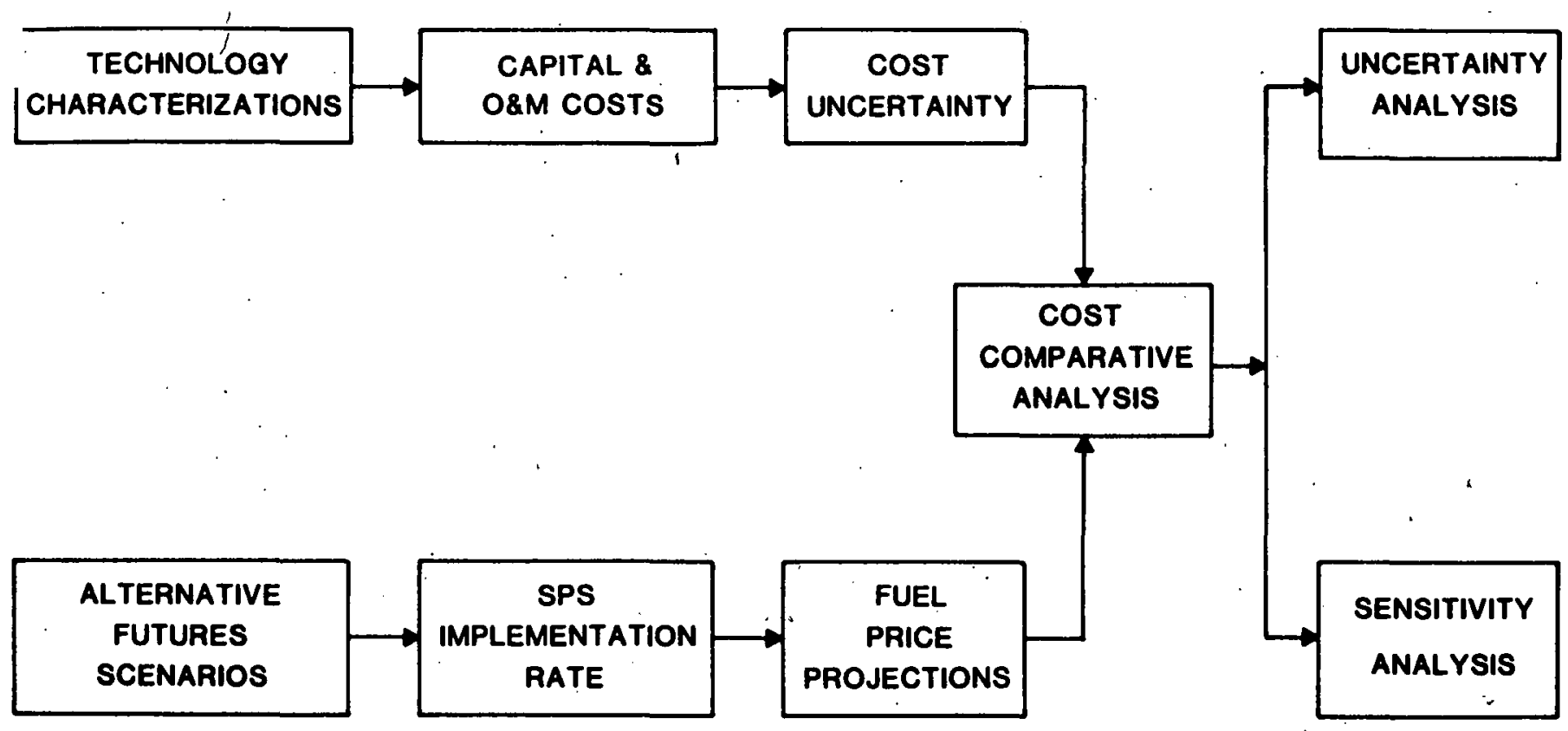

Fig: 4.11 Cost and Performance Evaluation Framework

\subsubsection{Uncertainty in Capital Cost Ranges for SPS and Alternatives}

Capital costs of technologies that have not yet been developed are highly uncertain and depend in part on the commitment made to, and the results of, future R\&D efforts. At this time the estimated ranges of capital costs for the SPS and the other advanced technologies are large. Significant uncertainties also exist in the projected cost of energy from current or conventional technologies. Capital costs for electric generation technologies to commence operation in the year 2000 are highly uncertain. Accurate projections of costs in that era, even for technologies that are in commercial operation today, are still difficult. Consideration of factors that contribute to the range of estimated costs is necessary for a valid pairwise comparieon of technologies, and these factors have been included in the following analysis and assessment.

There are many parameters that could be factored into the estimation of capital cost uncertainty, but we have chosen to aggregate the capital cost uncertainty into the following three factors that we feel represent the major uncertainties:

1. Uncertainty about future costs of materials, supplies, and labor necessary to construct power plant facilities;

2. Uncertainty about the future requirements and associated costs of environmental and safety equipment; and

3. Uncertainty about the capability of technologies to perform as conceptualized.

The uncertainty associated with factor 1 was generally accounted for through an analysis of the Handy-Whitman Index 43 of public utility construction costs, which is widely used as a "benchmark" index by the electric 
utility industry. It is here referred to as a benchmark since it is derived not from actual project construction costs, but rather from a periodic sampling of a market basket of over 50 standard commodities and components used in conventional utility plant construction. The market basket contents have not been updated significantly in many years, so that the index more closely tracks a lower bound of cost. increases. Thus, the Handy-Whitman Index does not appropriately account for technological or regulatory cost increases, as is typified by the added cost of sulfur-removal or nuclearsafety requirements imposed by legislation in recent years. 44

However, this index does measure the nominal real cost increases in power plant construction. The lack of revision in commodity mix is judged not to be a serious problem, since the mix of added environmental and safety equipment and personnel in post-1970 plants is the same as that of the plants overall.

Over the 30-year period 1948-1978, the Handy-Whitman Index has increased in real terms (relative to the GNP deflator) at an average compound rate of $1.5 \%$ per year. For the period 1948-1978, increases were about $1 \%$ per year, while for the period 1968-1978 increases averaged over $2 \%$ per year relative to the GNP deflator. The analysis of the Handy-Whitman Index indicates that the compound annual real cost increases exhibited over the past 10 years are $1.5 \%$ per year for coal and $2.0 \%$ per year for nuclear.

Information on factor 2 was derived from construction cost information assembled over the past decade. Although the available data contain the cost estimates of actual construction projects, these estimates are for a mix of plant sizes. However, the data indicate approximately a $10 \%$ per year real increase early in the period, with the rate of increase tapering off to about $7 \%$ per year more recently. These rates of real escalation are due primarily to added safety regulations and environmental controls that have been imposed over this period; no time-related factors are included. The easing of these rates in more recent years is a result of attempts to consolidate and simplify the existing regulations and of a decrease in the escalation rate due to new regulations. Although these rates may ease even more in the future, it is also possible that they may continue to be quite substantial. Thus, continuing rates of $5 \%$ and $6 \%$ per year have been assumed as a high range of escalation for the coal and nuclear technologies, tespectively.

Factor 3 uncertainties are based on judgments about the technical uncertainty surrounding an advanced technology. Since this is a comparative assessment, these numbers were derived from a range of estimates reported for each technology or from uncertainty in the technology definition.

Low, nominal, and high capital costs were derived for each technology, using the three factors just described. The uncertainties for each technology, at the low, nominal and high cost levels, are summarized in Table 4.10.

A factor of 1.3 was applied to the combined-cycle system and one of 1.35 to the LMFBR system. For the combined-cycle alternative, the gasifier elements make up the major technological uncertainty and also compose $30 \%$ of the nominal plant costs. It has been assumed that this component might increase in cost by as much as $100 \%$. For the LMFBR, two recent estimates provided by United Engineers and Constructors show plant costs to vary by $35 \%$. 
Table 4.10 Capital Cost Uncertainty Factors for Alternative Technologies (Low, Nominal, and High Values)

\begin{tabular}{|c|c|c|c|c|c|c|c|}
\hline Value & $\begin{array}{c}\text { Conventional } \\
\text { Coal }\end{array}$ & LWR & $\mathrm{CG} / \mathrm{CC}$ & LMFBR & TPV & Fusion & SPS \\
\hline Low & $\begin{array}{l}0.75 \% \text { per year - } \\
1 / 2 \text { che histori- } \\
\text { cal Hardy-Whitman } \\
\text { Index (HWI). }\end{array}$ & $\begin{array}{l}1.0 \% \text { per year - } \\
1 / 2 \text { the histori- } \\
\text { cal HWI. }\end{array}$ & $\begin{array}{l}\text { Same as conven- } \\
\text { tional coal. }\end{array}$ & Same as LWR. & $\begin{array}{l}\text { No real cost } \\
\text { increases assumed } \\
\text { in } 1978 \text { estimate; } \\
\text { a } 43 \% \text { decrease in } \\
\text { nominal solar cell } \\
\text { costs to } \$ 21.60 / \mathrm{m}^{2} \\
(1978 \$) \text { from } \\
\$ 37.80 / \mathrm{m}^{2} \text {. }\end{array}$ & $\begin{array}{l}\text { Assumed to be } \\
\text { the same value as } \\
\text { originally estimated } \\
\text { in the NUWMak report, } \\
\text { which served as the } \\
\text { basis for the } \\
\text { characterization. }\end{array}$ & $\begin{array}{l}\text { No cost increases assumed; } \\
\text { a cost reduction in solar } \\
\text { cells to } \$ 21.60 / \mathrm{m}^{2} \text { from } \\
\$ 37.80 / \mathrm{m}^{2} \text {. This reduction } \\
\text { in costs is an example } \\
\text { of the magnitude of cost } \\
\text { reduction believed achiev- } \\
\text { able by Westinghouse as } \\
\text { a result of a major pro- } \\
\text { duction technology break- } \\
\text { through beyond the pro- } \\
\text { jections currently being } \\
\text { assumed in the reference } \\
\text { design. }\end{array}$ \\
\hline Nominal & $\begin{array}{l}1.5 \% \text { per year - } \\
\text { historical HWI. }\end{array}$ & $\begin{array}{l}2.0 \% \text { per year - } \\
\text { historical HWI. }\end{array}$ & $\begin{array}{l}\text { Same as conven- } \\
\text { tional coal. }\end{array}$ & Same as LWR. & $\begin{array}{l}\text { Cost increases } \\
\text { equivalent to } 1.0 \% \\
\text { per year on the total } \\
\text { plant cost. Derived } \\
\text { Erom applying the } \\
\text { nominal coal plant } \\
\text { increase of } 1.5 \% \text { per } \\
\text { year to the non-solar } \\
\text { array portion of the } \\
\text { plant (about } 2 / 3 \text { the } \\
\text { total cost). }\end{array}$ & $\begin{array}{l}\text { Cost increases } \\
\text { equivalent to } 2.0 \% \\
\text { per year }(1978-2000) \text {, } \\
\text { or the nominal } \\
\text { nuclear rate. }\end{array}$ & $\begin{array}{l}\text { Nominal rate of increase } \\
\text { of } 1.5 \% / y r \text {, as for coal, } \\
\text { applied to the terrestrial } \\
\text { i.e., rectenna, portion of } \\
\text { the system, or about } 26.7 \% \\
\text { of the total costs. }\end{array}$ \\
\hline High & $\begin{array}{l}5.0 \% \text { per year - } \\
\text { continuation of } \\
\text { recent high rate } \\
\text { of environmental } \\
\text { regulatory } \\
\text { imposition. }\end{array}$ & $\begin{array}{l}6.0 \% \text { per year - } \\
\text { cont inuation of } \\
\text { recent high rate } \\
\text { cf safety re- } \\
\text { quirements being } \\
\text { imposed for next } \\
22 \text { years. }\end{array}$ & $\begin{array}{l}\text { Same as coal, } \\
\text { multiplied by } \\
1.30 \text {, which is } \\
\text { attributed to } \\
\text { a possible } \\
\text { doubling of the } \\
\text { gasifier vessel } \\
\text { costs that make } \\
\text { up about } 30 \% \text { of } \\
\text { the base plant } \\
\text { costs. }\end{array}$ & $\begin{array}{l}\text { Same as LWR, } \\
\text { mult iplied } \\
\text { by } 1.35 \text {, } \\
\text { which is } \\
\text { based on } \\
\text { the ratio } \\
\text { at different } \\
\text { cost esti- } \\
\text { mates repre- } \\
\text { senting } \\
\text { technology } \\
\text { uncertainty. }\end{array}$ & $\begin{array}{l}\text { Applies a factor of } \\
4 \text { to the year } 2000 \\
\text { nominal cost (mainly } \\
\text { cell cost uncertain- } \\
\text { ty). }\end{array}$ & $\begin{array}{l}\text { No estimate of the } \\
\text { high endpoint was } \\
\text { made because the. } \\
\text { scientific feasi- } \\
\text { bility of plasma } \\
\text { confinement has } \\
\text { not been demon- } \\
\text { strated. }\end{array}$ & $\begin{array}{l}\text { Technical uncertainty } \\
\text { factor of } 5.0 \text { applied } \\
\text { to } 1978 \text {-dollar cost } \\
\text { estimate. }\end{array}$ \\
\hline
\end{tabular}


An uncertainty factor of 5.0 was applied to the 1978-dollar costs of the SPS system. This value is equivalent to a factor of 4.6 applied to the year-2000 base construction cost and was estimated from various cost ranges recently documented in the SPS literature.45,46 During 1976 and 1977 , several independent study teams gave cost estimates that ranged from a low $\$ 1400$ per kilowatt to a high of $\$ 6000$ per kilowatt.

A recent ECON report 47 points out the sensitivity of the probability distribution of a cost to a change only in the solar cell assumptions of the Rockwell International design. 8 By a change in assumptions, the spread of a total cost distribution for the first theoretical unit was increased from a high/low ratio of 2 to one of 4 . In an article on SPS costs, 48 Glaser discusses the SPS price tag and cost distributions. He states that the cost of producing the second 5-GW SPS may range from $\$ 8$ to $\$ 35$ billion, with a median cost of $\$ 14$ billion.

Little information is available from which a possible range of costs for the terrestrial photovoltaic system can be derived. $\Lambda$ rcasonable assump$t$ ion, however, is that this cost range should lie somewhere between the range of the combined cycle or LMFBR and that of the SPS. Since most of the uncertainty results from technical unknowns related to solar cell technology, and in light of ECON's results 47 concerning the possible impact of ceil costs on SPS, a factor of 4.0 was assigned.

A combined factor; used to derive the high, year-2000 bounds of capital costs, was thus taken to be the product of the high multiplicative factor and the uncertainty factor for the appropriate technology option. The resultant combined factor was then multiplied by the 1978 base costs to arrive at the upper bound estimate.

An examination of the ratio of high to low year- 2000 capital cost estimates resulting from these assumptions shows a reasonable consistency with the level of current knowledge and state of development apparent for ench technology. This ratio varies from a value of 2.11 for conventional coal systems to come on 1 ine in the year 2000 , to 4.58 for the SPS in the same period. Table 4.11 summarizes the year-2000 capital cost ranges used in the analysis.

\subsubsection{Fuel Price Projections}

Background and Methodology. Projectinns of any type extending far int.n the future involve many uncertainties that are amplified when that forecast attempts to define energy supply, demand, and costs. Energy sector uncertainties arise in three principal areas: (1) Future energy policy decisions, reflecting actions and reactions between producers and consumers, are not predictable. (2). The ultimately recoverable reservcs of energy resources cannot be precisely defined and, similarly, the rate of improvement in production or efficiency for developing technologies such as photovoltaic cells cannot be rigorously determined. (3) The price elasticity of energy substitution in the total economy is not fully known, and therefore assumptions must be made about the adaptability of GNP to varying components of gross energy supply. 
Table 4.11 Capital Cost Ranges for Technical and Regulatory Uncertainty $(\$ / \mathrm{kW})$

\begin{tabular}{lccccccc}
\hline \multicolumn{1}{c}{ Costs } & Cosl & LWR & CG/CC & LMFBR & TPV & Fusion & SPS \\
\hline 1978 Costs (Nominal) & 549 & 712 & 690 & 1037 & 844 & 2378 & $3340 / 3079$ \\
2000 Costs & & & & & & & \\
Low & 647 & 886 & 813 & 1291 & 731 & 2378 & $3139 / 2874$ \\
Nominal & 762 & 1100 & 957 & 1603 & 1057 & 3677 & $3646 / 3362$ \\
High & 1605 & 2566 & 2623 & 5048 & 4229 & $?$ & $16,698 /$ \\
& & & & & & 15,398 \\
Cost Ratios: & & & & & & \\
2000 Low/1978 Nominal & 1.18 & 1.24 & 1.18 & 1.24 & 0.87 & 1.00 & $0.94 / 0.94$ \\
2000 Nominal/2000 Low & 1.18 & 1.24 & 1.18 & 1.25 & 1.45 & 1.55 & $1.16 / 1.16$ \\
2000 High/2000 Nominal & 2.11 & 2.33 & 2.74 & 3.14 & 4.00 & $?$ & $4.58 / 4.58$ \\
\hline
\end{tabular}

Possible future scenarios (described in Sec. 4.1) were defined by assuming certain values for key unknown parameters and by following an internally consistent computational pathway. Reasonable boundary assumptions were made concerning the key unknowns, which established the range of values within which most plausible futures will fall.

The long-run costs of fuel (primary energy) are, in part, predicated on OPEC maintaining petroleum prices just below the long-run costs of producing substitutes from oil shale or coal. The cost of synthetic natural gas from coal was projected from a non-fuel cost of $\$ 3.17 / 10^{6}$ Btu plus 1.25 times the cost of coal per $10^{6}$ Btu (to allow for the $80 \%$ efficiency estimated for the gasification process) plus an assumed $\$ 0.97 / 10^{6} \mathrm{Btu}$ for transmission and distribution. Similarly, the long-run cost of natural gas was determined to be equivalent to its alternative -- high-Btu gas from coal. Finally, the long-run cost of electricity was based on non-fuel capital costs for the projected coal/nuclear ratios, assuming generation from oil and natural gas phased out and modest improvements in conversion efficiency between now and 2030 .

Fuel Price Paths. The long-run costs dictate the price of electricity, but the cost of other energy forms can differ when there are supply constraints. Oil prices are estimated to increase at a rate that maintains OPEC production more or less at constant levels, and, at a relatively inelastic demand, OPEC could seek increased prices because of constraints on coal and oil shale. However, if the price should reach $\$ 9.20$ per $10^{6} \mathrm{Btu}$, it is estimated that large quantities of low-level solar thermal energy could become economically attractive, 40 free of the environmental constraints affecting the development of other resources. Natural gas prices essentially follow the pattern of oil prices and are set so that remaining resources are produced before higher-co'st gas from coal or substitutes such as solar enter the market. In scenarios featuring low elasticities (energy-intensive GNP), the rate of price increases is high, and particularly so when supply constraints affect coal production.

The price of coal is expected to increase from $\$ 1.15$ to $\$ 1.38 / 10^{6}$ Btu between 1980 and 1985 because of impacts from the Surface Mine Control and Reclamation Act of 1977 and the possible continuation of decline in 
productivity. Beyond 1985, new federal. leases of land with high-quality coal will keep prices constant until 2000, with modest increases thereafter to reflect increased long-run costs resulting from rapid production increases when the supply is not constrained. If the supplies are constrained and the price-demand elasticity is moderate or low, prices increase above the long-run costs until demand is dampened to the required level.

Uranium prices, for convenience, are assumed to differ only between the constrained and unconstrained scenarios. The rationale is that future supplydemand conditions of the world-wide market, not local markets, will determine prices.

Projections. Three scenarios were uocd to measure a range of possible fuel prices and supplies. They are:

UH: An unconstrained scenario wherein energy price elas$t$ icities of demand are low $(-0.25)$ and the energy/GNP ratio is thercfore relatively cunstant. The unconstrained scenario is defined as possessing controls at about the level that existed in 1970 .

UI: An unconstrained scenario wherein the energy price elasticities of demand are moderate $(-0.7$ for industrial fuel use, -0.4 for all other fue 1 uses and 0 for feedstock use):

CI: A constrained scenario wherein the energy price elasticities of demand are moderate, as in UI. The constraints impneed are based on environmental, health, ald safety aspects of coal and nuclear fuels and serve to restrict rapid expansion of production. Petroleum and natural gas are constrained only by world market conditions.

The delivered costs of fuels as projected by the RFF mode $1^{30}$ are shown in Table 4.12 and graphically displayed in Fig. 4.12 for the period 1980 to 2030. For comparison, the EPRI Technical Assessment Guide 49 gives coal price estimates of between $\$ 2.00$ and $\$ 2.40 / 10^{6} \mathrm{Btu}$, depending on the consuming and supply regions. Our unconstrained price trajectory for LWR fuel agrees very closely with the EPRT projectinn until 2000, aftcr which EFRI does not project $L W R$ fuel costs. The corresponding $U_{3} O_{8}$ prices for the unconstrained and constrained scenarios are shown in Fig. 4.13.

\subsubsection{Cost Comparisons}

The comparative costs reported in this section were calculated by the revenue-requirements (RR) method used by utilities and prescribed by regulatory agencies. Levelized 1 ife-cycle costs were calculated by a constantdollar revenue-requirements method similar to the approach recommended by the Electric Power Research Institute (EPRI) for the analys is of generating costs of alternative technologies.50 The important assumptions of this method will be briefly described here; a detailed description of the methodology is provided in the EPRI report. 50 
Table 4.12 Fuel Cost Projections (1978 $\$ / 10^{6}$ Btu): Délivered

Prices for Three Scenarios, 1980 to 2020

\begin{tabular}{lccccccc}
\hline \multirow{2}{*}{$\begin{array}{l}\text { Scénario and } \\
\text { Energy System }\end{array}$} & 1980 & 1985 & 1990 & 2000 & 2010 & 2025 & 2030 \\
\cline { 2 - 7 } UH & & & & & & \\
Oil & 5.75 & 6.49 & 6.49 & 6.79 & 7.13 & 7.65 & 7.82 \\
Natural Gas & 2.45 & 3.11 & 4.60 & 5.87 & 6.10 & 6.29 & 6.36 \\
Coal & 1.15 & 1.38 & 1.38 & 1.38 & 1.55 & 1.73 & 1.78 \\
LWR Nuc lear & 0.62 & 0.67 & 0.71 & 0.72 & 0.79 & 0.89 & 0.93 \\
LMFBR & - & - & - & 0.64 & 0.65 & 0.67 & 0.68 \\
UI & & & & & & & \\
Oil & 5.75 & 6.49 & 6.49 & 6.49 & 6.49 & 7.65 & 8.04 \\
Natural Gas & 2.45 & 3.53 & 4.60 & 4.60 & 4.60 & 5.98 & 6.44 \\
Co8l & 1.15 & 1.38 & 1.38 & 1.38 & 1.48 & 1.66 & 1.72 \\
LWR Nuc lear & 0.62 & 0.67 & 0.71 & 0.72 & 0.79 & 0.89 & 0.93 \\
LMFBR & - & - & - & 0.64 & 0.65 & 0.67 & 0.68 \\
CI & & & & & & & \\
Oil & & & & & & & \\
Natural Gas & 2.45 & 3.53 & 4.60 & 6.59 & 7.10 & 7.87 & 8.13 \\
Coal & 1.15 & 1.38 & 1.66 & 2.17 & 2.68 & 3.45 & 3.71 \\
LWR Nuc lear & 0.62 & 0.76 & 0.81 & 0.86 & 0.95 & 1.12 & 1.17 \\
LMFBR & - & - & - & 0.64 & 0.65 & 0.67 & 0.68 \\
\hline
\end{tabular}

Annual revenue requirements for an investment will normally vary from year to year over the 1 ife of the investment, but as a means of developing a single overall cost metric, the varying annual revenue requirements are converted to an equivalent stream of constant (levelized) annual revenue requirements. Equivalency is established by equating the present worth of the varying annual revenue-requirements stream with the present worth of the constant annual revenue-requirements stream. The revenue requirements are made up of the capital (i.e., return on equity, interest on debt, and depreciation) and operating costs (i.e., income and property taxes, fuel, operation and maintenance, and insurance).

Capital and operating costs usually proceed over the plant 1 ife as described in Fig. 4.14. The levelized annual revenue requirement (LARR) is arrived at by the following equation:

$$
\text { LARR }=\frac{\sum_{n=1}^{B} R_{n}\left(\frac{1}{1+D}\right)^{n}}{\sum_{n=1}^{B}\left(\frac{1}{1+D}\right)^{\prime n}}
$$




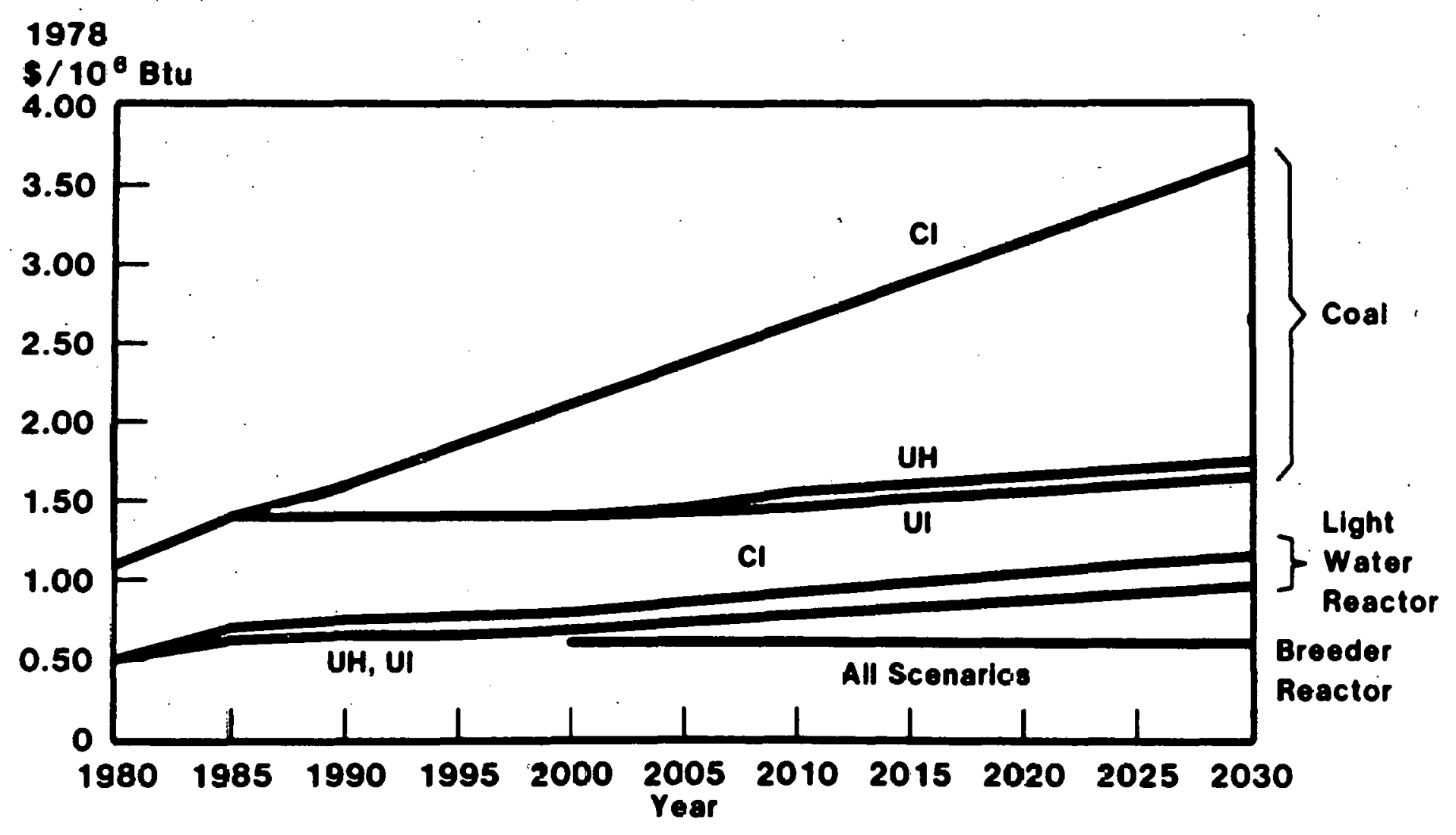

Fig. 4.12 Fuel Price Projections for Different Scengrios 


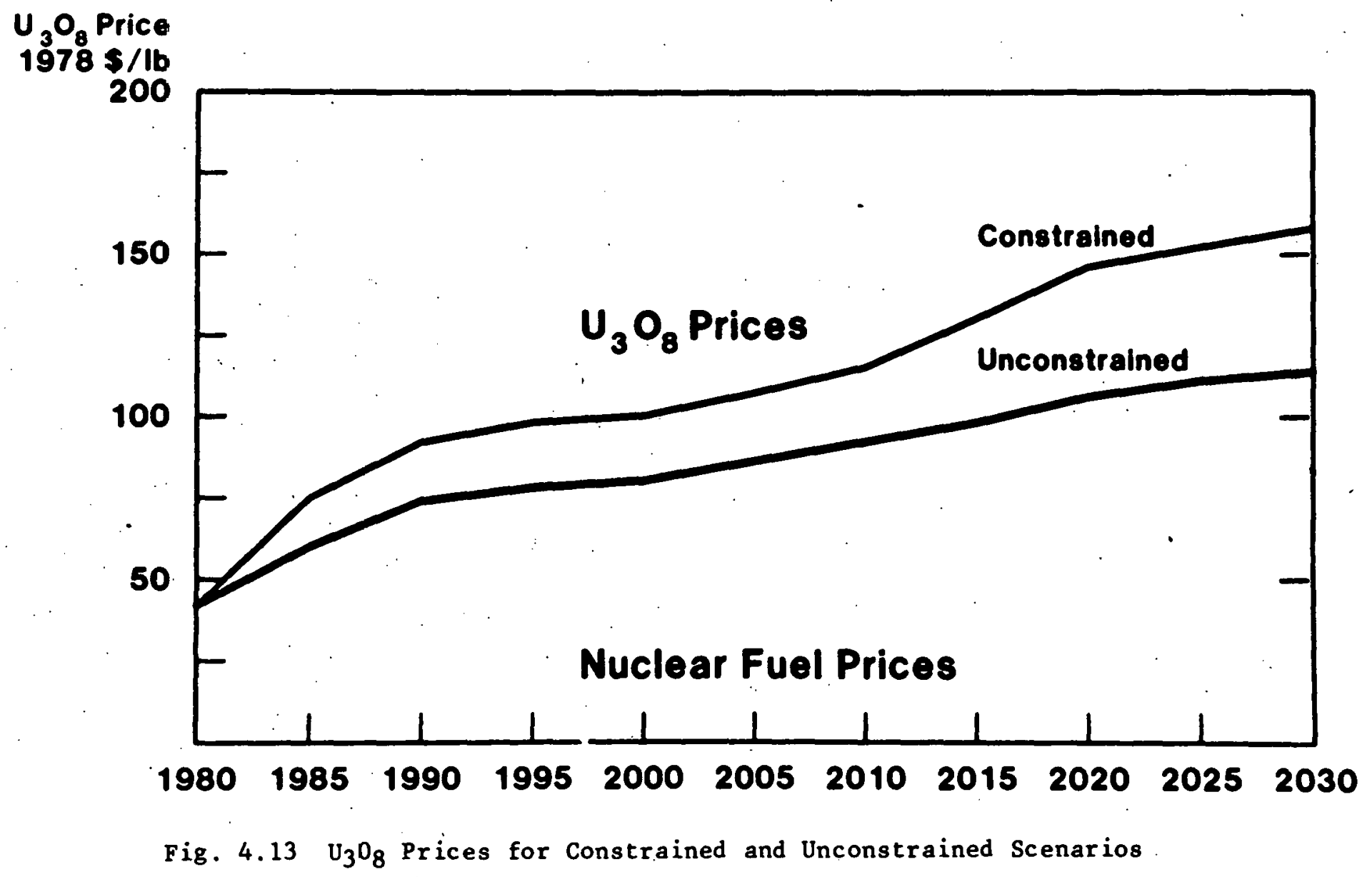




\section{REVENUE REQUIREMENT (DOLLARS)}

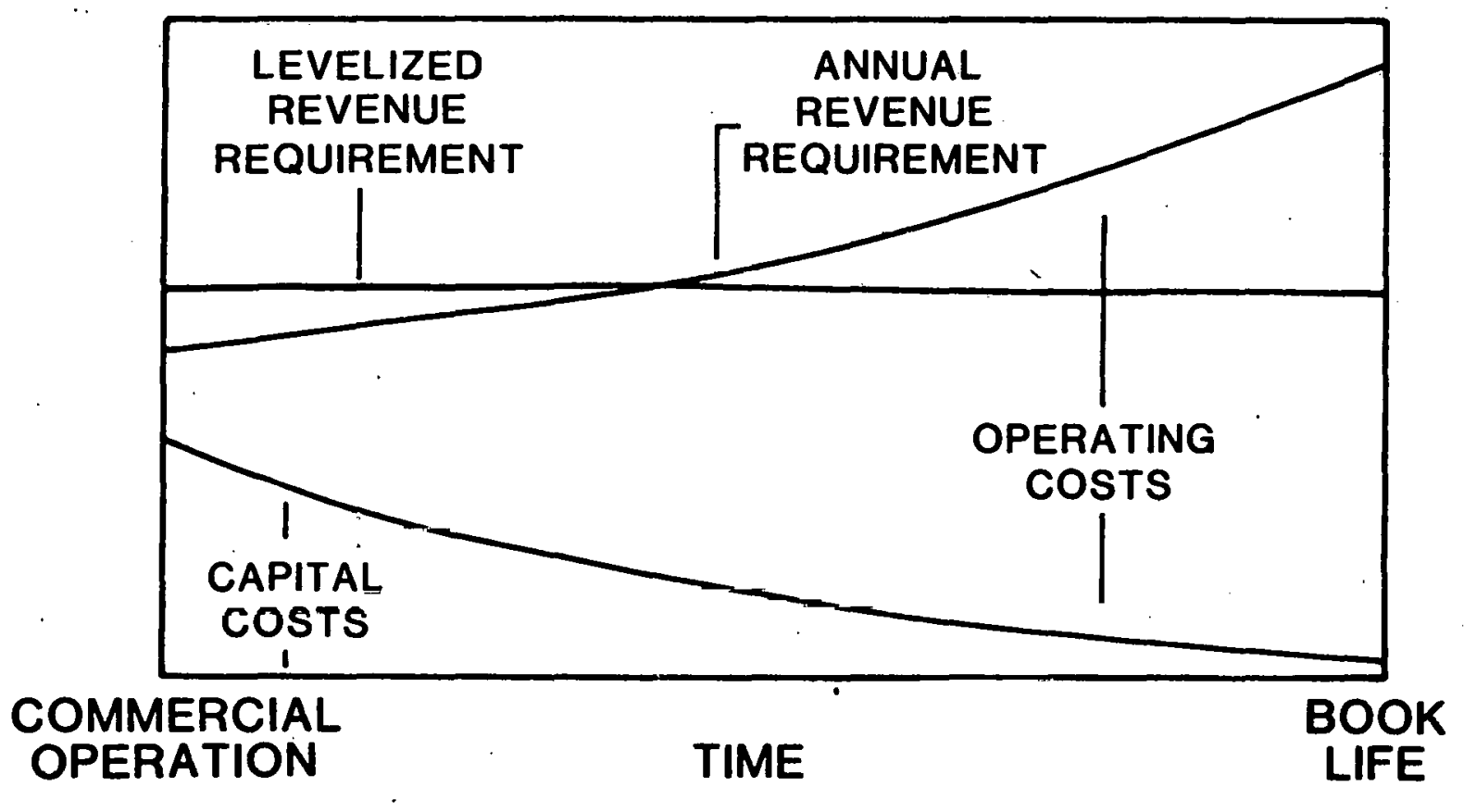

Fig. 4.14 Typical Patterns of Costs and Revenue Requirements

where:

$$
\begin{aligned}
R_{n} & =\text { revenue requirements in year } n \\
D & =\text { discount rate (weighted average cost of capital), and } \\
B & =\text { book } 1 \text { ife. }
\end{aligned}
$$

A discount rate consistent with financial assumptions is needed for the present worth and levelizing calculations. Most electric utilities use their own weighted average cost of capital as the discount rate for making these calculations. The weighted average cost of capital is composed of the appropriate fractions of preferred stock, common stock, and bonds multiplied by the corresponding rates of return required in the marketplace.

In general, observed market rates of return reflect the investor's expectation of future general inflation plus some premium known 28 a "real" rate of return. The GNP deflator was used to estimate the historic inflation and to adjust the current-dollar rates of return to obtain real rates of return. In the comparative analyses, annual and levelized revenue requirements were calculated in inflation-free or "constant" dollars. A 1978 dollar value was used as the constant-dollar basis. Hence, only the "real" part of the discount rate should be used. Future prices of goods were expressed in the 1978 values, and increases higher than general inflation were added to these prices.

Base capital structure and economic assumptions typical of privatelyowned utilities are used in the analysis and are summarized in Table 4.13. 
Table-4.13 Base Capital Structure and

Economic As sumptions



Variations in base capital structure and interest rates were examined as part of the analysis. Reasonable variations did not significantly affect the relative ranking or cost differential of technologies.* No investment tax credits were applied in this analysis because these politically determined incentives have had a history of frequent change. Current regulations are considered to be applicable only to the analysis of near-term projects.

Table 4.14 reports the levelized energy cost for the two SPS reference designs and the six alternative central station systems. These energy costs were calculated by using the capital cost ranges reported in Sec. 4.2.2, the fuel prices generated by the alternative futures scenarios, and the cost characterization information reported in Sec. 3.3. Figures 4.15-4.17 display the cost ranges for each of the scenarios for the six technologies and two SPS reference designs. Some sensitivity calculations using these numbers as a basis are described in the next section.

\subsubsection{Cost Sensitivity Analys is}

Several cost assumptions were made in the comparisons presented in the previous section, and a few of these assumptions were tested to determine their effect on the cost comparisons. The first sensitivity analys is was made on the plant capacity factors. Baseline capacity factors for the technologies were: SPS, 90\%; LWR, LMFBR, and coal, $70 \%$; fusion, $70 \%$; and TPV, $25 \%$. The relationship between capacity factor and energy costs is shown in Fig. 4.18, in which energy costs are plotted for the constrained scenario and nominal cost values. Generally speaking, the more capital-intensive the technology, the more sensitive it is to the capacity factor. The TPV curve is steeper than the others, mainly due to the fact that the scaling for this technology is much smaller and therefore the incremental change in capacity factor is much larger.

*These variations included higher real interest and return rates of $5 \%, 5.5 \%$ and $10.2 \%$ for bonds, preferred stock and common stock, respectively. Debt to equity ratio variation was also examined at $70 \%$ bonds, $20 \%$ common stock, and $10 \%$ preferred stock to bracket mnst utility financial configurations considered reasonable. 
Table 4.14 Levelized 2000-2030 Cost of Electricity from SPS and Alternative Technologies (1978 mills/kWh)

\begin{tabular}{|c|c|c|c|c|c|c|c|c|}
\hline \multirow{2}{*}{$\begin{array}{l}\text { Scenario and } \\
\text { Cost Level }\end{array}$} & \multicolumn{2}{|c|}{ SPS } & \multirow{2}{*}{ HS Coal } & \multirow[b]{2}{*}{ LWR } & \multirow{2}{*}{$\mathrm{CG} / \mathrm{CC}$} & \multirow[b]{2}{*}{ LMFBR } & \multirow[b]{2}{*}{ NUWMAK } & \multirow[b]{2}{*}{ TPV } \\
\hline & silicon & GaAlAs & & & & & & \\
\hline & \multicolumn{8}{|c|}{ Unconstrained Scenarios } \\
\hline Nonfuel O\&M & 5.7 & 5.7 & 3.1 & 2.3 & 2.7 & 3.0 & 7.3 & 3.6 \\
\hline $\begin{array}{c}\text { Capital Related } \\
\text { Low } \\
\text { Nominal } \\
\text { High }\end{array}$ & $\begin{array}{r}39.9 \\
46.4 \\
212.4\end{array}$ & $\begin{array}{r}36.6 \\
42.8 \\
196.0\end{array}$ & $\begin{array}{l}10.5 \\
12.3 \\
13.8\end{array}$ & $\begin{array}{l}14.4 \\
17.8 \\
20.0\end{array}$ & $\begin{array}{l}13.2 \\
15.5 \\
20.1\end{array}$ & $\begin{array}{l}20.9 \\
26.0 \\
35.1\end{array}$ & $\begin{array}{l}38.5 \\
59.6 \\
--\end{array}$ & $\begin{array}{r}33.0 \\
47.8 \\
192.1\end{array}$ \\
\hline UH: Fuel Cost & $\therefore \quad--$ & -- & 14.8 & 8.2 & 13.7 & 6.1 & 7.1 & -- \\
\hline $\begin{array}{l}\text { Electricity Cost } \\
\text { Low } \\
\text { Nominal } \\
\text { High }\end{array}$ & $\begin{array}{r}45.6 \\
52.1 \\
218.1\end{array}$ & $\begin{array}{r}42.3 \\
48.5 \\
201.7\end{array}$ & $\begin{array}{l}28.4 \\
30.2 \\
31.7\end{array}$ & $\begin{array}{l}24.9 \\
28.3 \\
30.5\end{array}$ & $\begin{array}{l}29.6 \\
31.9 \\
36.5\end{array}$ & $\begin{array}{l}30.0 \\
35.1 \\
44.2\end{array}$ & $\begin{array}{c}52.9 \\
74.0 \\
-\end{array}$ & $\begin{array}{r}36.6 \\
51.4 \\
195.7\end{array}$ \\
\hline UI: Fuel Cost & - & - & 14.4 & 8.2 & 13.3 & 6.1 & 7.1 & -- \\
\hline $\begin{array}{l}\text { Electricity Cost } \\
\text { Low } \\
\text { Nominal } \\
\text { High }\end{array}$ & $\begin{array}{r}45.5 \\
52.1 \\
218.1\end{array}$ & $\begin{array}{r}42.3 \\
48.5 \\
201.7\end{array}$ & $\begin{array}{l}28.0 \\
29.8 \\
31.3\end{array}$ & $\begin{array}{l}24.9 \\
28.3 \\
30.5\end{array}$ & $\begin{array}{l}29.2 \\
31.5 \\
36.1\end{array}$ & $\begin{array}{l}30.0 \\
35.1 \\
44.2\end{array}$ & $\begin{array}{c}52.9 \\
74.0 \\
--\end{array}$ & $\begin{array}{r}36.6 \\
51.4 \\
195.7\end{array}$ \\
\hline & & & & strain & Scenario & & & \\
\hline Nonfuel O\&M & 5.7 & 5.7 & 3.1 & 2.3 & 2.7 & 3.0 & 7.3 & 3.6 \\
\hline $\begin{array}{c}\text { Capital Related } \\
\text { Low } \\
\text { Nominal } \\
\text { High }\end{array}$ & $\begin{array}{r}39.9 \\
46.4 \\
212.4\end{array}$ & $\begin{array}{r}36.6 \\
42.8 \\
196.0\end{array}$ & $\begin{array}{l}-- \\
12.3 \\
26.0\end{array}$ & $\begin{array}{l}-- \\
17.8 \\
41.6\end{array}$ & $\begin{array}{c}-- \\
15.5 \\
42.5\end{array}$ & $\begin{array}{l}-\overline{-} \\
26.0 \\
81.8\end{array}$ & $\begin{array}{c}-- \\
59.6 \\
--\end{array}$ & $\begin{array}{r}33.0 \\
47.8 \\
192.1\end{array}$ \\
\hline CI: Fuel Cost & -- & -- & 25.7 & 9.9 & 23.8 & 6.1 & 7.1 & -- \\
\hline $\begin{array}{l}\text { Electricity Cost } \\
\text { Low } \\
\text { Nominal } \\
\text { High }\end{array}$ & $\begin{array}{r}45.5 \\
52.1 \\
218.1\end{array}$ & $\begin{array}{r}42.3 \\
48.5 \\
201.7\end{array}$ & $\begin{array}{c}-- \\
41.1 \\
54.8\end{array}$ & $\begin{array}{l}-- \\
30.0 \\
53.8\end{array}$ & $\begin{array}{l}-- \\
42.0 \\
69.0\end{array}$ & $\begin{array}{c}-- \\
35.1 \\
90.9\end{array}$ & $\begin{array}{c}- \\
74.0 \\
-\end{array}$ & $\begin{array}{r}36.6 \\
51.4 \\
195.7\end{array}$ \\
\hline
\end{tabular}




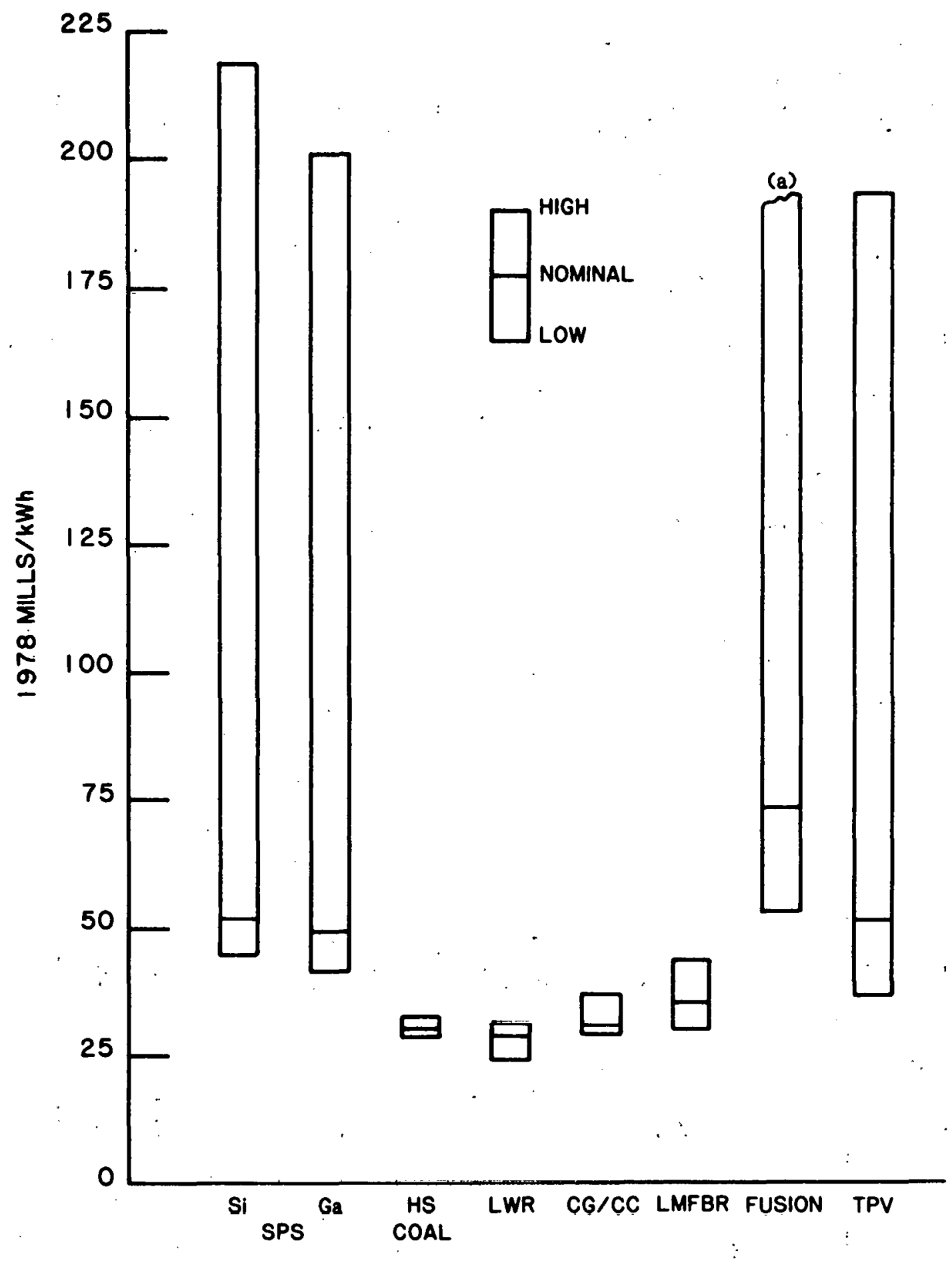

Fig. 4.15 Levelized Energy Cost Ranges for Scenario UH

ano upper limit of the range for fusion could be determined.

bunconstrained scenario, no significant restrictions on coal or nuclear power. There are relatively low prices and high energy demand. The price elasticity of demand is -0.25 . 


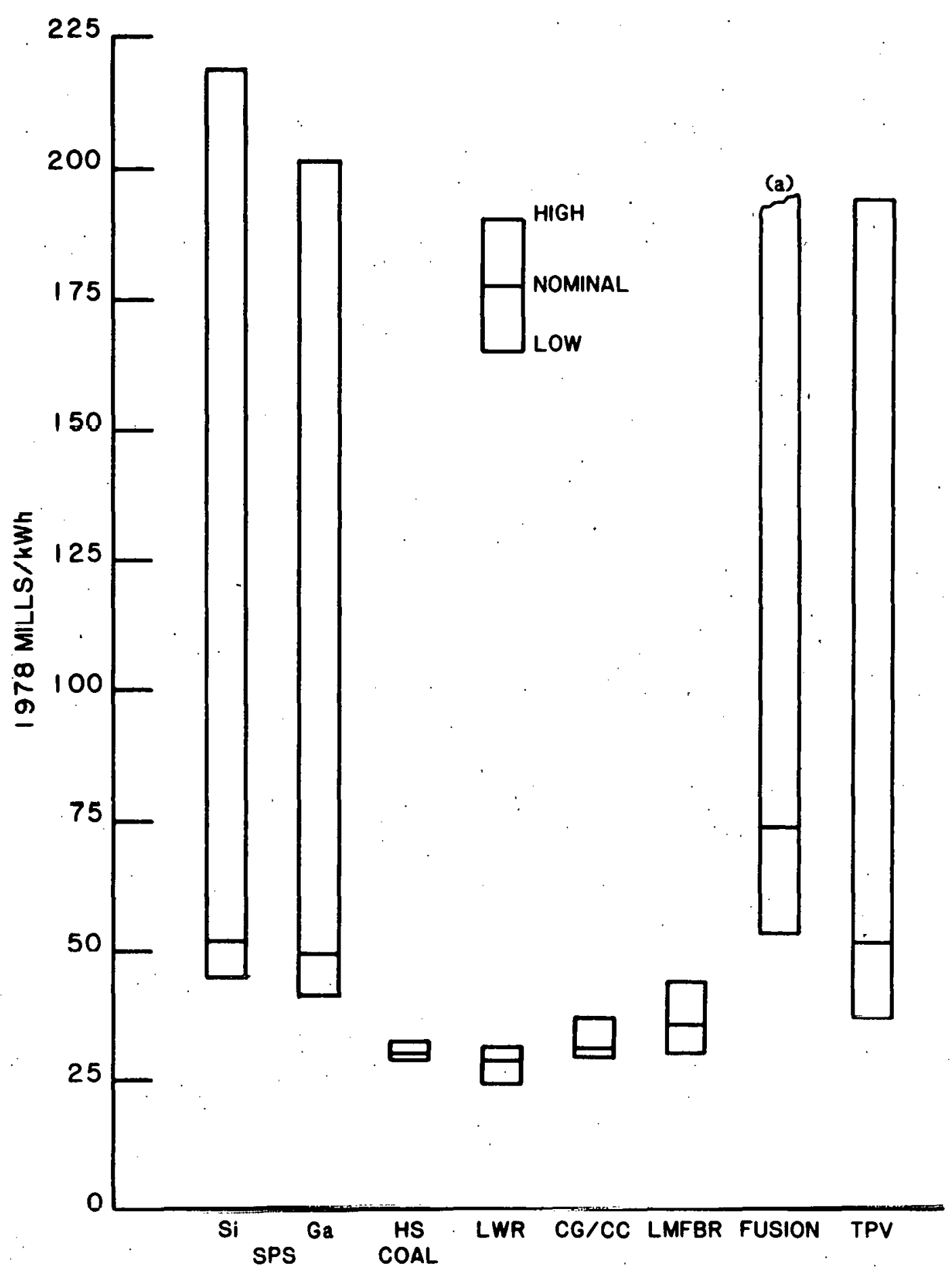

Fig. 4.16 Levelized Energy Cost Ranges for Scenario UI ${ }^{b}$

a No upper limit of the range for fusion could be determined.

bunconstrained scenario, no significant restrictions on coal or nuclear power. This is considered the most likely unconstrained scenario, with , moderate price elasticity of demand. Industrial fuels are -0.7 , all other fuel uses are -0.4 , and chemical feedstock elasticity is $0: 0$. 


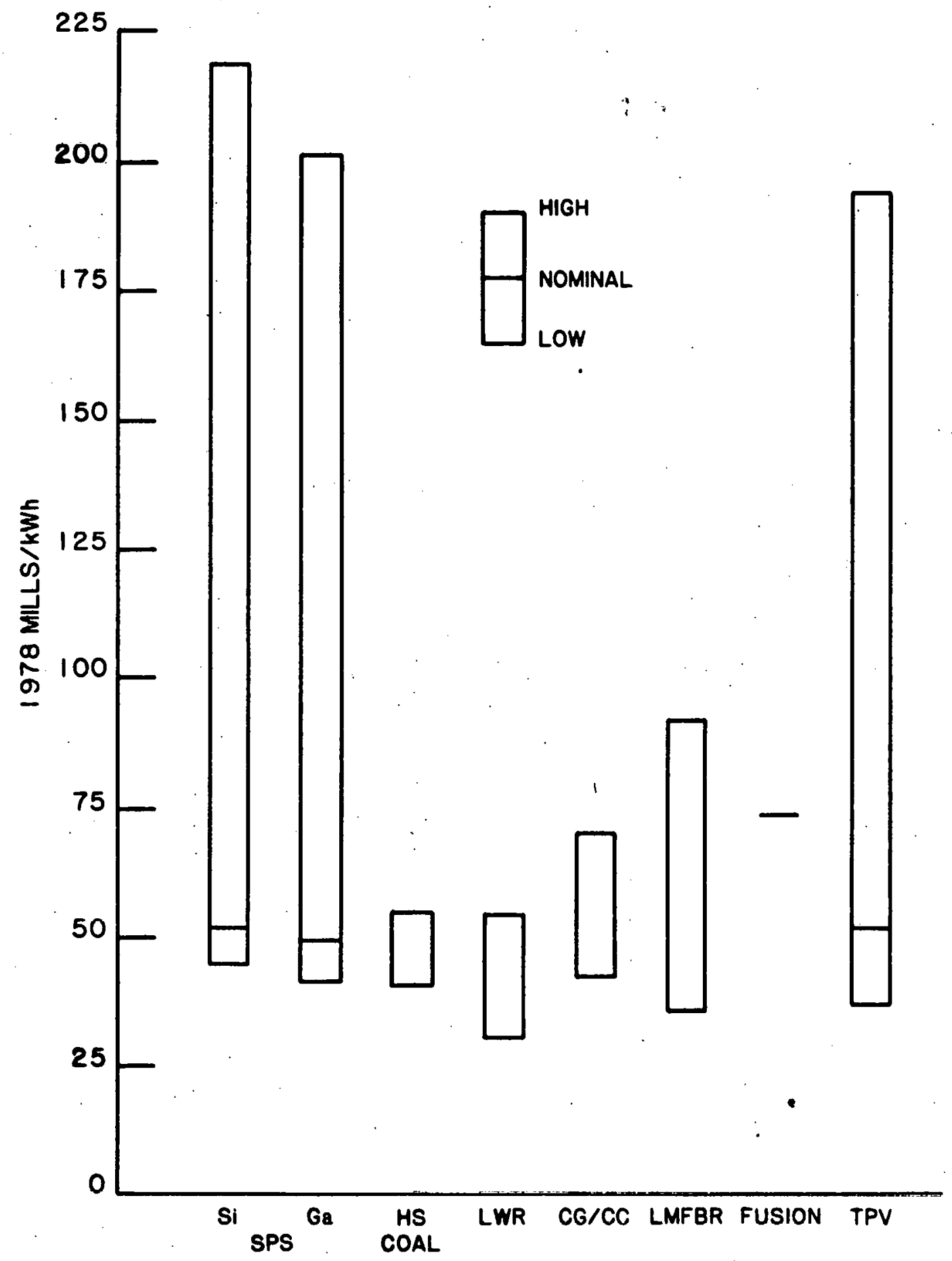

Fig. 4.17 Levelized Energy Cost Ranges for Scenario $\mathrm{CI}^{a}$

aThis constrained scenario represents a continuation and augmentation of current regulatory trends affecting emissions, health, and safety. The energy price elasticities of demand are moderate, and this is considered the most likely situation if constraints are maintained. 


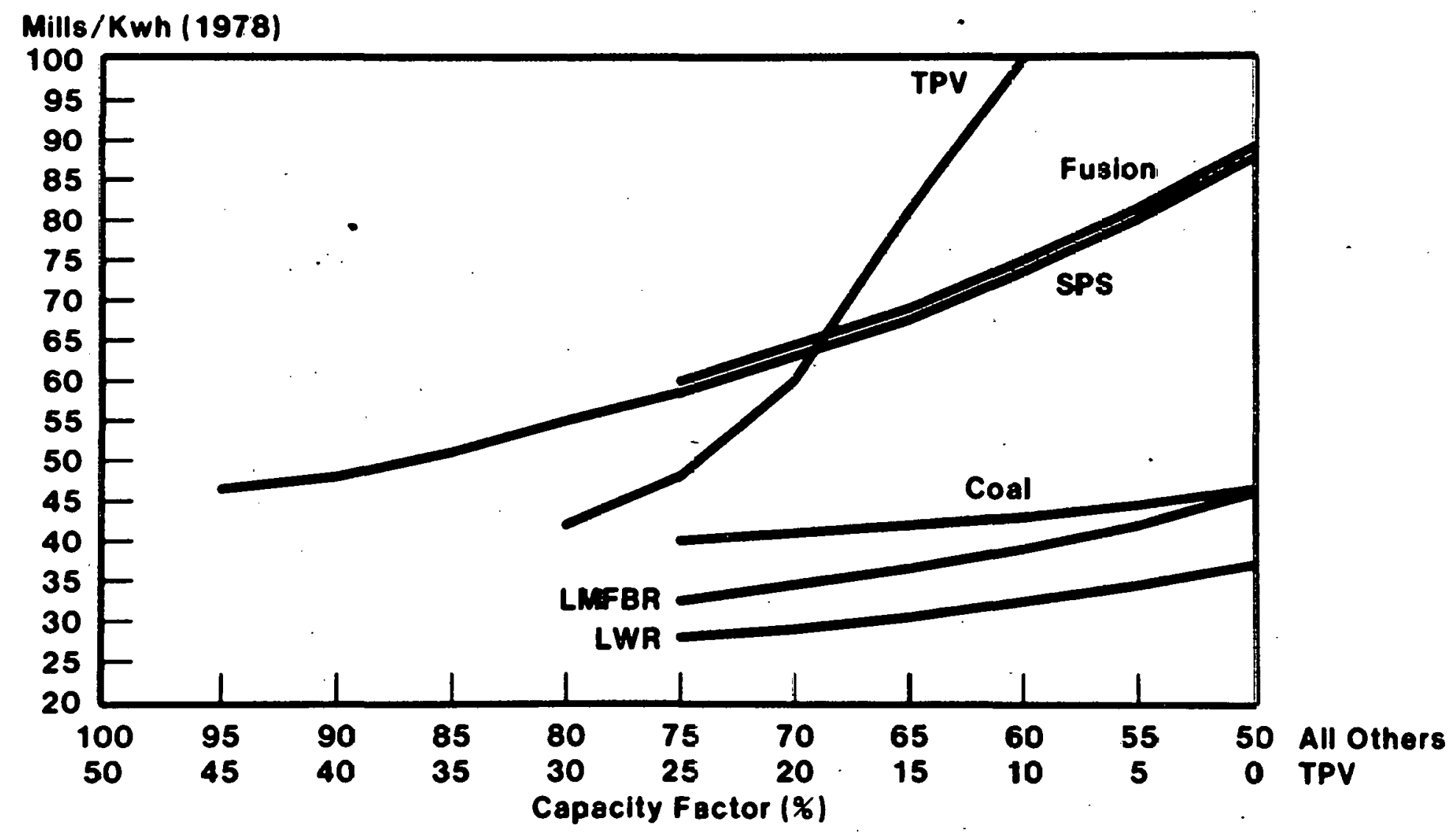

Fig. 4.18 Total Energy Costs as a Function of Capacity 
The second parameter that was investigated in the sensitivity analysis was the implementation rate for the satellite power system. The reference design scenario for the implementation of the SPS is to build $605,000 \mathrm{MW}$ satellites over a 30-year period. As was pointed out in the scenario description of this report, this number of satellites may not be feasible if the demand for energy is not adequate (e.g., in the unconstrained intermediate or the constrained intermediate supply/demand scenarios). Table 4.15 shows the change in cost with different building schedules for both the silicon and the gallium aluminum arsenide reference systems. The table shows the total capital cost per unit as a function of three different schedules. The first schedule entails building 60 units over a 30-year period, and the other schedules are 30 and 20 units, respectively, over a 30 -year period, a substantial reduction in the commitment to SPS. The increase in unit cost is less than $4 \%$ as the implementation rate decreases. However, this may be a result of the accounting system, rather than a real estimate, because the SPS base costs were derived under the assumption of a mature industry..

The third cost parameter that was examined for sensitivity to comparative costs was the set of economic or financial assumptions that were made in order to calculate energy costs. The baseline economic assumptions were reported in Table 4.13. Figure 4.19 shows the relative technology cost ranges and percentages for bonds, stock, and preferred stock returns on investment for the baseline assumptions and two other sets of assumptions. As shown in the figure, the cost range of each of the technologies varies slightly with different assumptions, but the overall comparative cost position does not change at all.

Table 4.15 Effect of Reduced SPS Implementation Rate on Costs: Nominal Average Unit Costs ( $10^{6} 1978$ \$)

\begin{tabular}{|c|c|c|c|c|c|c|}
\hline \multirow{2}{*}{$\begin{array}{l}\text { Unit Cost } \\
\text { Component }\end{array}$} & \multicolumn{3}{|c|}{$\begin{array}{c}\text { No. of SPS Units, } \\
\text { Silicon Reference System }\end{array}$} & \multicolumn{3}{|c|}{$\begin{array}{l}\text { No. of SPS Units, } \\
\text { GaAlAs Reference System }\end{array}$} \\
\hline & 60 & 30 & 20 & 60 & 30 & 20 \\
\hline $\begin{array}{l}\text { Direct } \\
\text { Ind irect } \\
\text { Investment }\end{array}$ & $\begin{array}{r}11,073 \\
464 \\
1,093\end{array}$ & $\begin{array}{r}11,073 \\
464 \\
1,324\end{array}$ & $\begin{array}{r}11,073 \\
464 \\
1,555\end{array}$ & $\begin{array}{r}10,035 \\
464 \\
1,093\end{array}$ & $\begin{array}{r}10,035 \\
464 \\
1,324\end{array}$ & $\begin{array}{r}10,035 \\
464 \\
1,555\end{array}$ \\
\hline $\begin{array}{l}\text { Subtotal } \\
\text { Contingency } \\
\text { Owner's Cost } \\
\text { Interest During } \\
\text { Construction }\end{array}$ & $\begin{array}{r}12,630 \\
2,020 \\
439\end{array}$ & $\begin{array}{r}12,861 \\
2,058 \\
448\end{array}$ & $\begin{array}{r}13,097 \\
2,095 \\
455\end{array}$ & $\begin{array}{r}11,592 \\
1,855 \\
404 \\
670\end{array}$ & $\begin{array}{r}1,823 \\
1,892 \\
411\end{array}$ & $\begin{array}{r}12,024 \\
1,929 \\
420\end{array}$ \\
\hline Total & 15,773 & 16,112 & 16,400 & 14,521 & 14,811 & 15,100 \\
\hline \% Increase & Base & 2.1 & 3.8 & Base & 2.0 & 4.0 \\
\hline
\end{tabular}




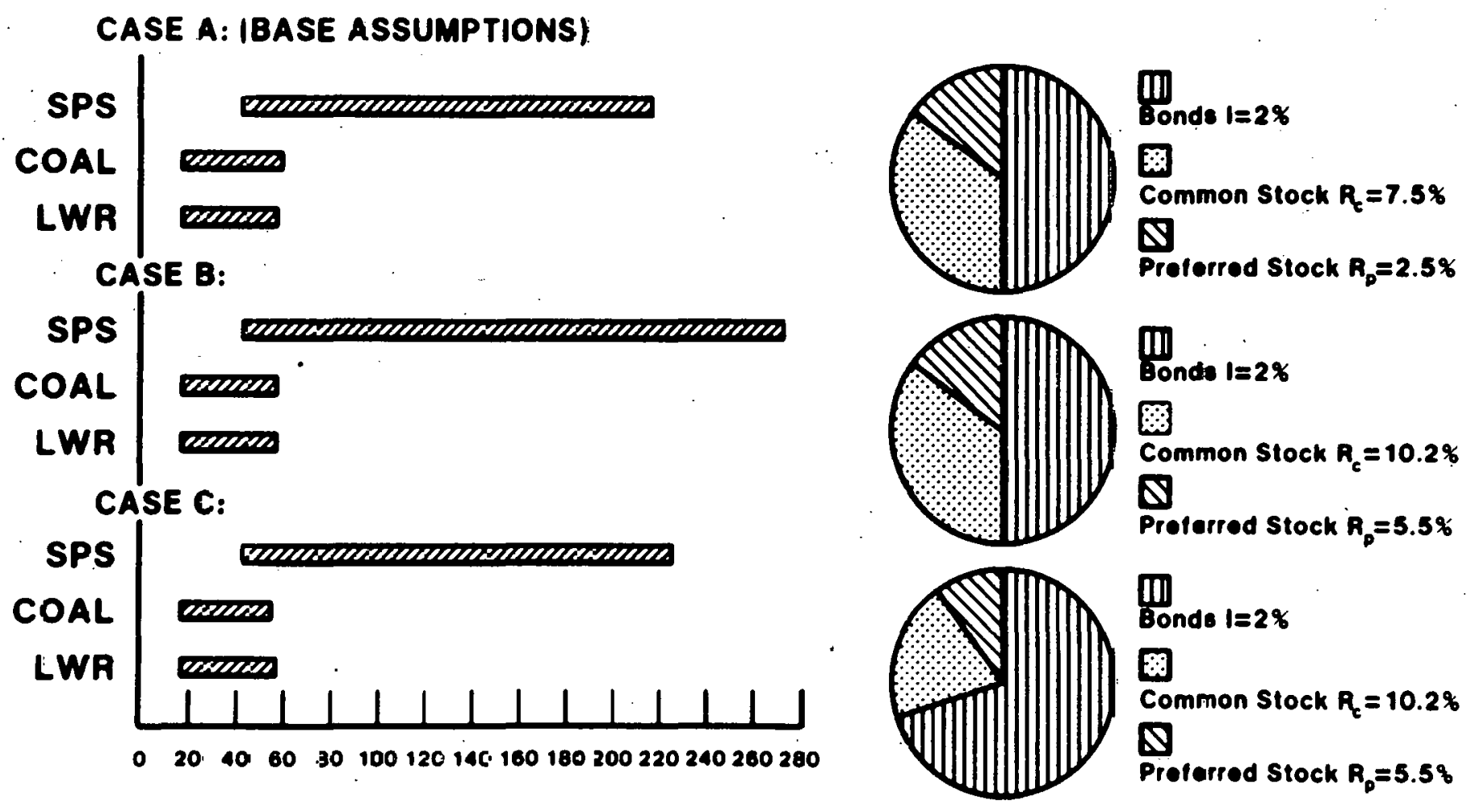

Fig. 4.19 Effect of Thanges in Financial Assumptions on Relative Positions of Technologies 


\subsubsection{Comparative Cost Uncertainty}

Previous sections of this report have compared the costs of the SPS and alternative technologies through an analysis of possible capital and fuel cost ranges. These ranges of capital and fuel cost uncertainty have resulted in substantial overlap in total generating costs for all of the energy technologies. The degree of overlap in these cost comparisons is large because the comparisons were made from independent data bases and have not taken into account the correlation between state-of-the-world variables (e.g., the cost of labor) and these independent estimates. In addition, the cost estimates for capital and fuel cost were developed deterministically, by including upper and lower bounds as a means of dealing with uncertainty.

In this section of the report, the question of uncertainty in technology cost comparisons is discussed in a probabilistic framework. This approach to cost comparison is primarily a method using historical data, and information used in other sections of the report was prepared to indicate the results of such an approach to uncertainty. The methodology was applied to a comparison between coal and the SPS but is equally relevant to comparisons between any technologies.

To illustrate the focus of the probabilistic cost comparison between coal and nuclear, consider the relationship between the cost of energy from coal technology vs. that of the SPS. Figure 4.20 illustrates the relationships for a fixed set of cost parameters and input assumptions. The typical levelized cost of electricity from coal is generally shown to increase in real terms because of increased coal costs. On the other hand, the cost of electricity from the SPS would not be expected to increase so rapidly, because it does not stem from a depleting resource base. Conceptually, the levelized cost of these two technologies should intersect somewhere in the future. There is no way of telling in what year the intersection will occur. Much

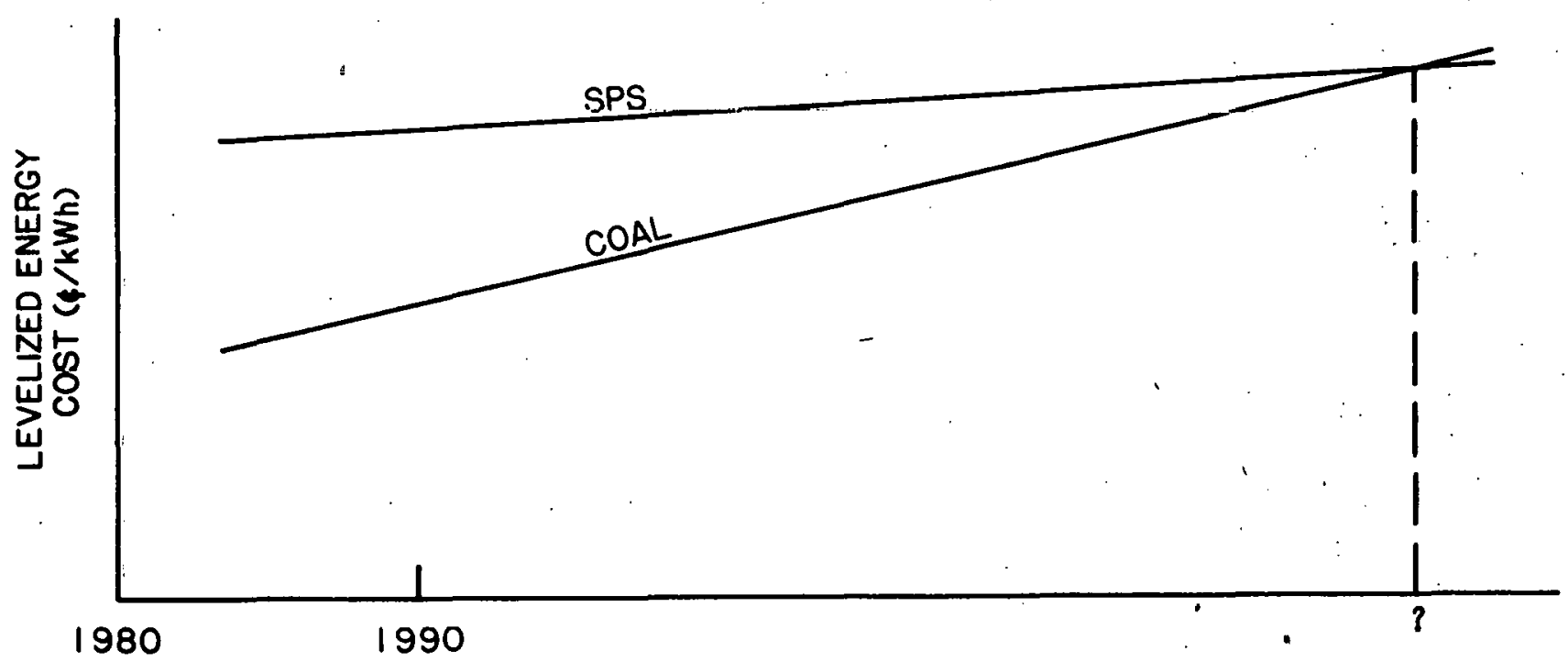

Fig. 4.20 Comparison of Coal and SPS Energy Costs with Fixed Parameters and Inputs 
depends on the supply and use of coal. Figure 4.20 is only a hypothetical and simplistic illustration of a complex relationship, and it is not expected that the levelized cost of energy from these technologies would follow such straight line projections.

The uncertainties in the cost of energy from coal are dominated by uncertain fuel costs, whereas the uncertainties in the cost of energy from the SPS are dominated by technologically uncertain fixed costs. The approach in this probabilistic analys is was to focus only on these two dominant variables (other uncertainties were ignored in this analysis) and to treat the costs as random variables; to determine a cost probability distribution for each of the technologies for any particular year; and to combine them to develop a probability distribution for the differences in energy cost between the technologies. First, the coal probability function will be described, along with its ties to historical data, and then the fonndatinn for sps rnst uncertainty will be discussed. The resultant combined probability function will then be shown for a few parameters.

Coal Price Relationships. Figure 4.21 shows a plot of constant-dollar coal prices from 1950 through 1977. From 1950 to 1968 , the real cost of coal declined by $1.2 \%$ per year, mainly due to decreased use because of substitution by oil and gas. After 1968 , the real cost of coal rose sharply (11\% per year), and this could be attributed to the passage of mine safety regulations

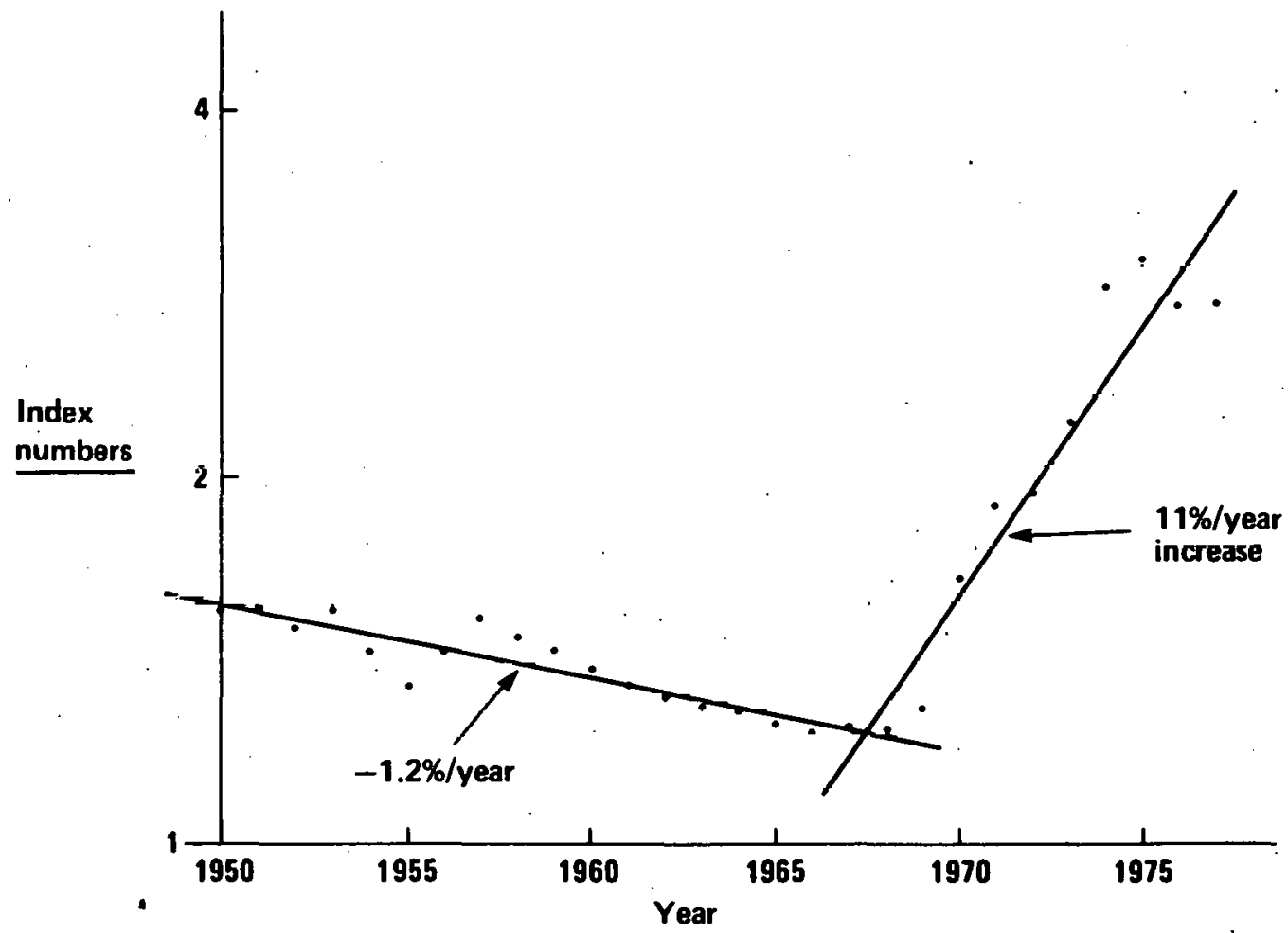

Fig. 4.21 Coal Prices (Constant Dollars) 
in 1969 and the increased use of coal. Coal prices fluctuated around these mean increases and decreases, with the average fluctuation between 1950 and 1968 being $3.5 \%$ and that between 1968 and 1977 being $14 \%$. The trend and fluctuation in coal prices in the future is uncertain. However, it is unlikely that the trend will be similar to either of the two shown in Fig. 4.21. More probable are some moderate real increases in coal prices (less than in the volatile period from 1968-1977) with fluctuation similar to that in the period from 1950 to 1968 (i.e., 3.5\%). The range of average price increases for coal, as described in the supply/demand futures analysis, is shown in Fig. 4.22. The figure shows that the average real increases in coal price ranged from $2.4 \% / y r$ to $0.87 \% / y r$ for the constrained intermediate case and unconstrained high case, respectively. In approximately the same period of time (i.e., 1964-1977), electrical equipment prices declined $1.5 \% / \mathrm{yr}$, with a $1.7 \%$ fluctuation. Similarly, construction costs increased $1.9 \% / y r$ with $2.6 \%$ fluctuation, and transportation and utility labor rose $1.6 \% / \mathrm{yr}$ with a $3.0 \%$ fluctuation.

The price of coal in any particular year $\left(Y_{t}\right)$ can be related to that of another year $\left(Y_{0}\right)$ through a series of factors.

Let :

$$
Y_{t}=Y_{0}\left(1+\mu+n_{1}\right)\left(1+\mu+\eta_{2}\right) \ldots\left(1+\mu+\eta_{t}\right)
$$

where:

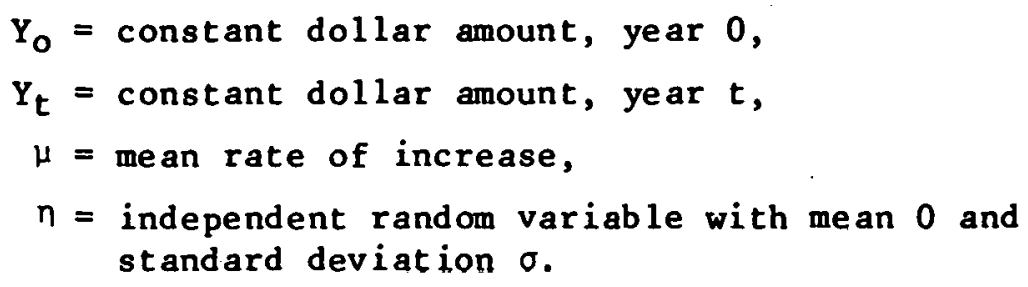

Examples of $\mu$ and $\sigma$

$\begin{array}{lcc} & \mu(\%) & \sigma(\%) \\ \text { Co.al prices, 1950-1958 } & -1.2 & 3.5 \\ \text { Coal prices, 1968-1977 } & 11 & 14 \\ \text { Electrical equip. prices 1964-1977 } & -1.5 & 1.7 \\ \text { Construction cost 1964-1977 } & 1.9 & 2.6 \\ \text { Transportation and utility labor 1964-1977 } & 1.6 & 3.0\end{array}$

This expression gives the price of coal in, say, the year 2000, but in reality, that figure is the levelized cost of coal. Thus the cost of coal for every year over the whole period of operation of the coal plant must be weighted by a discount factor so that the random variable is not just the price of coal in the year 2000 but the levelized cost of coal for the whole period. The equation for the levelized cost of coal, regarded as a random 


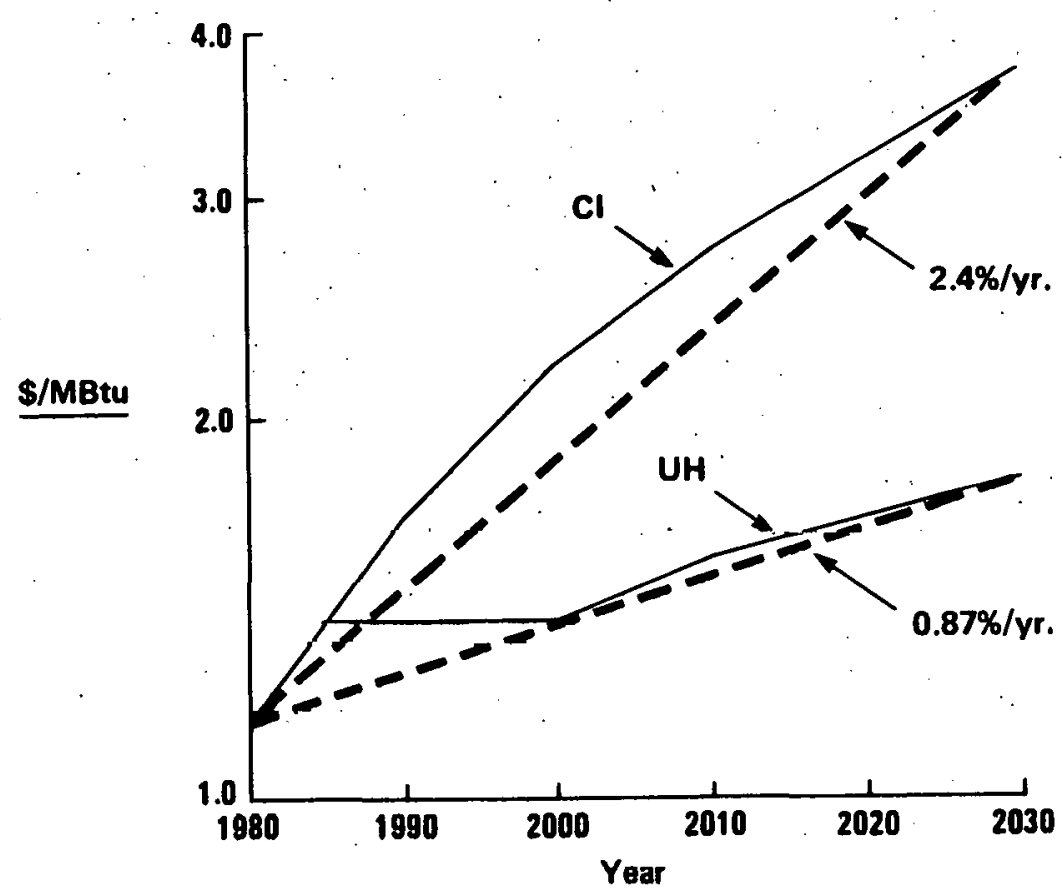

Fig. 4.22 Real Coal Price Increases

variable, for a plant that operates between the year $t^{\prime}$ and the year $t$, is as follows :

$$
\hat{Y}_{t-t^{\prime}}=Y_{0} \sum_{k=t^{\prime}+1}^{t}(1-\alpha)^{k} \prod_{i=1}^{k}\left(1+\mu+n_{t}\right) / \sum_{k=t^{\prime}+1}^{t^{\prime}}(1-\alpha)^{k}
$$

where:

$$
\begin{aligned}
& \hat{Y}=\text { the levelized cost of coal over the period } t-t^{\prime}, \\
& \dot{k}=\text { no. of years in the period, and }
\end{aligned}
$$

$1-\alpha=$ discount factor.

Figure 4.23 shows the distribution for levelized fuel cost and levelized capital charge for a $2 \%$ average growth with $4 \%$ fluctuation per year and a real disçount rate of $4 \%$. A normal distribution is plotted in dotted lines to show the slight skew of this distribution. The skewed distribution has a long tail on the high side, which is important because the high side of the coal distribution will be important in the comparison to SPS.

SPS Price Relationships. In the case of the SPS, the dominant uncertainty factor is technical uncertainty, since there is no economic experience. The SPS is made up of a number of subsystems that were broken up into 8 ix categories: energy conversion, space construction and support, power transmission, transportation, rectenna, and other. A typical probability distribution for the cost that one might expect for each of these subsystems is shown 
by the triangular distribution in Fig. 4.24. A skewed distribution was considered representative, because more factors seem to be left out than extra ones included at the early developmental stages of an advanced technology, since a design can never be complete 20 years in advance or before the technical problems have been solved.

What is needed, in reality, is a cost distribution for the SPS. How ever, to assemble a subsystem cost distribution like that illustrated in Fig. 4.24 requires the consideration of correlation* in the cost components, which means that several subsystems would fall into the high cost range because of the same factors. SPS subsystems are probably highly correlated in some areas and highly uncorrelated in others. For example, energy conversion is heavily dependent on the manufacturing cost for solar cells, which is very dependent on fuel cost. That would

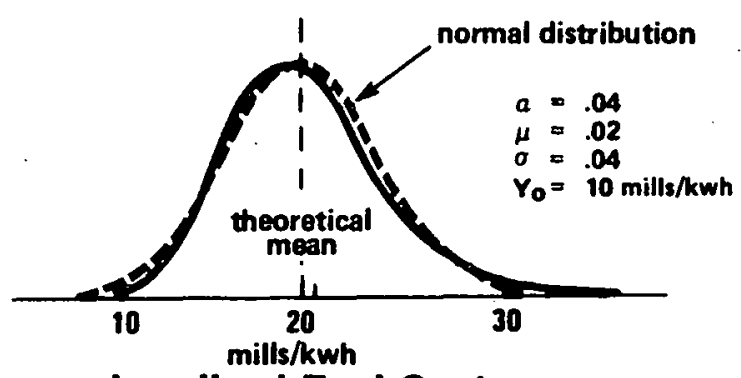

Levelized Fuel Cost

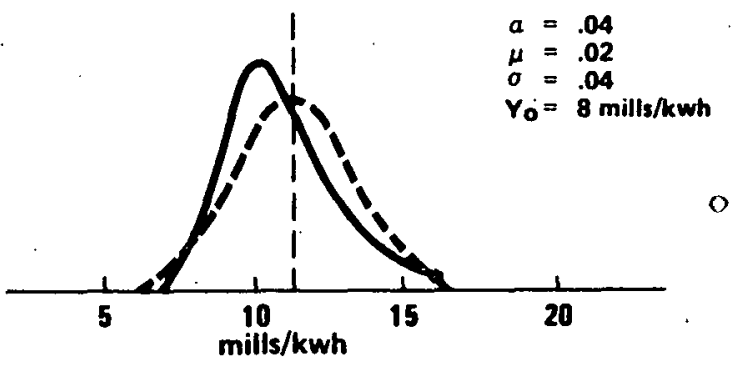

Levelized Capital Charge, Coal Plant

Fig. 4.23 Distributions of Levelized Fuel Cost and Levelized Capital Charge of a Coal Plant

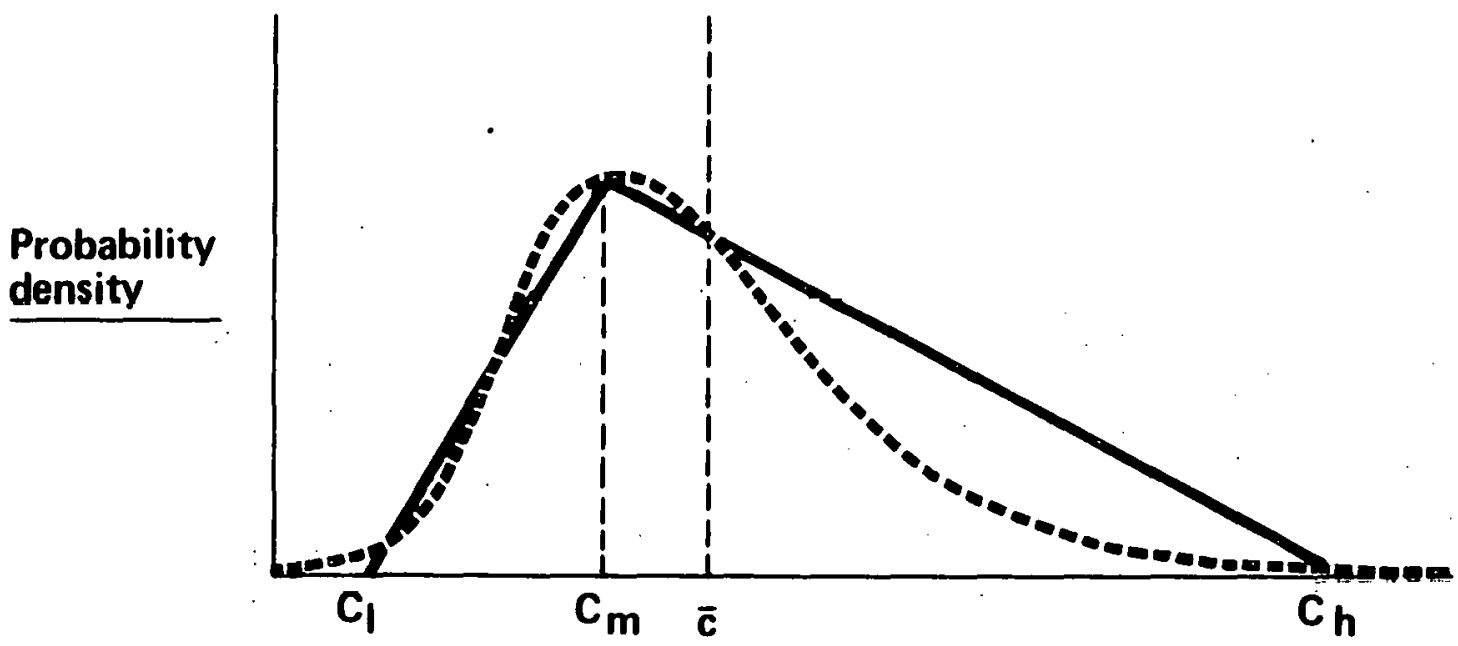

\section{Cost $\longrightarrow$}

Fig. 4.24 Typical Cost Distribution for Advanced Technologies

*A more detailed discussion of the correlation effects can be found in Ref. 2 , pp. 70-72. 
correlate with transportation. On the other hand, solar cell production depends on the manufacturing sector (not strongly fuel dependent), and this would be uncorrelated with transportation. If the subsystem cost components were completely correlated, the resulting distribution would look like the triangular figure in Fig. 4.25. If the components were completely uncorrelated the resulting distribution would look like the normal distribution in that figure. Since the SPS components are partially correlated, the distribution for the entire system starts out as a triangle and probably ends up something like the smooth distribution shown in Fig. 4.24 (dotted line). A distribution like this was obtained for the SPS, with $20 \%$ of the area to the left of the modal value and $80 \%$ to the right. This assumption was based on the earlier discussion that component projections for advanced technologies err more on the high side than on the low side. The resulting analysis could be performed using other distributions. This assumption is consistent with the capital cost range developed in Sec. 4.2.2.

- Probabilistic Cost Comparisons Between Coal and the SPS. The main problem in comparing the coal and SPS cost distributions is to establish the size of the overlap between the two technologies. Again, developing a cost distribution for the difference between these technologies is dependent on the degree of correlation of cost elements between coal and the SPS. The correlation was tẹsted and found to be unimportant, because the two technologies stem from such radically different bases.

The goal of this probabilistic analysis is to determine the probability that the cost of electricity from the SPS will equal that from coal, and the time at which this might occur. Figure 4.26 shows $1 \%, 10 \%$, and $20 \%$ probability curves for the difference in generating cost between coal and the SPS. For example, the slope of the $20 \%$ curve indicates that there is a $20 \%$ probability that the SPS will cost the same as coal in the year 2018. Similarly,

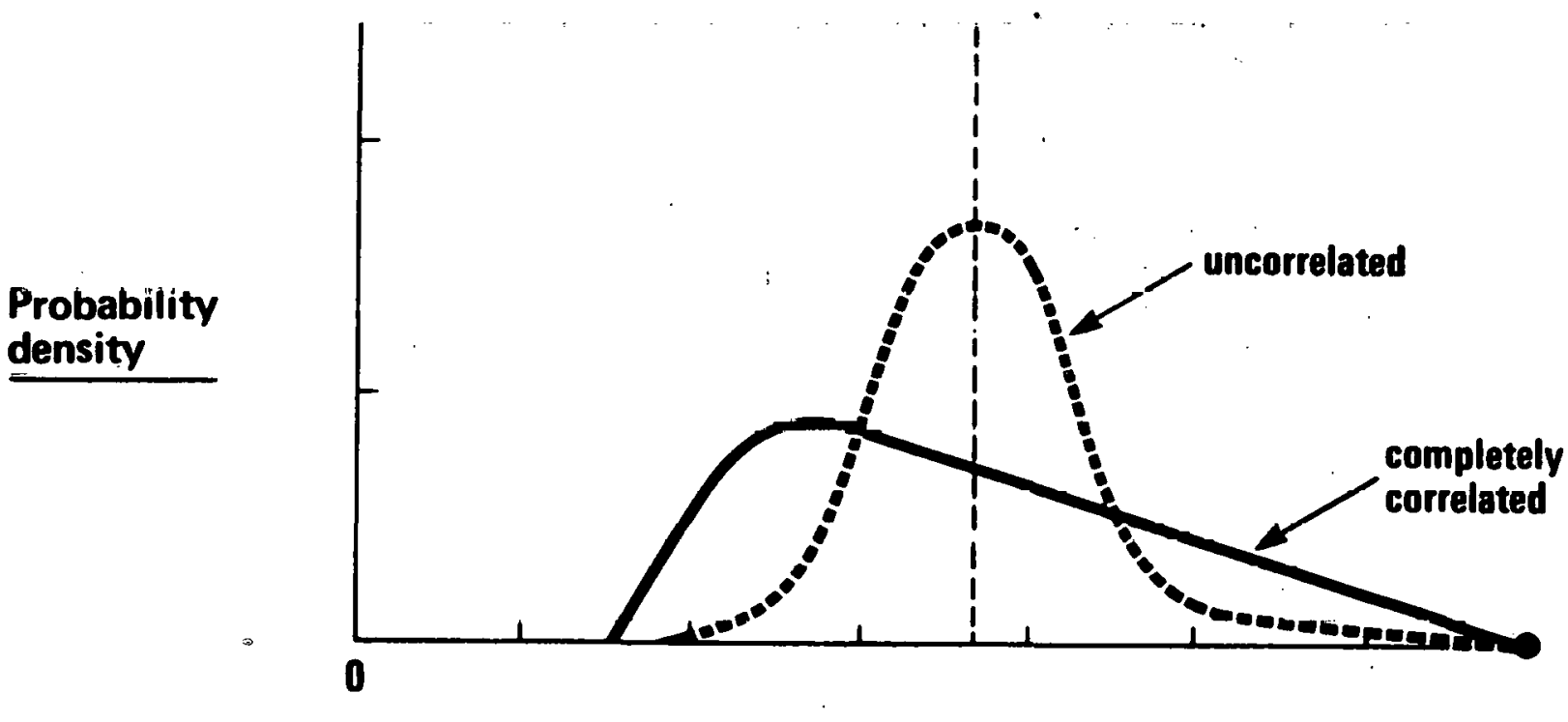
mills/kwhr

Fig. 4.25 Distributions of the Sum of Cost Elements 
there is a $20 \%$ probability that the cost differential will be around 16 $\mathrm{mills} / \mathrm{kWh}$ in the year 1990. This curve was plotted for the constrained intermediate coal price increases (2.4\% real per year) and a $3 \%$ fluctuation. A real $4 \%$ discount rate was used. Curves similar to those in Fig. 4.26 were calculated for other coal price increases and fluctuations, but the results are no more representative than those shown in the figure. It should be pointed out that the probabilistic results were obtained using nominal values for coal and the SPS and only show the conceptual probabilistic differences. The exact numbers plotted in Fig. 4.26 are illustrative and should not be used as hard conclusions, because changing some of the assumptions (e.g., SPS cost distribution, coal price rise and fluctuations) could change the results substantially.

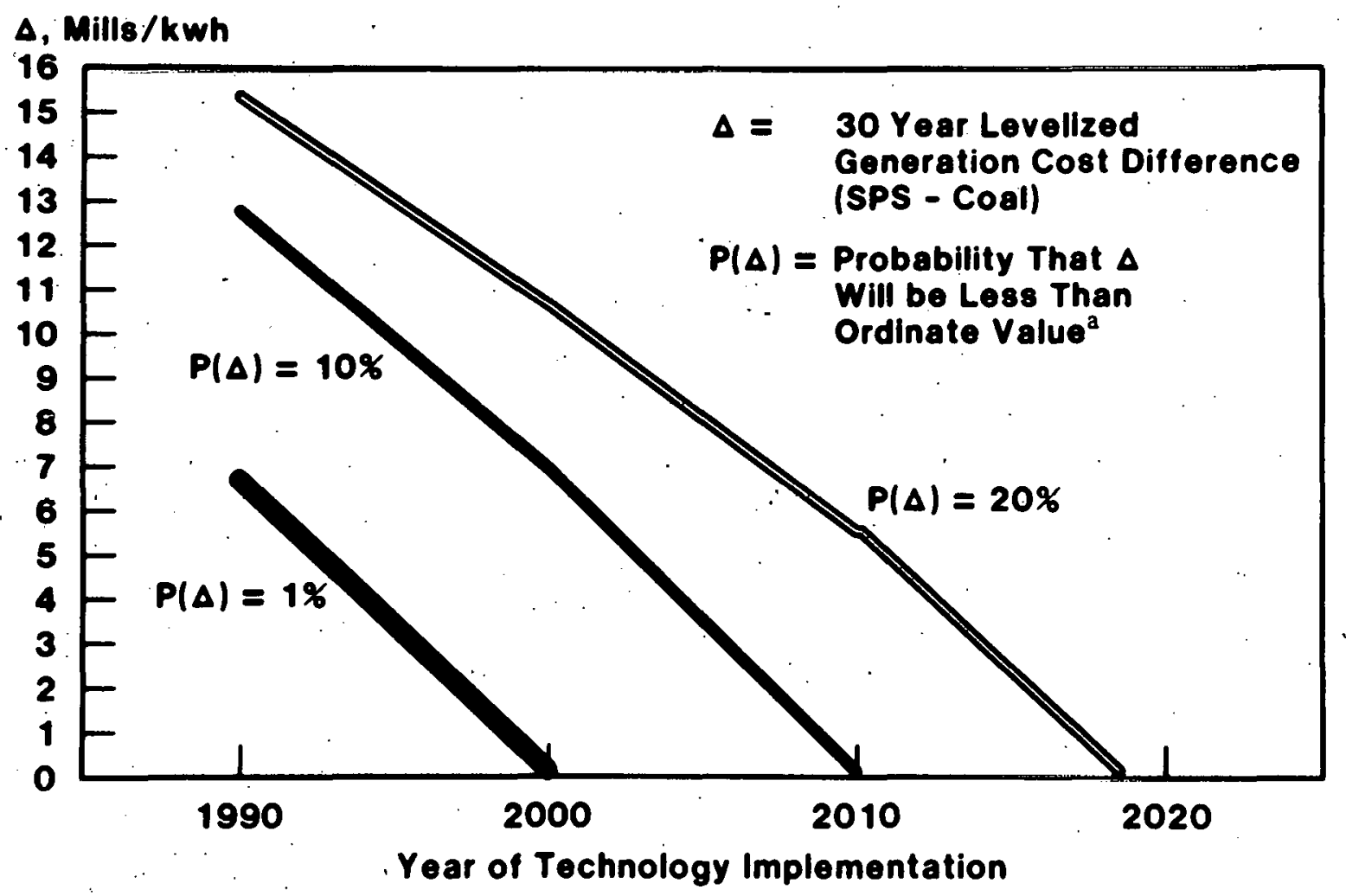

$a_{A} P(\Delta)$ value of $20 \%$ is the highest curve that can be calculated from the SPS cost-uncertainty,curve assumed in this study, i.e., with $20 \%$ of the probability distribution to the left of the modal cost.

Fig. 4.26 Probability Curves of SPS Costs Equalling Coal Costs 


\subsection{HEALTH AND SAFETY*}

\subsubsection{Introduction}

The evaluation of health and safety risks is of high priority in the assessment of alternative energy systems because of the increasing U.S. demand for energy as well as societal concern regarding the risks associated with energy technologies. Ideally, health and safety evaluations sum all risks associated with each system under comparison. However, this sort of evaluation is not currently feasible because of uncertainties surrounding system designs and risk estimates. In addition, an evaluation based solely on a summing of impacts would obscure the differences between energy systems that result from different societal perceptions of "acceptable" risks, which are important considerations for the policymaker.

This section describes an assessment taxonomy and results of the comparison of health and safety impacts from six energy systems: the SPS; a light water fission reactor system without fuel reprocessing (LWR); a low-Btu coal gasification system with an open-cycle gas turbine combined with a steam topping cycle (CG/CC); a liquid-metal, fast breeder fission reactor system (LMFBR); a central-station, terrestrial photovoltaic system (TPV); and a first generation fusion system with magnetic confinement.

Two levels of analysis are included in this assessment: the unit health and safety. risks associated with 1000-MW average electrical generation for each technology and the cumulative risks of alternative scenarios with different electrical generation technology mixes for the period 2000 to 2030. It must be stressed that the results described in this section are based on highly uncertain factors, and therefore the numbers are subjective; they should not be taken as strictly quantitative, but can provide only a qualitative view of the future.

\subsubsection{Methodology}

Assessing the health and safety risks of each technology required three major tasks: detailed characterization of each phase of the system as a basis for identifying the major health and safety issues associated with each of those phases; analysis of the magnitude of risk associated with each identified issue; and accumulation of risks by technology, by category of risk, and by generation scenario. Figure 4.27 illustrates this process and identifies the technology system activities and major sources of risk considered.

Detailed descriptions 5,52 of alternative, year-2000 baseload generation systems were compiled on a consistent basis for comparison as part of the larger SPS Concept Development and Evaluation Program. The design for the coal system with low-Btu gasification was based on an $\mathrm{SO}_{2}$ emission factor of $0.21 \mathrm{~b} \mathrm{SO}_{2} / 10^{6} \mathrm{Btu}$ of gas, or $0.326 \mathrm{lb} \mathrm{SO}_{2} / 10^{6} \mathrm{Btu}$ of coal. Load factors of

*The contents of this section are primarily a summary of results in $\operatorname{Ref}$. 51, which includes a more comprehensive list of basic references. 


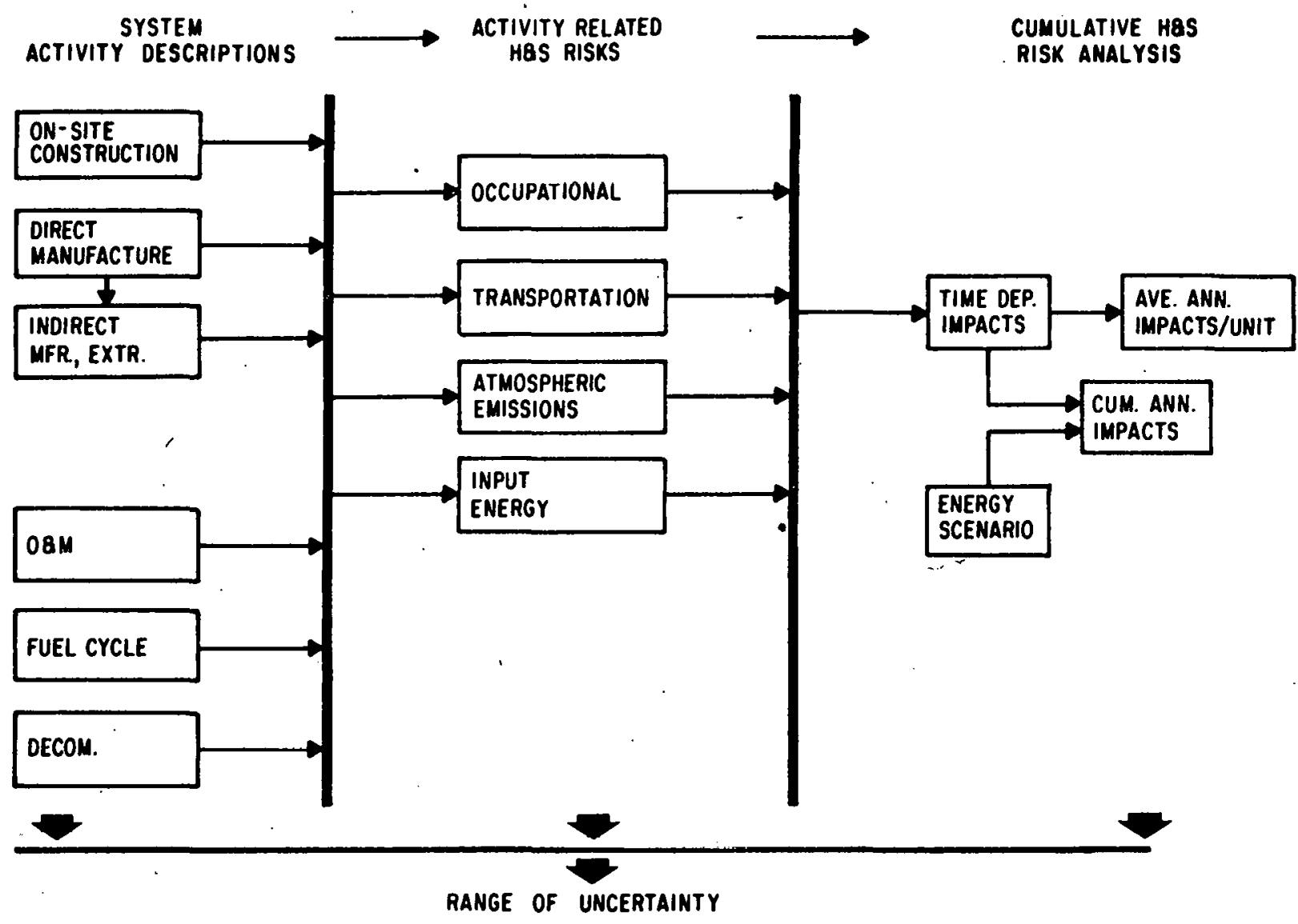

Fig. 4.27 Components of Comprehensive Health and Safety Impact Analys is

$70 \%$ were assumed for the coal, fission, and fusion systems, $90 \%$ for the SPS systems, and $26 \%$ for the centralized terrestrial photovoltaic systems. Silicon photovoltaic cells at an array cost of $\$ 35 / \mathrm{m}^{2}$ were assigned to the solar energy systems.

From the technology characterizations and other related information, we identified all known, potentially major health and safety issues that could be unambiguously defined and discussed. Each segment of the energy cycle was considered, including component fabrication, plant construction, fuel extraction and processing, operation and maintenance, and waste disposal. The health and safety risks of system storage or utility system back-up were not included for any of the systems.

Compared to the more conventional coal and $f$ ission technologies, the advanced solar and fusion technologies present a tradeoff of reduced fuel requirements but higher initial capital and construction requirements. Furthermore, the industries producing the energy system components in turn require certain commodity inputs (e.g., copper mining to produce electrical equipment), and the risks associated with the production of these indirect requirements must be considered in the uverall risk analysis, as shown in Fig. 4.28. Input-output tables based on the 1972 U.S. economic structure 53 

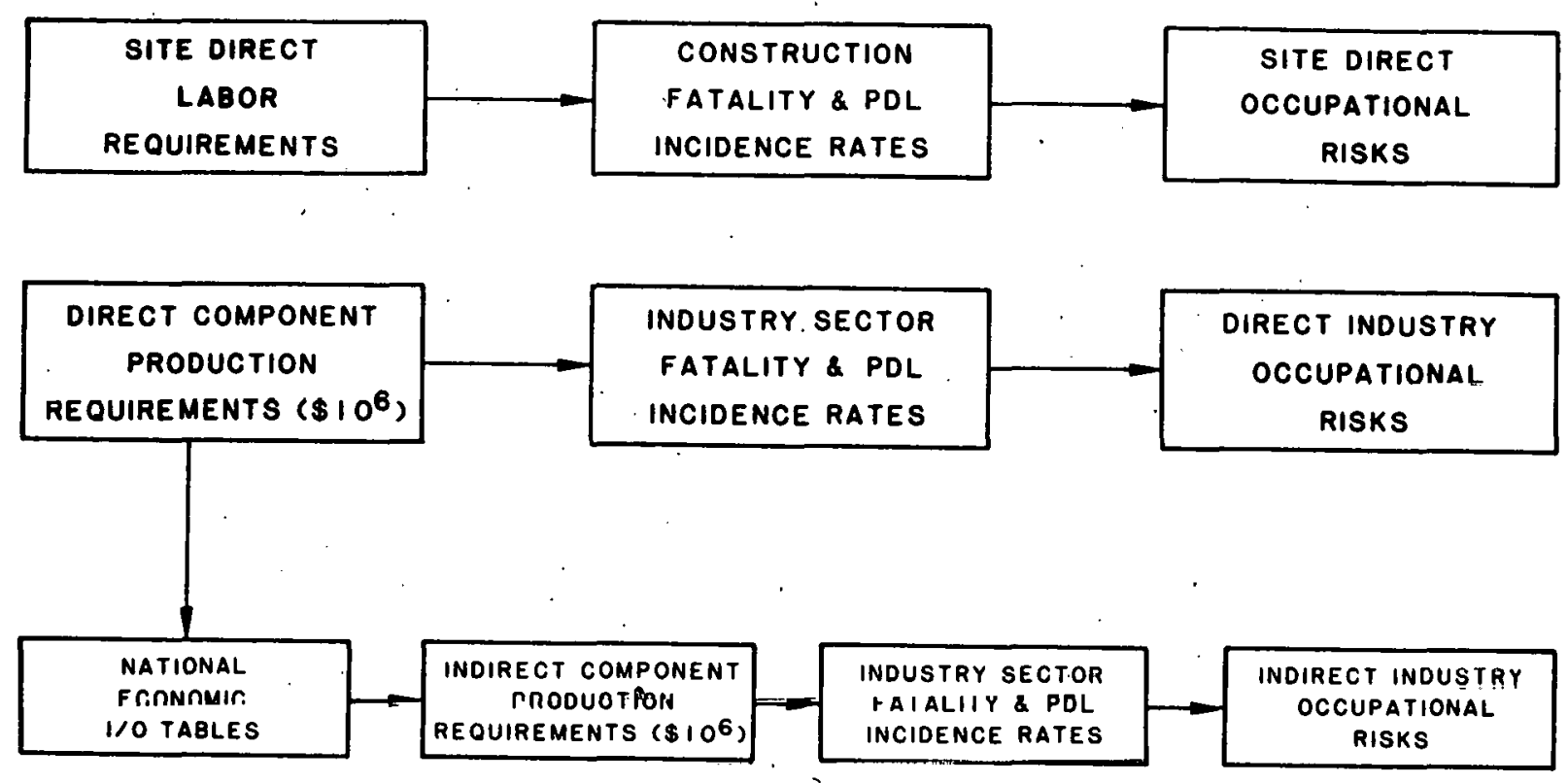

Fig. 4.28 Procedure for Computation of Occupational Impacts of Direct and Indirect. Construction and Component Production

were used to obtain these indirect output requirements for the various categories of industries. The associated occupational fatalities and persondays lost from non-fatal accidents and diseases were then determined from historical data54 for each of the categories of direct and indirect energy producers.

The analysis of health and safety risks of the remaining phases of the energy cycle was based primarily on adaptation of available literature. (See Ref. 51 for full literature citation.) Whenever possible, a quantitative estimate of fatalities and person days lost was made. Although these measures do not define, the total adverse impact of a health and safety issue, they do provide a means for comparison between technologies and categories of energy cycle activities.

A range of impact estimates is included in each quantification, reflecting the uncertainty associated with the magnitude of impact. In addition to the quantitative measure of uncertainty, issues identified for each system were classified according to qualitative uncertainty categories, as indicated in Table 4.16. Included is a category for those identified potential health and safety issués. Cur which. it ras not possible to pruvide any meaningful quantification. Lack of information, such as dose-response relationships at low-dose levels, siting patterns, populations exposed, and uncertainties regarding the probability of event occurrence and the characterizations of advanced technologies limited the estimation of risk magnitudes for these issues to qualitative discussion of potential severity or possible mechanisms for occurrence of the event.

For the unquantified or high-uncertainty category 3 , the risks were further evaluated as being of potential significance (risk category A, potentially more than 0.01 fatalities/1000 MW-yr) or of low significance ( $r$ isk category B, potentially fewer than 0.01 fatalities/1000 MW-yr). 
Table 4.16 Uncertainty Index for Health

and Safety Issues

\begin{tabular}{lcc}
\hline Description & $\begin{array}{c}\text { Uncertainty } \\
\text { Index }\end{array}$ & $\begin{array}{c}\text { Risk } \\
\text { Evaluation }\end{array}$ \\
\hline $\begin{array}{l}\text { Causal relationship and } \\
\text { impact levels relatively } \\
\text { well established (e.g., }\end{array}$ & 1 & $\begin{array}{c}\text { Quantified } \\
\text { Range }\end{array}$ \\
coal mining accidents) & & \\
$\begin{array}{l}\text { Established but poorly } \\
\text { quantified causal rela- } \\
\text { tionship (e.g., ionizing } \\
\text { radiation) }\end{array}$ & 2 & $\begin{array}{c}\text { Quantified } \\
\text { Range }\end{array}$ \\
$\begin{array}{l}\text { Cause-effect association } \\
\text { established but extremely } \\
\text { variable impact level esti- } \\
\text { mates (e.g., ground water } \\
\text { pollution, catastrophic }\end{array}$ & 3 & Qualitative \\
events) : & & Range \\
\hline
\end{tabular}

The risks resulting from electricity generation differ among the technologies not only in the magnitude but also in the manner in which impacts occur. These distinctions affect societal perceptions of the acceptability of each risk and need to be preserved in the analysis. Catastrophic events constitute a prime example of the need for categorization. Because of the engineered low risk of occurrence for these events, the number of expected deaths per year, averaged over the lifetime of the plant, may be lower than that from more probable low-impact events, but the public perception of the significance of these potential events may critically affect the viability of a technology. The varieus impact categories utilized in the analysis are listed in Table 4.17 .

\subsubsection{Discussion of: Results}

The results of the quantitative risk anslysis are summarized in Table 4.18 and Figs. 4.29-4.31. A detailed analysis of each issue considered is provided in Tables 4.19-4.23. The major unquantified issues are listed in Table 4.24, The following is a discussion of major features from those results.

Qccupational Risks of the Construction Phase. For each unit value of direet industrial output required to supply components for each of the energy syetems, an additional indirect in the range of $0.5-0.9$ units from other industries is required. This significant requirement for indirect industrial eutput results in a significant addition to the average number of occupational. fatalities per unit of component production, as illustrated in Fig. 4.29. The combined direct and indirect fatalities per unit of component requirement is within the same range for all the technologies, and, as a result, the tatal 
Table 4.17 Categorization of Health

and Safety Issues

\begin{tabular}{|c|c|}
\hline Is sue & Category \\
\hline Affected Population & $\begin{array}{l}\text { Pub } 1 \text { ic } \\
\text { Occupational }\end{array}$ \\
\hline Impact Period & $\begin{array}{l}\text { Intermediate Term (Component } \\
\text { Production, Plant Construction) } \\
\text { Long Term (Plant O\&M, Waste } \\
\text { Management) } \\
\text { Short Term (Catastrophic Events) }\end{array}$ \\
\hline Impact Cause & $\begin{array}{l}\text { Accidents } \\
\text { Chemical Pollutants (Toxic, } \\
\text { Carcinogenic) } \\
\text { Radiation. (Ionizing, Nonionizing) }\end{array}$ \\
\hline Impact Severity & $\begin{array}{l}\text { Fatalities } \\
\text { Person Days Lost (Nonfatalities) }\end{array}$ \\
\hline
\end{tabular}

component requirement per $1000 \mathrm{MW}$ of generation is the overriding factor in determining risk of component production. The total component production risks, combined with on-site construction risks, are shown in Fig. 4.30 and illustrate the higher construction-phase risk of the terrestrial solar and the fusion technologies, which is due to the more capital-intensive nature of these technologies. The terrestrial photovoltaic system requires nearly 20 units of component production at 200-MW peak capacity and $26 \% 10$ ad factor, and the SPS requires extensive ground and space facilities to construct and maintain the orbiting satellites.

Although not ohown, oimilar results are obtained for the number of work days lost. For this parameter, more disaggregated data on risk levels are available for individual industrial categories.

Occupational Risks of the Operation and Maintenance Phase. The total quantified risk of fatality, averaged over an assumed 30-year 1 ifetime, is shown for each technology in Fig. 4.31. Quantified risks of operation and maintenance (O\&M) are largest for the coal technology, primarily due to the risks of accidents and illness during coal mining. A major uncertainty in estimates of mining risk derives from uncertainty in the long-term effect of recent regulations for reducing the levels of dust in coal mines. Additional O\&M occupational risks of energy production from coal are related to rail transport of the coal, accidents in the coal processing and electrical generation plants, and exposure to potential carcinogenic emissions from the coal gasification process. The estimate for the risk from potential in-plant gasification emissions (0.0-0.2 fatalities/1000 MW-yr) is based on the estimated number of workers in the plant and on historical data from pilot plants with limited control measures.55 Approximately $70-80 \%$ of the 0\&M risks of the fission systems are related to conventional occupational hazards, and the remaining $20-30 \%$ are due to low-level radiation exposure, the impacts 
Table 4:18 Summary of Quantified Average Fatalities per Year per $1000 \mathrm{MW}$ Generation, 30-Year Plant Li fet ime ${ }^{a}$

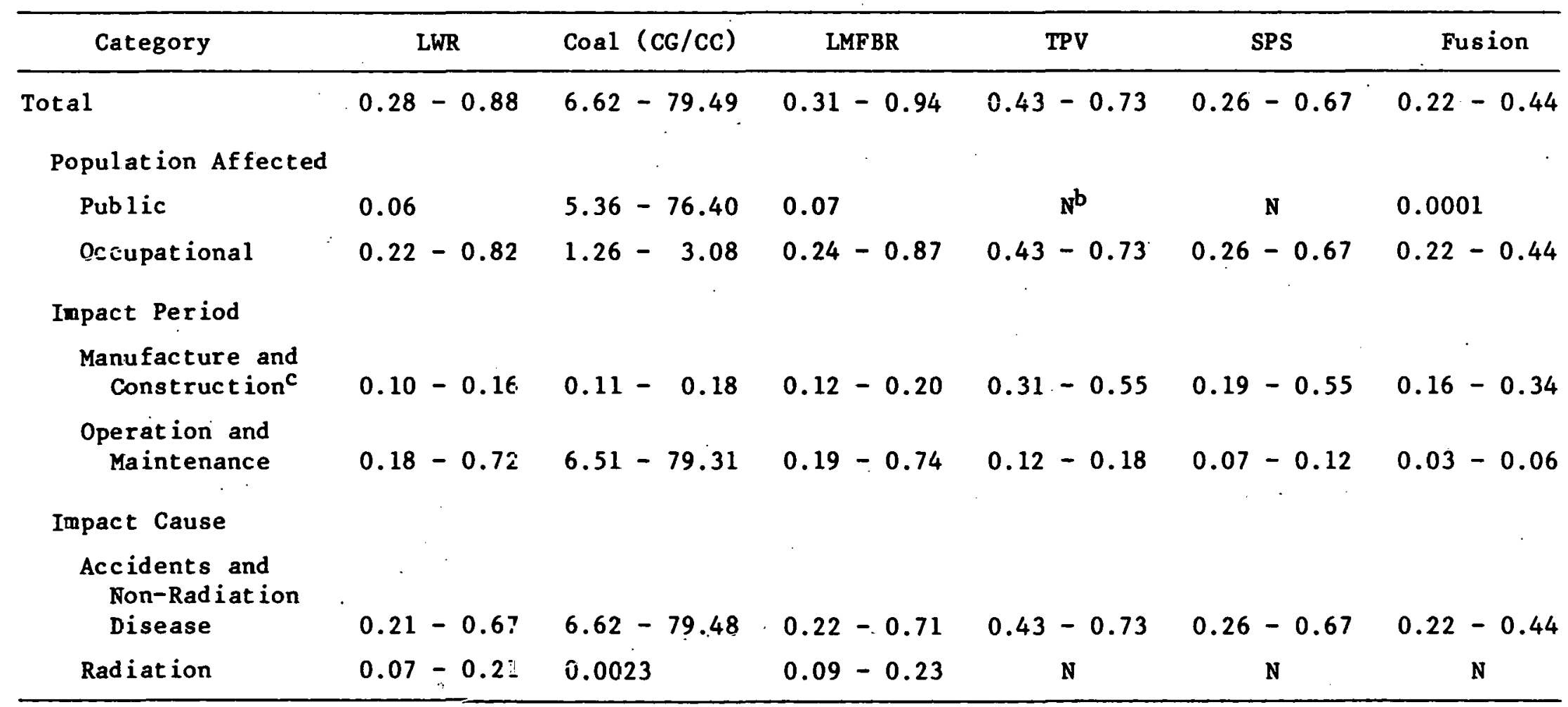

a The numbers in this table were calculated on the basis of the rational described in this report and do not necessarily represent past experience nor statistical expectation of future experience. - This limitation ipplies to all figures and tables in Sec. 4.3 of this report.

$\mathrm{b}_{\mathrm{N}}$ : Not quantified; expected to be small.

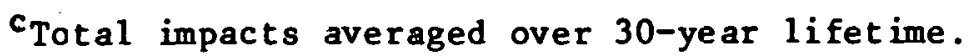




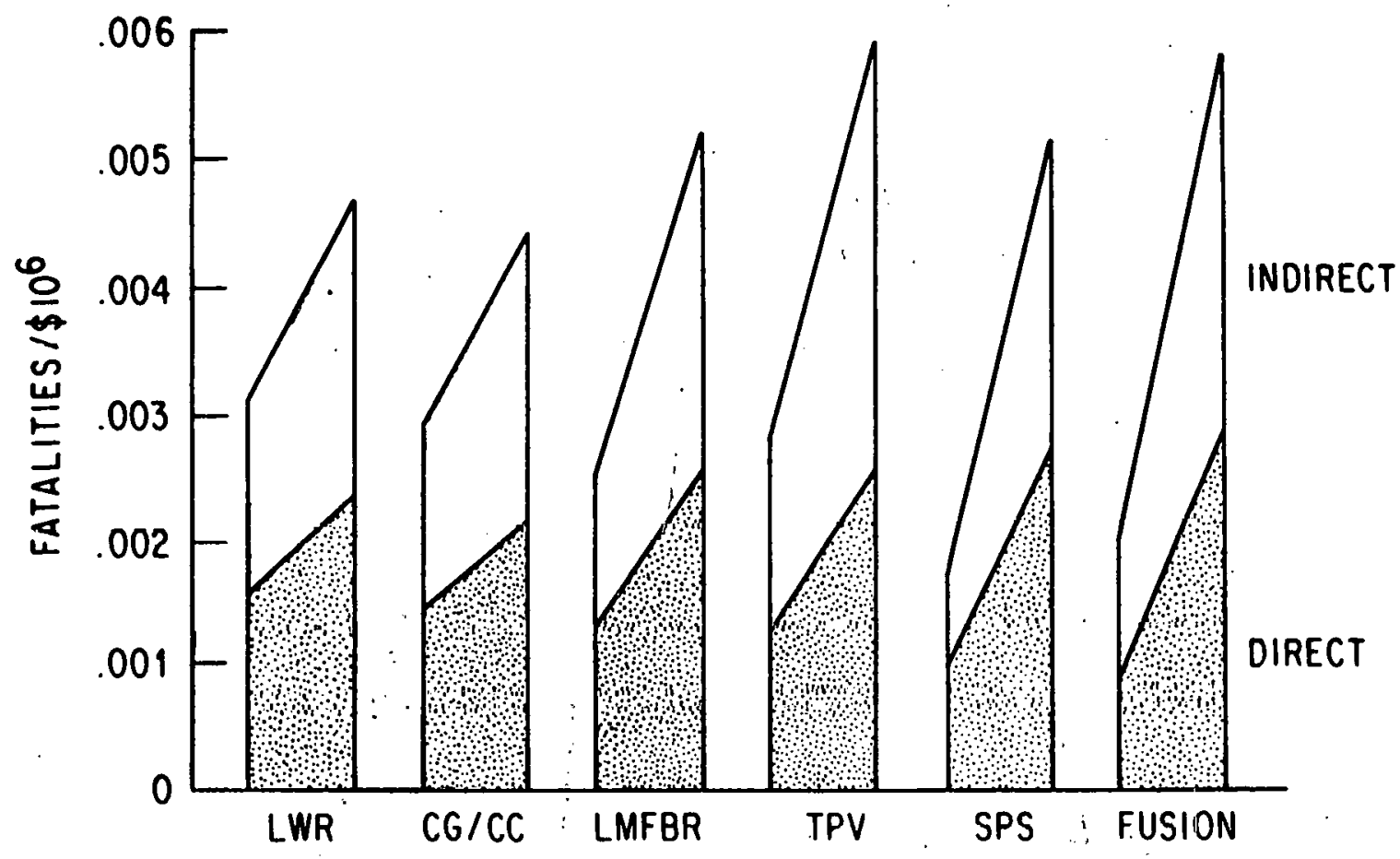

Fig. 4.29 Direct and Indirect Occupational Fatalities from Unit $\left(\$ 10^{6}\right)$ Facility Component Production

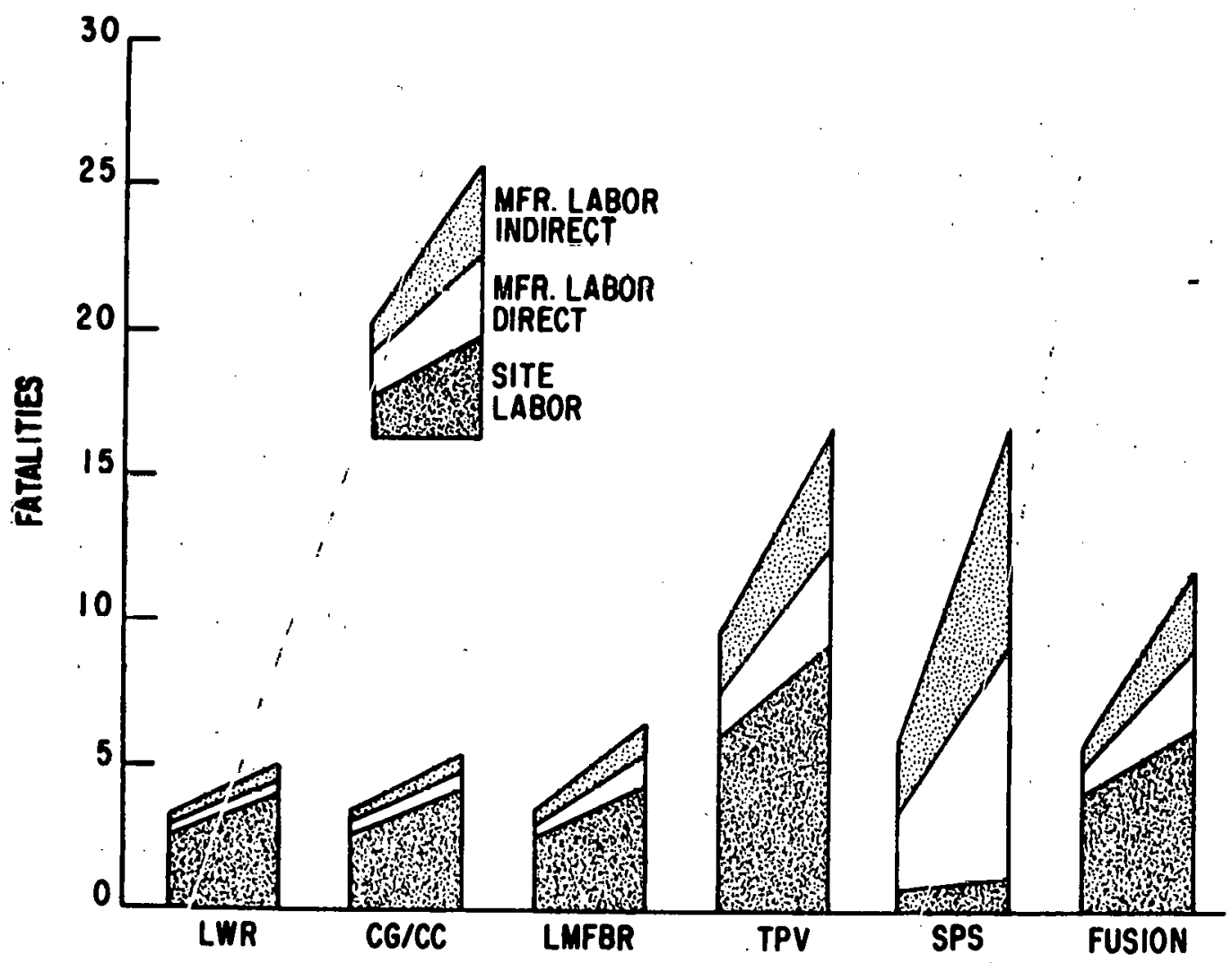

Fig. 4.30 Total Occupational Fatalities in Construction Phase of System with 1000 MW Average Generation 


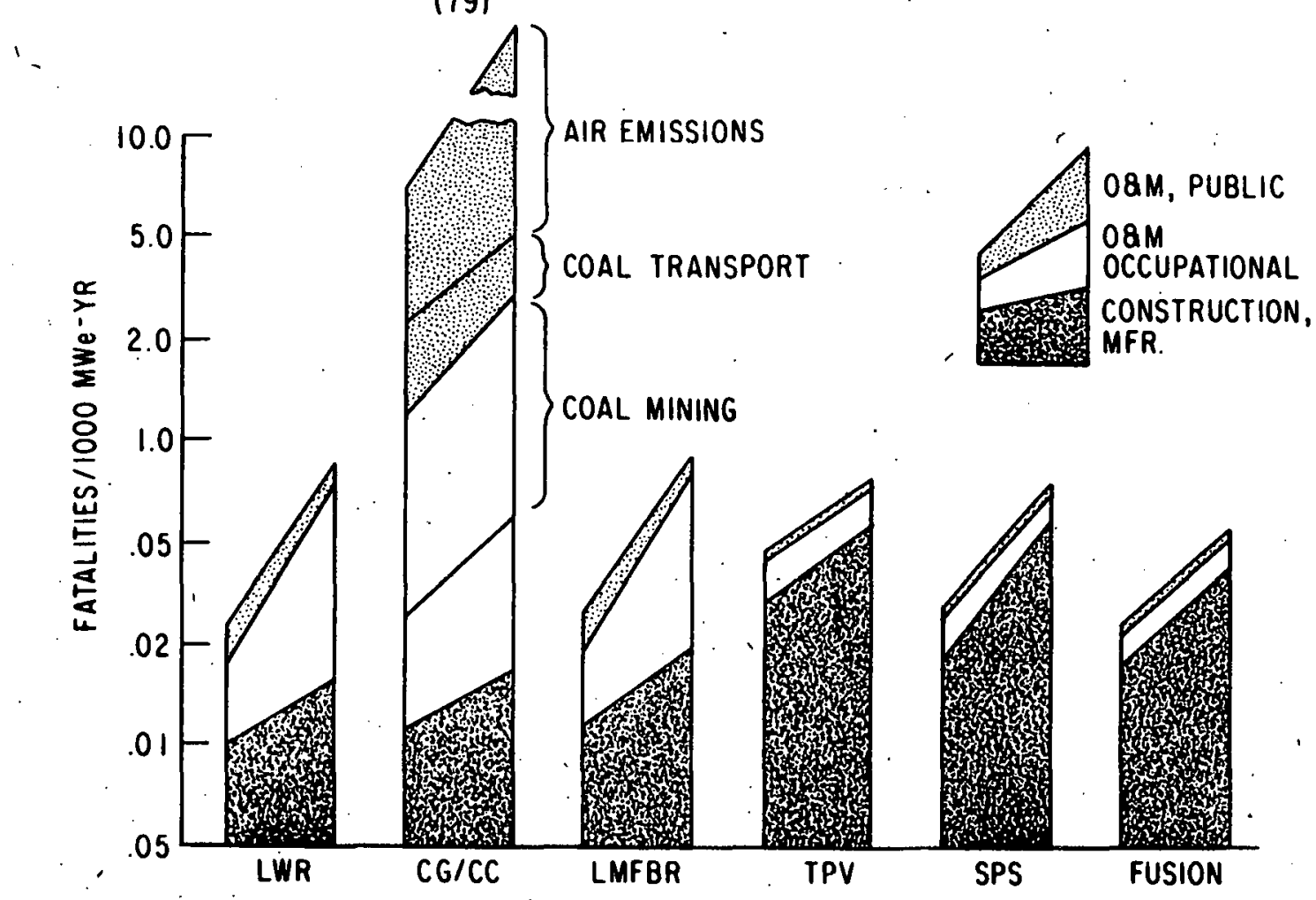

Fig. 4.31 Total Quantified Construction and O\&M Fatalities per 1000 MW-yr

of which are uncertain. The O\&M occupational risks of the advanced fusion, SPS, and centralized terrestrial photovoltaic systems have no historical basis and are projected from conventional risk levels for existing similar occupa$t$ ions and estimates of the number of $0 \& M$ employees required $.5,52$

Public Risks of the Operation and Maintenance Phase. The largest O\&M-phase public risks quantified for this study are those related to the coal technologies, and these are almost entirely due to coal transport accidents (0.8-1.9 fatalities/1000 MW-yr) and air pollutants (4.6-75 fatalities/1000 MW-yr). The estimates for air pollutant impacts include long-range transport, and the uncertainty range is based on a $60 \%$ confidence level for incidence rates of health effects (adapted from Ref. 56). It should be noted that a similar procedure using $90 \%$ confidence levels for air pollutant dose-response gives a range including zero impact. Low levels of public impact (less than 0.1 fatality/1000.MW-yr) can be attributed to normal O\&M of the fission and fusion systems, and these impacts are primarily due to low-level radiation, which has a high uncertainty level. The quantified public impacts from O\&M for the SPS and the TPV system are negligible.

Unquantified Health and Safety Issues. In contrast to the apparent willingness of the public to accept known limited risks of energy systems, recent experience with light water fission systems indicates that perceived major risks that are less quantifiable or predictable may restrict or completely halt energy system deployment if adequate assurances of very low 
Table 4.19 Summary of Health and Safety Issues for Nuclear Fission Reactors (LWR, LMFBR)

\begin{tabular}{|c|c|c|c|c|c|c|c|}
\hline \multirow[b]{2}{*}{ Is sue } & \multirow[b]{2}{*}{ Process } & \multicolumn{3}{|c|}{ Categories ${ }^{a}$} & \multirow{2}{*}{$\begin{array}{l}\text { Estimated } \\
\text { Fatalities per 1000 } \\
\text { MW of Genera:ion }\end{array}$} & \multirow[b]{2}{*}{ Uncertainties } & \multirow[b]{2}{*}{$\begin{array}{l}\text { Uncertainty } \\
\text { Rating }\end{array}$} \\
\hline & & $\begin{array}{l}\text { Af } f \epsilon=\text { ted } \\
\text { Grejp }\end{array}$ & Phase & $\begin{array}{l}\text { Primary } \\
\text { Cause }\end{array}$ & & & \\
\hline Accidental injury ${ }^{b}$ & $\begin{array}{l}\text { Ore extraction and } \\
\mathrm{U}_{3} \mathrm{O}_{\mathrm{Z}} \mathrm{milling}\end{array}$ & $c$ & OM & $A D$ & $0.05-0.2^{\prime} y \mathrm{r}$ & $\begin{array}{l}\text { Future use of lower-grade } \\
\text { ore will require larger } \\
\text { mining and milling. } \\
\text { operations. }\end{array}$ & 1 \\
\hline $\begin{array}{l}\text { Lung cancer as a } \\
\text { result of exposure } \\
\text { to radon and other } \\
\text { decay product.s of } \\
\text { natural uranismc }\end{array}$ & $\begin{array}{l}\text { Ore extraction and } \\
\mathrm{U}_{3} \mathrm{O}_{3} \text { milling: }\end{array}$ & $C$ & OM & IR & $0.001-0.1 . \mathrm{gr}$ & $\begin{array}{l}\text { Exposure levels prior to } \\
\text { establishment of standards } \\
\text { are not known precisely. } \\
\text { Effectiveness of ventila- } \\
\text { tior: for the removal of } \\
222 \text { En. }\end{array}$ & 2 \\
\hline Accidental injury ${ }^{d}$ & $\begin{array}{l}\text { Fuel fabrica:ion: } \\
\mathrm{U}_{3} \mathrm{O}_{8} \text { conversion, } \mathrm{UF}_{6} \\
\text { enrichment, } \mathrm{JO}_{2} \text { fabri- } \\
\text { cat ion }\end{array}$ & 0 & OM & $A D$ & $0.003-0.2^{\prime} \mathrm{gr}$ & $\begin{array}{l}\text { Occipational accident } \\
\text { potential for nuclear } \\
\text { fuel preparation. }\end{array}$ & 1 \\
\hline $\begin{array}{l}\text { Low-level radiation } \\
\text { exposure }\end{array}$ & $\begin{array}{l}\text { Fuel fabrica:ion: } \\
\mathrm{U}_{3} \mathrm{O}_{8} \text { conversion, } \mathrm{UF}_{6} \\
\text { enrichment, } \mathrm{JO}_{2} \text { Eabri- } \\
\text { cat ion }\end{array}$ & $\begin{array}{l}\mathbf{a} \\
\mathbf{P}\end{array}$ & $\begin{array}{l}\text { OM } \\
\text { OM }\end{array}$ & $\begin{array}{l}\text { IR } \\
\text { IR }\end{array}$ & $\begin{array}{c}0.003-0.03 \mathrm{~J} / \mathrm{yr} \\
0.0003 / \mathrm{gr}\end{array}$ & $\begin{array}{l}\text { Generic to all segments } \\
\text { of the fuel cycle; the } \\
\text { actual human response to } \\
\text { low-level exposures is } \\
\text { hypothetical. }\end{array}$ & 2 \\
\hline Exposure to $H F, F_{2} F$ & $\begin{array}{l}\text { Fue fabrica:ion: } \\
\mathrm{U}_{3} \mathrm{O}_{8} \text { conversion, } \mathrm{UF}_{6} \\
\text { enr =hment, } \mathrm{OO}_{2}, \mathrm{PuO}_{2} \\
\text { fabrication }\end{array}$ & 0 & OM & $\mathrm{C}$ & $0.005 / y^{t}$ & $\begin{array}{l}\text { Possible high level } \\
\text { expasure from industrial } \\
\text { mishaps; Population re- } \\
\text { sponse to excess fluorides. }\end{array}$ & 2 \\
\hline $\begin{array}{l}\text { Accidental in:ury } \\
\text { possible; radiation } \\
\text { hazard and chemical } \\
\text { toxicity from UF } 6 \\
\text { spilig }\end{array}$ & Transportation & $\begin{array}{l}0 \\
\mathbf{p}\end{array}$ & $\begin{array}{l}\text { OM } \\
\text { OM }\end{array}$ & $\begin{array}{l}\mathrm{AD} \\
\mathrm{AD}\end{array}$ & $\begin{array}{c}0.002-0.0 \Xi \epsilon / \mathrm{yr} \\
0.01 / \mathrm{yr}\end{array}$ & $\begin{array}{l}\text { Transport distances and } \\
\text { modes; trip frequencies. }\end{array}$ & 1 \\
\hline
\end{tabular}

a-Occupational, P-Public, C-Construction, M-Manufacture, OM-Operations and Maintenance, AD-Accidents and Disease, IR-Ionizing Radiation, ER-Electromagnet ic Radiation.

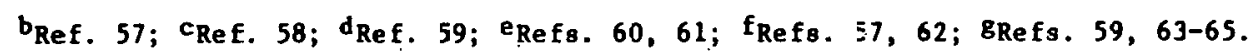

hrom lung damage or osteofluorosis from continuous axposure. 
Table 4.19 (Cont'd)

\begin{tabular}{|c|c|c|c|c|c|c|c|}
\hline \multirow[b]{2}{*}{ Is sue } & \multirow[b]{2}{*}{ Process } & \multicolumn{3}{|c|}{ Categories ${ }^{a}$} & \multirow{2}{*}{$\begin{array}{l}\text { Estimated } \\
\text { Fatalities per } 1000 \\
\text { MW of Generation }\end{array}$} & \multirow[b]{2}{*}{ Uncertainties } & \multirow[b]{2}{*}{$\begin{array}{l}\text { Uncertainty } \\
\text { Rating }\end{array}$} \\
\hline & & $\begin{array}{l}\text { Affected } \\
\text { Group }\end{array}$ & Phase & $\begin{array}{l}\text { Primary } \\
\text { Cause }\end{array}$ & & & \\
\hline $\begin{array}{l}\text { Low-ievel radiation } \\
\text { hazard, accidents }\end{array}$ & Reactor operation & $\begin{array}{l}P \\
0 \\
0\end{array}$ & $\begin{array}{l}\text { OM } \\
\text { OM } \\
\text { OM }\end{array}$ & $\begin{array}{l}\text { IR } \\
\text { AD } \\
\text { IR }\end{array}$ & $\begin{array}{c}0.05 / \mathrm{yr} \\
0.034-0.055 / \mathrm{yr} \\
0.012-0.024 / \mathrm{yr}\end{array}$ & $\begin{array}{l}\text { Health impacts of low } \\
\text { level radiation. }\end{array}$ & 2 \\
\hline $\begin{array}{l}\text { Acute and delayed } \\
\text { effects from cata- } \\
\text { strophic accidents }\end{array}$ & Reactor operation & $\mathbf{P}$ & OM & IR & $\mathrm{p}$ & $\begin{array}{l}\text { The operating experience } \\
\text { of large power reactors } \\
\text { is small. Catastrophic } \\
\text { risk estimates are based } \\
\text { on this experience. }\end{array}$ & 3-A \\
\hline Low-level radiationk & $\begin{array}{l}\text { Reprocessing } \\
\text { (LMFBR only) }\end{array}$ & $\begin{array}{l}0 \\
P\end{array}$ & $\begin{array}{l}\text { OM } \\
\text { OM }\end{array}$ & $\begin{array}{l}\text { IR } \\
\text { IR }\end{array}$ & $\begin{array}{l}0.006 / \mathrm{yr} \\
0.009 / \mathrm{yr}\end{array}$ & Extent of exposure. & 2 \\
\hline $\begin{array}{l}\text { Delayed response to } \\
\text { low-level radiation } \\
\text { exposure }\end{array}$ & $\begin{array}{l}\text { Radioactive- } \\
\text { waste storage }\end{array}$ & $\begin{array}{l}0 \\
P\end{array}$ & $\begin{array}{l}\text { OM } \\
\text { OM }\end{array}$ & $\begin{array}{l}\text { IR } \\
\text { IR }\end{array}$ & $\begin{array}{c}0.006 / \mathrm{yr} \\
0.0003-0.001 / \mathrm{yr}\end{array}$ & $\begin{array}{l}\text { Ability to contain radio- } \\
\text { active wastes over long } \\
\text { periods of time. }\end{array}$ & 2 \\
\hline $\begin{array}{l}\text { Intertional misuse of } \\
\text { nuclear materials } \\
\text { result ing in general } \\
\text { population injurym }\end{array}$ & $\begin{array}{l}\text { Fuel or by-product } \\
\text { theft }\end{array}$ & $\mathbf{P}$ & OM & IR, C & 9 & $\begin{array}{l}\text { Accessibility to nuclear } \\
\text { materials under future } \\
\text { reprocessing requirements, } \\
\text { use of non-explosive toxic } \\
\text { materials. }\end{array}$ & $3-A$ \\
\hline Liquid metal firen & $\begin{array}{l}\text { Re ector operat ions } \\
\text { (LWFBR only) }\end{array}$ & 0 & OM & $\mathrm{AD}$ & Not available. & $\begin{array}{l}\text { Initiating events, } \\
\text { including intentional }\end{array}$ & $3-A$ \\
\hline $\begin{array}{l}\text { Accidents and } \\
\text { disease }\end{array}$ & $\begin{array}{l}\text { Direct and indirect } \\
\text { material extraction an } \\
\text { component manufactur? }\end{array}$ & 0 & c & $\mathrm{AD}$ & $\begin{array}{l}\text { Total fatalities: } \\
\text { (LWR) } 0.79-1.18 \\
\text { (LMFBR) } 1.02-2.12\end{array}$ & $\begin{array}{l}\text { General manufacturing } \\
\text { incidence rates. }\end{array}$ & 1 \\
\hline $\begin{array}{l}\text { Accidents and } \\
\text { disease }\end{array}$ & Construction on-site & 0 & c & $A D$ & $\begin{array}{l}\text { Total fatalities: } \\
\text { (LWR) } 2.29-3.62 \\
\text { (LMFBR) } 2.56-4.04\end{array}$ & $\begin{array}{l}\text { General construction } \\
\text { incidence rates }\end{array}$ & 1 \\
\hline
\end{tabular}

a-0ecupational, P-Public, C-Construction, M-Manufacture, OM-Operations and Maintenance, AD-Accidents and Disease, IR-Ionizing Radiation, BR-Electromagnetic Fadiation.

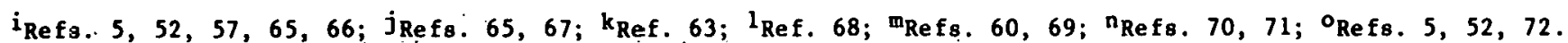

Pabout 3,500 immediate and 45,000 delayed fatalities per catastrophic incident.

qone small dirty terrorist bomb could destroy one city block, producing 50,000 casualties. 
Table 4.20 Sumary of Health and Safety Issues for Combined-Cycle Coal System

\begin{tabular}{|c|c|c|c|c|c|c|c|}
\hline \multirow[b]{2}{*}{ Is sue } & \multirow[b]{2}{*}{ Process } & \multicolumn{3}{|c|}{ Gategories ${ }^{a}$} & \multirow{2}{*}{$\begin{array}{c}\text { Estimated } \\
\text { Fatalities per } 1000 \\
\text { MW of Generation }\end{array}$} & \multirow[b]{2}{*}{ Uncertaint ies } & \multirow[b]{2}{*}{$\begin{array}{l}\text { Uncertainty } \\
\text { Rating }\end{array}$} \\
\hline & & $\begin{array}{l}\text { Affected } \\
\text { Group }\end{array}$ & Phase & $\begin{array}{l}\text { Primary } \\
\text { Cause }\end{array}$ & & & \\
\hline Coal dust inhalationb & $\begin{array}{l}\text { Unde }=\text { ground mining } \\
\text { (75\% of ccal) }\end{array}$ & 0 & OM & $\mathbf{A D}$ & $0-1.2 / y=$ & $\begin{array}{l}\text { Effect of regulations to } \\
\text { reduce dust levels. }\end{array}$ & 1 \\
\hline Mining accident $\theta^{c}$ & $\begin{array}{l}\text { Surface }(25 \%) \text { and } \\
\text { underground }(75 \%) \\
\text { coal mining }\end{array}$ & 0 & OM & $\mathbf{A D}$ & $0.94-1.16 / g x$ & $\begin{array}{l}\text { Many inexperienced miners, } \\
\text { new mining techniques. }\end{array}$ & 1 \\
\hline $\begin{array}{l}\text { Railroad crossing } \\
\text { accidents } \mathrm{d}\end{array}$ & Coal transport & $\begin{array}{l}\mathbf{0} . \\
\mathbf{P}\end{array}$ & $\begin{array}{l}\text { OM } \\
\text { OM }\end{array}$ & $\begin{array}{l}\mathrm{AD} \\
\mathrm{AD}\end{array}$ & $\begin{array}{l}0.07-0.17 / \mathrm{yr} \\
0.78-1.9 / \mathrm{yr}\end{array}$ & $\begin{array}{l}\text { Transport routes and } \\
\text { distances. }\end{array}$ & 1 \\
\hline $\begin{array}{l}\text { Inhalation and skin } \\
\text { contact with toxic } \\
\text { substances and } \\
\text { carcinogense }\end{array}$ & $\begin{array}{l}\text { Plant operation and } \\
\text { maintenance }\end{array}$ & 0 & OM & $\mathbf{A D}$ & $0-0.2 / y x$ & $\begin{array}{l}\text { In-plant exposures in } \\
\text { commercial facility, } \\
\text { impact of low-level } \\
\text { exposure. }\end{array}$ & 2 \\
\hline $\begin{array}{l}\text { Atmos pheric } \\
\text { emissions, long- } \\
\text { range transport }\end{array}$ & $\begin{array}{l}\text { Plant operation; } \\
0.326 \mathrm{lb}_{2} \text { emitted } \\
\text { per } 10^{6} \mathrm{Btu} \text { coal input }\end{array}$ & $\mathbf{P}$ & OM & $A D$ & $4.6-74.5 / y x^{-1}$ & $\begin{array}{l}\text { Long-range pollutant trans- } \\
\text { port; low-level exposures; } \\
\text { impact mechanism and } \\
\text { pollut ant synergisms. }\end{array}$ & 2 \\
\hline $\begin{array}{l}\text { Chemical pollutants } \\
\text { in aqueous effluents } \\
\text { and solid waste } \\
\text { leachates }\end{array}$ & $\begin{array}{l}\text { Coal extraction and } \\
\text { processing, plant } \\
\text { operazion }\end{array}$ & P & OM & $\mathbf{A D}$ & m & $\begin{array}{l}\text { Health effect of small } \\
\text { increments of pollutants; } \\
\text { effluent characteristics } \\
\text { of gasification facilities. }\end{array}$ & $3-B$ \\
\hline $\begin{array}{l}\text { Exposure, inhalation, } \\
\text { and dietary intake } \\
\text { of radioactive coal } \\
\text { constituentsh }\end{array}$ & Plant air enissions & $\mathbf{P}$ & OM & IR & $0.0023 / y^{n}$ & $\begin{array}{l}\text { Effects: of low-level radia- } \\
\text { tion; fate and impact of } \\
\text { solid waste radioactive } \\
\text { leachates. }\end{array}$ & 2 \\
\hline $\begin{array}{l}\text { Occupational health } \\
\text { and safetyi }\end{array}$ & $\begin{array}{l}\text { Direct and indirect } \\
\text { material extraction, } \\
\text { processing and component } \\
\text { fatrication }\end{array}$ & 0 & c & $\mathbf{A D}$ & $0.82-1.23 / \mathrm{yr}$ & $\begin{array}{l}\text { Component needs and asso- } \\
\text { ciated risks for commercial } \\
\text { gasification facilities. }\end{array}$ & 1 \\
\hline $\begin{array}{l}\text { Construction } \\
\text { accidents } \mathbf{j}\end{array}$ & $\begin{array}{l}\text { On-site plaint con- } \\
\text { struction. }\end{array}$ & 0 & c & $\mathbf{A D}$ & $\begin{array}{l}2.59-4.05 \\
(\operatorname{total})\end{array}$ & $\begin{array}{l}\text { Total and skill-specific } \\
\text { labor requirements. }\end{array}$ & 1 \\
\hline $\begin{array}{l}\text { Occupational } \\
\text { accidentsk }\end{array}$ & Cosl processing & 0 & $\mathrm{OM}$ & $\mathbf{A D}$ & $0.073 / \mathrm{yr}$ & $\begin{array}{l}\text { Year-2000 coal processing } \\
\text { practices. }\end{array}$ & 1 \\
\hline $\begin{array}{l}\text { Occupational } \\
\text { accidents } \mathrm{k}\end{array}$ & $\begin{array}{l}\text { Plant operation and } \\
\text { ma intenance }\end{array}$ & 0 & $\mathrm{OM}$ & $\mathbf{A D}$ & $0.066-0.105 / y x$ & $\begin{array}{l}\text { Lack of experience with } \\
\text { gasification facilities. }\end{array}$ & 1 \\
\hline
\end{tabular}

${ }^{a}$ O-Occupational, P-Public, C-Construction, M-Manufacture, OM-Operations and Maintenance, AD-Accidents and Disease, IR-Ionizing Radiation, ER-Electromagnetic Radiation.

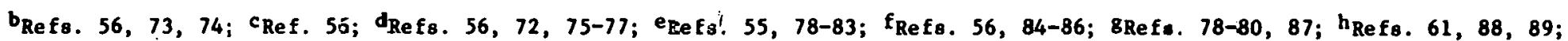

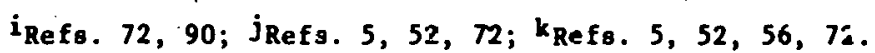

$160 z$ confidence interval for dose response.

many new and exacerbated riolationa of water-quality standards under scenario of large increse in utility and industrial coal use.

- 0.002 eventual genetic defects per year within 88.5 -km radius of aite. 
Table 4.21 Summary of Health and Safety Issues for Central-Station Terrestrial Photovoltaic Power System

\begin{tabular}{|c|c|c|c|c|c|c|c|}
\hline \multirow{2}{*}{ Is sue } & \multirow[b]{2}{*}{ Process } & \multicolumn{3}{|c|}{ Categories $^{a}$} & \multirow{2}{*}{$\begin{array}{l}\text { Estimated } \\
\text { Impact per } 1000 \\
\text { MW of Generation }\end{array}$} & \multirow[b]{2}{*}{ Uncertainties } & \multirow[b]{2}{*}{$\begin{array}{c}\text { Uncertainty } \\
\text { Rat ing }\end{array}$} \\
\hline & & $\begin{array}{l}\text { Af fected } \\
\text { Group }\end{array}$ & Phase & $\begin{array}{l}\text { Primary } \\
\text { Cause }\end{array}$ & & & \\
\hline $\begin{array}{l}\text { Exposure to Si dust, } \\
\text { doping agents, } \\
\text { process chemicalsb }\end{array}$ & $\begin{array}{l}\text { Raw material produc- } \\
t \text { ion and manufacture } \\
\text { of photovoltaic cells }\end{array}$ & $0, P$ & c & $\mathrm{AD}$ & $\begin{array}{l}\text { Potent.ial exposure } \\
\text { to } \mathrm{Si} \text { dust, phos- } \\
\text { gene, } \mathrm{BCl}_{3}, \mathrm{Cd}, \mathrm{Ga}, \\
\mathrm{As}, \mathrm{HF}, \mathrm{SnO}_{\mathrm{X}}, \mathrm{NH}_{3} \text {, } \\
\text { phenols, CdO, } \mathrm{nSO}_{4} \text {, } \\
\mathrm{Al}_{2} \mathrm{O}_{3} \text {, and other } \\
\text { processing chemicals }\end{array}$ & $\begin{array}{l}\text { Emission levels, bio- } \\
\text { accumulation potentials } \\
\text { of released wastes, } \\
\text { volume of wastes }\end{array}$ & $3-A$ \\
\hline $\begin{array}{l}\text { Accidents, exposure } \\
\text { to toxic process } \\
\text { chemicals and } \\
\text { environmentally } \\
\text { released wastes }\end{array}$ & $\begin{array}{l}\text { Direct and indirect } \\
\text { material extraction } \\
\text { and component manu- } \\
\text { facture }\end{array}$ & 0 & $\mathrm{C}$ & AD & $\begin{array}{l}3.45-7.18 \text { deaths } \\
(\text { total })\end{array}$ & $\begin{array}{l}\text { Material and manpower } \\
\text { requirements }\end{array}$ & 2 \\
\hline $\begin{array}{l}\text { Accifents, exposure } \\
\text { to toxic chemicals }\end{array}$ & Construct ion & 0 & C & $A D$ & $\begin{array}{l}5.92-9.30 \text { deaths } \\
(\text { total })\end{array}$ & $\begin{array}{l}\text { Manpower requirements of } \\
\text { sectors involved in con- } \\
\text { struction activities }\end{array}$ & 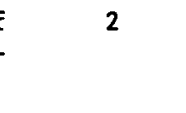 \\
\hline $\begin{array}{l}\text { Accidents, system } \\
\text { mel functionc }\end{array}$ & $\begin{array}{l}\text { Operation and main- } \\
\text { tenance (O\&M) }\end{array}$ & 0 & OM & $A D$ & $\begin{array}{l}0.12-0.18 \text { deaths/yr } \\
\text { o\&M will include risk } \\
\text { of electrical and } \\
\text { physical trauma and of } \\
\text { exposure to of } f-g a s e s \\
\text { during episodes of } \\
\text { array overheating. }\end{array}$ & $\begin{array}{l}\text { Manpower requirements } \\
\text { and system malfunction } \\
\text { potential }\end{array}$ & 2 \\
\hline $\begin{array}{l}\text { Expcsure to toxic } \\
\text { substances }\end{array}$ & $\begin{array}{l}\text { Disposal of spent } \\
\text { photovoltaic cells }\end{array}$ & $0, \mathbf{P}$ & & $\mathbf{A D}$ & $\begin{array}{l}\text { Disposal or recycling } \\
\text { of cells will increase } \\
\text { worker and public risk } \\
\text { of exposure to doping } \\
\text { sgents including As, } \\
\mathrm{Cd} \text {, and } \mathrm{Ga} \text {. }\end{array}$ & $\begin{array}{l}\text { Disposal and recycling } \\
\text { techniques }\end{array}$ & 3-A \\
\hline
\end{tabular}

a-cccupational, P-Public, C-Construction, t-Manufacture, OM-Operations and Maintenance, AD-Accidents and Disease, IR-Ionizing Radiation, ER-Electromagnetic Radiation.

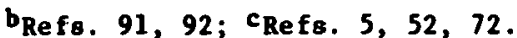


Table 4.22 Summary of Health and Safety Issues for Satellite Power System

\begin{tabular}{|c|c|c|c|c|c|c|c|}
\hline \multirow[b]{2}{*}{ Issue } & \multirow[b]{2}{*}{ Process } & \multicolumn{3}{|c|}{ Categorifs } & \multirow{2}{*}{$\begin{array}{l}\quad \text { Estimated } \\
\text { Impact per } 10,0 \\
\text { MW of Generation }\end{array}$} & \multirow[b]{2}{*}{ Uncertainties } & \multirow[b]{2}{*}{$\begin{array}{l}\text { Uncertainty } \\
\text { Rating }\end{array}$} \\
\hline & & $\begin{array}{l}\text { Af fected } \\
\text { Group }\end{array}$ & Phase & $\begin{array}{l}\text { Primary } \\
\text { Cause }\end{array}$ & & & \\
\hline $\begin{array}{l}\text { Occupational } \\
\text { accidents and } \\
\text { diseaseb }\end{array}$ & $\begin{array}{l}\text { [risect and indirect } \\
\text { material and component } \\
\text { fabrication }\end{array}$ & $: 0$ & $\mathrm{c}$ & $\mathbf{A D}$ & $\begin{array}{l}5.06-15.19 \text { deaths } \\
\text { (total) }\end{array}$ & $\begin{array}{l}\text { Changes in SPS conponents } \\
\text { and =hus in conventional } \\
\text { technology (e.g., mate- } \\
\text { rials extraction and } \\
\text { processing) may result } \\
\text { from SPS demand }\end{array}$ & 2 \\
\hline $\begin{array}{l}\text { Construction } \\
\text { accidents and } \\
\text { diseasec }\end{array}$ & $\begin{array}{l}\text { OEM cf groand launch } \\
\text { ard recove:y areas } \\
\text { dtring conistruction } \\
\text { phase; recienna con- } \\
\text { struction }\end{array}$ & c & c & $\because \quad \mathbf{A D}$ & $\begin{array}{l}0.72-1.11 \text { deaths } \\
\text { (total) }\end{array}$ & $\begin{array}{l}\text { Tota- and skill specific } \\
\text { labor requirements }\end{array}$ & 2 \\
\hline $\begin{array}{l}\text { Exposure to } S i \text { dust, } \\
\text { doping agents, } \\
\text { process chemicals }\end{array}$ & $\begin{array}{l}\text { Row material pro- } \\
\text { diction and manu- } \\
\text { facture of photo- } \\
\text { voltaic ceilis }\end{array}$ & $0, \mathbb{P}$ & c & $A D$ & $\begin{array}{l}\text { Potential exposure } \\
\text { to } \mathrm{Si} \text { dust, phcsgene, } \\
\mathrm{BCl}_{3} \text {, Cd, Ga, As, } \mathrm{HF} \text {, } \\
\mathrm{SnO}_{\mathrm{X}}, \mathrm{HH}_{3} \text {, pherols, } \\
\mathrm{CdO}_{2} \mathrm{ZSO}_{4}, \mathrm{Al}_{2} \mathrm{O}_{3} \text {, } \\
\text { and other processing } \\
\text { chemicals }\end{array}$ & $\begin{array}{l}\text { Emission levels, bio- } \\
\text { accunulation potentials } \\
\text { of released wastes, } \\
\text { volune of wastes }\end{array}$ & $3-A$ \\
\hline $\begin{array}{l}\text { Catastrophic Events } \\
\text { e.g., HLL.V mal- } \\
\text { functione }\end{array}$ & $\begin{array}{l}\text { Transportation of } \\
\text { materials end per- } \\
\text { soanel to low earth } \\
\text { orbit (LEO) }\end{array}$ & P. & $\mathrm{C}, \mathrm{OM}$ & $A D$ & $\begin{array}{l}\text { Maximum accident may } \\
\text { exceed } 1000 \text { fatali- } \\
\text { ties, Approximacely } \\
40 \text { flights per } 1000 \\
\text { MW capacity during } \\
\text { construction }\end{array}$ & $\begin{array}{l}\text { Probability of melfunc- } \\
\text { tion during launch and } \\
\text { navigation }\end{array}$ & $3-A$ \\
\hline $\begin{array}{l}\text { Public exposure to } \\
\text { fuel emissions, } \\
\text { noise fron HLLV }\end{array}$ & $\begin{array}{l}\text { Transportation of } \\
\text { materials and } \\
\text { personnel to LEO }\end{array}$ & 0 & $\mathrm{C}, \mathrm{OM}$ & $A D$ & $\begin{array}{l}95 \mathrm{dBa} \text { at } 6 \mathrm{~km} \text { furing } \\
\text { launch. Over-pressure } \\
\text { of sonic boom during } \\
\text { ascent and descent } \\
\text { sufficient to cause } \\
\text { nonprimary structural } \\
\text { damage at } 125 \mathrm{~km}\end{array}$ & $\begin{array}{l}\text { Dispersion patterns and } \\
\text { concentration of toxic } \\
\text { fuel components }\end{array}$ & $3-A$ \\
\hline $\begin{array}{l}\text { Occupational expo- } \\
\text { sure to noise, fuel } \\
\text { emissions, maifunc- } \\
\text { tions during HLLV } \\
\text { and PLV launch8 }\end{array}$ & $\begin{array}{l}\text { Transfortation of } \\
\text { materials and } \\
\text { personnel to LEO } \\
\text { and GEO }\end{array}$ & 0 & $\mathrm{C}, \mathrm{OM}$ & $A D$ & $\begin{array}{l}\text { Explosion of HLLV } \\
\text { could ignite com- } \\
\text { bustibles and cause } \\
\text { first degree burns at } \\
300 \mathrm{~m} \text {. Sound pressure } \\
\text { of HLLV launch exceeds } \\
\text { pain threshold }(130 \\
\text { lb) in launch area. }\end{array}$ & $\begin{array}{l}\text { Potential for exposure to } \\
\text { toxic chemicals; proba- } \\
\text { bilizy of system malfunc- } \\
\text { tion }\end{array}$ & $3-B$ \\
\hline
\end{tabular}

Oo-Occupational, P-Public: C-Construction, M-Manufacture, OM-Operations and Maintenance, AD-Accidents and Disease, IR-Ionizing Radiation,

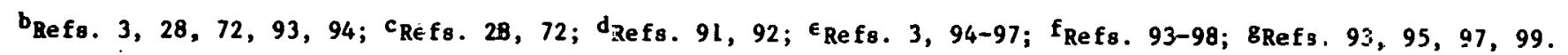


Table 4.22 (Cont'd)

\begin{tabular}{|c|c|c|c|c|c|c|c|}
\hline \multirow[b]{2}{*}{ Issue } & \multirow[b]{2}{*}{ Process } & \multicolumn{3}{|c|}{ Categories $^{a}$} & \multirow{2}{*}{$\begin{array}{l}\text { Estimated } \\
\text { Impact per } 1000 \\
\text { MW of Generation }\end{array}$} & \multirow[b]{2}{*}{ Uncertainties } & \multirow[b]{2}{*}{$\begin{array}{l}\text { Uncertainty } \\
\text { Rating }\end{array}$} \\
\hline & & $\begin{array}{l}\text { Af fected } \\
\text { Group }\end{array}$ & Phase & $\begin{array}{l}\text { Primary } \\
\text { Cause }\end{array}$ & & & \\
\hline $\begin{array}{l}\text { Stress of life in } \\
\text { space, accidents }\end{array}$ & $\begin{array}{l}\text { Construction of photo- } \\
\text { voltaic array and } \\
\text { microwave transmission } \\
\text { system }\end{array}$ & 0 & c & $A D$ & $\begin{array}{l}0.002-0.068 \text { deaths } \\
(\text { total })^{n}\end{array}$ & $\begin{array}{l}\text { Potential for system } \\
\text { malfunction events, } \\
\text { radiation exposure, and } \\
\text { vehicle collisions with } \\
\text { space debris. }\end{array}$ & 2 \\
\hline $\begin{array}{l}\text { Electromagnetic } \\
\text { radiation exposure, } \\
\text { accidents } i\end{array}$ & $\begin{array}{l}\text { Operation and mainten- } \\
\text { ance of photovoltaic } \\
\text { array and microwave } \\
\text { transmission system }\end{array}$ & 0 & OM & $A D$ & $0-0.003 \mathrm{deaths} / \mathrm{yr}^{\circ}$ & $\begin{array}{l}\text { Effects of high-energy } \\
\text { partic le exposure. Ef- } \\
\text { fects of chronic low- } \\
\text { level microwave exposure; } \\
\text { potential peak exposure } \\
2500 \mathrm{~mW} / \mathrm{cm}^{2} \text {. }\end{array}$ & 2 \\
\hline $\begin{array}{l}\text { Electromagnetic } \\
\text { radiat ion exposure, } \\
\text { chronic and acutej }\end{array}$ & $\begin{array}{l}\text { Operation and main- } \\
\text { tenance of microwave } \\
\text { transmission system }\end{array}$ & $\mathbf{P}$ & $O M$ & ER & $\begin{array}{l}\text { Effects of chronic } \\
\text { low-level exposure } \\
\text { unquantified }\end{array}$ & $\begin{array}{l}\text { Effects of large- } \\
\text { population exposure to } \\
\text { low levels of microwave } \\
\text { radiation. }\end{array}$ & 3-A \\
\hline $\begin{array}{l}\text { Electromagnetic } \\
\text { radiation exposurek }\end{array}$ & $\begin{array}{l}\text { Cperation and main- } \\
\text { tenance of ground } \\
\text { station rectennas }\end{array}$ & 0 & OM & $\mathbf{E R}$ & $\begin{array}{l}\text { Accidental exposures, } \\
\text { power beam reflec- } \\
\text { tions could result } \\
\text { in exposures of al- } \\
\text { most } 23 \mathrm{~mW} / \mathrm{cm}^{2} \text { under } \\
\text { normal operating } \\
\text { condit ions }\end{array}$ & $\begin{array}{l}\text { Effects of long-term } \\
\text { exposure to low levels } \\
\text { of microwaves and low- } \\
\text { frequency electro- } \\
\text { magnetic radiation. }\end{array}$ & $3-B$ \\
\hline $\begin{array}{l}\text { Conventional } \\
\text { occupational } \\
\text { accidents and } \\
\text { disease }\end{array}$ & $\begin{array}{l}\text { Operation and main- } \\
\text { tenance of ground } \\
\text { rectennas, launch } \\
\text { and recovery areas }\end{array}$ & $c$ & OM & $A D$ & $0.07-0.12$ deaths $/ y r$ & $\begin{array}{l}\text { Limited historical dáta } \\
\text { on space-travel support } \\
\text { requirements. }\end{array}$ & 2 \\
\hline $\begin{array}{l}\text { Acute exposure to } \\
\text { power beam }\end{array}$ & $\begin{array}{l}\text { Operation and main- } \\
\text { cenance of satellite } \\
\text { power system }\end{array}$ & $\mathbf{P}$ & OM & ER & $\begin{array}{l}\text { Current reference } \\
\text { design has low prob- } \\
\text { abilicy for acute } \\
\text { public exposure to } \\
\text { peak power beam } \\
\text { density of } 23 \mathrm{~mW} / \mathrm{cm}^{2}\end{array}$ & $\begin{array}{l}\text { Accessibility to sub- } \\
\text { version of beam-aiming } \\
\text { controls in final system } \\
\text { design; realiability of } \\
\text { directional system shut- } \\
\text { down controls. }\end{array}$ & 3-B \\
\hline
\end{tabular}

a-Occupational, P-Public, C-Construction, M-Meitufacture, OM-Operations and Maintenance, AD-Accidents and Disease, IR-Ionizing Radiation, ER-Electromagnet ic Radiation.

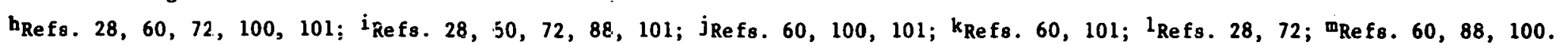

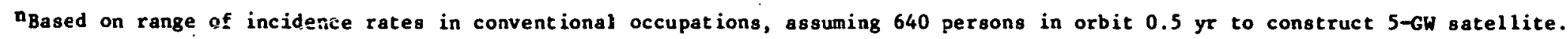

OBased on range of incidence rates in conventional occupations, assuming 1400-person maintenance crew in orbit for $300-\mathrm{GW}$ sytem. 
Table 4.23 Summary of Health and Safety Issues for the Fusion Power System

\begin{tabular}{|c|c|c|c|c|c|c|c|}
\hline \multirow[b]{2}{*}{ Is sue } & \multirow[b]{2}{*}{ Process } & \multicolumn{3}{|c|}{ Categories $^{a}$} & \multirow{2}{*}{$\begin{array}{l}\text { Est imated } \\
\text { Impact per } 100 C \\
\text { MW of Generation }\end{array}$} & \multirow[b]{2}{*}{ Uncertainties } & \multirow[b]{2}{*}{$\begin{array}{c}\text { Uncertainty } \\
\text { Rating }\end{array}$} \\
\hline & & $\begin{array}{l}\text { Af fected } \\
\text { Group }\end{array}$ & Phase & $\begin{array}{c}\text { Primary } \\
\text { Cause }\end{array}$ & & & \\
\hline $\begin{array}{l}\text { Safety of open pit } \\
\text { and brine pumping } \\
\text { operations }{ }^{b}\end{array}$ & $\begin{array}{l}\text { Lith ium ore extraction } \\
\text { and processing }\end{array}$ & 0 & OM & $A D$ & $\begin{array}{l}0.0018 \text { deaths and } \\
0.0068 \text { nonfatal acci- } \\
\text { dents per yr }\end{array}$ & $\begin{array}{l}\text { Injury and disease } \\
\text { incidence rates of } \\
\text { liticium ore extraction }\end{array}$ & 1 \\
\hline $\begin{array}{l}\text { Occupational health } \\
\text { and safetyc }\end{array}$ & $\begin{array}{l}\text { Material extraction } \\
\text { and fabrication of } \\
\text { strucsural components, } \\
\text { direct and indirect }\end{array}$ & 0 & c & $A D$ & $\begin{array}{l}1.83-5.53 \text { deaths } \\
(\text { total })\end{array}$ & $\begin{array}{l}\text { System design, size; } \\
\text { quantity and identity } \\
\text { of } 3 \text { tructural com- } \\
\text { ponents }\end{array}$ & 2 \\
\hline $\begin{array}{l}\text { Exposure to toxic } \\
\text { agent }(\mathrm{Be})^{\mathrm{d}}\end{array}$ & Companent fabrication & 0 & c & $A D$ & $\mathrm{TLV}_{\mathrm{i}}^{\mathrm{i}}$ for $\mathrm{me} \mathrm{m}^{3}$ : & $\begin{array}{l}\text { Satisfactory protection } \\
\text { by workplace exposure } \\
\text { stardards }\end{array}$ & $3-A$ \\
\hline $\begin{array}{l}\text { Low-level radio- } \\
\text { logical hazardse }\end{array}$ & $\begin{array}{l}\text { Fuel (tritium) prepa- } \\
\text { ration }\end{array}$ & 0 & OM & $A D$ & $\begin{array}{l}\text { Tritium required for } \\
\text { plant startup only }\end{array}$ & $\begin{array}{l}\text { Size of tritium produc- } \\
\text { tion facilities and } \\
\text { worker exposure levels }\end{array}$ & $3-B$ \\
\hline $\begin{array}{l}\text { Exposure to toxic } \\
\text { agent }\left(\mathrm{H}_{2} \mathrm{~S}\right) \mathrm{f}\end{array}$ & Fuel freparation & 0 & OM & $A D$ & $\begin{array}{l}\text { TLVi for } \mathrm{H}_{2} \mathrm{~S}: \\
15 \mathrm{mg} / \mathrm{m}^{3}\end{array}$ & $\begin{array}{l}\mathrm{Z}_{2} \mathrm{~s} \text { exposure specific } \\
\text { =0 the Girdler process } \\
\text { for deuterium extraction }\end{array}$ & $3-A$ \\
\hline $\begin{array}{l}\text { Low-level radiation } \\
\text { exposure. Exposure } \\
\text { to high-intensi=y } \\
\text { electromagentic } \\
\text { fields }\end{array}$ & Plant operation & $0, P$ & ом & IR, ER & $\begin{array}{l}\text { Maximum tritium dose } \\
\text { downwind of plant: } 1 \\
\text { rem/yt. Data on } \\
\text { electromagnetic field } \\
\text { inconclusive }\end{array}$ & $\begin{array}{l}\text { Tritium exposure level } \\
\text { inside of plant; health } \\
\text { effects of electromag- } \\
\text { netic fields }\end{array}$ & $3-B$ \\
\hline $\begin{array}{l}\text { Occupational acci- } \\
\text { dents and disease, } \\
\text { conventionalg }\end{array}$ & Plant operation & 0 & OM & $A D$ & $\begin{array}{l}0.034-0.055 \text { dezths } f \\
\mathrm{yr}\end{array}$ & Plant 0\&M requirements & 2 \\
\hline $\begin{array}{l}\text { Exposure to activa- } \\
\text { tion product } \mathrm{s}^{\mathrm{h}}\end{array}$ & $\begin{array}{l}\text { Waste disposal, } \\
\text { damage repair }\end{array}$ & $0, P$ & OM & IR & $\begin{array}{l}\text { Finite lifetime of } \\
\text { first wall and blan- } \\
\text { ket due to radiation } \\
\text { damage, nonvolatile } \\
\text { components }\end{array}$ & $\begin{array}{l}\text { Eotential for migration } \\
\text { cf wastes }\end{array}$ & 3-B \\
\hline
\end{tabular}

${ }^{a} 0$-Occupational, P-Public, C-Construction, H-Manufacture, OM-Operations and Maintenance, AD-Acciden:s and Disease, IR-Ionizing Radiation, ER-Electromagnetic Radiatior.

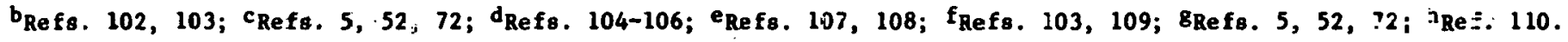

i TLV = threohold limit value. 
Table 4.23 (Cont'd)

\begin{tabular}{|c|c|c|c|c|c|c|c|}
\hline \multirow[b]{2}{*}{ Is sue } & \multirow[b]{2}{*}{ Process } & \multicolumn{3}{|c|}{ Categories ${ }^{a}$} & \multirow{2}{*}{$\begin{array}{l}\text { Estimated } \\
\text { Impact per } 1000 \\
\text { MW of Generation }\end{array}$} & \multirow[b]{2}{*}{ Uncertainties } & \multirow[b]{2}{*}{$\begin{array}{c}\text { Uncertainty } \\
\text { Rating }\end{array}$} \\
\hline & & $\begin{array}{l}\text { Af fected } \\
\text { Group }\end{array}$ & Phase & $\begin{array}{l}\text { Primary } \\
\text { Cause }\end{array}$ & & & \\
\hline Highway safetyj & $\begin{array}{l}\text { Transport of materials, } \\
\text { fuel, and waste }\end{array}$ & $\mathbf{P}$. & OM & $A D$ & $\begin{array}{l}\text { Truck transport: } \\
0.000128 \text { deaths and } \\
0.0011 \text { nonfatal acci- } \\
\text { denes/yr }\end{array}$ & $\begin{array}{l}\text { Amount and mode of re- } \\
\text { quired transportation }\end{array}$ & 2 \\
\hline $\begin{array}{l}\text { Low-level radia- } \\
t \text { ion exposure }\end{array}$ & $\begin{array}{l}\text { Transport of materials, } \\
\text { fue } 1 \text {, and waste }\end{array}$ & $0, \mathbf{P}$ & OM & IR & Unknown & $\begin{array}{l}\text { Amount and mode of re- } \\
\text { quired transportation }\end{array}$ & $3-B$ \\
\hline $\begin{array}{l}\text { Component failure, } \\
\text { plant safety, } \\
\text { liquid metal fires } \\
\text { and spills, pressure } \\
\text { and thermal explo- } \\
\text { gions, missile } \\
\text { generation due to } \\
\text { magnet or vacuum } \\
\text { failure }\end{array}$ & $\begin{array}{l}\text { Operation and } \\
\text { maintenance }\end{array}$ & 0 & OM & $A D$ & $\begin{array}{l}\text { Similar to other indus- } \\
\text { trial experience with } \\
\text { high-energy material }\end{array}$ & $\begin{array}{l}\text { System reliability and } \\
\text { likelihood of a fire } \\
\text { or explosion }\end{array}$ & 3-A \\
\hline $\begin{array}{l}\text { Occupational acci- } \\
\text { dents and diseasem }\end{array}$ & $\begin{array}{l}\text { On-site plant } \\
\text { construction }\end{array}$ & 0 & C & $\mathbf{A D}$ & $\begin{array}{l}3.80-5.95 \text { deaths } \\
(\operatorname{tot} a 1)\end{array}$ & $\begin{array}{l}\text { Personnel requirements } \\
\text { for materials and con- } \\
\text { struction }\end{array}$ & 2 \\
\hline $\begin{array}{l}\text { Radiation exposure } \\
\text { from activation } \\
\text { procluct } 8^{n}\end{array}$ & Plent deactivation & $\mathbf{0 , P}$ & . & IR & $\begin{array}{l}\text { Nonvolatile nature of } \\
\text { activation products } \\
\text { suggests a low level } \\
\text { of impact for this } \\
\text { issue }\end{array}$ & $\begin{array}{l}\text { Human response to } \\
\text { low-level exposure } \\
\text { uncertain. Probability } \\
\text { of exposure unknown }\end{array}$ & $3-B$ \\
\hline $\begin{array}{l}\text { Bigh-level radia- } \\
\text { tiom exposure }\end{array}$ & Catastrophic event & $0, \mathrm{P}$ & & IR & Unknown & $\begin{array}{l}\text { Likelihood of exposure } \\
\text { during such an event }\end{array}$ & $3-A$ \\
\hline
\end{tabular}

a-Occupational, P-Fublic, C-Construction, M-Manufacture, OM-Operations and Maintenance, AD-Accidents and Disease, IR-Ionizing Radiation, ER-Blectromagnetic Radiation.

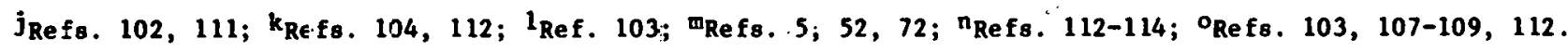


Table 4.24 Summary of Potentially Major but Unquantified Issues

\begin{tabular}{|c|c|}
\hline $\begin{array}{l}\text { Solar Technologies (TPV, SPS) } \\
\text { Exposure to Cell Production } \\
\text { Emissions }\end{array}$ & $\begin{array}{l}\text { Nuclear Technologies (LWR, LMFBR, Fusion) } \\
\text { System Failure with Major Public } \\
\text { Exposure to Radiation. }\end{array}$ \\
\hline $\begin{array}{l}\text { Hazardous Waste From Disposal or } \\
\text { Recycling of Cell Materials }\end{array}$ & $\begin{array}{l}\text { Occupational Exposure to Chemically } \\
\text { Toxic Materials during Fuel Cycle }\end{array}$ \\
\hline $\begin{array}{l}\text { Chronic Exposure of Large } \\
\text { Populations to Low-Level } \\
\text { Microwaves (SPS on } 1 \text { y) }\end{array}$ & $\begin{array}{l}\text { Diversion of Fuel or By-product for } \\
\text { Military or Subversive Uses (LWR, } \\
\text { LMFBR only) }\end{array}$ \\
\hline $\begin{array}{l}\text { Space Vehic1p Crash into Urban } \\
\text { Area (SPS only) }\end{array}$ & Liquid Metal Fire (LMFBR, Fusiun only) \\
\hline \multicolumn{2}{|l|}{$\begin{array}{l}\text { Exposure to Rocket Exhaust } \\
\text { Emissions from HLLV (SPS only) }\end{array}$} \\
\hline oal Tecl & \\
\hline (None Identified) & . \\
\hline
\end{tabular}

impact probability cannot be given. For this reason potentially major, but unquantified, risks should be given prominence comparable to the quantified risks discussed above. Table 4.24 is a listing of potentially major (Category A) but unquantified issues identified for the six technologies considered.

Estimates of expected health and safety impact levels have been developed for certain catastrophic events (i.e., events with low probability of occurrence but high impact per event), in particular, for fission reactor systems.115 However, these impacts were not included as quantified issues in this study because of inherently high uncertainties ascociated with predicting occurrence rate and impact per occurrence. Furthermore, averaging expected catastrophic impacts over plant lifetime does not indicate the full significance of these potential events. The issues of potential diversion of fission fuel for weapons use and the potential for a crash of a SPS spacetransport vehicle into an urban area are also included in the potential catastrophic event category. Through engineered safeguards, the probability of occurrence of these events can be reduced to very low levels, but essentially zero probability is very difficult if not impossible to achieve at reasonable cost.

A further important distinction concerning unquantified issues is whether the potentially affected persons are part of the general public or are workers producing or operating the system. Issues in the latter category (e.g., emissions from solar cell production, emissions of toxic materials from the fission system fuel cycle, liquid-metal fire hazards in the LMFBR and fusion systems) affect a wel1-defined group, i.e., occupational workers, and those impacts $c$ an be more easily monitored and mitigating actions implemented. In contrast, impacts from low-level microwave radiation, if they exist, may be difficult to identify because of their potentially small and subtle effects on a large exposed group. 
In general, the better-defined technologies (e.g., CG/CC, LWR) have a greater number of quantifiablé risks and fewer unquantifiable risks. The opposite is true for the less-defined technologies (e.g., fusion, SPS). Table 4.24 does not attempt to rank the unquantified issues, although, for example, potential radiation release from $f$ ission is expected to be greater than that from fusion. 108

Cumulative Risks From National Energy Scenarios. A further perspective on the significance of relative technology risks is provided by Fig. 4.32, which indicates the range of annual occupational risks for scenarios of energy production in 2000-2020 with and without the SPS system. A nearly constant total electrical energy generation is assumed in this period for the scenarios (Table 4.25). The SPS units were assumed to operate at the design load factor of $90 \%$. However, because of the large SPS unit size ( $5000 \mathrm{MW}$ ), it is assumed that because of reliability requirements, the overall capacity, including conventional technologies, is the same for the SPS scenario as for the non-SPS scenario in which the overall load factor was assumed to be $70 \%$. In the SPS scenario, the non-SPS technologies serve in part as back-up for the SPS and operate at less than $70 \%$ load factor.

Because of high construction and manufacturing impacts, the sPS scenario has a higher initial value for the mean occupational health and safety risks. By 2020 , in this scenario, these occupational risks have dropped to nearly the same values as those for the non-SPS scenario.

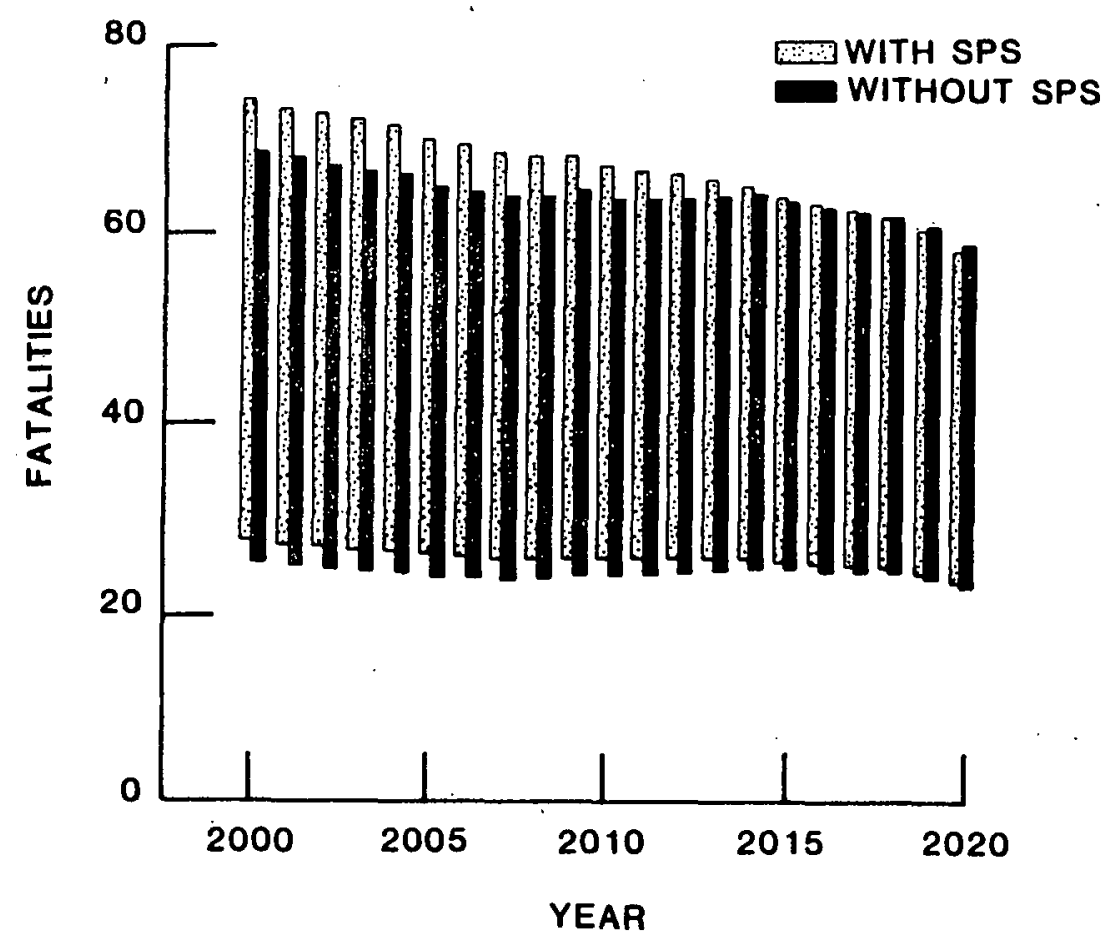

Fig. 4.32 Annual Occupational Fatalities from Construction and O\&M in Baseload Scenarios with and without SPS 
Table 4.25 Scenario Baseload Capacities and Electrical Generation

\begin{tabular}{|c|c|c|c|c|c|c|c|c|}
\hline \multirow[b]{2}{*}{ Year } & \multicolumn{7}{|c|}{ Capacity (GW) } & \multirow{2}{*}{$\begin{array}{c}\text { Total } \\
\text { Generat ion } \\
(\mathrm{GW}-\mathrm{yr})\end{array}$} \\
\hline & LWR & $\mathrm{CG} / \mathrm{CC}$ & LMFBR & SPS & TPV & Fusion & Total & \\
\hline 2000 & 263 & 238 & 34 & 0 & 0 & 0 & 535 & 375 \\
\hline 2020 (SPS) & 199 & 145 & 96 & 100 & 29 & 19 & 578 & 405 \\
\hline $\begin{array}{l}2020 \\
\quad \text { (No SPS) }\end{array}$ & 213 & 159 & 140 & 0 & 29 & 37 & 578 & 405 \\
\hline
\end{tabular}

The addition of quantified public risks to the occupational risks in Fig. 4.32, in particular those from coal, would favor the SPS scenario with reduced conventional generation. However, the unquantified risks to the public in Table 4.24 restrict the delineation of definitive conclusions related to total scenario risks.

Conclusions. Under the assessment taxonomy and the assumptions described in this report, the coal technology appears to have the largest overall quantified risk of the various systems considered, primarily due to coal extraction, processing and transport, and air pollution, although large uncertainties remain in the actual effect of the air pollution. On the other hand, no additional issues were identified for the coal system that are potentially major but remain largely unquantifiable. Quantified risks from the remaining technologies (fission, fusion, SPS, and centralized TPV) are comparable within the "range of quantified uncertainty. The occupational $r$ isks for component production, both direct and indirect, are a substantial fraction of the total risk, in particular for the advanced, capital-intensive solar and fusion technologies.

of potential major significance for public acceptance of new energy systems, but not included in the quantification,. is the possibility of catastrophic incidents that exist for the fission and fusion systems. Unique, unquantified possibilities of catastrophic incidents also exist for the SPS, in relation to the use of microwave transmission of energy and extensive space trave 1 .

\subsection{ENVIRONMENTAL WELFARF: FTFECTS}

\subsubsection{Introduction}

Several types of effecls from environimental degradation that are not directly related to public or occupational health and safety will be referred to as environmental welfare effects, since they concern the well-being of individuals. For example, deterioration of building materials from $\mathrm{SO}_{2}$ emissions, reduced crop productivity due to water pollution, and aesthetic impacts such as plumes from stacks and cooling towers are considered. This evaluation of coal (conventional coal and CG/CC), nuclear (LWR, LMFBR, and fusion), and solar (TPV and the GaAlAs version of SPS) systems identifies the 
extent and severity of these welfare effects and develops a set of priority effects that require more in-depth analysis. Specifically excluded from this category are effects on health and safety, natural biological systems, resource depletion (including direct land and water use), and social and economic dislocations. Conditions following accidents were also not included in this study.

The sequencel16 for determining the environmental welfare effects of each energy technology begins with an examination of the various activities involved in each fuel cycle, starting with the extraction of the resource and extending to the delivery of electricity to a utility grid. These activities result in environmental impacts such as noise and air and water pollution. In turn, the environmental impacts could result in welfare effects such as property damage, climatic change, interference with other activities, and aesthetic disturbances. This activity-impact-effect chain is illustrated in Fig. 4.33. The structure is used for: categorizing the impacts and effects of the various activities in the fuel cycle.

The physical environmental impacts and their effects caused by the various activities associated with selected coal, nuclear, and solar technol'ogies are listed in Tables 4.26-4.32.

\subsection{2 . Comparative Impacts}

The wielfare effect of each energy-related activity is examined in the context of, the additional bur:den imposed on a community by that activity. Typical facility sizes -- for a mine, processing plant, or power plant -are used whenever possible as a basis for determining local welfare effects (the assimed facility sizes represent current opinion regarding the most likely urit sizes to be constructed in the near future). The welfare effects are not. scaled to a common metric, such as cost or impact per 1,000 MW of electrical capacity. Use of a common metric tends to obscure information because of the need to introduce various assumptions in converting impacts to a single unit of measure. The approach used in this assessment takes into accoun't the fact that smali, dispersed power plants often have smaller local welfare effects than would a large centralized facility, even though the quantity of emissions, per megawat of electricity generated may be smaller for the larger facility and the larger facility could more easily be sited in an isolated area. At the same time, it is recognized that many minor impacts may have a cumulative impact that could equal or exceed a major impact from a single, large facility. Other assumptions that underlie this analysis ar:e that all activities use advanced pollution control technology representa$t$ ive of newer facilities and that facilities operate routinely (that is, without accidents).

The environmental welfare impact of each activity was quantified by the magnitude of some physical effect (e.g., noise level), and its capacity to be mitigated was evaluated. It is thought that this approach provides a qualitative judgment that reflects, the more recent trends in emissions and anticipated effects. Direct comparison between technologies tends to obscure the welfare issues associated wich each energy technology and was therefore avoided. 
ACTIVITY

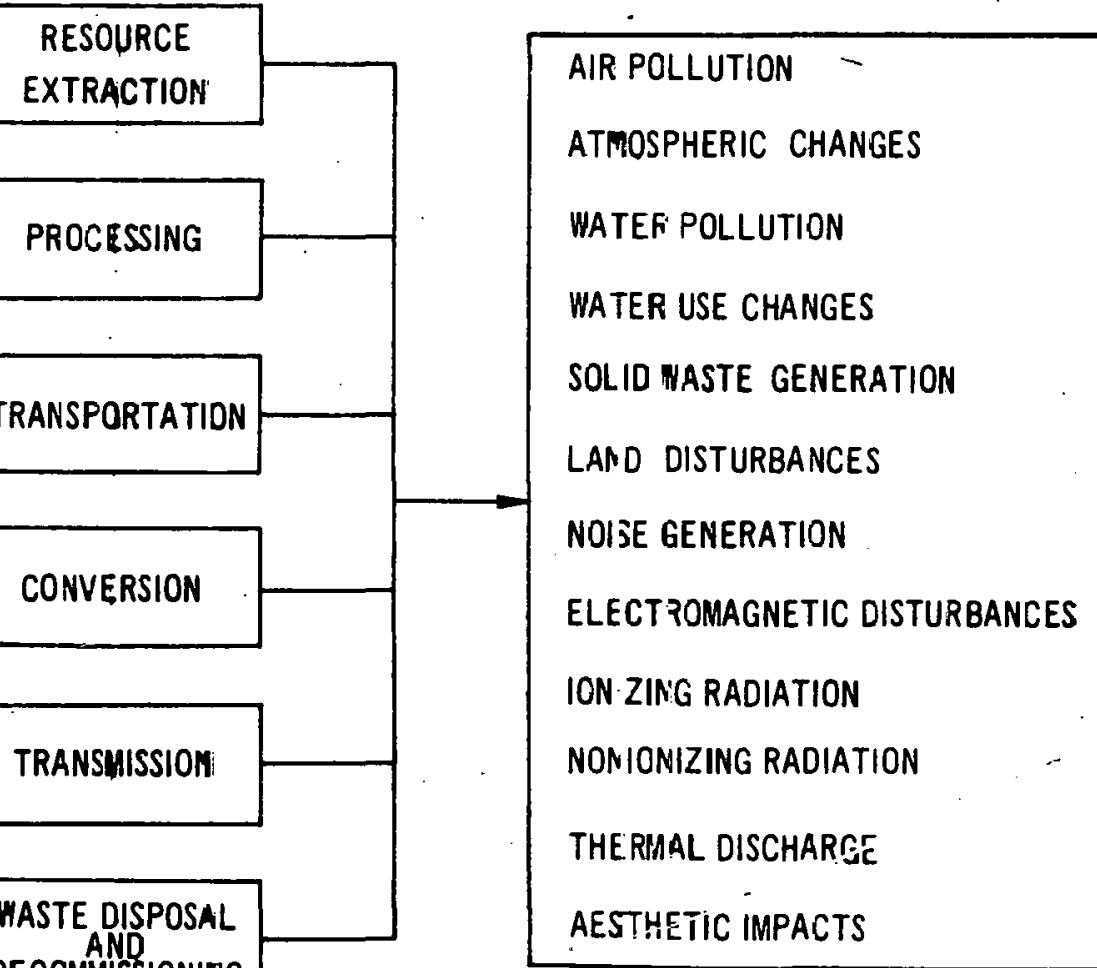

RESOURCE

DECOMMSSHONIIG

ENVIRONMENTAL IMPACT
WELFARE EFFECTS

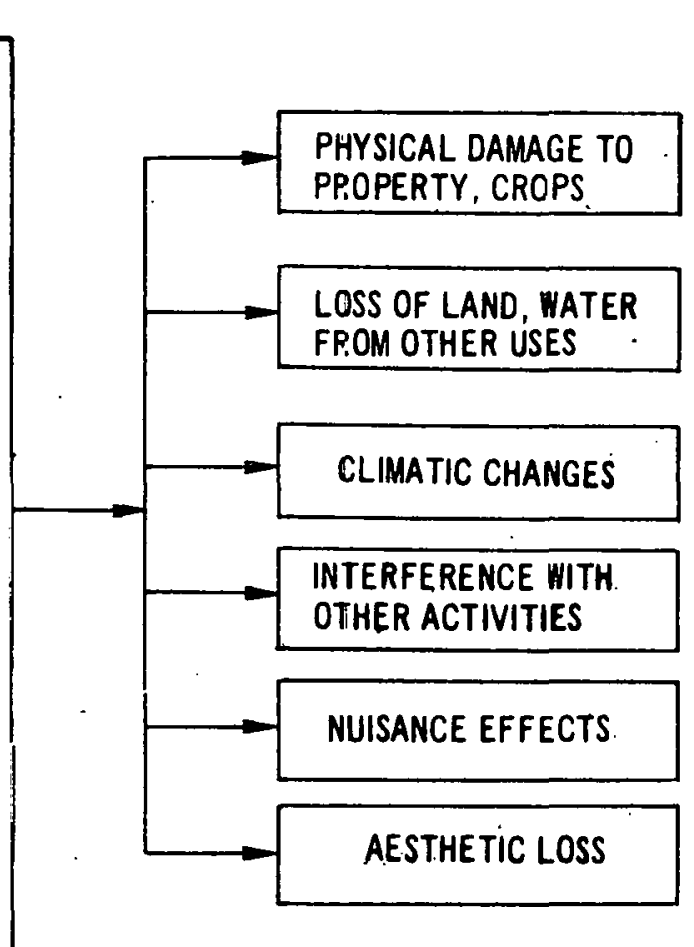

Fig. 4.33 Pathway of Energy Activities, Impacts, and Effects 
Table 4.26 Welfare Effects of a Conventional Coal Fuel Cyclea

\begin{tabular}{|c|c|c|}
\hline Environmental Impact & Activities Involved & Welfare Effects \\
\hline Air Pollution & $\begin{array}{l}\text { Mining } \\
\text { Processing } \\
\text { Transportation } \\
\text { Power generation }\end{array}$ & $\begin{array}{l}\text { Emissions of } \mathrm{SO}_{2} \text { and } \mathrm{NO}_{x} \text { from power generation can } \\
\text { lead to acid rainfall, which can reduce crop yield and } \\
\text { yield and remove lakes or rivers from commercial or } \\
\text { recreational use. Emissions of } \mathrm{SO}_{2} \text { and particulates } \\
\text { can cause or augment material damege and reduce crop } \\
\text { yields. Secondary particulates can impair visibility. } \\
\text { bility. }\end{array}$ \\
\hline Atmospheric Changes & Power generation & $\begin{array}{l}\text { Injection of large amounts of } \mathrm{CO}_{2} \text { and other green- } \\
\text { house gases into.the atmoshere may promote global } \\
\text { warming, with effects on precipitation, agriculture, } \\
\text { and ocean levels. Particulate emissions may also play } \\
\text { a minor role in climatic change. }\end{array}$ \\
\hline Thermal Discharges & Power generation & $\begin{array}{l}\text { Cooling tower operation can increase local fogging } \\
\text { and icing, with effects on visibility, traffic, and } \\
\text { convenience for nearby residents. cloud and precipi- } \\
\text { tation augmentation is possible but should be minor, } \\
\text { with little effect on crop productivity. }\end{array}$ \\
\hline Water Pollution & $\begin{array}{l}\text { Mining } \\
\text { Processing } \\
\text { Power generation }\end{array}$ & $\begin{array}{l}\text { Discharges of acids, dissolved solids, suspended } \\
\text { solids, and other chemicals can degrade drinking water } \\
\text { supplies, contaminate waterways, lower crop productiv- } \\
\text { ity because of acidified irrigation or ground water, } \\
\text { and reduce commercial and recreational use of streams } \\
\text { and lakes. }\end{array}$ \\
\hline Water Use & $\begin{array}{l}\text { Mining } \\
\text { Processing } \\
\text { Power generation }\end{array}$ & $\begin{array}{l}\text { Mining can disrupt water flow patterns. Cooling needs } \\
\text { during power production require extensive amounts of } \\
\text { water if evaporative systems are used. Both impacts } \\
\text { can conflict with downstream and competing uses. }\end{array}$ \\
\hline Solid Waste & $\begin{array}{l}\text { Mining } \\
\text { Processing } \\
\text { Power generation }\end{array}$ & $\begin{array}{l}\text { Demand for disposal sites can be increased. Land } \\
\text { use, value, and productivity can be reduced by over- } \\
\text { burden and refuse from mining and processing, ash and } \\
\text { scrubber wastes, and by hazardous trace metals from } \\
\text { cosl. }\end{array}$ \\
\hline Land Use Disturbance & $\begin{array}{l}\text { Mining } \\
\text { Processing } \\
\text { Transportation } \\
\text { Power generation } \\
\text { Transmission }\end{array}$ & $\begin{array}{l}\text { Surface mining and power generation (waste disposal) } \\
\text { remove land from alternate uses; reclaimed land may } \\
\text { be less productive agriculturally than before mining. } \\
\text { Subsidence of land over underground mines can reduce } \\
\text { land values; damage crops, buildings, and livestock; } \\
\text { rupture pipes; and distupt drainage. Coal processing } \\
\text { can contaminate and lower value of surrounding land. } \\
\text { Transportation and transmisaion land requirements are } \\
\text { significant and limit other uses of the land. }\end{array}$ \\
\hline $\begin{array}{l}\text { Electromagnet ic } \\
\text { Disturbances }\end{array}$ & Transmisgion & $\begin{array}{l}\text { High intensity magnetic fields around transmission } \\
\text { lines can cause radio and TV interference in fringe } \\
\text { reception areas. }\end{array}$ \\
\hline Ionizing Radiation & Power generation & $\begin{array}{l}\text { Small quantities of radioactive materials are emitted } \\
\text { during coal combustion. Welfare effects of these } \\
\text { emissions, which are uncertain, include effects of } \\
\text { long-term exposure of crops and livestock to radiation. }\end{array}$ \\
\hline Noise & $\begin{array}{l}\text { Mining } \\
\text { Transportation } \\
\text { Power generation } \\
\text { Trangmisaion }\end{array}$ & $\begin{array}{l}\text { Welfare impacts of noise generation from most coal- } \\
\text { related activities are relatively minor due to the } \\
\text { remote locations of the operations. Audible hum from } \\
\text { high-voltage transmission lines may occur. }\end{array}$ \\
\hline $\begin{array}{l}\text { Aesthet ic } \\
\text { Disturbances }\end{array}$ & $\begin{array}{l}\text { Mining } \\
\text { Processing } \\
\text { Transportation } \\
\text { Power generat ion } \\
\text { Transmission }\end{array}$ & $\begin{array}{l}\text { Visual impacts will occur from mines, tailing piles, } \\
\text { power plants, stack plumes, and transmission corridors. }\end{array}$ \\
\hline
\end{tabular}

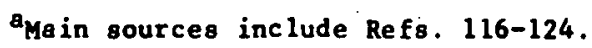


Table 4.27 Welfare Effects of a Light Water Reactor Fuel Cyclea

\begin{tabular}{|c|c|c|}
\hline Environmental Impact & Activities Involved & Welfare Effect \\
\hline Air Pollution & $\begin{array}{l}\text { Mining } \\
\text { UF }_{6} \text { production } \\
\text { Enrichment } \\
\text { Fuel fabrication } \\
\text { Transportation } \\
\text { Power generat ion } \\
\text { Reprocessing }\end{array}$ & $\begin{array}{l}\text { Fluorine and sulfuric acid emissions could damage live- } \\
\text { stock, grazing land, and crops. Other air pollutants } \\
\text { are emitted from coal plants, which may be used to } \\
\text { supply process power. }\end{array}$ \\
\hline Thermal Discharges & $\begin{array}{l}\text { Enrichment } \\
\text { Power generation } \\
\quad:\end{array}$ &  \\
\hline Water Pollution & $\begin{array}{l}\text { Mining } \\
\text { Milling } \\
\text { UF } 6 \text { production } \\
\text { Enrichment } \\
\text { Fuel fabrication } \\
\text { Puwer generation } \\
\text { Reprocessing }\end{array}$ & $\begin{array}{l}\text { Process effluents can on occasion degrade drinking } \\
\text { water supplies; degrade irrigation water, impairing } \\
\text { crop growth; and reduce commercial and recreational } \\
\text { use. }\end{array}$ \\
\hline Water Use Changes & $\begin{array}{l}\text { Mining } \\
\text { Power generation } \\
\text { Enrichment }\end{array}$ & $\begin{array}{l}\text { Mining operations can disrupt water flow. Cooling needs } \\
\text { during power production require extensive amounts of } \\
\text { water if evaporative systems are used; uranium enrich- } \\
\text { ment also has significant water requirements. All three } \\
\text { impacts can conflict with downstream uses. }\end{array}$ \\
\hline Sol id Waste & $\begin{array}{l}\text { Mining } \\
\text { Milling } \\
\text { UF } 6 \text { production } \\
\text { Fuel fabrication }\end{array}$ & $\begin{array}{l}\text { Release of trace elements into terrestrial ecosystems } \\
\text { may locally reduce crop productivity. Lateral and up- } \\
\text { ward movement of leachates may contaminate rooting } \\
\text { zones of otherwise productive cropland. }\end{array}$ \\
\hline Land Use Disturbance & $\begin{array}{l}\text { Mining } \\
\text { Pnrirhment } \\
\text { Reprocessing } \\
\text { Decomissioning }\end{array}$ & $\begin{array}{l}\text { Agrlculturial use ot reslaimed mines may be less pro- } \\
\text { duotivo. Bmuluoion sones around em iclueul aul te- } \\
\text { processing plants remove land from other uses, whereas } \\
\text { burial of nuclear wastes may remove all further use of } \\
\text { land involved. }\end{array}$ \\
\hline $\begin{array}{l}\text { Electromagnetic } \\
\text { Disturbances }\end{array}$ & Transmission & $\begin{array}{l}\text { High intensity magnetic fields around transmission lines } \\
\text { can cause radio and } \mathrm{TV} \text { interference in fringe-reception } \\
\text { areas. }\end{array}$ \\
\hline Ionizing Radiation & $\begin{array}{l}\text { Mining } \\
\text { Milling } \\
\text { Conversion } \\
\text { Enrichment } \\
\text { Fuel fabrication } \\
\text { Pulwer generac Ion } \\
\text { Reprocessing }\end{array}$ & $\begin{array}{l}\text { Low-level radiation emissions could act as an extremely } \\
\text { low-level mutating agent for crops and livestock. Know- } \\
\text { ledge of a threshold level for adverse effects from } \\
\text { ionizing radiarinn is uncertain. }\end{array}$ \\
\hline No ise & $\begin{array}{l}\text { Mining } \\
\text { Power generation } \\
\text { Transaission }\end{array}$ & $\begin{array}{l}\text { No major effects. High-voltage transmission lines } \\
\text { create a barely audible hum. }\end{array}$ \\
\hline $\begin{array}{l}\text { Aesthet ir. } \\
\text { Disturbances }\end{array}$ & $\begin{array}{l}\text { Mining } \\
\text { Power generation } \\
\text { Transmission }\end{array}$ & $\begin{array}{l}\text { Acsthetic degradation due lu mines, cuoling tower } \\
\text { plumes, transmission corridors. }\end{array}$ \\
\hline
\end{tabular}

${ }^{8}$ Main sources include Refs. 20,116, 117, 120, 125-129. 
Table 4.28 Welfare Effects of a Coal-Gasification/ Combined-Cycle Fuel Cycle ${ }^{a}$

\begin{tabular}{|c|c|c|}
\hline Environmental Impact & Activities Involved & Welfare Effects \\
\hline Air Pollution & $\begin{array}{l}\text { Mining } \\
\text { Processing } \\
\text { Transportation } \\
\text { Power generation }\end{array}$ & $\begin{array}{l}\text { Emissions of } \mathrm{SO}_{2} \text { and } \mathrm{NO}_{\mathrm{x}} \text { greatly reduced by } \mathrm{CG} / \mathrm{CC} \\
\text { compared to the conventional coal-fuel cycle. These } \\
\text { emissions do contribute to acid rainfall, which can } \\
\text { reduce crop yield and remove lakes or rivers from } \\
\text { commercial or recreational use. Emissions of } \mathrm{SO}_{2} \text { and } \\
\text { particulates can cause or augment material damage and } \\
\text { reduce crop yields. Secondary particulates can } \\
\text { impair visibility. }\end{array}$ \\
\hline Atmospheric Changes & Power generation & $\begin{array}{l}\text { Injection of large amounts of } \mathrm{CO}_{2} \text { and other green- } \\
\text { house gases into the atmosphere may promote global } \\
\text { warming, with effects on precipitation, agriculture, } \\
\text { and ocean levels. Particulate emissions may also } \\
\text { play a minor role in climatic change. }\end{array}$ \\
\hline Thermal Discharges & Power generation & $\begin{array}{l}\text { Cooling tower operation can increase local fogging } \\
\text { and icing, with effects on visibility, traffic, and } \\
\text { convenience for nearby residents. cloud and precipi- } \\
\text { tation augmentation is possible but should be minor, } \\
\text { with little effect on crop productivity. }\end{array}$ \\
\hline Water Pollution & $\begin{array}{l}\text { Mining } \\
\text { Processing } \\
\text { Power generation }\end{array}$ & $\begin{array}{l}\text { Discharges of acids, dissolved solids, suspended } \\
\text { solids, and other chemicals can degrade drinking } \\
\text { water supplies, contaminate waterways, lower crop } \\
\text { productivity because of ac idified irrigation or } \\
\text { ground water, and reduce commercial and recreational } \\
\text { use of streams and lakes. }\end{array}$ \\
\hline Water Use & $\begin{array}{l}\text { Mining } \\
\text { Processing } \\
\text { Power generation }\end{array}$ & $\begin{array}{l}\text { Mining can disrupt water flow patterns. Cooling } \\
\text { needs during power production require extensive } \\
\text { amounts of water if evaporative systems are used. } \\
\text { Both impacts can conflict with downstream and } \\
\text { competing uses. }\end{array}$ \\
\hline Solid Waste & $\begin{array}{l}\text { Mining } \\
\text { Processing } \\
\text { Power generation }\end{array}$ & $\begin{array}{l}\text { Demand for disposal sites can be increased. Land } \\
\text { use, value, and productivity can be reduced by over- } \\
\text { burden and refuse from mining and processing, ash } \\
\text { and scrubber wastes, and by hazardous trace metals } \\
\text { from coal. Ash wastes are about } 25 \% \text { less than those } \\
\text { for the conventional coal fuel cycle. }\end{array}$ \\
\hline Land Use Disturbance & $\begin{array}{l}\text { Mining } \\
\text { Processing } \\
\text { Transportation } \\
\text { Power generat ion } \\
\text { Transmission }\end{array}$ & $\begin{array}{l}\text { Surface mining and power generation (waste disposal) } \\
\text { remove land from alternate uses; reclaimed land may } \\
\text { be less productive agriculturally than before mining. } \\
\text { Subsidence of land over underground mines can reduce } \\
\text { land values; danage crops, buildings, and livestock; } \\
\text { rupture pipes; and disrupt drainage. Coal process- } \\
\text { ing can contarinate and lower value of surround- } \\
\text { ing land. Transportation and transmission land re- } \\
\text { quirements are significant and limit other uses of } \\
\text { the land. }\end{array}$ \\
\hline $\begin{array}{l}\text { Electromagnet ic } \\
\text { Disturbances }\end{array}$ & Transmission & $\begin{array}{l}\text { High intensity magnetic fields around transmission } \\
\text { lines can cause radio and TV interference in fringe } \\
\text { reception areas. }\end{array}$ \\
\hline Ionizing Radiation & Power generation & $\begin{array}{l}\text { Sms ll quantities of radioactive materials are emitted } \\
\text { during coal combustion. Welfare effects of these } \\
\text { emissions, which are uncertain, include effects of } \\
\text { long-term exposure of crops and livestock to radiation. }\end{array}$ \\
\hline No ise & $\begin{array}{l}\text { Mining } \\
\text { Transportation } \\
\text { Power generation } \\
\text { Transmission }\end{array}$ & $\begin{array}{l}\text { Welfare impacts of noise generation from most coal- } \\
\text { related activities are relatively minor due to the } \\
\text { remote locations of the operations. Audible hum from } \\
\text { high-voltage transmission lines may occur. }\end{array}$ \\
\hline $\begin{array}{l}\text { Aesthet ic } \\
\text { Disturbances }\end{array}$ & $\begin{array}{l}\text { Mining } \\
\text { Processing } \\
\text { Transportation } \\
\text { Power generation } \\
\text { Transmission }\end{array}$ & $\begin{array}{l}\text { Visual, impacts will occur from mines, tailing piles, } \\
\text { power plants, stack plumes, and transmission corridors. }\end{array}$ \\
\hline
\end{tabular}

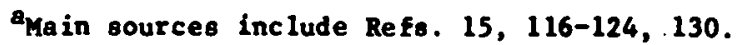


Table 4.29 Welfare Effects of a Liquid-Metal, Fast-Breeder Reactor Fuel Cyclea

\begin{tabular}{|c|c|c|}
\hline Environmental Impact & Activities Involved & Welfare Effect \\
\hline Air Pollution & $\begin{array}{l}\text { Fuel fabrication } \\
\text { Transportation } \\
\text { Power generation } \\
\text { Reprocessing }\end{array}$ & $\begin{array}{l}\text { Air pollutants are emitted from coal plants } \\
\text { which may be used to supply process power. }\end{array}$ \\
\hline Thermal Discharges & Power generation & $\begin{array}{l}\text { Cooling tower operation can increase local } \\
\text { fogging and icing with effects on visibility, } \\
\text { traffic, and convenience for nearby resi- } \\
\text { dents. cloud and precipitation augmentation } \\
\text { is possible, but should be minor, with little } \\
\text { effect on crop productivity. Nuclear power } \\
\text { parks would release much more heat than } \\
\text { silly le puwe platsly, but such parks would } \\
\text { probably be sited in lightly populated areas. }\end{array}$ \\
\hline Water Pollution. & $\begin{array}{l}\text { Fuel tabrication } \\
\text { Power generation } \\
\text { Reprocessing }\end{array}$ & $\begin{array}{l}\text { Process effluents can on occasion degrade } \\
\text { drinking water supplies; degrade irrigation } \\
\text { water, impairing crop growth; and reduce } \\
\text { commercial and recreational use. }\end{array}$ \\
\hline Water Use Changes & Power generation & $\begin{array}{l}\text { Cooling needs during power production require } \\
\text { extensive amounts of water if evaporative } \\
\text { systems are used and can conflict with down- } \\
\text { stream uses. }\end{array}$ \\
\hline Solid Waste & Fuel fabrication & $\begin{array}{l}\text { Small releases of trace elements into terres- } \\
\text { trial ecosystems may locally reduce crop. } \\
\text { productivity. }\end{array}$ \\
\hline Land Use Disturbance & $\begin{array}{l}\text { Reprocessing } \\
\text { Decomissioning }\end{array}$ & $\begin{array}{l}\text { Exclusion zones around reprocessing plants } \\
\text { remove land from other uses, whereas burial } \\
\text { of low-level nuclear wastes may remove all } \\
\text { further use of land involved. }\end{array}$ \\
\hline $\begin{array}{l}\text { Electromagnetic } \\
\text { Disturbances }\end{array}$ & Transmission & $\begin{array}{l}\text { High inţensity magnetic fields around trans- } \\
\text { mission lines can cause radio and TV inter- } \\
\text { foronco in fringo-roogtion aroao. }\end{array}$ \\
\hline Ionizing Radiation & $\begin{array}{l}\text { Fuel fabrication } \\
\text { Power generation } \\
\text { Reprocessing }\end{array}$ & $\begin{array}{l}\text { Low-level radiation emissions could act as an } \\
\text { extremely low-level mutating agent for crops } \\
\text { and livestock. Knowledge of a threshold } \\
\text { level for adverse effects from ionizing radi- } \\
\text { ation is uncertain. }\end{array}$ \\
\hline Noise & $\begin{array}{l}\text { Power generation } \\
\text { Transmission }\end{array}$ & $\begin{array}{l}\text { No major effects: High-voltage transmission } \\
\text { lines create a barely audible hum. }\end{array}$ \\
\hline $\begin{array}{l}\text { Aesthet ic } \\
\text { Disturbances }\end{array}$ & $\begin{array}{l}\text { Power generation } \\
\text { Transmission }\end{array}$ & $\begin{array}{l}\text { Aesthet ic degradarinn due to rnnling tower } \\
\text { plumes and transmission corridors. }\end{array}$ \\
\hline
\end{tabular}

${ }^{a}$ Main sources include Refs. 23, 110, 116, 120, 131-133. 
Table 4.30, Welfare Effects of a Terrestrial Photovoltaic Fuel Cyclea

\begin{tabular}{|c|c|c|}
\hline Environmental Impact & Activities Involved & Welfare Effects \\
\hline Air Pollution & $\begin{array}{l}\text { Mining } \\
\text { Manufacturing } \\
\text { Construction } \\
\text { Transportation }\end{array}$ & $\begin{array}{l}\text { Solar cell manufacturing may produce toxic } \\
\text { emissions -- exact emissions and welfare } \\
\text { effects are unknown. Environmental prob- } \\
\text { blems from fugitive dust from mining and } \\
\text { construction could occur -- welfare effects } \\
\text { are not expected to be as severe as those. } \\
\text { of toxic emissions. }\end{array}$ \\
\hline Atmospheric Changes & Solar Collectors & Negligible effects on climate likely. \\
\hline Water Pollution & $\begin{array}{l}\text { Mining } \\
\text { Manufacturing }\end{array}$ & $\begin{array}{l}\text { Water pollutants generated by conventional } \\
\text { mining and manufacturing activities could. } \\
\text { degrade drinking water supplies and cause } \\
\text { reduced commercial and recreational yield } \\
\text { in affected waters. }\end{array}$ \\
\hline Water Use & $\begin{array}{l}\text { Mining } \\
\text { Manufacturing } \\
\text { Construction }\end{array}$ & $\begin{array}{l}\text { Mining of materials could disrupt aquifers } \\
\text { and bodies of water; impacts unknown. }\end{array}$ \\
\hline Solid Waste & $\begin{array}{l}\text { Mining } \\
\text { Manufacturing }\end{array}$ & $\begin{array}{l}\text { Mine tailings and residuals from photo- } \\
\text { voltaic cell manufacturing could increase } \\
\text { demand for disposal sites. Toxic manufac- } \\
\text { turing wastes could reduce productivity. } \\
\text { and use fulness of land to some degree. }\end{array}$ \\
\hline Land Use Disturbance & $\begin{array}{l}\text { Mining } \\
\text { Solar Collectors } \\
\text { Transmission }\end{array}$ & $\begin{array}{l}\text { Mining operations and solar collector sites } \\
\text { remove large parcels of land from alternate } \\
\text { uses. Post-mining agricultural use of } \\
\text { reclaimed areas may be less productive. } \\
\text { Large solar collector sites could require } \\
\text { relocation of homes, roads, and right-of- } \\
\text { ways and inconvenience persons having to } \\
\text { drive around an area that they formerly } \\
\text { could drive through. }\end{array}$ \\
\hline $\begin{array}{l}\text { Electromagnet ic } \\
\text { Disturbance }\end{array}$ & Transmission & $\begin{array}{l}\text { Power transmission can effect fringe TV and } \\
\text { radio reception. }\end{array}$ \\
\hline Noise & Transmission & $\begin{array}{l}\text { No major effects. High voltage transmis- } \\
\text { sinn lines create a barely audible hum. }\end{array}$ \\
\hline $\begin{array}{l}\text { Aesthetic } \\
\text { Disturbances }\end{array}$ & $\begin{array}{l}\text { Mining } \\
\text { Transmission }\end{array}$ & $\begin{array}{l}\text { Mining activities and transmission lines } \\
\text { would have visual impacts. }\end{array}$ \\
\hline
\end{tabular}

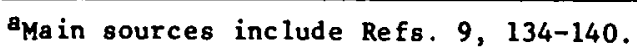


Table 4.31 Welfare Effects of a Satellite Power System Fuel Cyclea

\begin{tabular}{|c|c|}
\hline Environmental Impact & Activities Involved \\
\hline Air Pollution & $\begin{array}{l}\text { Launch and recovery } \\
\text { Mining } \\
\text { Manufacturing } \\
\text { Construct ion } \\
\text { Transportat ion }\end{array}$ \\
\hline Atmospheric Changes & $\begin{array}{l}\text { Launch and recovery } \\
\text { Rectenna }\end{array}$ \\
\hline Thermal Discharges & $\begin{array}{l}\text { Launch and recovery } \\
\text { Reclelulu }\end{array}$ \\
\hline Water Pollution & $\begin{array}{l}\text { Mining } \\
\text { Manufacturing } \\
\text { Launch and recovery }\end{array}$ \\
\hline Water Use & $\begin{array}{l}\text { Mining } \\
\text { Manufacturing } \\
\text { Construct ion } \\
\text { Launch and recovery }\end{array}$ \\
\hline Solid Waste & $\begin{array}{l}\text { Mining } \\
\text { Manufaccur ing } \\
\text { Launch and recovery }\end{array}$ \\
\hline Land Use Disturbance & $\begin{array}{l}\text { mining } \\
\text { Launch and recovery } \\
\text { Rectenna } \\
\text { Trangmigsion }\end{array}$ \\
\hline
\end{tabular}

Electromegnet ic Disturbance

Noise

Launch and recovery Transmission

Mining

Satellite

Transmission

Launch and recovery Satellite Microwave power transmission Transmission
Welfare Effects

Solar cell manufacturing and rocket launches may produce toxic emissions -- exact emissions and welfare effects are unknown. Environmental problems from fugitive dust from mining and construction and spills of rocket propellants could occur -- welfare effects are not expected to be as severe as those of toxic emisoions.

Rocket emissions of $\mathrm{CO}_{2}$ and $\mathrm{H}_{2} \mathrm{O}$ would augment the greenhouse warming effect to a small extent, with slight effects on precipitation, agriculture, and ocean levels.

Waste heat from the rectenna would raise local temperatures slightly, possibly produce slight changes in local cloudiness, and contrihute to hast island efferta. Hagr, from launch geound eloud could utodify local weather. Welfare impacts wnuld likely he minor.

Water pollutants generated by conventional mining and manufacturing activities could degrade drinking water supplies and cause reduced commercial and recreational yield in affected waters. (Transportation of propellants could result in accidental spills, with similar welfare effects.)

Mining of materials could disrupt aquifers and budies of water; impacts unknown. Local water shortages due to cooling needs of the launch tower would be possible, but should be avoidable.

Mine tailings, residuals from photovoltaic cell manufacturing, and wastes from launch-related activities could increase demand for disposal sites. Toxic manufacturing wastes could reduce productivity and usefulness of land to some degree.

Mining operations, launch and recovery sites, and rectenna sites remove large parcels of land from alternate uses. Post-mining agricultural use of reclaimed areas may be less productive. Large rectenna and launch complex sites cauld require relocation of homes, roads, and right-of-ways and inconvenience persons having to drive around an area that. they formerly could drive through .

Launch vehicle emissions could modify the electron density of the ionosphere and distupt communications systems. Reflected light and waste heat from the satellite could create EM disturbances; affected systems could include radio astronomy. SPS microwave coupling with electronic systems up to $100 \mathrm{~km}$ from ' the rectenna could occur. Power transmission can effect fringe TV and radio reception.

Rectenna operation would emit low levels of microwave radlation beyond exclusion area. The effects of these emissions are unknown, but pnssibly. rould Include indirect impacts on beneficial insects and invertebrates. Microwave radiation could also make crops wore susceptible to other environmental stresses.

Noise from HLLV launches could exceed recommended EPA noise standards. Sonic booms would occur during launch and reentry. High voltage transmission lines produce a barely audible hum. High noise levelo near residential areas could reduce property values, cause annoyance, and interfere with other activities.

Mining activities and transmission lines would have visual impacts. The satellites would be visible as bright objects in the night sky, affecting optical as t ronomy.

amain sources include Refs. 3, 90, 97, 116, 141-144. 
Table: $4: 32$ Welfare Effects of a Fusion Fuel Cyclea

\begin{tabular}{|c|c|c|}
\hline Environmental Impact & Activities Involved & Welfare Effect \\
\hline Air Pollution & Mining & $\begin{array}{l}\text { Impacts of mining lithium are } \\
\text { unknown. }\end{array}$ \\
\hline Thermal Discharges & Power generation & $\begin{array}{l}\text { Cooling tower operation can } \\
\text { increase local fogging and } \\
\text { icing with effects on visibil- } \\
\text { ity, traffic, and convenience } \\
\text { for nearby residents. cloud } \\
\text { and precipitation augmenta- } \\
\text { tion is possible but should be } \\
\text { minor. }\end{array}$ \\
\hline Water Pollution & Power generation & $\begin{array}{l}\text { Releases of tritium into water } \\
\text { supplies would be a health and } \\
\text { safety issue. }\end{array}$ \\
\hline $\begin{array}{c}\text { Water Use Changes } \\
\text {. }\end{array}$ & Power generation & $\begin{array}{l}\text { Cooling needs during power } \\
\text { production could require ex- } \\
\text { tensive amounts of water if } \\
\text { evaporative systems are used. }\end{array}$ \\
\hline Land Use Disturbance & Decommissioning & $\begin{array}{l}\text { Burial of nuclear wastes may } \\
\text { remove all further use of land } \\
\text { involved. }\end{array}$ \\
\hline $\begin{array}{l}\text { Electromagnet ic } \\
\text { Disturbances }\end{array}$ & Transmission & $\begin{array}{l}\text { High intensity magnetic fields } \\
\text { around transmission lines can } \\
\text { can cause radio and TV inter- } \\
\text { ference in fringe-reception } \\
\text { areas. }\end{array}$ \\
\hline Noise & $\begin{array}{l}\text { Mining } \\
\text { Power generation } \\
\text { Transmission }\end{array}$ & $\begin{array}{l}\text { No major effects. High-voltage } \\
\text { transmission lines create a } \\
\text { barely-audible hum. }\end{array}$ \\
\hline $\begin{array}{l}\text { Acsthctic } \\
\text { Disturbances }\end{array}$ & $\begin{array}{l}\text { Mining } \\
\text { Power generation } \\
\text { Transmission }\end{array}$ & $\begin{array}{l}\text { Aeothetic degradation due to } \\
\text { mines, cooling tower plumes, } \\
\text { transmission corridors. }\end{array}$ \\
\hline
\end{tabular}

aMain sources include Refs. 24, 103-105, 107, 109, 110, 112, 116, 120, 145-152.

Table 4.33 indicates the key areas of impact that have been identified. In the following sections, the principal areas of concern and the rationales for their selection are summarized.

\subsubsection{Generation of Air Pollution}

Air pollutants consisting of trace and toxic elements could be the major area of concern for coal, TPV, and SPS activities. Such emissions will arise in differing amounts from specific activities within each technology. Insufficient data exist for characterizing the type and quantity of trace 
Table 4.33. Potential Severity ${ }^{a}$ of and Status of Knowledge ${ }^{b}$ about Key Environmental Welfare Issues

\begin{tabular}{|c|c|c|c|c|c|c|c|c|c|c|c|c|c|c|c|}
\hline \multirow{2}{*}{$\begin{array}{c}\text { Environmental Impacts } \\
\text { with Possible } \\
\text { Welfare Effects }\end{array}$} & \multicolumn{2}{|c|}{ Conventional coal } & \multicolumn{2}{|c|}{ LWR } & \multicolumn{2}{|c|}{$\mathrm{CG} / \mathrm{CC}$} & \multicolumn{2}{|c|}{ LMFBR } & \multicolumn{2}{|c|}{ TPV } & \multicolumn{2}{|c|}{ SPS } & \multicolumn{2}{|c|}{ Fusion } & \multirow{2}{*}{$\begin{array}{l}\text { Activities Causing } \\
\text { Potentially Severe } \\
\text { Welfare Effects }\end{array}$} \\
\hline & IS & SK & PS &.$j \mathrm{~K}$ & PS & SK & PS & SK & PS & SK & PS & $\mathbf{S K}$ & PS & SK & \\
\hline $\begin{array}{c}\text { Air Pollution } \\
\text {. }\end{array}$ & $\mathbf{I}$ & $B-1)$ & $2-3$ & B & $1-2$ & $B-C$ & $2-3$ & B & 1 & $\mathrm{c}$ & 1 & c & 2 & C & $\begin{array}{l}\text { Coal-fired power generation } \\
\text { (toxic and secondary } \\
\text { pollutants). } \\
\text { Solar cell materials manu- } \\
\text { facture and SPS rocket } \\
\text { launches. }\end{array}$ \\
\hline Atmospheric Cì anges & 1 & $B-C$ & 4 & B & 1 & $B-C$ & 4 & B & 3 & B & 3 & B. & 4 & B & $\begin{array}{l}\text { Coal-fired power generation } \\
\left(\mathrm{CO}_{2} \text { emissions }\right) \text {. }\end{array}$ \\
\hline Thermal Discharges & 2 & B & 2 & B & 2 & B & 2 & B & 2 & B & 2 & B & 2 & B & -- \\
\hline Water Pollution & 1 & B & 1 & B & 1 & B & $2-3$ & B & 1 & $\mathbf{c}$ & 1 & c & $2-3$ & $\mathbf{C}$ & $\begin{array}{l}\text { Coal mining (underground). } \\
\text { LWR fuel fabrication. } \\
\text { Solar cell materials } \\
\text { manufacture. }\end{array}$ \\
\hline Water Use & 2 & B & 2 & B & 2 & B & 2 & B & 3 & B & 3 & c & 2 & c & - \\
\hline Solid Waste & $2-3$ & A & 3 & B & $2-5$ & A & 3 & B & $2-3$ & C & $2-3$ & C & $3-4$ & c & -- \\
\hline Land-Use Disturbances & $1-i$ & $\mathbf{A}$ & 1 & B & $1-2$ & A & 1 & B & 1 & B & 1 & $\mathrm{~B}-\mathrm{C}$ & 1 & C & $\begin{array}{l}\text { Coal mining (surface) } \\
\text { Nuclear waste disposal. } \\
\text { Solar cell materials } \\
\text { mining, SPS rocket } \\
\text { launch and rectenna } \\
\text { sites. }\end{array}$ \\
\hline $\begin{array}{l}\text { Electromagnetic } \\
\text { Disturbances }\end{array}$ & 3 & B & 3 & B & 3 & B & 3 & B & 3 & $\mathbf{B}$ & 1 & $\mathrm{~B}-\mathrm{C}$ & 3 & $\mathrm{~B}-\mathrm{C}$ & SPS rectenna operation. \\
\hline Microwave Radiation & 4 & B & 4 & B & 4 & B & 4 & B & 4 & B & 1 & $z$ & 4 & B & SPS power transmission. \\
\hline Ionizing Radiaticn & 3 & B & 3 & . B & 3 & B & 3 & B & 4 & B & 4 & $\mathbf{3}$ & 3 & $\mathrm{~B}-\mathrm{C}$ & - \\
\hline Noise & 3 & A & 3 & $A$ & 3 & A & 3 & A & 3 & A & - 1 & $A$ & 3 & A & SPS rocket launch. \\
\hline Aesthetic Disturtances & 2 & $\mathbf{A}$ & 2 & $A$ & 2 & $\mathbf{A}$ & 2 & $A$ & 2 & B & 2 & 3 & 2 & C & - \\
\hline
\end{tabular}

apotential Severity (PS) ranking is based on tie most serious welfare effects of the activities withir each fuel cycle. Potential severity is ranked according to the following criteria:

1 - Very aignificant contribution to welfare effects. 3 - Minor but measurable contribution to welfare effects.

2 - Significant contribution to welfare effacts. $\quad 4$ - regligible contribution to welfare effects.

btatus-of-knowledge (SK) ranking:

A - Is sue thoroughly documented and understiod.

B - Parts of josue understood, but gaps in knowledge exist.

C - Very little knowledge of issue exists. 
emissions resulting from the solar cell manufacturing process and rocket launch activities. However, the potential exists for atmospheric emissions of gallium, arsenic, hydrogen sulfide, and other compounds during GaAlAs manufacture. 141

Emissions of potentially hazardous trace metals are discharged into the atmosphere with the waste gases from combustion at coal-fired generating plants. Although the quantities emitted are small, their degree of enrichment in the flyash and their hazardous nature requires that this be considered an area for concern. Other coal-related emissions require attention: coal combustion emits primary $\mathrm{SO}_{2}$ and $\mathrm{NO}_{\mathrm{x}}$, which are precursors of secondary sulfate and nitrate particles and have been implicated in acid precipitation and impairment of visibility. Lakes with reduced buffering capacity can acidify and deteriorate the aquatic environment, resulting in commercial and recreational losses. Degraded visibility may impair navigation and result in cancelled or delayed airline flights.

Emissions of regulated criteria pollutants from coal combustion $\left(\mathrm{SO}_{2}\right.$, $\mathrm{NO}_{\mathrm{x}}$, TSP, HC, CO), releases of cooling tower drift from coal and nuclear generating stations, and fluoride from nuclear fuel-conversion facilities are areas of moderate concern and are likely to be controlled to acceptable levels. However, these pollutants have been implicated in the physical damage to and reduced useful life of metals, building materials, and stone objects such as sculptures. Pollutants at elevated levels have affected the productivity, appearance, and yield of crops, thereby causing economic damage.

\subsubsection{Climatic Changes Due to Air Pollution}

The impact on global climate that is currently given the most attention is the global warming effect caused by increasing $\mathrm{CO}_{2}$ levels in the atmosphere and the resulting "greenhouse effect." Atmospheric models predict that doubling of $\mathrm{CO}_{2}$ levels above pre-industrial levels will produce a global average warming of $1^{\circ}$ to $3^{\circ} \mathrm{C} .153$ This could occur as early as 2025, although noticeable warming should not be detected before 2000 . Such a temperature increase may significantly. affect precipitation patterns, agricultural produc$t$ ion, energy use, and ocean levels through melting of polar ice.

Combustion of coal releases substantial amounts of $\mathrm{CO}_{2}$ into the atmosphere ( $5 \times \cdot 10^{6}$ metric tons annually for a 1,000-MW power plant). Although this is not a local problem, coal combustion contributes significantly to the total man-made input of $\mathrm{CO}_{2}$ into the atmosphere. Furthermore, coal combustion also releases amounts of other "greenhouse" gases such as $\mathrm{SO}_{2}$ and $\mathrm{H}_{2} \mathrm{O}$, which appear to be of a less severe nature.

Another area of concern is the increase in global levels of atmospheric particles, which, depending on their location and optical properties, act to change the radiative properties of the earth-atmosphere system and effectively warm or cool the earth's surface. It has not been established whether or not the increase in atmospheric particle concentrations over the past century has produced a net warming or cooling effect. The direct emissions of particles from coal combustion, and emissions of gaseous species such as sulfur and nitrogen oxides which are converted to particles in the atmosphere, do not contribute significantly to global levels of atmospheric particles.154 
The major emissions into the atmosphere from SPS activities will occur from rocket launches. Rocket effluents include substantial amounts, of $\mathrm{CO}_{2,2}$ but these emissions. are at least 100 times smaller than the $\mathrm{CO}_{2}$ emissions from coal combustion for an equivalent amount of system capacity.153 The possibility exists for some upper-level clouds to be formed by $\mathrm{H}_{2} \mathrm{O}$ injec$t$ ions into the mesosphere. The impacts of these clouds do not appear to be significant but are not well known at present. A slight depletion of the total ozone column due to emissions of $\mathrm{H}_{2} \mathrm{O}$ and $\mathrm{NO}_{x}$ is possible but is not expected to affect global climate to a noticeable extent. 141

The ability to reliably predict climatic change resulting from air pollution emissions is currently limited by several factors. There is considerable uncertainty concerning the extremely complex nature of the earthatmosphere system and the interrelations between the various parts of the system. Insufficient knowledge hampers the prediction of how second-order coupled processes or "feedback mechanisms". might enhance or suppress a firstorder effect on climate such as a surface warming due to $\mathrm{CO}_{2}$. There is also uncertainty about the magnitude of the effect of other greenhouse gases and atmospheric particles compared to the $\mathrm{CO}_{2}$ effect. 155 The role of natural climatic fluctuations in enhancing or masking trends due to man-made emissions further contributes to the uncertainty of predictions. It is expected that the ability to predict climatic change will improve with additional research; however, drastic improvements in forecast reliability are probably not to be expected in the near future because of the complexity of the problem.

\subsubsection{Thermal Discharges and Resulting Climatic Change}

Production of electrical energy results in the rejection. of waste heat to the environment. A nuclear power plant with an efficiency of: $32 \%$ releases two units of waste heat for each unit of heat used to produce electrical energy, as do coal- and oil-fired plants that operate on the Rankine cycle. However, with nuclear plants all of this waste heat is rejected to cooling towers. The impacts of this waste heat are local and dependent on the type of cooling technology, the amount of heat released, and the local ambient meteorological conditions. Most existing and all planneri nuclear power plants employ cooling towers.141 Most new and planned coal.fired plants also use cooling towers. Mechanical-draft cooling towers can produce an increase in local ground fog a few days per year within a few thousand feet of the towers. Some local icing may occur during the winter when the moist thermal plume contacts the ground. Production or enhancement of cloudiness in the vicinity of large cooling towers has also been observed.156 In areas where these problems occur, technology is available at a moderate incremental cost to eliminate the adverse effects.

A relatively unlikely, but potentially significant impact could oecur in the future if nuclear power plants are clustered into energy "parks." The large release rate of waste heat (e.g., 72,000 MWt from a 36,000 MWe power park) over an area of relatively small radius ( 10 to $100 \mathrm{~km}$ ) could produce or enhance severe local weather events such as thunderstorms and hail.157 of the three nuclear options characterized here, the LMFBR has the lowest heat rate and fusion has the highest. 
A coal-fired power plant is a little more efficient than a nuclear power plant $(36 \%$ versus $34 \%)$. Thus, the local waste heat impacts for coal technologies should be smaller than those of nuclear technologies for a plant of equal size and similar cooling technology. In addition, the waste heat effects from coal-fired power plants are reduced because not all of the waste heat is emitted from the cooling tower. About $25 \%$ of the total waste heat of a coal-fired plant is emitted from the stack.

The SPS rectenna will release waste heat with a density of $7.5 \mathrm{~W} / \mathrm{m}^{2}$ over a $100 \mathrm{~km}^{2}$ area. This is an energy density of about $10 \%$ of the average net solar radiation at the earth's surface. In conditions of light winds, temperature perturbations of as much as $1^{\circ} \mathrm{C}$ could occur in the vicinity of the rectenna. 158 Changes in cloudiness near an SPS rectenna or a TPV solar collector area could occur, but an impact on precipitation distribution seems unlikely.

\subsubsection{Water Pollution}

Insufficient information concerning the solar cell manufacturing process precludes an accurate assessment of the severity of water-polluting emissions from this activity. However, the toxicity of the raw materials and the possibility of accumulation in the environment warrants further attention. With data currently available, it is not possible to identify specific water pollution problems or effects that could occur during normal operation. However, it is possible that water pollution may result from SPS launches, SPS rectenna construction runoff, and TPV construction runoff.

Acid mine drainage from underground coal mining activity is an impact of concern, and in the past such drainage has degraded many eastern waterways. Acid-contaminated waters endanger aquatic populations by altering species type, diversity, and quantity, thereby limiting commercial and recreational opportunities. Various federal-and state programs have instituted water quality criteria, effluent limitations, and reclamation requirements to control the problems associated with mining activity. There is controversy over the ability of these laws to achieve the desired effect. LMFBR and fusion technologies require minimal mining activities by comparison, hence significantly smaller environmental welfare effects.

LWR fuel fabrication is also an area of concern although a minor one. Existing plants have occasionally discharged ammonia, nitrates, and fluorides into low-flow streams, thereby reducing the quality of the water.

\subsubsection{Water Use Changes}

Heavy consumption of water is treated in sec. 4.5 as a resource issue. However, heavy use of water can decrease the amount of water available downstream for dilution and therefore can be a welfare issue as well. Mining operations can disrupt aquifers, resulting in lowering of the ground water table and alteration of water flow patterns, which could affect crop irriga$t$ ion. Wet cooling towers at coal or nuclear power stations can consume large quantities of water. Technologies that do not consume water could be utilized in areas where water is scarce. During the LWR fuel cycle, the production of 
uranium hexafluoride and enriched uranium (gaseous diffusion process) also requires heavy consumption of water.

\subsubsection{Generation of Solid Waste}

The impact of solid waste generation cannot be entirely separated from land use issues. However, small amounts of waste can have large impacts on future land use when the nature of the waste affects the disposition of the land into which it is placed. Issues concerned with the quantity of land necessary for the disposal of solid waste are treated in Sec. 4.4 as a land-resource issue.

Manufacture of the GaAlAs solar cell will produce $2 \times 10^{7}$ metric tons of aluminum oxide waste for each 5-GW satellite produced. This quantity of waste could present a disposal problem if all cells were manufactured at a single facility. Aluminum oxide does have commercial value for other purposes, which could lessen the impact of its disposal. Similar uncertainties exist for the manufacture of silicon cells for the TPV system.

A $1,250 \mathrm{MW}$ conventional coal power plant using Wellman-Lord $\mathrm{SO}_{2}$ removal will produce about $5 \times 10^{5}$ metric tons of solid waste and sludges annually. CG/CC plants will produce about $20 \%$ less solid wastes and sludges. The quantity of waste leaving the power plant site will vary depending on the availability of land for on-site disposal. Procedures for returning these areas to productive use are available but are not mandated. Regulations governing the toxic nature of these wastes are currently being considered.

Modest amounts of solid and liquid waste are generated in support of the LWR power cycle. However, most of these activities generate radioactive waste that must either be sent off site for commercial burial or buried on site. Among these wastes are:

- sUU metric tons per tacility per year of uranıum hexafluoride-process effluents consisting of iron, calcium, magnesium, copper, and nonvolatile fluorides (shipped of $f$ site).

- 90 metric tons per facility per year of enrichmentcleanup sludge consisting of mostly settleable solids, precipitated metals and soil runoff (retained on site).

- 700 metric tons per facility per year of calcium fluoride from fuel-fabrication activities (generally retained on site).

- Numerous liquid and solid radwastes that are released through fission product leakage, activation of chemical inhibitors, reactor purification procedures and spent reactor parts (shipped off site).

- Spent reactor fuel shipped to the reprocessing center.

Large amounts of mine and mill tailings should not present any specific problem since they are often used as backfill and retained on site. However, inadequate precautionary measures have, on occasion, permitted low-level 
radioactive tailings to enter the environment. LMFBR and fusion technologies would have significantly fewer environmental welfare impacts in this area due to minimal mining requirements. LMFBRs could obtain fuel from LWR tailings for many years.

Coal, nuclear, and solar technologies each require the extraction of conventional materials, such as steel and aluminum. These activities will not produce any unique problems with respect to solid waste generation.

\subsubsection{Land Use Changes}

The quantity of land removed from public use and the permanent isolation of land are not considered here since these are principally resource issues. Additional questions concerning changes in land use remain. Mining operations for fuel and materials have the potential of contaminating or eroding other land areas. Reclamation of mined areas may not be entirely effective in returning the land to its formerly productive state. Reclamation of mined areas in arid climates such as the southwestern U.S. is difficult. Proper operation and reclamation techniques should reduce the level of concern.

Electromagnetic interference with communication systems near the SPS rectenna location has the potential for limiting the type and diversity of land use activities around the site; although it is conceptually possible to mitigate these effects, specific measures and cost estimates are currently unavailable. The removal of large land areas from public use, because of the presence of the rectenna, will inconvenience persons having to drive around the site; a similar problem will occur if the rectenna site is near a navigable waterway.

\subsubsection{Noise Generation}

The major noise disturbances (noise exceeding 60-80 dBa, 24-h weighted average) will be from SPS rocket launch operations, 141 and will likely exceed EPA recommended 24-h, time-averaged noise standards and elevate noise levels in surrounding communities to a distance of $30 \mathrm{~km}$. Launches are projected to occur several times a day. Sonic booms during launch and reentry operation will elevate noise levels to a lesser degree. Elevated noise levels near residential areas could lead to depressed property values. These effects could be mitigated by launching far from populated areas.

Coal and nuclear mining and power generation have a moderate noise impact. Noise from power production arises from cooling tower fans and plant support activities. Blasting and drilling during mining may also elevate noise levels in the immediate vicinity. Noise measurements assessed at the property 1 ine in most cases are not expected to be significant, and use of a buffer zone between the noise source and the property line frequently serves as a mitigation technique.

Another source of noise that is common to the energy technologies will vccur during rail transport of fuels and materials. Transmisoion line noise is only barely audible with $345 \mathrm{kV}$ AC lines but increases with the use of higher-voltage lines. 


\subsubsection{Electromagnetic Disturbances}

Significant electromagnetic disturbances from the SPS may occur from microwave coupling with electronic systems at distances of up to $100 \mathrm{~km}$ from the rectenna site. 141 Functional degradation can affect military radar, law enforcement, emergency, and utility communications, and other susceptible systems. However, it is anticipated that modifications (currently undefined both technically and from a cost point of view) could be made to these systems to mitigate these effects.

other electromagnetic disturbances related to SPS activities may be anticipated. Rocket effluents may induce ionospheric alterations that may affect communication systems relying on the ionosphere. Debris clouds consisting of orbiting gaseous and particulate effluents cuuld inlerfere with radioastronomy and radionavigation. The likelihood and severity of these occurrences is unknown but is currently under investigation in the environmental assessment of the SPS. 141

High-intensity electromagnetic fields generated around power transmission lines have, in some instances, caused radio and TV disturbances in fringe reception areas. This effect is thought to be of minor concern. However, it is common to all centralized energy technologies and is likely to increase with the higher transmission-line voltages.

\subsubsection{Radioactive Emissions}

Radiation releases containing trace radioactive materials result from the burning of fossil fuels 123 and all other activities in the nuclear fuel cycle. 20,117 SPS activities do not result in emission of ionizing radiation.

The study of airborne radioactive particles from coal combustion has not been comprehensive. Radioactive effluents originate in coal and are emitted with the stack gases. Uranium, thorium, and radon constitute the radioactive emissions of coal combustion, which may release on the order of $1.2 \mathrm{Ci}$ annually, depending on the nuclide concentration in the coal seam. Radioactive airborne releases from a 1,250-MW coal plant are considerably below the amount resulting from a comparably-sized boiling water reactor. Standards limiting radioactive emissions from fossil-fueled power plants do not currently exist but could be promulgated under the Federal Clean Air Act Amendments of 1977 .

Low-level radiation emissions from routine operation of nuclear power facilities are greatest during power generation and milling activities. In addition, fuel reprocessing is required by the LMFBR, and causes the release of larger amounts of radionuclides, primarily krypton, than would be released from an LMFBR power plant. The use of exclusion zones around nuclear facilities reduces the off-site exposure. Radiation emissions are below the levels established by. federal Nuclear Regulatory Commission regulations (10 CFR* 20, $10 \mathrm{CFR}$ 50), and are characterized as having low welfare impact. However, the radiation threshold level beneath which an effect will not be observed is uncertain, and therefore these standards are being reexamined.

*Code of Federal Regulations 


\subsubsection{Microwave Radiation}

Microwave radiation levels will be elevated in the vicinity of the SPS rectenna station. Levels within the exclusion zone will be as high as $23 \mathrm{~mW} / \mathrm{cm}^{2}$. Levels below $0.1 \mathrm{~mW} / \mathrm{cm}^{2}$ will be experienced beyond the exclusion zone. 1

Limited information exists regarding the direct impact of microwave radiation on biological systems. All of the information that is available. relates to high-level microwave exposures.141 Although the likelihood of occurrence of microwave effects is unknown, the potential severity could be significant. Microwave exposure may alter the mortality, reproduction, and behavior of birds, invertebrates, and beneficial insects. Disturbances of pollinization by bees could affect food supplies and is currently under study. 141 Direct microwave exposure could increase the susceptibility of crops to environmental stress such as drought, resulting in decreased yields. Birds relying on the earth's magnetic field for navigation may show altered migration patterns. 141 Judicious siting may reduce the extent of impact from microwave exposure.

\subsubsection{Aesthetic Disturbances}

Direct aesthetic impacts are site-specific, and the extent of these disturbances can be moderated by avoiding archaeological, cultural, and historical areas, protected scenic and recreational areas, and habitats of rare and endangered species during the siting process. Other types of aesthetic degradation may arise from unsightly mines; visually disturbed areas, e.g., facilities sited in rural areas; transmission corridors; visible cooling tower and stack plumes and plume shadows; and noise-producing operations.

The aesthetic impacts of satelliţe operation include the brightness of the satellites visible in the night sky. The diffuse glare from reradiated light may also interfere with optical astronomy.

\subsection{RESOURCES}

This section summarizes the comparative assessment of five resources -land, materials, energy, water, and labor. The materials, energy, and labor assessments include only a side-by-side analysis; for land and water, the assessments include an alternative futures perspective using the results of the scenario analys is described earlier in Sec. 4.1.

Seven technologies are compared with regard to the land and water issues, which are considered to be the most important resource issues. Conventional coal with flue gas desulfurization, LWR, CG/CC, LMFBR, TPV, SPS, and fusion were the technologies compared for these issues, and subsets of this group were compared for the other issue areas.

The essential ingredient of the alternative futures analys is for land and water use is energy supply, by technology, through the year 2030. These data (baseload capacities), produced, as part of the scenario development, are 
listed in Tables 4.7 through 4.9 in Sec. 4.1. Each of the three scenarios CI, $U I$, and $U H$ is considered under two conditions: (1) excluding the SPS from the energy supply system, and (2) including the SPS after 2000.

Results of the side-by-side analysis are listed qualitatively in Table 4.34. Details of these results, as well as those of the alternative futures analysis, are presented in the following sections.

\subsubsection{Land}

Overview. Land requirements were developed as part of the energy systems characterizations summarized in Sec. 3. These data were then normalized and compared on a side-by-side basis, by computing the amount of land required to obtain $1,000 \mathrm{MW}$ of installed capacity. Both plant site and annual fuel cycle requirements were considered. Another side-by-side comparison was made on the basis of land per unit energy. This comparison accounted for load factor and, in the case of TPV, average daily insolation. Next, the scenario data were brought into the analysis to determine total land requirements for baseload electrical generation for the period 1980-2030. The 1980 figures provide a frame of reference for the differing results of the three scenarios (CI, UI, and UH) with and without inclusion of the SPS in the energy supply system.

Transmission requirements were not included in any of the calculations because they have been shown to be about the same for all technologies, particularly in view of studies showing that 60 SPS rectennas can be sited within $500 \mathrm{~km}$ of a load center.

Side-by-side results show that the solar options (TPV and the SPS) require very large, contiguous land areas. TPV could be deployed in smaller units (with the question of economio effects left unanswered), mitigating the requirement for contiguous land. On the basis of land per unit energy, TPV requires about three times as much land as the SPS, whereas coal requires about half the land of the SPS, and the nuclear options are about a factor of 10 lower than the SPS in this regard.

Scenario results indicate that total land use (excluding transmission) increases $0-500 \%$ without SPS and $100-900 \%$ with SPS by the year 2030, Over the same period of time, baseload capacity increases $90-800 \%$. SPS land requirements for the year 2030 are about 2-5 times the total land in use today for baseload electrical generation. In all cases, the low figures reoule from scenario $U$, and the high rigures result from scenarlo UH; results for scenario UI fall between these values.

Side-by-Side Comparisons. The energy technology characterizations of Sec. 3 provide the plant and fuel cycle requirements. The latter are significant only for coal (conventional coal and CG/CC are very similar and are aggregated for the calculations in this section) and the LWR. Assuming that land disrupted during the fuel cycle is restored in six years, the land use estimates are as 1 isted in Table 4.35. 
Table 4.34 Side-by-Side Comparative Assessments: Resources

\begin{tabular}{|c|c|c|c|c|c|c|c|}
\hline Resource & $\begin{array}{l}\text { Conventional } \\
\text { Coal }\end{array}$ & LWR & $\mathrm{CG} / \mathrm{CC}$ & LMFBR & TPV & SPS & Fusion \\
\hline \multirow[t]{2}{*}{ Land } & $\begin{array}{l}\text { Small plant } \\
\text { requirements }\end{array}$ & $\begin{array}{l}\text { Small plant } \\
\text { requirements }\end{array}$ & $\begin{array}{l}\text { Small plant } \\
\text { requirements }\end{array}$ & $\begin{array}{l}\text { Smaller impacts } \\
\text { than LWR due to } \\
\text { smaller mining } \\
\text { requirements }\end{array}$ & $\begin{array}{l}\text { Large land areas } \\
\text { required for } \\
\text { solar collectors }\end{array}$ & $\begin{array}{l}\text { Large, contiguous } \\
\text { rectenna sites }\end{array}$ & $\begin{array}{l}\text { Small plant } \\
\text { requirements }\end{array}$ \\
\hline & $\begin{array}{l}\text { Mining impacts } \\
\text { are the main } \\
\text { problem }\end{array}$ & $\begin{array}{l}\text { Some mining } \\
\text { impacts }\end{array}$ & $\begin{array}{l}\text { Slightly less } \\
\text { mining. impacts } \\
\text { than conven- } \\
\text { tional coal }\end{array}$ & ' & & & \\
\hline Materials & $\begin{array}{l}\text { Good supply } \\
\text { of coal }\end{array}$ & $\begin{array}{l}\text { Uranium supply } \\
\text { is limited }\end{array}$ & $\begin{array}{l}\text { Good supply } \\
\text { of coal }\end{array}$ & $\begin{array}{l}\text { More efficient } \\
\text { ise of uranium } \\
\text { supply than LWR }\end{array}$ & $\begin{array}{l}\text { Seven potential } \\
\text { problem materials } \\
\text { identified }\end{array}$ & $\begin{array}{l}\text { Three problem } \\
\text { materials iden- } \\
\text { tified (mercury, } \\
\text { tungsten, gallium) }\end{array}$ & $\begin{array}{l}\text { Lithium supply } \\
\text { could be a } \\
\text { constraint }\end{array}$ \\
\hline \multirow[t]{2}{*}{ Energy } & $\begin{array}{l}\text { Payback about } \\
\text { on year }\end{array}$ & $\begin{array}{l}\text { Payback abourt } \\
\text { one year }\end{array}$ & $\begin{array}{l}\text { Payback about } \\
\text { one year }\end{array}$ & $\begin{array}{l}\text { Payback about } \\
\text { one year }\end{array}$ & $\begin{array}{l}\text { Payback }^{a} \text { for } S i \\
\text { system about } \\
19 \text { years }\end{array}$ & $\begin{array}{l}\text { Payback for } S i \\
\text { about six years; } \\
\text { Ga about one year }\end{array}$ & Not evaluated \\
\hline & & & & · & $\begin{array}{l}\text { High energy } \\
\text { intensity of cell. } \\
\text { production }\end{array}$ & $\begin{array}{l}\text { Less sensitive to } \\
\text { energy intensity } \\
\text { of cells }\end{array}$ & . \\
\hline Water & $\begin{array}{l}\text { Contamination } \\
\text { due to coal } \\
\text { mining }\end{array}$ & $\begin{array}{l}\text { Small cooling } \\
\text { losses }\end{array}$ & $\begin{array}{l}\text { Mining impacts } \\
\text { smaller than } \\
\text { those of con- } \\
\text { vent ional coal } \\
\text { Small cooling } \\
\text { losses }\end{array}$ & $\begin{array}{l}\text { Small cooling } \\
\text { losses }\end{array}$ & $\begin{array}{l}\text { Negligible } \\
\text { water use }\end{array}$ & $\begin{array}{l}\text { Negligible } \\
\text { water use }\end{array}$ & $\begin{array}{l}\text { Comparable } \\
\text { to LWR }\end{array}$ \\
\hline $\begin{array}{l}\text { Labor } \\
\text { Requirements }\end{array}$ & $\begin{array}{l}\text { Skills avail- } \\
\text { able today }\end{array}$ & $\begin{array}{l}\text { Small but } \\
\text { highly-skil led } \\
\text { operations and } \\
\text { maintenance } \\
\text { force }\end{array}$ & $\begin{array}{l}\text { Skills avail- } \\
\text { able today }\end{array}$ & $\begin{array}{l}\text { Small but } \\
\text { highly-skilled } \\
\text { operations and. } \\
\text { maintenance } \\
\text { force }\end{array}$ & $\begin{array}{l}\text { Skills readily } \\
\text { available }\end{array}$ & $\begin{array}{l}\text { Space construction } \\
\text { requires new and } \\
\text { highly-skilled } \\
\text { work force }\end{array}$ & $\begin{array}{l}\text { Construction } \\
\text { requirements } \\
\text { similar to } \\
\text { LMFBR }\end{array}$ \\
\hline
\end{tabular}

${ }^{a}$ Improved cell efficiency and/or production energy requirements would reduce payback significantly. 
Table 4.35 Land Requirements, by Technology, in $\mathrm{km}^{2}$ per GW of Installed Capacity

\begin{tabular}{lccc}
\hline Technology & Plant & Fue 1 Cycle & Total \\
\hline Coal & 2 & 8 & 10 \\
LWR & 2 & 1 & 3 \\
LMFBR & 2 & 0 & 2 \\
TPV & 20 & 0 & 20 \\
SPS & 30 & 0 & 30 \\
Fusion & 2 & 0 & 2 \\
\hline
\end{tabular}

Fuel cycle figures reflect the fact that LWR activities disrupt about one-eighth the land disrupted for coal technologies. Por the remaining technologies, fuel cycle activities result in negligible land disruption. The land area needed for disposal of nuclear waste is negligible (less than $5 \%$ of that required for the plant). In the case of coal, fuel cycle activities at any point in time will have disrupted about four times as much land as that required for the plant, assuming that a 6-year land reclamation program has been successfully implemented.

To obtain results in terms of land per unit energy output, the operating factor (accounting for availability, load factor, and insolation for TPV) must be specified. These factors, along with the land requirements in $\mathrm{km}^{2}$ / GW-yr, based on a 30-year life for each technology, are listed in Table 4.36. The operating factor for TPV represents an average figure for the two locations (Phoenix and Cleveland) considered in the technology characterizations.

The results of Table 4.36 indicate that only-one comparison changes: although SPS requires the most land on an installed-capacity basis, TPV requires the most land on the basis of energy output. One reason for this is the 1 imfeed number of hours per day that insolation is avallable.

Alternative Futures Comparison. Demand data have been listed in Tables 4.7 through 4.9 in Sec. 4.1 . These data, plus the land requirements data in Table 4.35, can be used to estimate total land requirements. These results are shown for individual scenariog in Figs. 4.34 through 4.39. Figure 4.40 illustrates the overall land requirements for all scenarios.

Table 4.36 Land Requilrements per Unit Energy Output

\begin{tabular}{lccc}
\hline Technology & $\mathrm{km}^{2} / \mathrm{GW}$ & Operating Factor & $\mathrm{m}^{2} / \mathrm{GW}-\mathrm{yr}$ \\
\hline Coal & 10 & 0.70 & 450 \\
LWR & 3 & 0.70 & 130 \\
LMFBR & 2 & 0.70 & 100 \\
TPV & 20 & 0.22 & 3000 \\
SPS & 30 & 0.90 & 1100 \\
Fusion & 2 & 0.70 & 100 \\
\hline
\end{tabular}




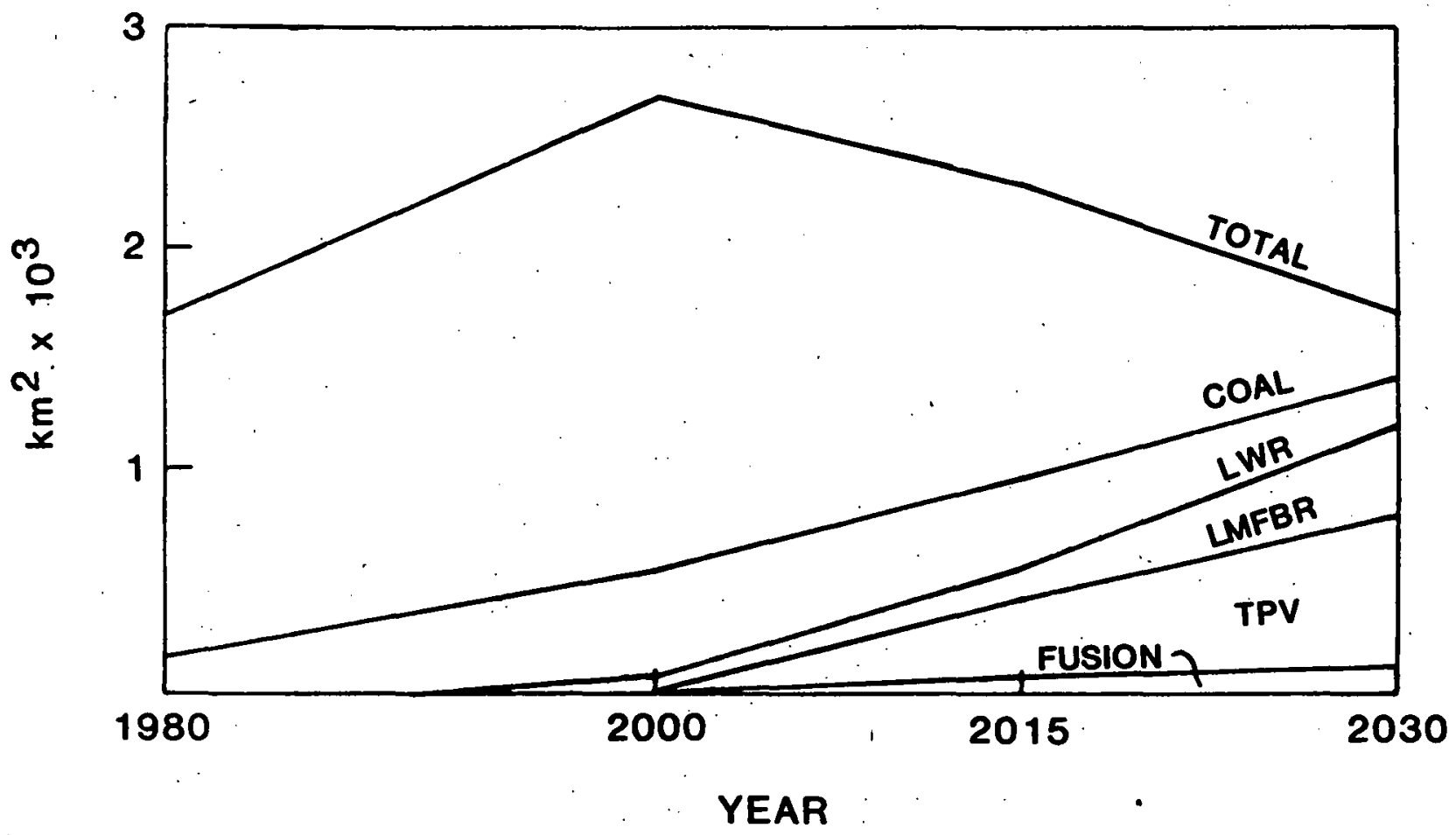

Fig. 4.34 Land Requirements for Scenario CI, without SPS

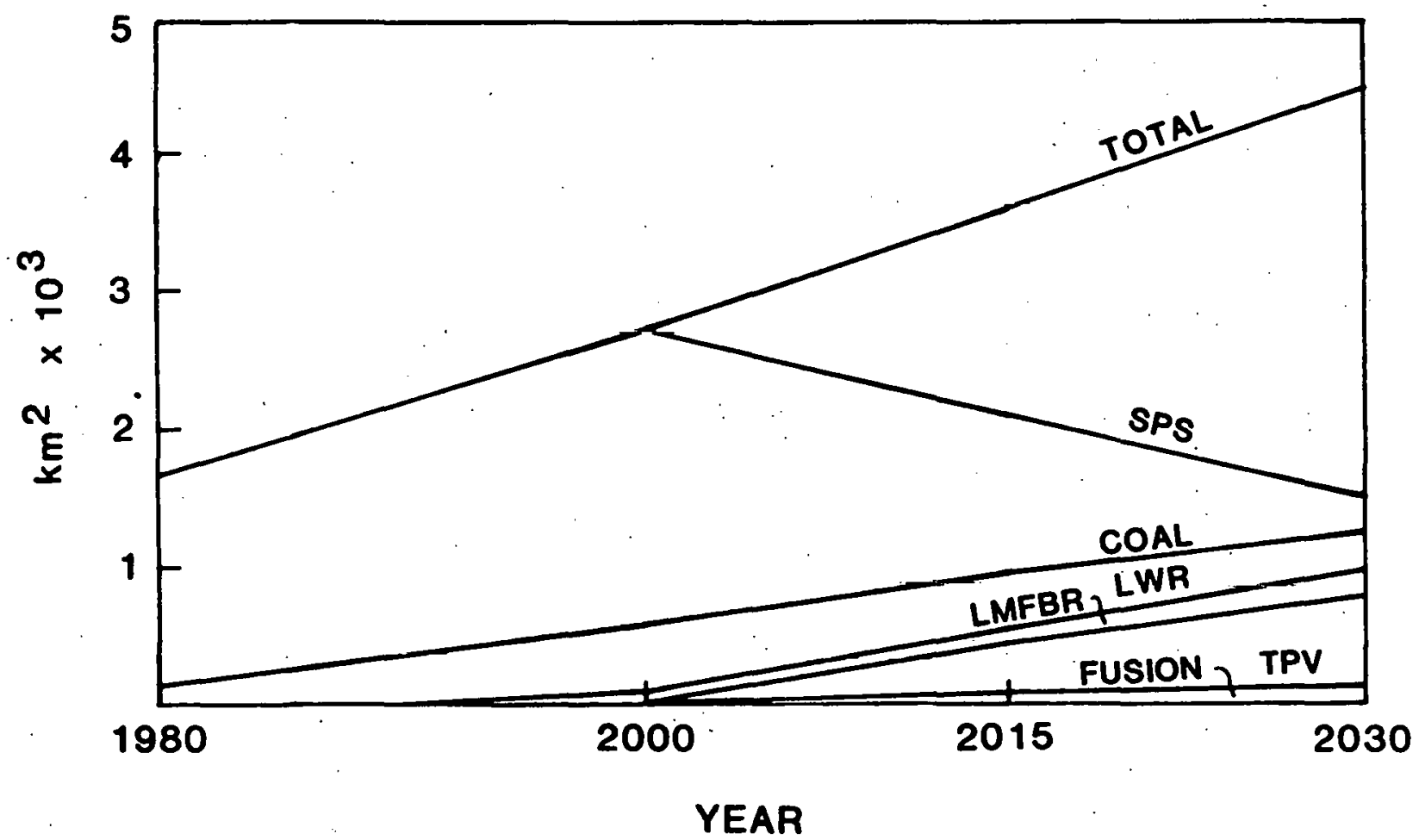

Fig. 4.35 Land Requirements for Scenario CI, with SPS 


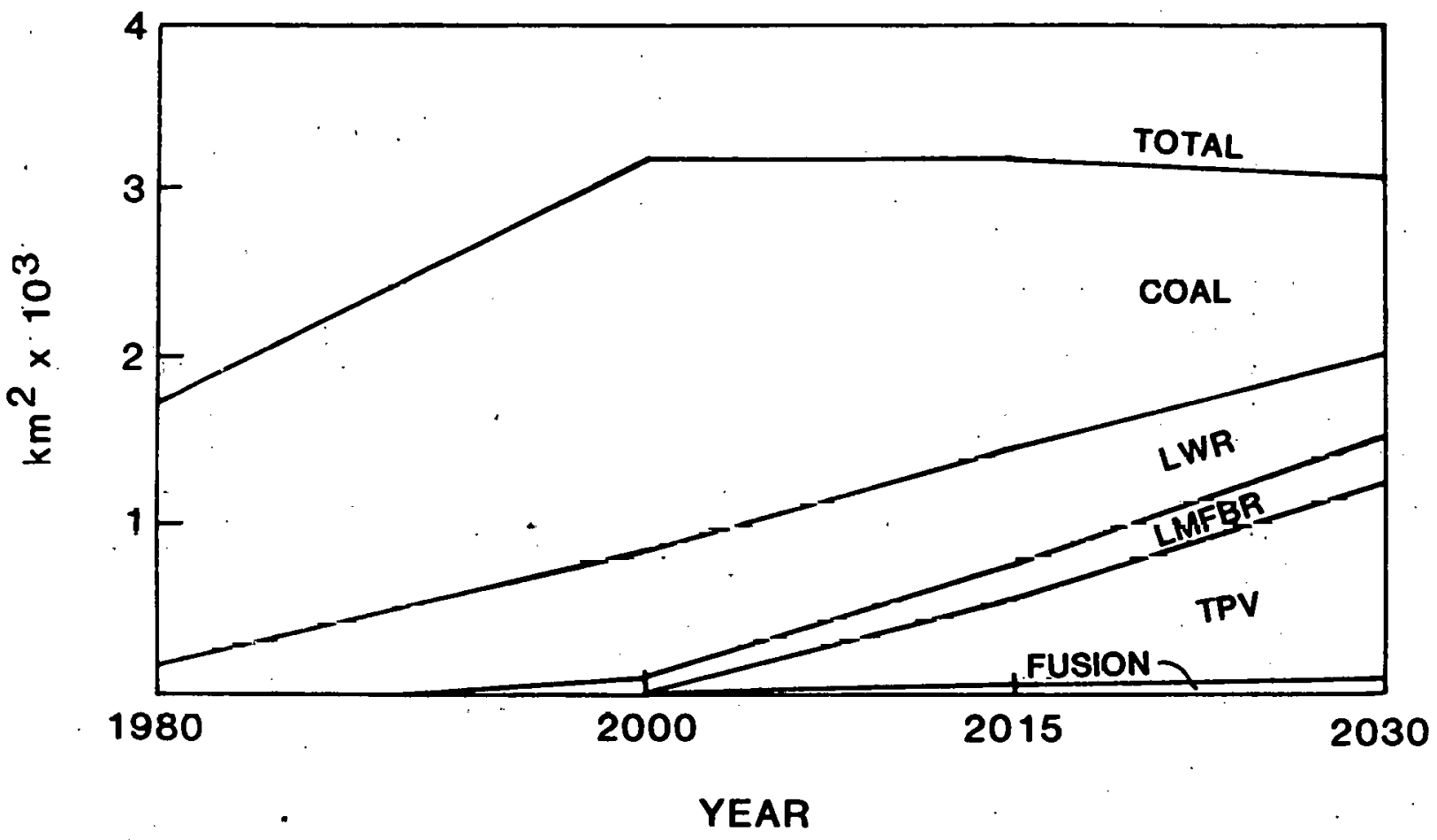

Fig: 4.36 Land Requirements for Scenario UI, without SPS

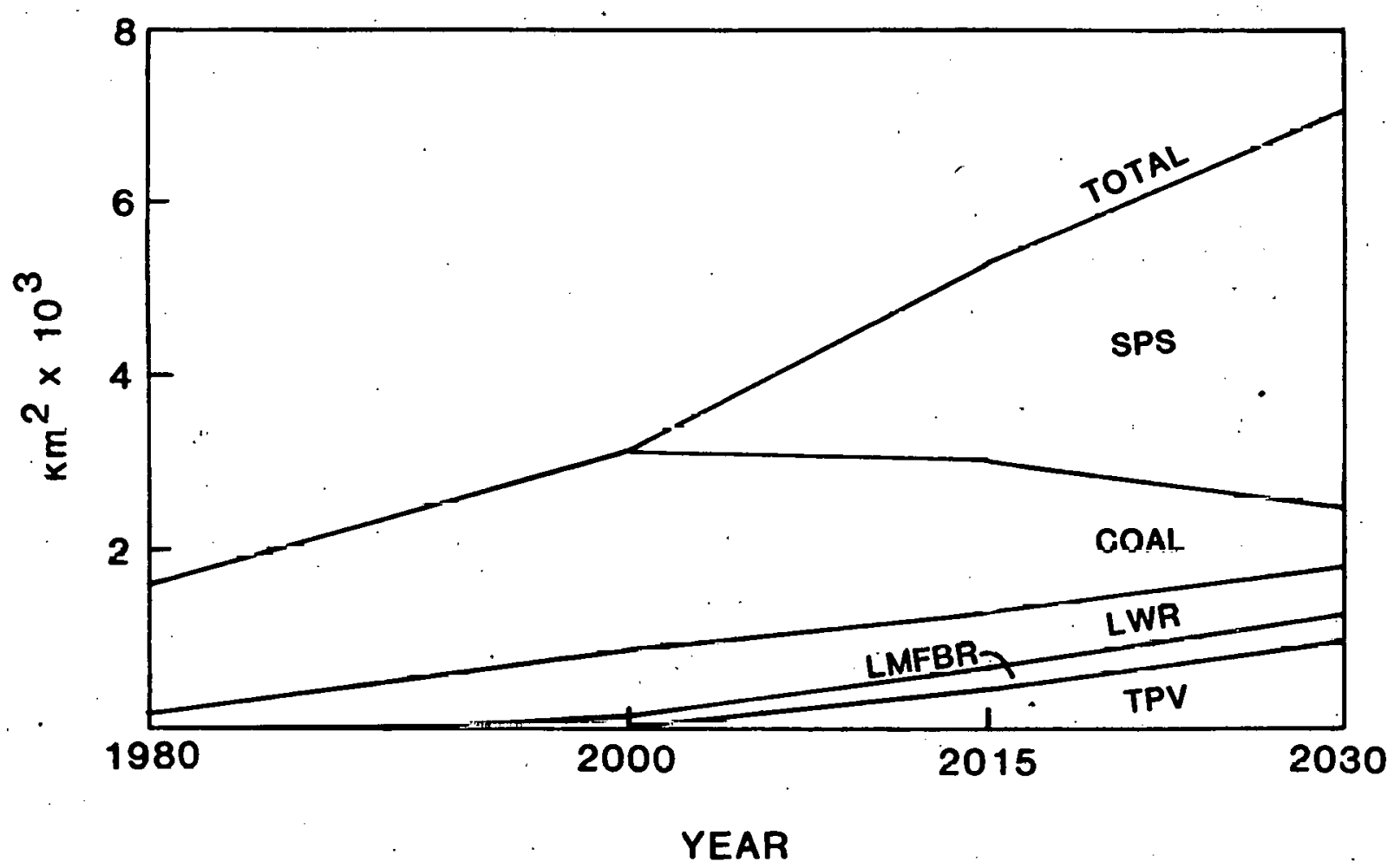

Fig. 4.37 Land Requirements for Scenario UI, with SPS 


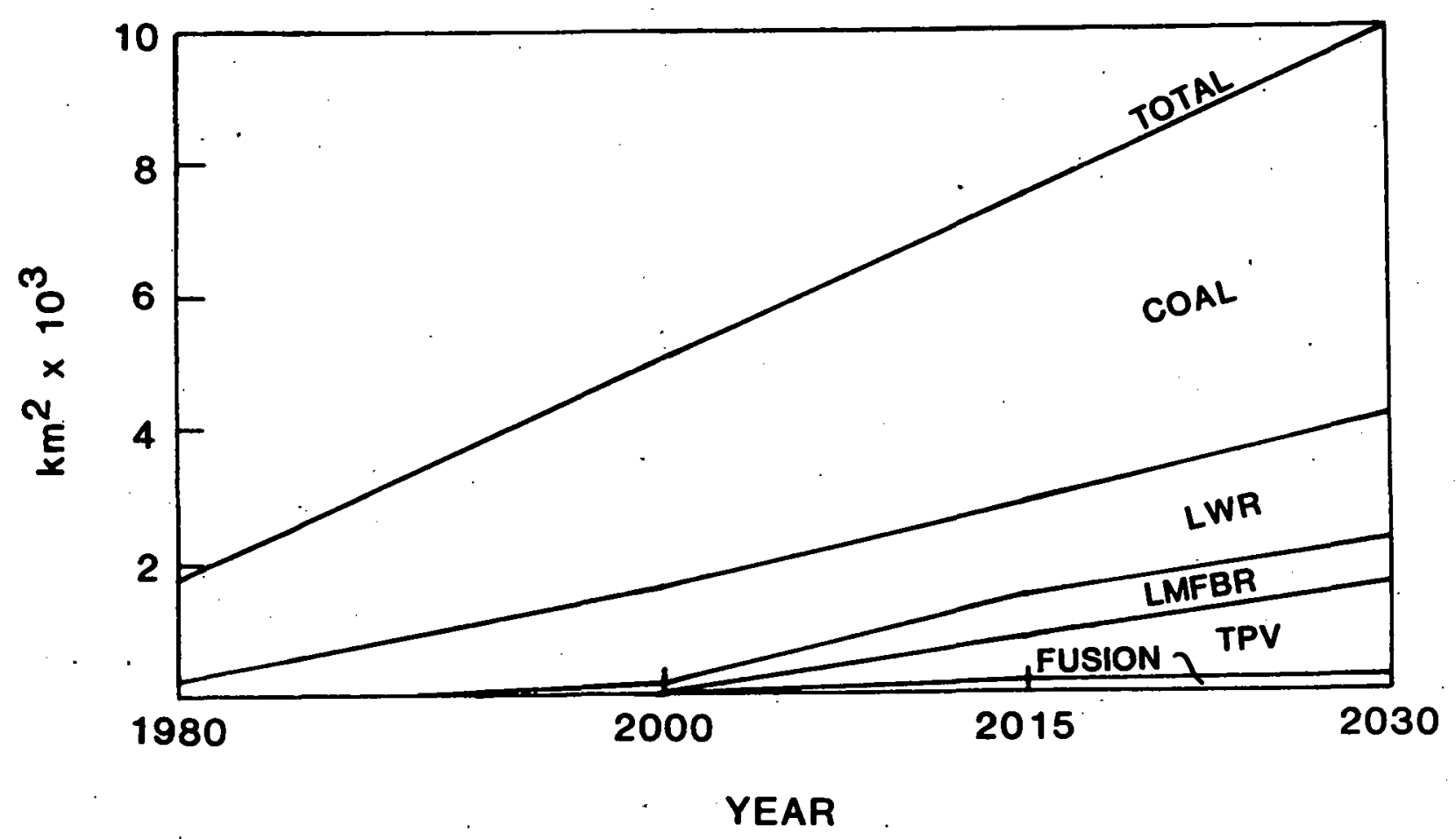

Fig. 4.38 Land Requirements for Scenario UH, without SPS

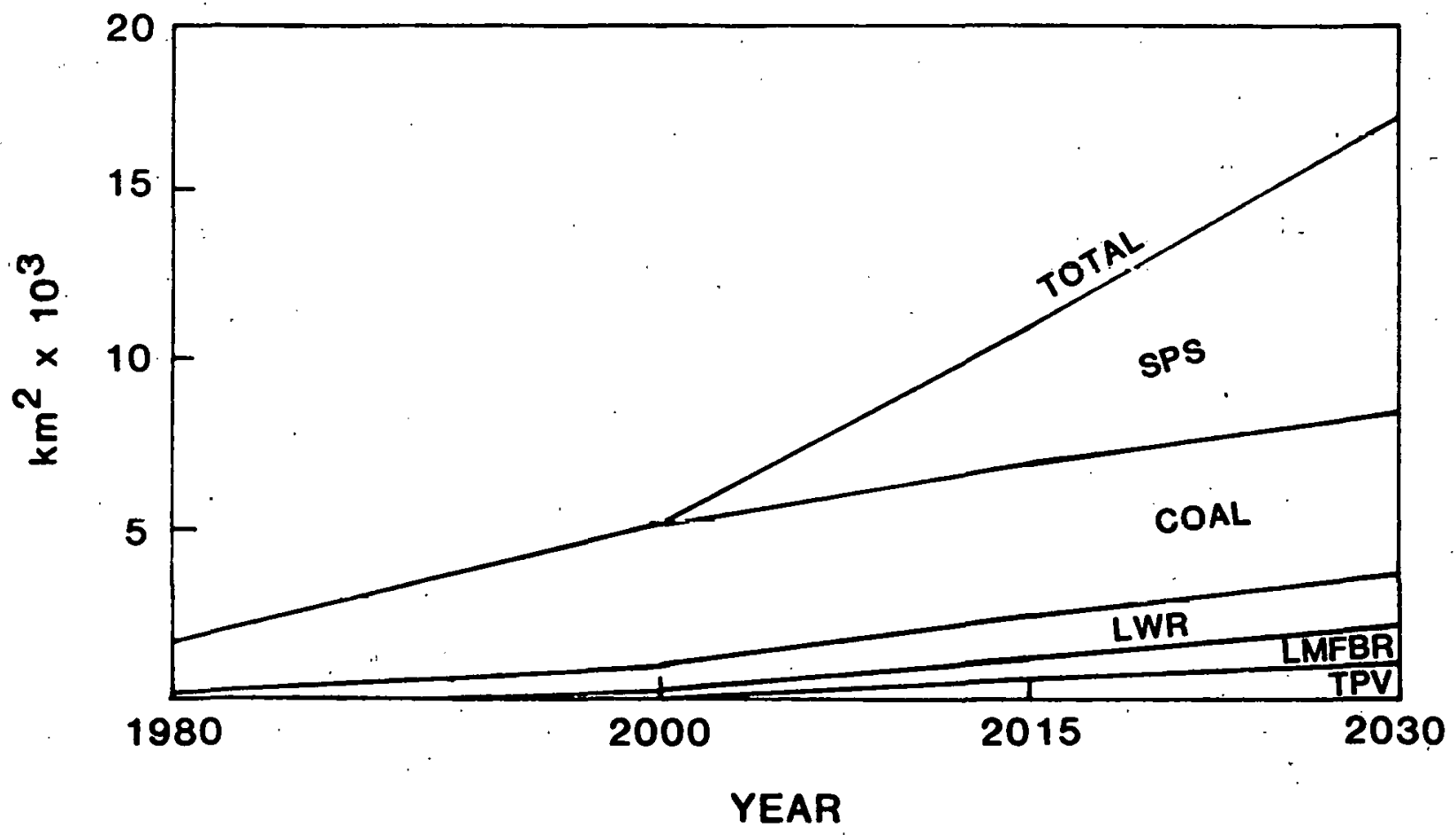

Fig. 4.39 Land Requirements for Scenario UH, with SPS 


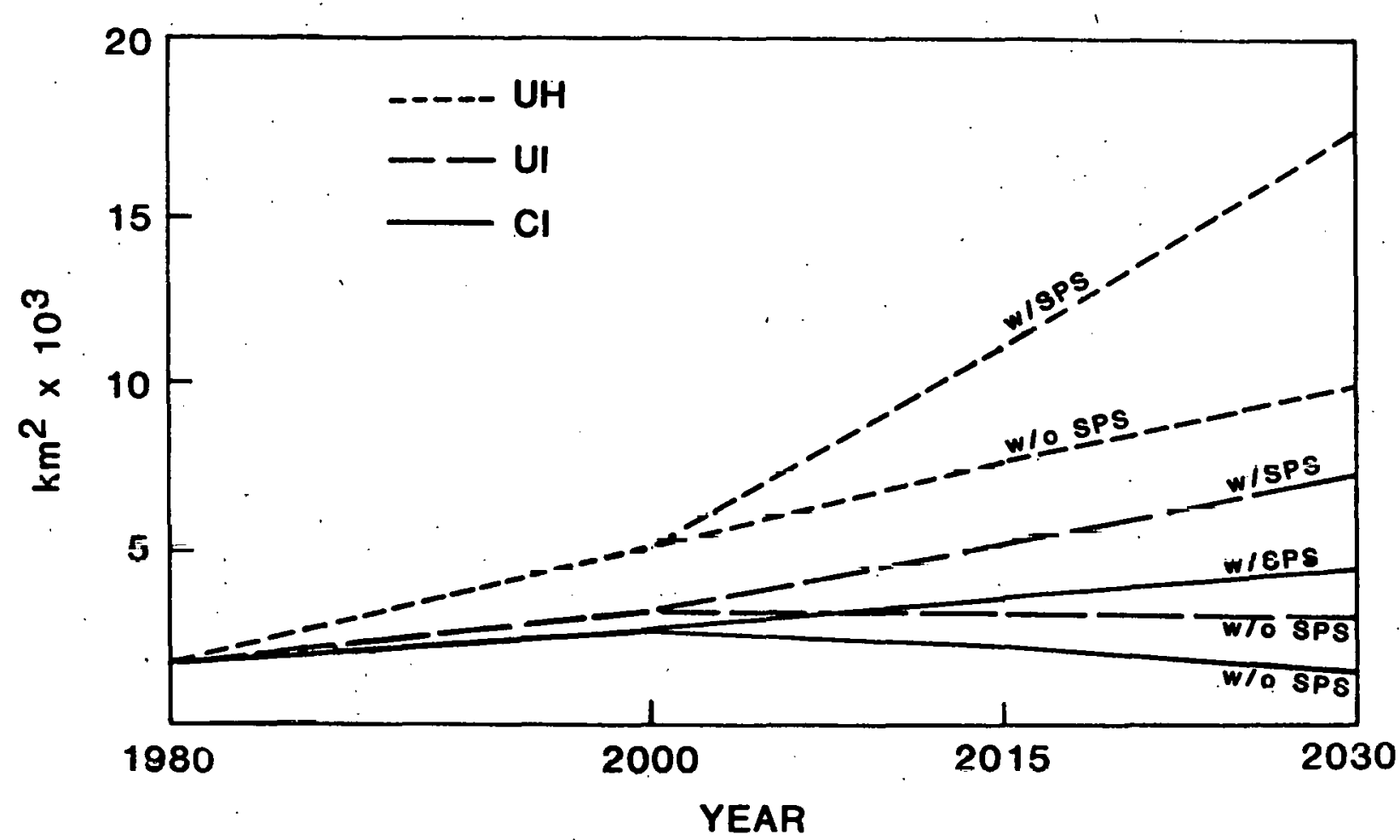

Fig. 4.40 Alternative Futures Analysis of Land Requirements

Observations. An unconstrained energy future with high energy intensiveness will likely result in much larger land requirements than used today. With SPS deployment, land requirements go up even higher. If TPV were to be deployed at a higher rate, further increases would be required. Without deploying SPS, it may be possible to keep land requirements for baseload energy production within a factor of two of today's requirements if lower energy intensiveness prevails.

In scenario CI, considered to be the most likely, deployment of SPS would itself result in the use of about $75 \%$ more land than the 1980 est imate for all technologies. Without SPS, the 1980 and 2030 figures are about equal in that scenario.

This analysis does not address the issue of acquisition of the needed land areas. Acquisiton may prove to be a difficult constraint in the case of the SPS, whlch requires large amounts of contlguous land in the current baseline design. A mitigating strategy is to reduce the size of the rectenna, which would decrease the installed capacity if power densities cannot be increased appropriately.

Since the question of land use is likely to play an important role in the siting of future energy technologies, the effects of SPS deployment and/or highly energy-intensive economies must not be overlooked. 


\subsubsection{Materials}

The objective of the materials analysis was to assess potential materials problems by identifying the types and quantities of materials required by the SPS and alternative technologies. Defining materials problems is not simple; many important factors should be included: resources, reserves, production capacity, import dependence, price, and opportunity costs.

The possibility of resource and/or reserve constraints depends on market penetration scenarios. Domestic production factors include current capacity, normal growth rate, and required growth rate to meet a given demand level. If domestic supplies of a material are inadequate, the balance must come from foreign markets; consequently, the possibility of cartels and the effects on the U.S. balance of trade must be considered. Since price is influenced by supply and demand, the possible effects of large increases in. supply or demand must be investigated. If a material is largely used by a single energy technology, opportunity costs result from the limited use of the resource for other purposes. The possibility of substitute materials becones an important issue for any materials judged to be a potential problem.

This comparative assessment is based on available research. In general, conclusions about materials problems published in the open literature were not based on rigorous considerations. of the above-mentioned criteria. Thus there is a lack of uniformity in conclusions from technology to technology because the assessments were done by different researchers. Where possible, an attempt was made to reconcile these differences for this assessment.

Sources include environmental impact statements, 23,159 system designs, 137,160,161 system descriptions, 139,162 federal documents, 163, 165 and comparative studies. $90,166-168$

The present comparison focuses on three screening criteria: Import dependence, availability (resources/reserves), and demand. Table 4.37. summarizes potential materials problems, by technology, for the three sereening criteria. There are two materials that raise all three flags: gallium and tungsten. Gallium is used for the SPS, and tungsten is used for both coal and the SPS. A number of materials raise the import dependence flag, probabily the iost important from a national security point of view. Nine SPS materials are indicated for reasons of import dependence.

. Because of the lack of complete and highly reliable materials data, a scenario perspective was not explicitly attempted for materials. Thus, the assessment has proceeded only to a qualitative side-by-side level.

\subsubsection{Eñergy}

Objective. The objective of the net energy analysis 169 was to provide a comparison of the net energy requirements of the SPS (silicon and GaAlAs solar cells) and alternative energy supply systems (CG/CC, LWR, and TPV with silicon solar cells). Conventional energy systems provide substantially more energy than was required to put them into operation, and so the concept of net 
Table 4.37 Potential Materials Problems, by Technology, for Three Screening Criteria

\begin{tabular}{|c|c|c|c|c|c|c|}
\hline & Coal & LWR & LMFBR & TPV & SPS & Fusion \\
\hline Aluminum & & & & & $\Delta$ & \\
\hline Antimony & & $\Delta$ & & & & \\
\hline Carbon Steel & O & 0 & 0 & 은 & 0 & 0 \\
\hline Chromium & $\Delta$ & $\Delta \square$ & $\Delta \square$ & & & $\Delta \square$ \\
\hline Cobalt & $\Delta$ & & & & & \\
\hline Gallium & & & & & $\Delta \square \quad 0$ & \\
\hline GFRTPa & & & & & 0 & \\
\hline Lithium & & & & & & 0 \\
\hline Manganese & & $\Delta$ & $\Delta$ & & $\Delta$ & $\Delta$ \\
\hline Mercury & & & & & $\Delta \square$ & \\
\hline Molybdenum & & $\square$ & $\square$ & & & $\square$ \\
\hline Nicke1 & $\Delta \square$ & $\Delta \square$ & $\Delta \square$ & $\Delta \square$ & $\Delta \square$ & $\Delta \square$ \\
\hline Silicon & & & & 0 & 0 & \\
\hline Silver & & & & & $\Delta \square$ & \\
\hline Titanium & & . & & & $\Delta$ & $\Delta$ \\
\hline Tungsten & $\triangle \square \quad 0$ & & & & $\triangle \square 0$ & \\
\hline Zinc & & & $\triangle$ & $\Delta \square$ & $\Delta$ & $\Delta$ \\
\hline
\end{tabular}

KEY : $\triangle$ Import Dependence

${ }^{a}$ Graphite Fiber Reinforced Thermoplastic.

energy analysis was not important to the decision-making process. Advanced technologies, however, require more energy investment to recover each unit of usable energy, and so the net energy assessment becomes a more important decision parameter.

Approach. This preliminary analysis considers state-of-the-art (circs 1985) capabilities for materials extraction and fabrication in order to identify cilical areas needing improvement. The possibility of technological improvements was considered in a number of key areas. The energy content of the fuel is not considered.

The boundary of each energy system was defined as extending from the primary resource (coal, uranium, and solar radiation) to electricity transmitted from the generating plant. The boundary includes environmental control systems and procedures to the extent that they are directly attributable to the energy system. Materials, fuels, and electricity required for plant construction and operation are also considered. 
A combination of process analysis and input/output analys is was used to compute the energy balance parameters for each supply system. Process analysis involves a detailed balance of energy flows into and out of a system. It is the most accurate and most involved method and can be applied to situations where a great deal of process-specific information exists. Input/ output ( $I / O)$ analysis uses an analogy to economic input/output analys is to determine the energy "costs" of any energy supply. It involves an identification of the interactions between sectors of the economy required to produce energy and a translation of the flow of goods and services among sectors into energy equivalents.

Each of the systems chosen for evaluation is described as a collection of system elements. Each element represents a particular piece of hardware, processing step, energy conversion step, or transportation mode. The energy balance of each system element is described in Fig. 4.41. The primary input is in the form of fuel (e.g., coal into a coal-processing plant) or energy (e.g., heat from a solar collector into a boiler). The ancillary operating inputs are those energy forms required to keep the process operating. The gross output is the energy or processed fuel that results from the system element. A portion of this gross output may be used to meet internal energy requirements. The balance is the net output that goes on to become the primary input of the next system element. The losses are the difference between the outputs and the inputs.

Up to this point, a straightforward energy balance can be carried out since all quantities of materials and their energy contents can be directly computed. This is the extent of the process analysis used in this assessment.

The indirect energy requirements of the system are embodied in the capital energy inputs, i.e., the materials, fuels, and electricity required to build the system element, and in the energy required to supply the electricity, fuels, and materials for operating inputs. A simplified analysis was used to compute direct energy requirements during this phase of the analysis.

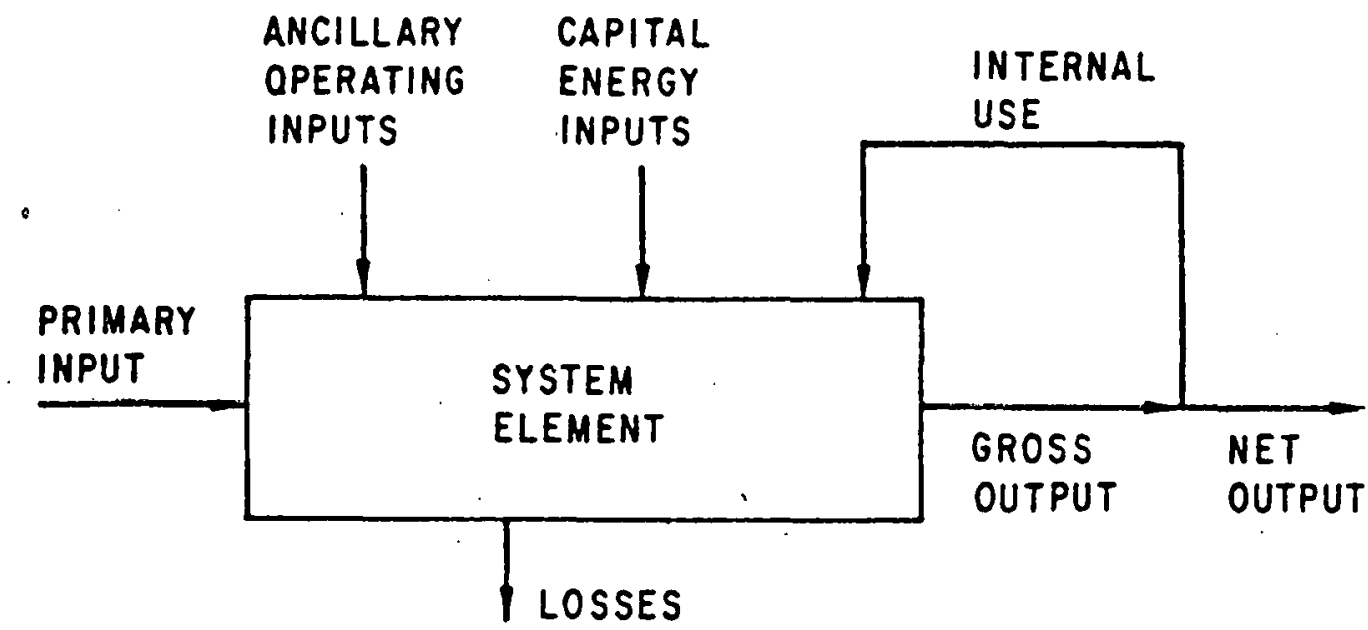

Fig. 4.41 Schematic of Energy Balance 
For each system element the quantities of materials, fuels, and electricity required to build and operate the system were compiled with the aid of published data on energy requirements 170-173 expressed either in joules per ton of materials or joules per dollar of material cost. The physical material quantity or material cost is converted into an energy requirement equivalent.

Energy Balance Parameters. A number of energy balance parameters were calculated, including gross efficiency, operating efficiency, operating ratio, lifetime efficiency, lifetime ratio, and payback period. Gross efficiency measures the amount of energy delivered per unit of input energy. Operating efficiency is a more complete measure of how effectively the basic energy resource is being utilized, i.e., how efficiently a given technology extracts use ful energy from a primary energy form. The operating ratio eliminates the energy content of the primary resource from the calculation, This parameter is a measure of how much useful energy can be extracted from a primary resource. It considers the primary resource as fundamentally unusable in its basic state and measures the amount of energy that must be expendnd tn convert it into usable form. The 1 ifetime efficiency and 1 ifetime ratio are analogous to the operating efficiency and operating ratio. They include the capital energy investment in the balance process, which represents the energy required to construct the system. Payback period is the time required for the system to produce enough useful energy to match the energy investment in building and operating it. All of these parameters must be considered because the efficiency and payback calculations tend to be better for the coal and nuclear systems than for the solar energy systems, whereas the operating ratio and lifetime ratio calculations tend to be better for the solar-based systems than for the coal and nuclear systems.

Annual and 1 ifetime net outputs are computed in terms of electrical units. All inputs are computed in thermal units but do not consider the thermal energy content of the fuels or materials involved, only the energy expended on such activities as mining, processing, and transportation. Theoe are the usual conventions for doing a net energy analysis. Thus, this approach represents a short-term view of the use of a nonrenewable resource base; for example, in computing payback, the interest is in determining at what rate an energy system returns electrical energy, given the investments (inputs) required. It does not consider the issue of depletion of a nonrenewable resource base, which must be addressed as a lost opportunity issue for alternative uses of the resource. Furthermore, if the thermal content of a nonrenewable resource were considered, the payback period for systems based on nonrenewable resources would be infinite, by the second law of thermodynamics.

Results. Table 4.38 summarizes the baseline calculations. The coal and nuclear* systems are two to five times more efficient than the solar systems but operate on nonrenewable resources. The calculation of efficiency

*of the nuclear systems, only the LWR was studied in detail. The LMFBR, although it has higher capital energy costs, should at least break even due to lower fuel energy costs. LMFBR fuel is produced by chemical separation, which is less energy intensive than the diffusion process needed to enrich fuel for the LWR. 
Table 4.38 Summary of Energy Balance Data

\begin{tabular}{|c|c|c|c|c|c|}
\hline \multirow[b]{2}{*}{ Parameter } & \multirow{2}{*}{$\frac{\text { Nuclear }}{\text { LWR }}$} & \multirow{2}{*}{$\frac{\text { Coal }}{\mathrm{CG} / \mathrm{CC}}$} & \multirow{2}{*}{$\begin{array}{c}\begin{array}{c}\text { Terrestrial } \\
\text { Solar }\end{array} \\
\text { Photovoltaic }\end{array}$} & \multicolumn{2}{|c|}{ SPS } \\
\hline & & & & Silicon & GaAlAs \\
\hline Gross Efficiency ${ }^{a}(\%)$ & 22 & 37 & 6 & 7 & 7 \\
\hline Operating Efficiency $\mathrm{b}(\%)$ & 20 & 33 & 6 & 7 & 7 \\
\hline Operating Ratioc & 3 & 4 & 27 & 17 & 78 \\
\hline Lifet ime Efficiency (\%) & 20 & 33 & 5 & 7 & 7 \\
\hline Lifetime Ratioe & 3 & 3 & 1 & 4 & 18 \\
\hline Payback Periodf (yr) & 1 & 1 & 20 & 6 & 1 \\
\hline
\end{tabular}

Source: Ref. 130 .

Annual net output/annual primary input.

bAnnual net output/annual primary, operating, and internal inputs.

cAnnual net output/annual operating and internal inputs.

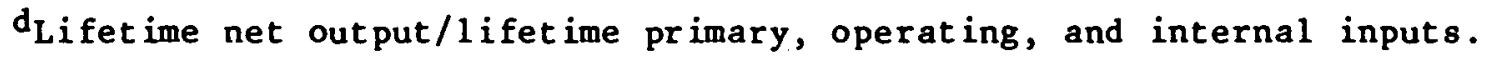

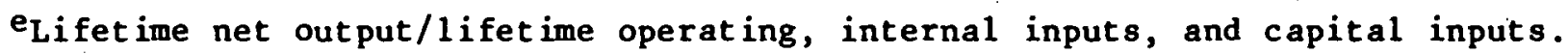

$f_{\text {Time }}$ at which net output equals operating + capital inputs.

for each system is not sensitive to the gross, operating, or lifetime calculations. The conversion efficiency of the system dominates the result.

The operating ratio calculation shows that the solar energy systems require substantially less operating energy per unit of electrical output. However, the 1 ifetime ratio calculation shows that the intensive capital investment reduces their energy ratios significantly. The payback period for all systems except SPS/Si and terrestrial photovoltaic is less than 1.5 years. In both of these cases, sensitivity analysis shows that long payback is dominated by the energy intensity of silicon production. A number of possibilities, including reduction in the overall energy requirements of cell production, the use of solar-generated electricity in place of conventional electrical power for cell manufacture, increased cell 1 ifetime, and decreased silicon requirements could reduce the SPS/Si payback period to a level comparable to the other systems (i.e., one to two years); the best combination of conditions for the terrestrial photovoltaic system would still result in a payback of about six years. 169

Comparison to Other Studies. The comparison of these SPS results with those of previous studies is of particular interest. Direct comparison is difficult because each study is based on a different reference design and methodology. Some approximate comparisons $c$ an be made however, noting the major sources of difference. 
A Planning Research Corporation study 174 used I/O analys is of a GaAlAs SPS. The study assumed higher energy intensiveness and resulted in a 2.5 year payback (vs. 1.3 years calculated here).

Herendeen 172 used $\mathrm{I} / 0$ analysis and uncertainty to set a range for the 1 ifetime ratio from 0.7 to 6.6 , with a mean of 2.1 , for a 10-GW SPS. This is surprisingly close to our result of 4.0 , considering major differences in the assumption about silicon cell life. Herendeen assumed an exponentially decreasing cell power output over a 30-year lifetime. This analysis assumes maintenance to obtain constant power output and a 30-year 1 ife.

A Jet Propulsion Laboratory (JPL) study171 computed a payback period in the range of 1.2 to 1.6 years for a system of $4810-G W$ silicon satellites (vs. 6.4 years here). Three major factors account for the difference in the estimates. JPL assumes a reduction in the requirements for gilicon cell production to about one-fourth of the energy requirements assumed here, and only half as much silicon. Most important, JPL converts electrical energy to a thermal equivalent by multiplying by a factor of three. Removing only this last difference results in a payback of 3.6 to 4.8 years for the JPL study.

Summary. The current state of knowledge indicates that energy balance is not a significant factor precluding the development of certain coal; nuclear, and satellite power systems. There are indications that reductions in energy requirements for silicon cell production will be needed, since those requirements constitute a large factor in net energy calculation for silicon systems. In addition, although current data indicate that GaAlAs cells provide a viable alternative, further studies are warranted because information on the energy requirements of these cells is extremely limited.

In conclusion, the net energy analysis has shown that the SPS system with silicon cells is a viable alternative, having a payback period substantially smaller than its lifetime; a TPV system using silicon cells does not look as attractive. However, if the most optimistic projections were realized for silicon cell production, the TPV option, would become a viable alternative from an energy-balance perspective.

If development of a gallium photocell proceeds as currently projected, an SPS system with GaAlAs cells will result in a payback period comparable to CG/CC and nuclear. In any event, the SPS is a viable alternative using state-of-the-art technologies, with promise of even better technology in the foreseeable future.

\section{5 .4 Water}

Overview. As for the land assessment, both a side-by-side analysis and an alternative futures analysis were completed for water use. The side-byside comparison is based on the technology characterization data. Scenario data are coupled with the side-by-side data to provide water use estimates over the 1980-2030 time frame. 
Side-by-side Analysis. All technologies; except for TPV and SPS, require about the same amounts of water. The range is $14-77 \times 10^{6}$ $\mathrm{m}^{3} / \mathrm{GW} / \mathrm{yr}$ (installed). Water use for SPS and TPV is negligible. Table 4.39 summarizes the side-by-side data. The entries are the volumes of water consumed; withdrawal requirements were not identified in the technology characterizations.

Alternative Futures Analysis. Scenario data do not disaggregate coal use by technology. It is necessary to make an assumption about the ratio of deployment of conventional coal combustion to that of CG/CC. Assuming equal deployment, the average water consumption is about $45 \times 10^{6}$ $\mathrm{m}^{3} / \mathrm{GW} / \mathrm{yr}$ (installed) for coal technology. For non-solar technologies, the range of water consumption is then $32-45 \times 10^{6} \mathrm{~m}^{3} / \mathrm{GW} / \mathrm{yr}$ (installed).

Since the real issue here is the impact solar technologies might have on water consumption, the precision gained by considering the individual technologies is of little value. Therefore, a mid-range value of $40 \times 10^{6}$ $\mathrm{m}^{3} / \mathrm{GW} / \mathrm{yr}$ (installed) is used to estimate these effects. Figure 4.42 illustrates these results.

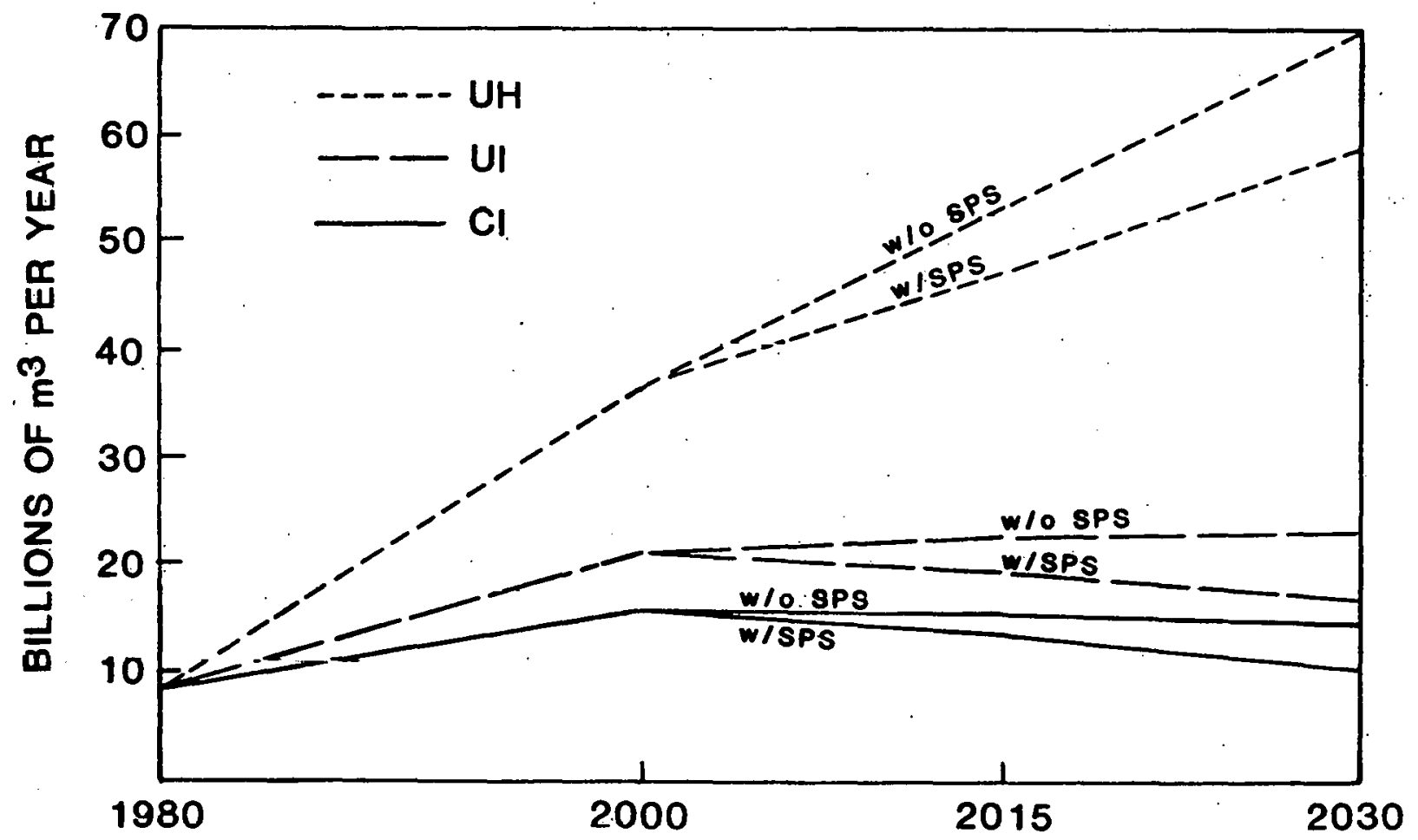

YEAR

Fig. 4.42 Alternative Futures Analys is of Annual Water Consumption for Baseload Electricity Generation 
Deployment of SPS avoids the consumption of $4 \times 10^{9}, 6 \times 10^{9}$, and $10 \times 10^{9} \mathrm{~m}^{3}$ of water in the year 2030 for scenarios CI, UI, and UH, respectively. These are $30 \%, 28 \%$, and $19 \%$ of the amounts that would otherwise be consumed in the respective scenarios. Another point of reference is the estimated $8.1 \times 10^{9} \mathrm{~m}^{3}$ of water consumed for baseload electricity generation in 1980 .

The main factor driving water consumption (and consumption of any other resource) is energy demand. The saving due to SPS deployment in scenario UH is dominated by the issue of supplying roughly $50 \times 10^{9} \mathrm{~m}^{3}$ of water on an annual basis. Clearly, the probability that the water demands of scenario CI or scenario UI will be met has to be much higher than that for scenario UH:

4.5 .5 Labor

Overview. The labor assessment estimated the number of workers required for plant construction, operation and maintenance, and fucl cycle fơ each of the technologies. Again, both side-by-side and alternative futures analyses were performed.

Side-by-Side Analysis. Labor requirements were developed by the technology characterizations activity and are listed in Tables 4.40 and 4.41. Table 4.40 lists requirements for a specific plant design and is useful for considering socioeconomic impacts during the construction phase and the o\&M phase. Table 4.41 lists requirements on a per-GW (installed) basis, which is useful for the alternative futures analysis. Labor categories are construc$t$ ion, operation (including maintenance), and fuel cycle.

Except for SPS and TPV, there is little difference in the per-unit labor requirements for construction; $8 P G$ requires the largest crew oize but also has the largest capacity, while TPV requires the gmallest crew size but also has the smallest capacity. These differences are important in considering socioeconomic impacts on localities during construction, discussed in Sec. 4.6.

Annual labor requirements for operation and maintenance (O\&M) are significantly different from fuel cycle labor requirements. The approximate numbers of persons required per plant for $0 \& M$ and the fuel cycle are 900 for coal, 400 for fission and SPS, 200 for fusion, and 26 for TPV. The large coal number is attributable to its fuel cycle (mainly mining) requirements. Opera$t$ ion and maintenance requirements are about the same for all technologies, except for TPV. The ratio of construction force to O\&M force is generally about 4 or 5. However, for SPS the difference amounts to about 2000 people, which could be a significant factor affecting the magnitude of a boom/bust transition at a rural location.

Alternative Futures Analysis. There is little difference in the construction labor requirements per GW of installed capacity among the technologies. Since SPS requires the smallest labor force, scenarios with higher penetration rates for SPS would result in lower total construction labor requirements. 
Table 4.40 Labor Requirements for Specific Plant Designs

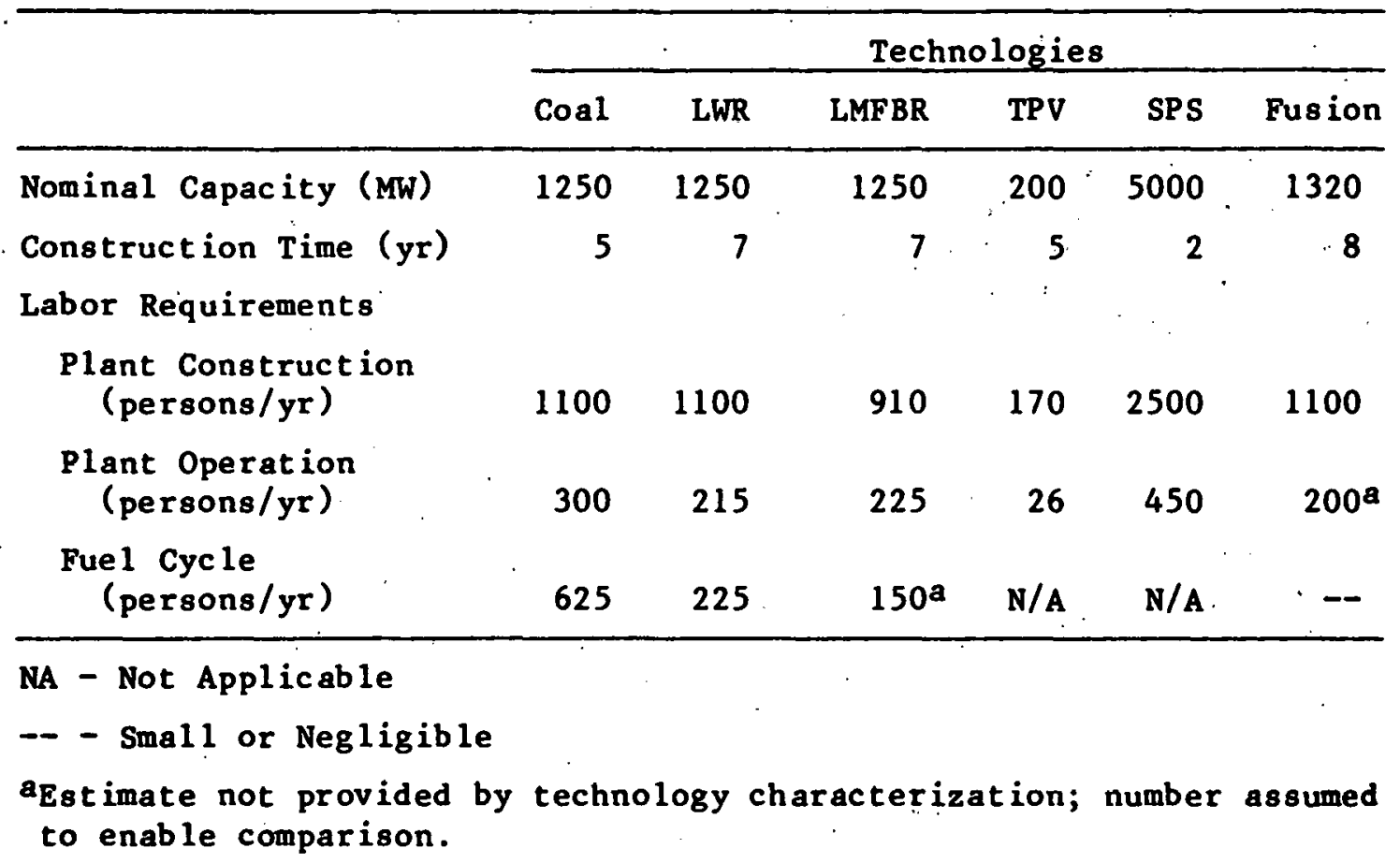

Tab le 4.41 Normalized Labor Requirements (per GW)

\begin{tabular}{|c|c|c|c|c|c|c|}
\hline Activity & Coal & LWR & LMFBR & TPV & SPS & Fusion \\
\hline $\begin{array}{l}\text { Plant Construction } \\
\text { (persons/yr) }\end{array}$ & .880 & 880 & 730 & 850 & 500 & 830 \\
\hline $\begin{array}{c}\text { Plant Operation } \\
\text { (persons/yr) }\end{array}$ & 240 & 170 & - 180 & 130 & 9 & 150 \\
\hline Fuel Cycle (persons/yr) & 500 & 180 & 120 & $\mathbf{N} / \mathbf{A}$ & $\mathbf{N} / \mathbf{A}$ & . -- \\
\hline
\end{tabular}

There are larger differences for the annual $0 \& M$ and the fuel cycle labor requirements among the technologies. In all scenarios, these requirements are abnut 1.5 to 30 times the annual construction requirements for coal and the LWR technologies, which dominate the technology mixes. Replacement of coal and nuclear with solar technologies would reduce these requirements significantly.

Figure 4.43 illustrates these comparisons. The earlier scenario data and the labor data for $0 \& M$ and the fuel cycle from Table 4.41 form the basis for the figure. The reductions in the year 2030 labor requirements for $O \& M$ and the fuel cycle due to SPS deployment are about 20,000, 40,000, and 120,000 . persons for scenarios CI, UI, and UH, respectively. 


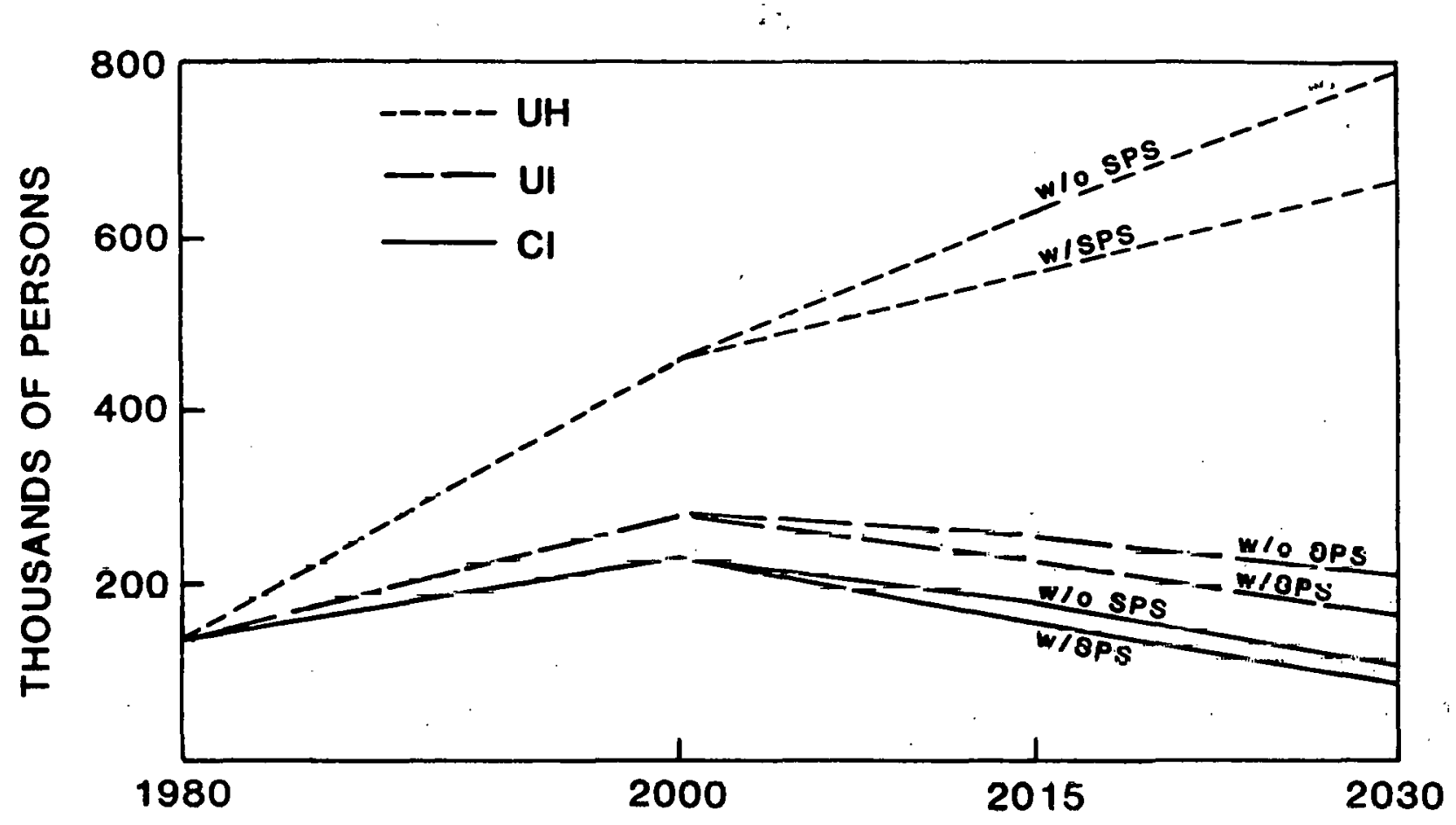

YEAR

Fig. 4.43 O\&M and Fuel Cycle Labor Requirements

The annual construction labor force for SPS has been estimated at 2500 persons per installation. Assuming that construction takes place over two years and that the construction crew must stay at a single site for the entire $t$ ime period, then the number of crews required (after the first year) would be one or two for scenario CI, two for scenario UI, and four for scenario UH. In scenario $\mathrm{CI}$, the distribution of labor requirements from year to year is uneven due to the deployment rate of two systems every three years.

The skills required are not identified in this analysis. However, they are likely to be much different between technologies (e.g.; space construction workers for SPS); further treatment of these differences is beyond the scope of this analysis.

\subsection{MACROECONOMIC AND SOCIOECONOMIC ISSUES}

\subsubsection{Introduction}

This section uses results from earlier sections on scenarios (Sec. 4.1) and cost and performance (Sec. 4.2).

Results* of the macroeconomic analysis indicate that (1) if uranium and coal supplies are highly constrained, then the costs due to deployment of more

*A1l cost figures in this section are in 1978 dollars. 
expensive but fuel-saving technologies may be offset by savings in other energy sectors (e.g., deployment of $3.3 \mathrm{GW}$ per year of the SPS priced at 60 mills/kWh could result in a reduction of about $\$ 20$ billion in energy expenditures for the year 2025, because of savings in nuclear- and coal-based energy technologies); (2) deployment of technologies requiring large capital investments tends to cause a reduction in the GNP growth rate (e.g., deployment of $10 \mathrm{GW}$ per year of SPS could reduce the GNP growth rate by $10-25 \%$ in the year 2000 which, if continued and compounded to the year 2030, would result in a $\$ 400-1000 \times 10^{9}$ reduction in a $\$ 7 \times 10^{12}$-GNP economy); (3) all the constrained scenarios are inflationary, because the prices of scarce fuels are higher than they would be otherwise; and (4) deployment of fuel-saving technologies counteracts to some degree the inflationary aspects of a constrained environment, but quantitative estimates are difficult.

Qualitative macroeconomic assessments on a regional level show that the impacts across technologies are quite different, with different regions having a vested interest in particular technologies. Similarly, income-class macroeconomic assessments show that income groups (low, medium, high) have vested interests in particular technologies during both construction and operation. Public infrastructure costs and social stresses during both construction and operation were considered in a socioeconomic analysis. During construction, these effects may be quite significant for any remotely sited technology; however, due to the large amount of construction involved, this issue is particularly relevant for the SPS and TPV. All technologies should have minimal socioeconomic effects during operation.

One major potential socioeconomic effect, though controversial and unquantifiable, is that successful development of the SPS could provide the technical and industrial infrastructure necessary for further exploration of and industrialization in space.

\subsubsection{Macroeconomic Analys is}

Calculations performed here are based on data for the years 2000 and 2025 because data for these years are available from the RFF model. Results for other years are largely based on interpolation and extrapolation of these results.

Discussion. The average cost of central-station electricity generation (excluding fuel) in the U.S. is about $25 \mathrm{mills} / \mathrm{kWh}$ for coal and $30.5 \mathrm{mills} / \mathrm{kWh}$ for nuclear power. These figures may increase somewhat, in constant dollars, as mandated environmental and safety controls are implemented. The added costs will be compensated for, in part, by gradual improvements in technical pffiriency: In contrast, the future cost of SPS -- as for other untested technologies -- is quite uncertain. The lower bound of present estimates appears to be at least a factor of two above the present nonfuel cost of nuclear electricity, or around $60 \mathrm{mills} / \mathrm{kWh}$. This translates to $\$ 17.50$ per million Btu.

The macroeconomic impact of introducing a high-cost alternative technology such as SPS arises from three factors: 
- Reduced dependence on imports, with possible associated effects on international energy prices, the U.S. balance of payments, the international value of the dollar, the cost of imports, and the volume of exports;

- Reduced dependence on scarce or constrained domestic fuels, resulting in lower domestic prices for most forms of energy; and

- Diversion of capital away from the most productive forms of investment, with consequent reductions in the rate of GNP growth.

The relative importance of the first two factors depends on which fuels are replaced by the alternative. If SPS were available today, for instance, it would have its primary impact on the need for oil imports. Assuming the international oil (spot) market is competitive -- at least at the margin the direct consequence of a reduction in U.S. demand (say by 1 quad per year -- 1 quad $=1015 \mathrm{Btu}$ ) would be a drop in the internatiulul sput price of oil, depending on short-run elasticities of demand and supply. Indirect further consequences would include an improved U.S. balance of payments, a stronger dollar, reduced cost of other imports, a lower domestic inflation rate, and more dollars spent in the U.S. for domestically produced goods and services.

After the year 2000, however, it seems unlikely that oil from any source would be used as a boiler fuel. In such circumstances, SPS would effectively substitute for coal or uranium. A reasonable (perhaps optimal) strategy in a constrained economy would be to replace all coal used by utilities first, since lower coal prices would then result in lower prices for syngas manufactured for coal and (because of their direct equivalence) for natural gas. Lower costs would also be experienced by the steel industry, which is a major coal user.

Supporting Data. The magnitude of the impact depends on the extent of the deployment of SPS. Some rough calculations of the effect for three representative scenarios have been carried out. A set of baseline data for GNP and energy use is shown in Table 4.42. Table 4.43 disaggregates energy use by fuel and lists the prices by scenario for the year 2025. Figures 4.44 through 4.46 display supply and demand data for scenarios CI, UI, and UH, respectively. Table 4.44 summarizes the 2025 baseload generating capacitie $\$$, SPS deployment, and percentage SPS for the three scenarios.

Calculating Net Energy Expenditures. In scenario CI, SPS is deployed at the rate of $3.3 \mathrm{GW}$ per year beginning in the year 2000 . At this rate, 83 GW will be in place by the year 2025, about $21 \%$ of the total baseload capacity of $391.4 \mathrm{GW}$. These $83 \mathrm{GW}$ of installed electrical generation capacity, operating at a capacity factor of 0.9 , could displace the burning of $5.2 x$ $1015 \mathrm{Btu}$ of coal (at a heat rate of $8125 \mathrm{Btu}$ per $\mathrm{kWh}$ ). Only $3.3 \times 10^{15} \mathrm{Btu}$ of coal are burned for electricity in scenario $\mathrm{CI}$; an upper bound of the economic benefit of $83 \mathrm{GW}$ of SPS capacity $\left(2.2 \times 10^{15} \mathrm{Btu}\right)$ can be calculated assuming that no coal is burned for electricity production, with the remaining SPS generating capacity displacing nuclear electricity production. 
Table 4.42 Baseline Energy/Economic Data

\begin{tabular}{cccccc}
\hline & GNP & & \multicolumn{3}{c}{ Energy (Quads)* } \\
\cline { 2 - 3 } \cline { 5 - 6 } Year & $\$ 10^{12(1978)}$ & & CI & UI & UH \\
\hline 1980 & 2.1 & 92.4 & 92.4 & 92.4 \\
2000 & 3.7 & 98.4 & 99.6 & 132.3 \\
2015 & 5.4 & 117.1 & 128.8 & 169.8 \\
2025 & 6.5 & 129.6 & 148.3 & 194.7 \\
2030 & 7.0 & 135.3 & 158.1 & 207.1
\end{tabular}

$* 1$ quad $=10^{15}$ Btu

Table 4.43 Energy Use and Prices for 2025 without SPS

\begin{tabular}{|c|c|c|c|c|c|c|}
\hline \multirow[b]{2}{*}{ Scenario } & \multicolumn{2}{|c|}{ Electricity } & \multicolumn{2}{|c|}{ Gas } & \multicolumn{2}{|c|}{ Coal (Direct) } \\
\hline & Quads* & $\$ / 10^{6}$ Btu & Quads* & $\$ / 10^{6}$ Btu & Quads* & $\$ / 10^{6}$ Btu \\
\hline CI & 10.3 & 15.76 & 45.6 & 7.87 & 7.6 & 3.45 \\
\hline UI & 14.2 & 13.40 & 56.2 & 5.98 & 9.8 & 1.66 \\
\hline UH & 36.3 & 13.55 & 34.7 & 6.29 & 15.0 & 1.73 \\
\hline
\end{tabular}

$\star_{1}$ quad $=10^{15} \mathrm{Btu}$

To perform these calculations, the change in the price of coal must first be determined. The effect of adding a new source in a constrained economy is to reduce demand for one of the existing fuels (e.g., coal). Consequently, in situations where the market-clearing price lies above the cost, the equilibrium (supply = demand) price level must drop, as illustrated in Fig. 4.44. Demand and supply intersect at point $A$ (from the demand schedule for scenario UI); the market-clearing price for coal is $\$ 1.66$ per million Btu. In scenario $C I$, the supply of coal is restricted and the market clears at a price of $\$ 3.45$ per million Btu (point B). A straight line through points $A$ and $B$ provides an approximation to the demand schedule.

Under these conditions, there are four impacts of SPS, provided only that output exceeds 3.3 quads:

(1) SPS displaces 3.3 quads of coal-fired electricity (gross) -- reducing coal-fired electricity to zero -- and thereby shifts the demand curve for coal to the left by 3.3 quads. This, in turn lowers the market clearing price for coal to $\$ 3.08$ per million Btu (point C in Fig. 4.44). 


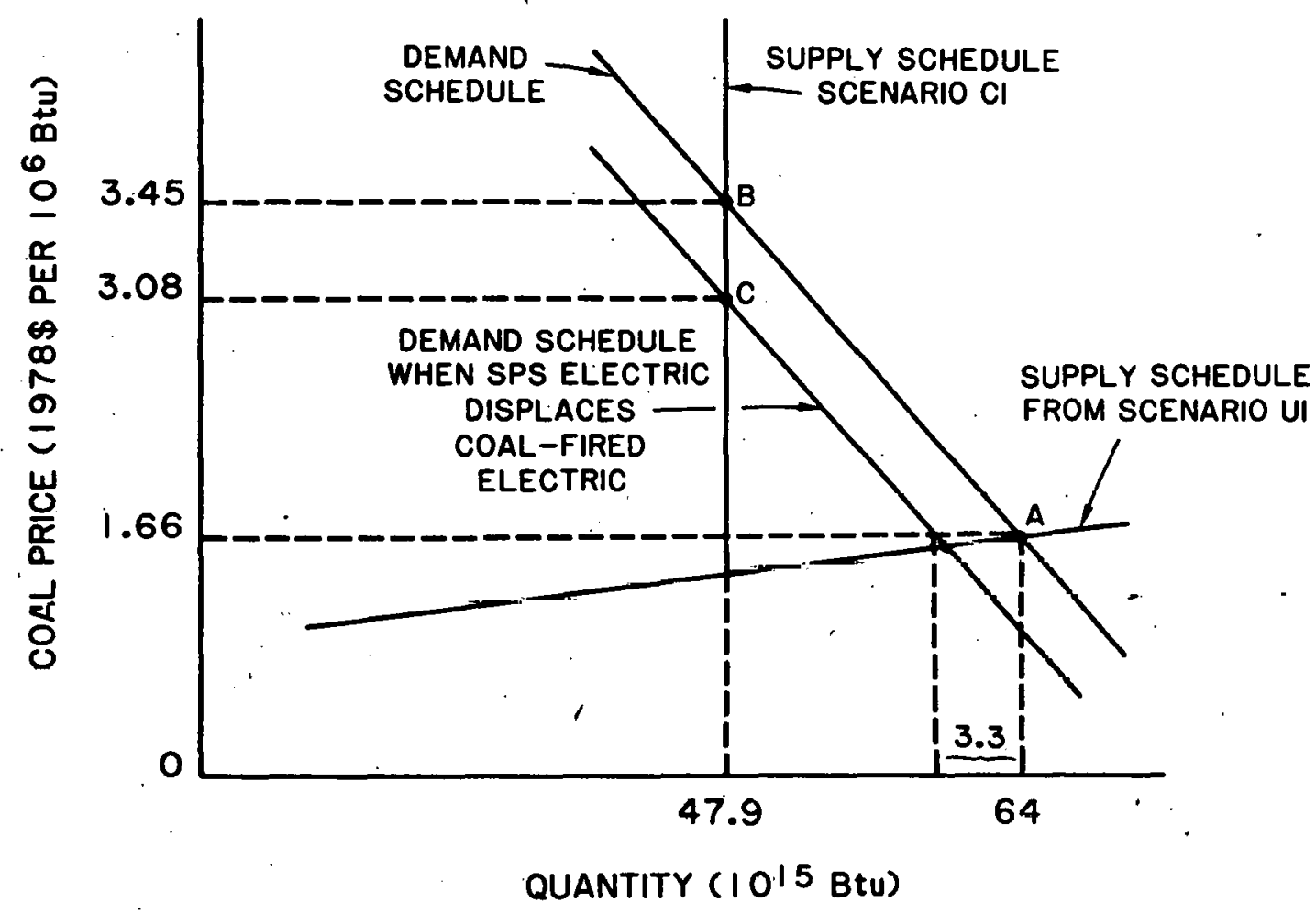

Fig. 4.44 Coal Demand and Supply, Scenario CI (2025)

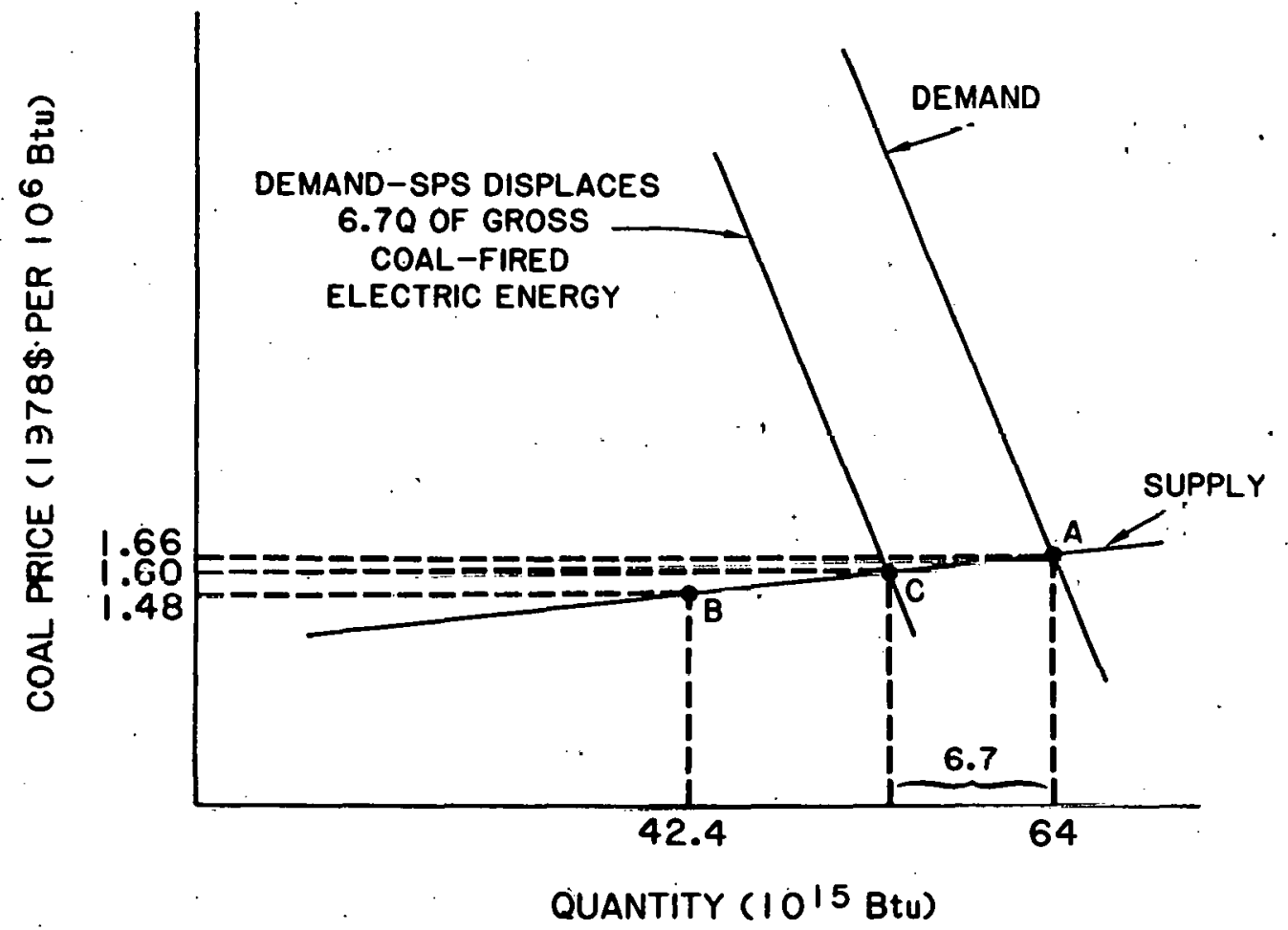

Fig. 4.45 Coal Demand and Supply, Scenario UI (2025) 


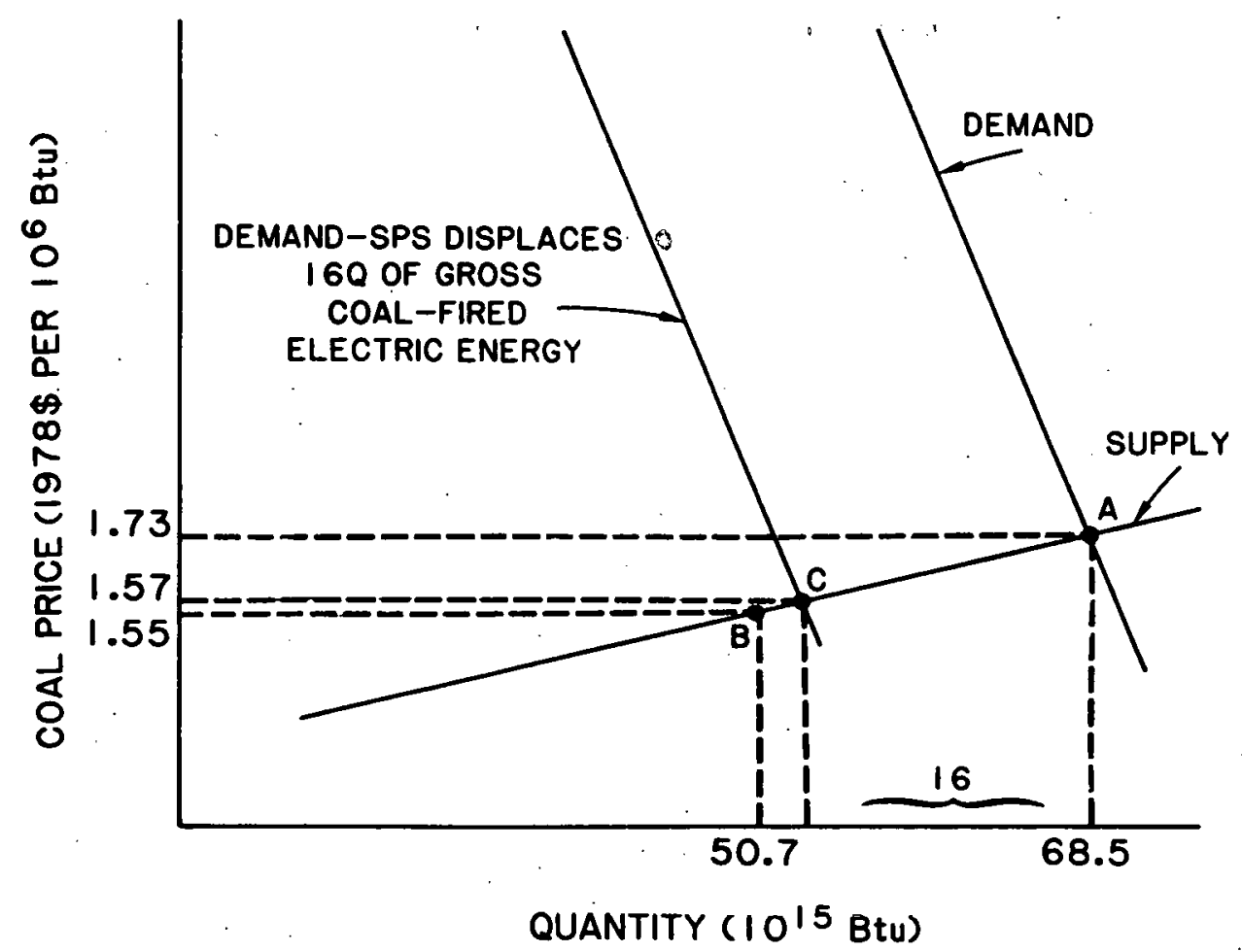

Fig. 4.46. Coal Demand and Supply, Scenario UH (2025)

Table 4.44 Baseload and SPS Deployment Data

\begin{tabular}{|c|c|c|c|}
\hline Scenario & Baseload (GW) & SPS (GW) & $\%$ SPS \\
\hline CI & 391.4 & 83 & 21 \\
\hline UI & 589.9 & 125 & 21 \\
\hline UH & 1647.9 & 250 & 15 \\
\hline
\end{tabular}

(2) The average direct cost of electricity changes by an amount depending on the cost and deployment of SPS, accompanied by reduced costs of electricity production by other technologies.

(3) The price for gas falls from $\$ 7.87$ per million Btu to $\$ 7.48$ per million $B t u$ as a result of the fall in the price of coal.

(4) The fall in the price of coal reduces the direct expenditure for coal to be used as industrial boiler fuel and feedstock.

At a price of $60 \mathrm{mills} / \mathrm{kWh}\left(\$ 17.60 / 10^{6} \mathrm{Btu}\right)$ for SPS electricity, the average direct cost of electricity increases slightly from $\$ 15.76 / 10^{6}$ Btu to 
$\$ 15.78 / 10^{6} \mathrm{Btu}$. The price for gas is related to the cost of converting coal to gas at an $80 \%$ conversion efficiency; the quantity of gas involved includes both coal conversion and natural gas sources. Table 4.45 summarizes these data for the three scenarios, with SPS at the appropriate level of deployment. There are two entries for electricity in each scenario, one for SPS electricity, one for non-SPS electricity.

The data in Tables 4.43 through 4.45 provide the basis for the energy expenditures 1 isted in Table 4.46. Net expenditure is the total energy expenditure without SPS, subtracted from the total with SPS. A result greater than zero means that SPS does not trigger enough savings of scarce fuels to offset the increased cost of electricity; a result less than zero indicates the savings are greater than the increased cost of electricity.

The calculation of energy expenditures for different SPS electricity prices is straightforward (approximated by a linear function of the SPS electricity price) given the calculations just described. Figure 4.47 shows year-2025 results for all scenarios over the 30-120 mills/kWh range for SPS electricity.

Table 4.45 Energy Use and Prices for 2025 with SPS Deployment at $60 \mathrm{mills} / \mathrm{kWh}(1978$ \$)

\begin{tabular}{|c|c|c|c|c|c|c|}
\hline \multirow[b]{2}{*}{ Scenario } & \multicolumn{2}{|c|}{ Electricity } & \multicolumn{2}{|c|}{ Gas } & \multicolumn{2}{|c|}{ Coal (Direct) } \\
\hline & Quads & $\$ / 10^{6}$ Btu & Quads & $\$ / 10^{6} \mathrm{Btu}$ & Quads & $\$ / 10^{6}$ Btu \\
\hline CI & $\begin{array}{l}8.1 \\
2.2\end{array}$ & $\begin{array}{l}15.27 \\
17.60\end{array}$ & 45.6 & 7.48 & 7.6 & 0.08 \\
\hline UI & $\begin{array}{r}10.8 \\
3.4\end{array}$ & $\begin{array}{l}13.33 \\
17.60\end{array}$ & 36.2 & 5.91 & 9.8 & 1.60 \\
\hline UH & $\begin{array}{r}29.6 \\
6.7\end{array}$ & $\begin{array}{l}13.36 \\
17.60\end{array}$ & 34.7 & 6.13 & 15.0 & 1.57 \\
\hline
\end{tabular}

Table 4.46 Energy Expenditures with SPS at $60 \mathrm{mil} 1 \mathrm{~s} / \mathrm{kWh}$ and without SPS, for the year 2025 (\$109, 1978)

\begin{tabular}{|c|c|c|c|c|c|c|c|}
\hline Srenario & SP S & Elcctricity & Gas & Coal & (Direct) & Total & $\begin{array}{c}\text { Net } \\
\text { Expenditure }\end{array}$ \\
\hline CI & $\begin{array}{l}\text { No } \\
\text { Yes }\end{array}$ & $\begin{array}{l}162.3 \\
162.5\end{array}$ & $\begin{array}{l}358.9 \\
341.1\end{array}$ & & $\begin{array}{l}26.2 \\
23.4\end{array}$ & $\begin{array}{l}547.4 \\
527.0\end{array}$ & -20.4 \\
\hline UI & $\begin{array}{l}\text { No } \\
\text { Yes }\end{array}$ & $\begin{array}{l}190.3 \\
204.0\end{array}$ & $\begin{array}{r}336,1 \\
332,1\end{array}$ & & $\begin{array}{l}16.3 \\
15.8\end{array}$ & $\begin{array}{l}542.7 \\
551.9\end{array}$ & 9.2 \\
\hline UH & $\begin{array}{l}\text { No } \\
\text { Yes }\end{array}$ & $\begin{array}{l}491.9 \\
513.5\end{array}$ & $\begin{array}{l}218.3 \\
212.7\end{array}$ & & $\begin{array}{l}26.0 \\
23.6\end{array}$ & $\begin{array}{l}736.2 \\
749.8\end{array}$ & 13.6 \\
\hline
\end{tabular}




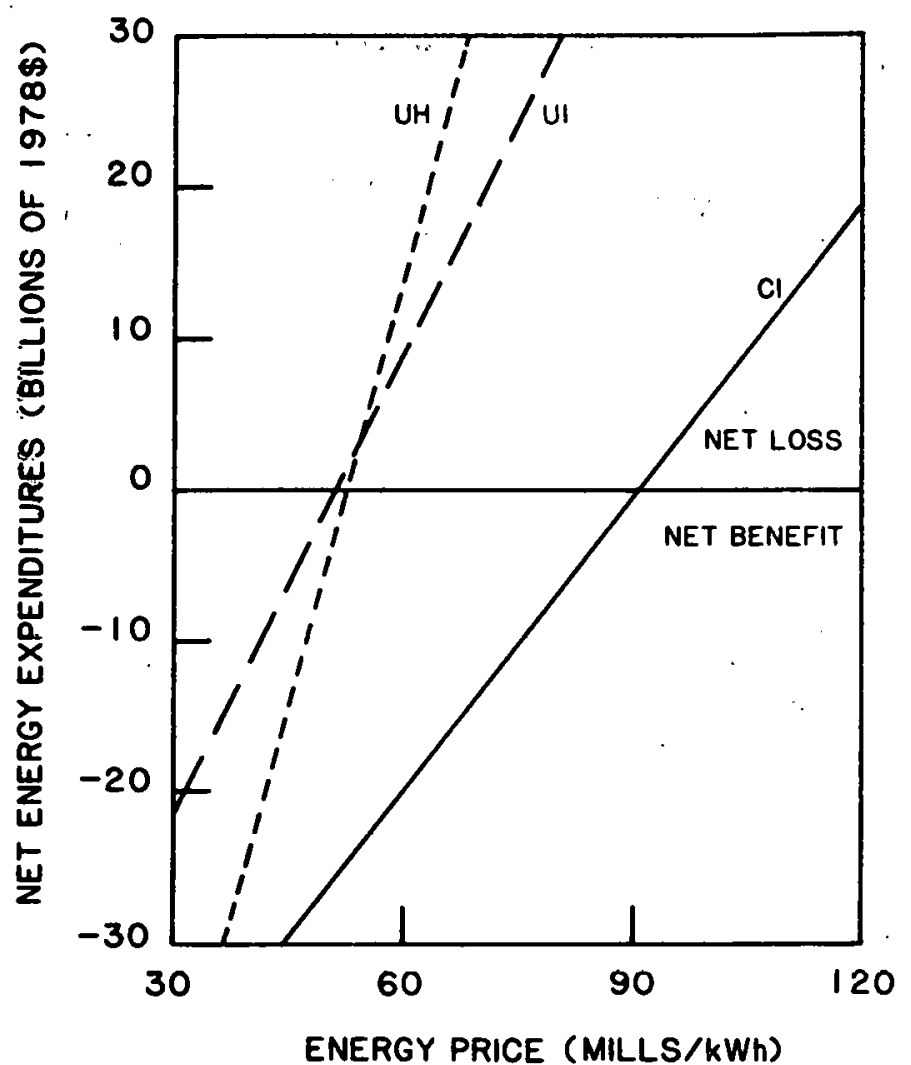

Fig. 4.47 Changes in Annual Energy Expenditures with and without SPS in 2025, as a Function of SPS Energy Price

SPS (or any technology that saves scarce fuels) has its best advantage, from an energy expenditures point of view, in a constrained scenario. For scenario $\mathrm{CI}$, there is a net benefit (i.e., reduction in total energy expenditures) when price is below about $90 \mathrm{mills} / \mathrm{kWh}$. In scenarios UI and UH, a net benefit results for prices in the $50-55 \mathrm{mills} / \mathrm{kWh}$ range. At $60 \mathrm{mills} /$ kWh, a likely level for SPS as indicated in Sec. 4.2, there is a net benefit only in scenario CI. The reason for this is that in an unconstrained economy, the primary effect of introducing a high-cost alternative is to raise the average cost of electricity, with small compensating price advantages elseWhere.

Figure 4.48, derived in a fashion similar to that for Fig. 4.47, depicks the net changes in energy expenditures that would be expected for the various scenarios over the 2000-2030 time frame at 60 and $120 \mathrm{mills} / \mathrm{kWh}$. It also illustrates. that net benefits result only in a constrained scenario at sufficiently low prices for SPS energy.

Capital Investments and GNP. To put these expenditure levels in perspective Tassuming that SPS is selected over the least costly technology i.e., coal - for other than economic reasons), the amounts of excess investment per year due to deployment of SPS instead of coal are $\$ 7-17$ billion in scenario CI, $\$ 10=25$ billion in scenario UI, and $\$ 20-50$ billion in scenario $U H$. 

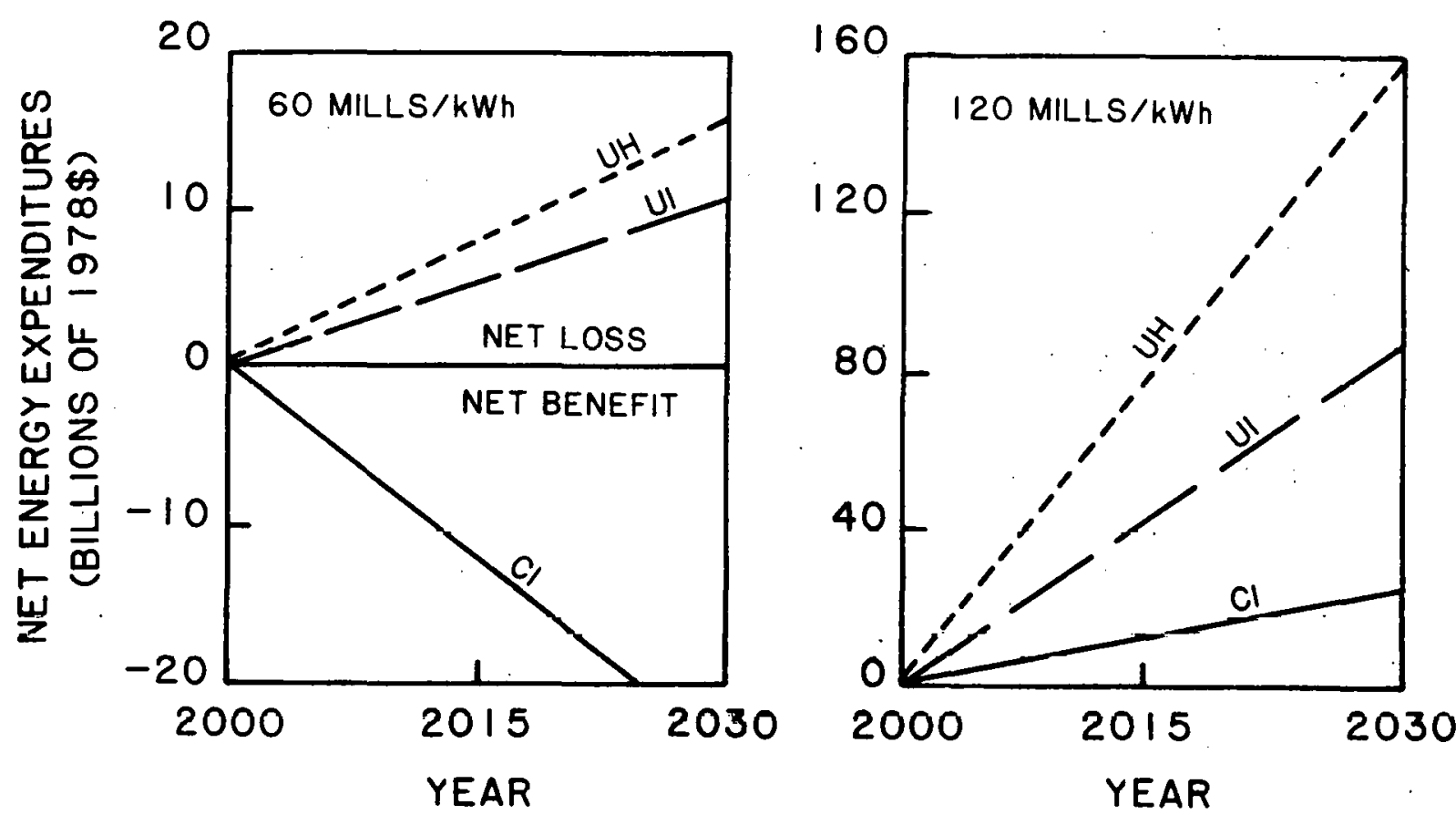

Fig. 4.48 Changes in Energy Expenditures for 2000-2030

Excess energy expenditures at $120 \mathrm{mills} / \mathrm{kWh}$ for SPS electricity would soon exceed the upper bound on the extra amount of capital investment needed to deploy SPS in all scenarios.

The $\$ 20-50$ billion range is calculated assuming SPS deployment at 10 GW/yr, SPS capital costs in the range of $\$ 3000-6000 / \mathrm{kW}$, and coal capital costs of about $\$ 1000 / \mathrm{kW}$. The ranges for scenarios UI and $\mathrm{CI}$ are based on reduced deployment rates of $5 \mathrm{GW}$ and $3.3 \mathrm{GW}$ per year, respectively, and assume that there are no increases in SPS costs at the lower deploynent rates.

Annual investment for the present $\$ 2$ trillion-dollar economy (1978 $\$$ ) is on the order of $\$ 300$ billion. At the relatively slow growth rates that appear likely for the next twenty years, a scaled-up $\$ 3.7$ trillion economy with annual investments of the order of $\$ 4.25$ billion might be feasible. It can be reasonably assumed that replacement of depreciated capital assets accounts for at least $6 \%$ of annual GNP in the year 2000 , or $\$ 225$ billion, leaving no more than $\$ 200$ billion available to finance economic growth. of around $2.1 \%$ per annum. Ihe "extra" invesstment required to build $10 \mathrm{GW}$ of sPS per year (scenario UH) after the year' 2000 -- as compared to the cheapest alternative (coal) -- would be in the range of $\$ 20-50$ billion, or $10-25 \%$ of the investment increment dedicated to economic growth. Obviously a less ambitious rate of deployment, such as $3.3 \mathrm{GW} / \mathrm{yr}$, would have a smaller impact on economic growth.

This extra investment could possibly cut potential GNP growth rates below the target level of $2.1 \%$ by $0.2-0.5 \%$ per annum. This drag effect would not be offset by low coal and gas prices even in a supply-constrained scenario. On the other hand, the drag would be proportionally smaller if SPS 
investment were held to a level just sufficient to eliminate the use of coal for electricity production in a constrained economy. In such a case the drag could almost certainly be kept below $0.1 \%$ per annum. It would also be less significant as the economy grows larger after the year 2000 .

Nevertheless, when the effect of compounding is considered, the economy of 2030 could be lower than the target level ( $\$ 7$ trillion) by anywhere from \$400-1000 billion for scenario UH. Results for the other scenarios are: a $\$ 300-500$ billion reduction for UI, $\$ 100-400$ billion for CI. (Growth that would likely be created by "spin-offs" from SPS have not been included in these calculations.) These results also illustrate the sensitivity of 30-year projections in GNP growth to small changes in the growth rate.

Inflationary Aspects. It must be acknowledged that calculations of this kind are predicated on so many uncertain factors that 1 imited weight should be placed on them. It is probably enough to say that the capital demands of SPS could possibly hold back real economic growth to some degree, relative to the "cheapest" alternative sources of electric power. Assuming that the rate of capital accumulation through savings and al lowable depreciation remains constant -- or declines -- and that capital becomes progressively less productive over time (SPS is itself an example), then economic "growth" for firms tends to be increasingly financed by borrowing, which is inflationary. Thus capital-intensive projects like sPS are also intrinsically inflationary. However, on this score, the counter-inflationary impact of reduced coal and gas prices would probably be more significant than the impact of financing.

Macroeconomic Effects of Other Technologies. The earlier calculations of energy expenditures were accomplished by first determining total energy expenditures without SPS and then substituting a fixed amount of SPS-generated electricity for that from other technologies. This requires an assessment of the economic effects of reduced demand for a particular fuel, resulting generally in reduced electrical generation costs for the technologies that use the fuel. To go the other way, that is, to assess the effects of eliminating part or all of coal (or nuclear) generating capacity, would require extrapolation of the supply/demand relationships for those technologies left in the power generation portfolio. This is necessary to complete the "with vs. without" comparison but is beyond the scope of the present effort. Since the scenarios were developed considering equilibrium conditions, it is probably safe (and enough) to say that the cost of electricity would rise, perhaps even dramatically, if significant mounts of electricity produced by one fue 1consuming technology were unavailable and had to be produced by other fuelconsuming technologies. This would undoubtedly result in an increase in total energy expenditures. Merely eliminating one of several technologies that use the same type of fuel (e.g., the CG/CC system) would probably have little impact on total energy expenditures, assuming that other coal technologies covered the difference.

One exception to the above reasoning is the case of TPV. TPV has been included in the scenarios in much the same fashion as SPS, but at about one-third the rate of deployment of sis. Thus, while the nominal electriciry 
prices to the consumer of TPV $(60-75 \mathrm{mills} / \mathrm{kWh})$ are about the same as those for SPS $(60-70 \mathrm{mills} / \mathrm{kWh})$, penetration considerations indicate that the impact on total energy expenditures (in absolute dollars) would be less than that of SPS with the net impact (with vs. without TPV) unresolved. TPV, like SPS, would probably have to be priced below $60 \mathrm{mills} / \mathrm{kWh}$ in order to realize a net benefit, assuming the same linear supply/demand models for electricity as used in the SPS calculations.

Similar arguments would apply to fusion since it would burn an essentially unlimited fuel. In relative terms, the impact of fusion would be about the same as that of TPV, since it is deployed at about the same level as TPV in the scenarios and costs about the same at the low end.

Estimates of the impacts on GNP growth due to technologies other than SPS are difficult for similar reasons. The scenarios were developed assuming a particular GNP and GNP-energy ratio; principles of equilibrium economics were used to determine the technology mix. Thus, estimation of the impact on GNP of a technology that is not the least costly is of questionable accuracy and value.

An order-of-magnitude calculation of impact on GNP can be made by combining capital cost and deployment data, assuming there are no changes in the economics of the other systems. The result can then be compared to SPS results.

Earlier results for SPS were based on the following assumptions: a $\$ 1000 / \mathrm{kW}$ nominal value for coal, a $\$ 3000 / \mathrm{kW}$ low value and a $\$ 6000 / \mathrm{kW} \mathrm{high}$ value for SPS in the year 2000 (which should be compared to the $\$ 3400 / \mathrm{kW}$ nominal and $\$ 15,400 / \mathrm{kW}$ high values 1 isted in Table 4.11 for the GaAlAs option). Results for SPS at $\$ 3000 / \mathrm{kW}$ indicate a $10 \%$ reduction in the GNP growth rate for scenario UH, $5 \%$ for scenario UI, and $3.3 \%$ for scenario CI. Nominal capital costs for the LWR and the CG/CC are also about $\$ 1000 / \mathrm{kW}$. These, along with conventional coal, form the basis for comparison.

At the nominal $\$ 1500 / \mathrm{kW}$ for the LMFBR, a $2-1 / 2 \%$ reduction (v8. $10 \%$ for SPS) in GNP growth rate for scenario UH would be expected if the breeder is deployed at the same rate as SPS. The deployment rates for SPS and the LMFBR are about the same in scenarios UH and UI, and the breeder deployment rate is about 50\% higher in scenario $C I$. The result is that the drag effect on GNP growth due to the LMFBR would be about one-fourth to one-third that due to SPS. At the high end (about $\$ 6000 / \mathrm{kW}$ ) of capital costs for the LMFBR, the drag effect would be about the same as that for SPS.

For fusion, the nominal capital cost of about $\$ 3000 / \mathrm{kW}$ (no upper limit of the range is available) is close to that for SPS, but the deployment rate is about one-fifth that of SPS across all scenarios. Thus, fusion would have a nominal drag effect about twice that of SPS for each scenario.

Regional Macroecomic Effects. The results of the regional analyses are more qualitative than earlier macroeconomic results. Increased coal utilization will provide economic stimulus to the mountain West, the location of much of the low-sulfur coal in the U.S. If the power plants are located near the coal sources, this will provide an additional source of economic growth for 
that region. Transporting this coal or transmitting this electrical power to the coastal regions would result in higher charges for electricity consumed in those locations. In contrast, the nuclear options (LWR, LMFBR, and fusion) could be sited in any region, minimizing the differences in macroeconomic effects between regions.

TPV is most economically located in areas of high insolation. These are primarily in the South and Southwest. Deployment at a significant level relative to national electrical energy needs could result in long-haul transmission, as in the case of low-sulfur western coal, and subsequently higher prices to consumers in other areas.

It may be possible to site SPS rectennas in every region in the U.S. This would minimize regional differences just as the nuclear options would. However, if it became necessary to transmit SPS power for long distances due to local siting difficulties (or any other reason), regional differences would result.

\subsubsection{Socioeconomic Comparisons}

The focus of the socioeconomic analysis is on labor requirements of the various technologies, with some comments on potential "boomtown" effects.

Table 4.47, compiled from technology characterization data in Sec. 3.2, lists the labor requirements of the energy technologies. The average number of people on site during construction and during operation (for operations and maintenance) are given along with construction time. The entries for SPS include only the rectenna site.

The figures given for construction are for the average work force per year over the construction interval. The peak work force would be somewhat higher (by about $30 \%$ ) than this. Furthermore, families would

Table 4.47 Energy Technology Labor Requirements

\begin{tabular}{lcccc}
\hline Technology & $\begin{array}{c}\text { Nominal Capacity } \\
\text { (MW) }\end{array}$ & $\begin{array}{c}\text { Construction } \\
\text { Average Labor } \\
\text { (persons/yr) }\end{array}$ & $\begin{array}{c}\text { Construction } \\
\text { Time } \\
\text { (years) }\end{array}$ & $\begin{array}{c}\text { O\&M } \\
\text { Labor } \\
\text { (persons/yr) }\end{array}$ \\
\hline $\begin{array}{l}\text { Conventional } \\
\text { Coal }\end{array}$ & 1250 & 900 & 5 & 250 \\
LWR & 1250 & 1100 & 7 & 220 \\
CG/CC & 1250 & 1300 & 5 & 340 \\
LMFBR & 1250 & 900 & 7 & 230 \\
TPV & 200 & 200 & 5 & 30 \\
SPSa & 5000 & 2500 & 2 & 450 \\
Fusion & 1220 & 1100 & 8 & b \\
\hline
\end{tabular}

asPS figures are for the rectenna construction only.

$b_{\text {Not estimated. }}$ 
be relocating with some of the workers, further adding to the population (by a factor of about three) of the surrounding area. These population increases affect the amounts of services (e.g., water, sewer, food, housing, schools, health care, police, fire protection) required, again adding to the population, although creating permanent jobs for the area in some instances. If the site is fairly distant from a large population center, these impacts $c$ an be severe for the affected locality.

On a normalized basis, SPS would require the smallest work force, about 500 persons per year per $1000 \mathrm{MW}$. Al1 others would be in the range of 700-1000 persons per year per $1000 \mathrm{MW}$. However, because of the large size ( $5000 \mathrm{MW})$ of the SPS, its impact would be much greater when compared to any other single plant of typical size. If plants were located in power parks of comparable size (with regard to capacity) then these differences would decrease, assuming all the plants at a single location were built simultaneously. Another option for any technology is to extend the time period over which construction takes place. This strategy would lessen the peak level of an impact.

\subsection{INSTITUTIONAL ISSUES}

\subsubsection{Introduction}

The relative institutional impacts of energy technologies are becoming increasingly important in the assessment of policy priorities for federal research, development, and demonstration expenditures. The environmental impact statement process created by the National Environmental Policy Act of 1969 (NEPA) has been interpreted in many legal opinions to require the consideration of factors beyond air and water pollution. Institutional impacts fall within this spirit, even if they are not covered by the letter of the law.

There is a practical, as well as legal, basis for institutional analysis of new energy technologies. A recent publication of a nuclear industry trade organization, the Atomic Industrial Forum, 175 alleges that government regulation accounted for an increase in nuclear power plant engineering man-hours of nearly $40 \%$ in the 1970 s alone. Thus, a comparative assessment of the contribution of the Satellite Power System (SPS) to the nation's energy resources should include a discussion of the effects of energy technology deployment on existing and potential regulatory institutions and the effects of these institutions on the deployment of energy technologies.

This section will compare the regulatory issues surrounding electricity systems based on the SPS, coal, light water or breeder reactors, and centralized terrestrial photovoltaics. The comparison is based on the assumption that decision makers who must choose between energy technologies are interested primarily in the significant differences between those technologies, not in a complete catalogue of all of their characteristics. In the case of institutional analysis, this means that the most relevant information is that which highlights the different responses of regulatory institutions to different energy technologies and projects the impact of these institutions on deployment. 
To perform this analysis, it is necessary to imagine the regulatory scheme for each technology at the same stage of development. Therefore, this analys is is divided into two parts. Section 4.7 .2 will compare the regula$t$ ions for each technology as they exist at present, without regard to probable future areas of regulatory activity. Section 4.7 .3 will attempt to evaluate how national trends are likely to influence technology regulation in the near future.

\subsubsection{Comparison of Present Regulatory Schemes}

Approach. Analys is of the overall regulatory schemes associated with different technologies will focus on three areas:

- The justifications for government regulation of energy technology.

- The level of government that is primarily responsible for the regulatory task.

- Where possible, the cost of regulation to both the government and the owner of the electricity system.

For the purposes of this section, the term "government regulation" is defined as any conscious and systematic government effort to influence the development and deployment of an energy technology that would otherwise be left to evolve in the private market place.

Justifications for Regulation. A recent article by Stephen Breyer 176 represents one of the most up-to-date efforts at an overview of our regulatory institutions. He organizes regulations into a number of categories, each of which represents a distinct justification for regulation. Justifications, he points out, consist of the best "public interest" arguments of those who have advocated regulatory measures, regardless of whether these reasons actually motivated the governmental action. In effect, these justifications represent the best policy explanation of why government does what it does.

Breyer defines a number of regulatory. categories that are not applicable to the issues being considered here. For the purposes of this section, his regulatory justifications $c$ an be reduced and adapted to three:

- Control of Monopoly Power. This category includes all of the numerous forms of regulation intended to control the freedom of monopolies or to restrict competition in favor of monopolies.

- Correction for Externalities. This includes any government-imposed requirement intended to prevent the general public from paying for costs that are more properly assumed by the entity that creates them. Environmental control regulations, for example, are included in this category. 
- Correction for Inadequate or Improper Information.

This category covers all regulations intended to promote

the free flow of information for its own sake or to

restrict the free flow of information for national

security purposes.

Regulations effectuated primarily through the tax system are not included in this discussion, except where specifically noted.

Level of Government. Each type of regulation for each electricity system will be classified by the level of government that has primary jurisdiction for enforcing it. Local, state, federal, and international governmental bodies will be covered. llybrid bodies, such as regional agencies or federal laws that are enforced by, state agencies, are classified at the level of government that has the most direct power over their conduct. For example, the clean air laws are considered federal regulations even though state Implementation Plans guide their use, because the federal government sets the standards those Plans must meet.

Cost of Regulation. A rough eatimate of the annual cost of each justification for federal regulation will be included for coal and nuclear technologies. The figures listed will cover both the measurable costs to taxpayers through the operation of the federal government and the compliance costs to industry. A fourth category, "hybrid purposes," will include funding levels for programs that fulfill all three of the justifications for regulations discussed above but which could not be broken down more specifically.

These figures must be read with extreme caution because their statistics are derived largely from untested sources and thus may be incomplete. The sole purpose of this overall analysis is to enable comparisons of the differences between orders of magnitude of the costs of regulating these energy resources.

Results. As Tables 4.48-4.51 indicate, substantially different regulatory systems are associated with the four different electricity production systems under consideration. The regulatory systems ditter both in the overall burden of regulation and in the levels of government that have primary jurisdiction over different aspects of regulation. Under the least favorable circumstances, significant and unprecedented regulatory burdens and conflicts could accompany the establishment of SPS.

Obvious regulatory difficulties inevitably would accompany SPS deployment because of its international character. As Tables 4.48 and 4.50 indicate, neither coal nor centralized terrestrial photovoltaic electricity production systems are faced with any significant regulation by international bodies. Although Table 4.49 reveals that 1 ight water and breeder reactors are subject to certain international restrictions on proliferation and information disclosure, such basic decisions as reactor location, damage liability in the event of accident, and permissible emissions are made within the United States. Only SPS appears to require an internationally-empowered body or negotiated treaties to make the types of decisions listed in Table $4.51--$ 
Table 4.43 Justifications for Regulating Coal Technologies at Each Level of Government

\begin{tabular}{|c|c|c|c|c|}
\hline Just if ication & Local & State & Federal & International \\
\hline $\begin{array}{l}\text { Control of } \\
\text { Monopoly Power }\end{array}$ & None & $\begin{array}{l}\text { Certificate of need, } \\
\text { Antitrust, } \\
\text { Retail electric rates. }\end{array}$ & $\begin{array}{l}\text { Antitrust, } \\
\text { Coal leases on federal land, } \\
\text { Wholesale electric rates, } \\
\text { Research and development funding. }\end{array}$ & None \\
\hline $\begin{array}{l}\text { Correction for } \\
\text { Externalities }\end{array}$ & Land Use & $\begin{array}{l}\text { Mine and miner health } \\
\text { and safety. }\end{array}$ & $\begin{array}{l}\text { Environmental impacts of surface } \\
\text { and underground mining, } \\
\text { Air and water pollution discharges, } \\
\text { Worker safety, } \\
\text { Endangered species protection, } \\
\text { Research and development funding, } \\
\text { Equal employment opportunity. }\end{array}$ & None \\
\hline $\begin{array}{l}\text { Correction for } \\
\text { Inadequate or } \\
\text { Improper Infor- } \\
\text { mation }\end{array}$ & None & Mining claims. & $\begin{array}{l}\text { Corporate securities disclosure, } \\
\text { Freedom of information, } \\
\text { Patent protection, } \\
\text { Research and development funding. }\end{array}$ & None \\
\hline
\end{tabular}


Tab ¿e 4.49 Justificaticns for Regulating Light Water or Breeder Reactors at Each Level of Government

\begin{tabular}{|c|c|c|c|c|}
\hline Justification & Local & St ate & Federai & International \\
\hline $\begin{array}{l}\text { Control of } \\
\text { Monopoly Power }\end{array}$ & None & $\begin{array}{l}\text { Certificate of need, } \\
\text { Antitrust, } \\
\text { Fetail electric rates. }\end{array}$ & $\begin{array}{l}\text { Antitrust, } \\
\text { Wholesale electric rates, } \\
\text { Research and development funding. }\end{array}$ & $\begin{array}{l}\text { Nuclear non- } \\
\text { proli fera- } \\
\text { tion treaty. }\end{array}$ \\
\hline $\begin{array}{l}\text { Correction for } \\
\text { Externalities }\end{array}$ & $\begin{array}{l}\text { Land Ise, } \\
\text { Nuclear } \\
\text { materials } \\
\text { transfort }\end{array}$ & $\begin{array}{l}\text { Nuclear materials } \\
\text { transport, } \\
\text { Industrial waste dis- } \\
\text { charge, } \\
\text { Nuclear waste disposal. }\end{array}$ & $\begin{array}{l}\text { Nuclear materials transport, } \\
\text { Siting, } \\
\text { Operation, } \\
\text { Insurance, } \\
\text { Air pollution discharge, } \\
\text { Water pollution dis:harge, } \\
\text { Worker safety, } \\
\text { Nuclear waste disposal, } \\
\text { Power plant deconmissioning, } \\
\text { Power plant control during } \\
\text { emergencies, } \\
\text { Endangered species protection, } \\
\text { Research and development funding, } \\
\text { Equal employment opportunity. }\end{array}$ & $\begin{array}{l}\text { Nuclear non- } \\
\text { prolifera- } \\
\text { tion treaty. }\end{array}$ \\
\hline $\begin{array}{l}\text { Correction for } \\
\text { Inadequate or } \\
\text { Improper Infor- } \\
\text { mation }\end{array}$ & None" & $\begin{array}{l}\text { Emergency evacuation } \\
\text { procedures. }\end{array}$ & $\begin{array}{l}\text { Corporate securities disclosure, } \\
\text { National security restrictions, } \\
\text { Freedom of information, } \\
\text { Patent protection, } \\
\text { Research and development funding. }\end{array}$ & $\begin{array}{l}\text { International } \\
\text { Atomic Energy } \\
\text { Agency. }\end{array}$ \\
\hline
\end{tabular}


Table 4.50 Justifications for Regulating Terrestrial Photovoltaics at Each Level of Government

\begin{tabular}{|c|c|c|c|c|}
\hline Just ification & Local & State & Federal & International \\
\hline $\begin{array}{l}\text { Control of } \\
\text { Monopoly Power }\end{array}$ & None & $\begin{array}{l}\text { Certificate of need; } \\
\text { Antitrust, } \\
\text { Retail electric rates. }\end{array}$ & $\begin{array}{l}\text { Antitrust, } \\
\text { Utility interconnection for de- } \\
\text { centralized plants, } \\
\text { Wholesale electric rates, } \\
\text { Research and development funding. }\end{array}$ & None \\
\hline $\begin{array}{l}\text { Correction for } \\
\text { Externalities }\end{array}$ & Land Use & $\begin{array}{l}\text { Industrial waste } \\
\text { discharge from } \\
\text { cell production. }\end{array}$ & $\begin{array}{l}\text { Air pollution discharge, } \\
\text { Water pollution discharge, } \\
\text { Worker safety, } \\
\text { Endangered species protection, } \\
\text { Research and development funding, } \\
\text { Equal employment opportunity. }\end{array}$ & None \\
\hline $\begin{array}{l}\text { Correction for } \\
\text { Inadequate or } \\
\text { Improper Infor- } \\
\text { mation }\end{array}$ & None & None & $\begin{array}{l}\text { Corporate securities disclosure, } \\
\text { Freedom of information, } \\
\text { Patent protection, } \\
\text { Research and development funding. }\end{array}$ & None \\
\hline
\end{tabular}


Table 4.51 Eustifications for Regulating SPS at Each Level of Government

\begin{tabular}{|c|c|c|c|c|}
\hline Justification & Local & State & Federal & International \\
\hline $\begin{array}{l}\text { Control of } \\
\text { Monopoly Power }\end{array}$ & None & $\begin{array}{l}\text { Certificate of need, } \\
\text { Antitrust, } \\
\text { Retail electric } \\
\quad \text { rates. }\end{array}$ & $\begin{array}{l}\text { Antitrust, } \\
\text { Financial structure and decision- } \\
\text { making process of SPS governing } \\
\text { entity, } \\
\text { Wholesale electric rates, } \\
\text { Research and development funding. }\end{array}$ & $\begin{array}{l}\text { Orbit availability, } \\
\text { Radio frequency } \\
\quad \text { al location. }\end{array}$ \\
\hline $\begin{array}{l}\text { Correction for } \\
\text { Externalities }\end{array}$ & Land Use & $\begin{array}{l}\text { Reztenna site } \\
\text { selection, } \\
\text { Industrial waste } \\
\text { discharge from } \\
\text { cell production. }\end{array}$ & $\begin{array}{l}\text { Land use on federal lands, } \\
\text { Air pollution discharge, } \\
\text { Water pollution discharge, } \\
\text { Aeronautical planning and control, } \\
\text { Worker safety, } \\
\text { Endangered species protection, } \\
\text { Research and development E.nding, } \\
\text { Equal employment opportun }\end{array}$ & $\begin{array}{l}\text { U.S. guarantee } \\
\text { of damage payment } \\
\text { for torts, } \\
\text { Possible interna- } \\
\text { tional microwave } \\
\text { emission standards. }\end{array}$ \\
\hline $\begin{array}{l}\text { Correction for } \\
\text { Inadequate or } \\
\text { Improper Infor- } \\
\text { mation }\end{array}$ & None & None & $\begin{array}{l}\text { Corporate securities disclosure, } \\
\text { National security restrictions, } \\
\text { Freedom of information, } \\
\text { Research and development funding. }\end{array}$ & None \\
\hline
\end{tabular}


decisions which, like orbit availability, would vest in foreign countries the control over the right to produce and transmit energy. The United States Government would have to be prepared to accept the inevitable extra bureaucratic delay that accompanies such complex decisions.

The international regulation of the SPS is likely to increase the amount of regulation required at the federal level. As Table 4.51 indicates, the 1967 Treaty on Principles Governing the Activities of States in the Exploration and Use of Outer Space, Including the Moon and other Celestial Bodies and the 1972 Convention on International Liability for Damage Caused By Space objects both guarantee that the United States Government will pay for damages resulting from any SPS activities undertaken with its assistance, regardless of negligence and regardless of the extent of direct government sponsorship. It is logical to assume that the federal government will insist on a powerful voice in the operation of any entity which, 1 ike the SPS, could incur substantial liability for which American taxpayers would ultimately be responsible.

Table 4.52 lists the similarities and differences between the costs of regulating coal and regulating nuclear-generated electricity. This comparison has important implications for SPS. Although the costs associated with each justification for regulation make up about the same percentage of the total cost of regulating coal as of the cost of regulating nuclear-derived electricity, the total costs associated with the nuclear option exceed those of the coal option by more than $50 \%$. Moreover, the bulk of the extra money spent on nuclear regulation appears to be concentrated in two areas of justification -- "correction for externalities" and the "hybrid purpose" categories.

The reasons for these differences between costs for coal-electric and nuclear-electric regulation could provide important indications of what would happen if an SPS system were deployed. If the specific programs within the nuclear "correction for externalities" and "hybrid purpose" categories are examined, it becomes-apparent that the bulk of spending is on various research and development activities. Programs like back-end fuel-cycle waste management and civilian reactor development account for a large percentage of the total costs in their respective categories. Coal regulatory costs, on the other hand, result from regulations aimed mainly at mitigating adverse impacts that already are relatively well-organized, e.g., protection of miner health and safety and control of surface mining externalities.

The fact that a large portion of the nuclear regulatory spending is on research and development activities intended to improve safety may reflect a more general concern that could also affect the SPS. Nucleargenerated electricity is one example chosen by Talbot Page in a recent article 177 Lo illustrate the "zero-infinity dilemma," which Page defines as the question of whether a decision to proceed with a technology should ever be made if that technology could result in a virtually infinite catastrophe even though the probability of such an event is virtually zero. It is clear that the United States Government has decided that a nuclear accident that results in a high-level radiation release into the environment would be infinitely costly and therefore intolerable; 178 the substantial spending on research and development illustrated by Table 4.52 testifies to the commitment of the government to reduce the probability of such an accident to zero by effective preventive measures. 
Table 4.52 Comparative Co.st Estimates (in 1978 dollars) for Federal Regulation of Coal. and Light Water Reactor Electricity Production Systems

\begin{tabular}{|c|c|c|c|c|c|c|c|}
\hline Justification & Coal-Fired Electricity & $\begin{array}{l}\text { Cost of } \\
\text { Regulation, } \\
\$ 1 C^{6} / y r\end{array}$ & $\begin{array}{l}\% \text { of Total } \\
\text { Cost of } \\
\text { Regulation }\end{array}$ & $\begin{array}{l}\text { Light Water or } \\
\text { Breeder Reactor Electric itty }\end{array}$ & $\begin{array}{l}\text { Cost of } \\
\text { Regulation, } \\
\$ 10^{6} / y r\end{array}$ & $\begin{array}{l}\text { \% of Total } \\
\text { Cost of } \\
\text { Regulation }\end{array}$ & $\begin{array}{l}\text { Total Cost of } \\
\text { Justification, } \\
\$ 10^{6} / \text { yr } \\
(\% \text { Coal; } \% \text { Nuc lear) }\end{array}$ \\
\hline \multirow[t]{2}{*}{$\begin{array}{l}\text { Control of } \\
\text { Monopoly Power }\end{array}$} & $\begin{array}{l}\text { Coal Leases an Federal Lands } \\
\text { Depletion Al lowarces Revenue Equiva- } \\
\text { lent }\end{array}$ & $\begin{array}{l}32.3^{a, b} \\
44 \Xi \cdot 0^{a}\end{array}$ & & $\begin{array}{l}\text { Uranium Enrichment } \\
\text { Advanced Isotope Separation }\end{array}$ & $\begin{array}{l}220.0^{e} \\
39.2^{a, e}\end{array}$ & & \\
\hline & Total & 475.3 & 13,8 & Total & .259 .2 & 4.3 & $734.5(64.7,35.3)$ \\
\hline \multirow[t]{2}{*}{$\begin{array}{l}\text { Correction for } \\
\text { Externalities }\end{array}$} & $\begin{array}{l}\text { Office of Surface Mining } \\
\text { Pollue ion Comtrol (Air: Water) } \\
\text { Miner Health and Safet? (OSHA, MESA) } \\
\text { Domestic, Foneign Waterway Subsidy } \\
\text { Coal Hydrologr }\end{array}$ & $\begin{array}{c}2.29 G .4^{c} \\
66.9^{d} \\
113.5^{a, b} \\
90.3^{a} \\
13.2^{a}\end{array}$ & & $\begin{array}{l}\text { Waste Management } \\
\text { Nuclear Materials Trans- } \\
\text { port away from Reactor } \\
\text { Storage } \\
\text { Encapsulation Facility } \\
\text { Geologic Repository } \\
\text { Overhead } \\
\text { Decommissioning } \\
\text { Insurance (potential liabil- } \\
\text { ity) } \\
\text { Site Safety Research }\end{array}$ & $\begin{array}{c}46.2^{\mathrm{f}} \\
(500.0)^{\mathrm{g}} \\
24.7^{\mathrm{a}, \mathrm{e}}\end{array}$ & & t. \\
\hline & Total & $2,574.8^{\mathrm{h}}$ & 75.0 & Total & $4,809.9$ & 79.0 & $7384.7(34.9,65.1)$ \\
\hline \multirow[t]{2}{*}{$\begin{array}{l}\text { Correction for } \\
\text { Insufficient } \\
\text { Information }\end{array}$} & Data Collect $i=n$ and Anzlys is & $29.0^{a, b}$ & & Uranium Resource Assessment & $24.7^{a}$ & & \\
\hline & Total & $\quad 29.0$ & 0.9 & Total & 24.7 & 0.4 & $53.7(54.0,46.0)$ \\
\hline \multirow[t]{3}{*}{$\begin{array}{l}\text { Hybrid } \\
\text { Purpose }\end{array}$} & $\begin{array}{l}\text { Coal Utilization Research and } \\
\text { Development }\end{array}$ & $354.5 \mathrm{a}, \mathrm{b}$ & & $\begin{array}{l}\text { Nuclear Regulatory Commissi.or: } \\
\text { Regulations } \\
\text { Civilian Reactor Developmen: } \\
\text { Nuclear Materials Research }\end{array}$ & $\begin{array}{l}240.0^{\mathrm{e}} \\
584.3^{\mathrm{a}, \mathrm{e}} \\
68.4^{\mathrm{a}, \mathrm{e}}\end{array}$ & & \\
\hline & Total & 354.5 & 10.3 & Total & 392.7 & 16.3 & $1347.2(26.3,73.7)$ \\
\hline & Total Cost of Regulaticn & $3,433.6$ & $: 00$ & Total Cost of Regulation & $6,085.5$ & 100 & $9519.1(36.1,63.9)$ \\
\hline
\end{tabular}

Source: Ref. 179 .

bsource: Ref. 180. While no specific figures were used fron this source because they have not yet been approved, they provided a source of cowparison for the future.

'Sources: Ref. 181; Joe Jewkes, Office of Surface Mining, Office af the Budget, personal communication on revenues received from fees of $35 t /$ ton for surface-ained cosil and 15t/ton for underground coal, July 13, 1979.

¿source: Ref. 182.

esource: Ref. 183 .

fource: Average of the various possible methods af decomissioning from Ref. 183.

BSource: Ref. 184 .

hThis figure fails to include costs attributable ta Equal Employment Opportunity. Although dats are available, they were excluded $i$ toe of their relative insignificance. 
If the SPS is perceived to present a zero-infinity dilemma, it is probable that its regulatory costs will look much more like those of nuclear power (Table 4.52) than those of coal-fired electricity. Like nuclear power, the SPS would be faced with continual regulation. Its international character might not provide an "escape route" around United States regulatory requirements -- the rest of the world cannot be expected to be any more willing to permit even a small possibility of a catastrophic SPS accident for the sake of supplying energy to the United States than the United States has been willing to risk a catastrophic nuclear accident within its own borders.

Of course, whether the SPS does present a zero-infinity dilemma as serious as nuclear power is a question on which there is no consensus. How serious an accident must be to become "catastrophic" and how small the probability to be viewed as "impossible" are political decisions that this study is intended to facilitate. It is important to recognize, however, that when a technology has come to be perceived as posing a zero-infinity dilemma, the total costs associated with regulating it could become a determinant of its economic viability.

\subsubsection{Regulatory Trends}

The comparative evaluation of the regulatory system that is likely to accompany any of the technologies considered here will continue to evolve. The extraordinary public attention that has been focused for a variety of reasons on energy production over the past ten years appears to be having $a$ long-term impact on the ways in which the problem is being perceived and resolved. The purpose of this section is to analyze some of these trends in a qualitative fashion.

In concluding that "the weight and importance of the decentralization trend in America is greater than the 150-year-old trend toward more centralization," John Naisbitt 185 calls attention to developments that have important implications for the regulatory system that would be associated with the SPS, as well as other electricity production technologies. Naisbitt states that if the decentralization trend continues, it is likely to cause intergovernmental conflicts in the regulation of all electricity technologies, but especially the SPS. He further contends that increasing decentralization probably, will make uniform regulations more difficult than would otherwise be the case. of course, it is dangerous to draw too many conclusions from such recent deve1opments. Nonetheless, it is important to understand their implications in the event they become long-term realities.

Incergovernmental contlicts. As Naisbitt 185 points out, numerous events suggest a growth of power among states and communities at the expense of the federal government. Increasing activity on the part of regions, states, and local governments is leading to greater assertion of decisionmaking authority by these entities. Naisbitt illustrates this trend with examples of states and localities that have tried recently to gain regulatory control over certain stages of the nuclear fuel cycle, including siting, transportation, and disposal of nuclear materials, and disaster emergency plans. 
The present conflict between federal and local governments in the context of nuclear power could be even worse in the case of the SPS. Several studies 186-188 of the SPS have concluded that an international regulatory body probably would be desirable for regulation of the technology. If this move to centralize energy technology regulation comes at a time when the dominant national trend is exactly the opposite, substantial intergovernmental duplica$t$ ion and conflict could result, not only between the federal and local governments, but also between local governments and the international regulatory body. For example, Kotin 189 suggests the possibility that states could attempt to regulate microwave exposure levels to their citizens -- an area ripe for international regulation if the SPS is deployed.

Such disputes, should they arise, could cause unexpected delays, costs, and uncertainties in the deployment of the SPS. While it is true that world-wide commitment to international regulatory bodies such as the Law of the Sea Conference and the International Whaling Commission has grown in recent years, these bodies derive their authority to regulate the United States from the federal government. If the decentralization trend should continue, it is conceivable that state and local interests would reduce the ability of these international regulatory bodies to govern effectively. For example, recent 1 itigation on 'behalf of Alaskan Eskimos to exempt their whaling activities from regulation by the International Whaling Commission may be decided in their favor, despite vigorous opposition by the federal government.

Non-Uniform Regulation. Regardless of whether the difficulties suggested above materialize, great potential exists for the SPS regulatory system, concurrent with other centralized energy technologies, to become more expensive than is predicted. Naisbitt 185 concluded that governments "have stopped looking for the one best way to accomplish a particular social goal, and are now experimenting with a wide variety of approaches." If the decentralization trend continues, the regulatory system for any of the electricity technologies covered in this section -- at whacever level of government that is vested with primary jurisdiction -- will likely have to be sufficiently flexible to meet this demand for individuality. The cost advantages of the uniform regulatory system that would normally evolve will be reduced as the system becomes unwieldy in the attempt to please widely divergent constituencies. Although the President has proposed a new regulatory body whose explicit purpose is to counteract this tendency, it is unclear whether his objective will be met.

\subsubsection{Summary}

Institutional (regulatory) considerations are increasingly affecting the viability of new energy technologies. A comparison of regulatory schemes for the SPS, coal, nuclear, and terrestrial photovoltaic technologies suggests that the SPS could be faced with unprecedented regulatory burdens as a result of the number of jurisdictions that might seek to govern it. Moreover, this trend could be exacerbated by the developing tendency of local governmental units to attempt to gain regulatory control from the federal government. 


\subsection{INTRODUCTION}

The objective of this assessment is to provide a traceable and consistent comparison of the SPS and selected energy technologies operating after 2000. The approach in this comparative assessment was to analyze each of the technologies issue by issue (side-by-side analysis), on the basis of a preselected set of issues, and then to do an analysis that evaluated the technologies, given different post-2000 economic climates and the economic trajectories that would lead to those climates (alternative futures analysis). The alternative futures analys is was also performed issue by issue, although some issue analyses were qualitative and therefore relatively insensitive to quantitatively defined economic futures.

It is the goal of this section to formulate some conclusions on the basis of the analyses described in earlier sections of this report and the supporting documents. Because the analysis was performed in two ways, two different types of conclusions will be reported. The first type will focus on the issue-by-issue analysis (side by side) and incorporate the key issues for each technology. Conclusions will be made in each major issue category (e.g., health and safety) by looking across the technologies. The second type of conclusion will be concerned with the parameters (e.g., energy demand and fuel prices) of various futures and will include statements about the comparative viability of different supply paths. Conclusions will be formulated in this case for mixes of technologies in different demand scenarios. These two types of concluding analyses will form the basis of this section. No statements regarding the overall viability of the SPS concept will be made. Such a statement is the objective of the overall CDEP program, of which this assessment is only one part.

\subsection{SIDE-BY-SIDE CONCLUSIONS}

Tables 5.1 through 5.6 summarize the comparison, issue by issue, among the seven technologies. The comparisons in these tables are described in terms of key, issues, uncertainties about the understanding of those issues, and a concluding comparative statement that cuts across all technologies for that issue area. Only one or two key issues were identified for each technology unless several were equally important.

Cost and Performance. The SPS is economically competitive with coal and nuclear energy prices if high coal and nuclear fuel prices continue and if further environmental regulations continue to raise the capital costs of these technologies at a rate substantially above inflation. However, if the capital costs of coal and nuclear technology $r$ ise because of the increasing regulatory restrictions, the regulatory climate will be such that it may also affect the cost of SPS. If coal prices increase at a rate only moderately above inflation, the probability that the SPS will be competitive with coal energy is relatively small until after the year 2000, although this result is dependent on the amount of coal use. 
Table 5.1 Cost and Performance: Key Issues, Uncertainties, and Comparative Conclusions

\begin{tabular}{|c|c|c|c|}
\hline System & Key Issues & Uncertainties & Comparative Conclusions \\
\hline $\begin{array}{l}\text { Nuclear } \\
\text { (LWR, } \\
\text { LMFBR) }\end{array}$ & $\begin{array}{l}\text { Capital cost will probably } \\
\text { escalate due to environ- } \\
\text { mental and safety regula- } \\
\text { tions. Uranium prices } \\
\text { expected to increase. }\end{array}$ & $\begin{array}{l}\text { Capital cost increases } \\
\text { are uncertain. }\end{array}$ & $\begin{array}{l}\text { logies. However, if the regula- } \\
\text { tory climate is severe for coal } \\
\text { and nuclear it may also affect } \\
\text { SPS. The probability that SPS } \\
\text { will be cost competitive with } \\
\text { coal is very small until well } \\
\text { after } 2000 \text {. }\end{array}$ \\
\hline TPV & $\begin{array}{l}\text { Costs depend strongly on } \\
\text { cell production cost. }\end{array}$ & $\begin{array}{l}\text { Large improvements } \\
\text { required in cell cost. }\end{array}$ & $\begin{array}{l}\text { SPS has approximately the same } \\
\text { cost range as TPV and fusion, } \\
\text { but the range is very large and }\end{array}$ \\
\hline
\end{tabular}


Table 5.2 Health and Safety: Key Issues, Uncertainties, and Comparative Conclusions

\begin{tabular}{|c|c|c|c|}
\hline System & Key Issues & Uncertainties & Comparative Conclusions \\
\hline $\begin{array}{l}\text { Coal } \\
\text { (Conventional, } \\
\text { CG/CC) }\end{array}$ & $\begin{array}{l}\text { Coal extraction, transpor- } \\
\text { tation and air pollution } \\
\text { are the main contributors } \\
\text { to impacts. All issues } \\
\text { are well-defined. }\end{array}$ & $\begin{array}{l}\text { Data still not accepted } \\
\text { for air pollution but } \\
\text { more defined than other } \\
\text { issues. }\end{array}$ & \multirow{3}{*}{$\begin{array}{l}\text { SPS has no health advantage over } \\
\text { other technologies. Problems } \\
\text { are different and less defined. } \\
\text { Quantified impacts of coal are } \\
\text { highest but this is the most } \\
\text { studied technology. The problem } \\
\text { of SPS microwave impacts is sim- } \\
\text { ilar to low-level ionizing radi- } \\
\text { ation and low-level air pollu- } \\
\text { tion: it is difficult to quan- } \\
\text { tify the impact, but it will } \\
\text { concern many people. This is a } \\
\text { potential problem for SPS that } \\
\text { does not have a short term } \\
\text { solution. }\end{array}$} \\
\hline $\begin{array}{l}\text { Nuc lear } \\
\text { (LWR, } \\
\text { LMFBR) }\end{array}$ & $\begin{array}{l}\text { Most impacts are occupa- } \\
\text { tional. Low-probability } \\
\text { catastrophic impacts } \\
\text { affect the perception of } \\
\text { this technology. }\end{array}$ & $\begin{array}{l}\text { Low-leve } 1 \text { radiation } \\
\text { impacts are uncertain. }\end{array}$ & \\
\hline TPV & $\begin{array}{l}\text { Extraction of materials } \\
\text { for and manufacture of } \\
\text { solar cells are the main } \\
\text { contributors to impacts. } \\
\text { Construction and main- } \\
\text { tenance of facilities } \\
\text { will have large safety } \\
\text { impacts. }\end{array}$ & $\begin{array}{l}\text { The production industry } \\
\text { may have large impacts. }\end{array}$ & \\
\hline SPS & $\begin{array}{l}\text { Extraction of raw materials } \\
\text { and component manufacture } \\
\text { are key problems. Other } \\
\text { problems of key concern } \\
\text { remain unquant if ied or } \\
\text { undetermined. }\end{array}$ & $\begin{array}{l}\text { Impacts on space worker } \\
\text { health are uncertain. } \\
\text { Low-level microwave } \\
\text { effects are uncertain. }\end{array}$ & $\cdots$ \\
\hline Fusion & Tritium release. & $\begin{array}{l}\text { Tritium pathways are } \\
\text { not well-defined. }\end{array}$ & \\
\hline
\end{tabular}


Table 5.3 Environmental Welfare: Key Issues, Uncertainties, and Comparative Conclusions

\begin{tabular}{|c|c|c|c|}
\hline System & Key Issues & Uncertainties & Comparative Conclusions \\
\hline $\begin{array}{l}\text { Nuclear } \\
\text { (LWR, } \\
\text { LMFBR) }\end{array}$ & $\begin{array}{l}\text { Radiation waste disposal. } \\
\text { Safeguards problens. }\end{array}$ & $\begin{array}{l}\text { Waste disposal tech- } \\
\text { nology performance is } \\
\text { unproven. }\end{array}$ & $\begin{array}{l}\text { production is only a small } \\
\text { part of the overall problem. } \\
\text { Microwave problems will not be } \\
\text { solved for many years, possibly } \\
\text { not unt il after a system is } \\
\text { built and operated. }\end{array}$ \\
\hline TPV & $\begin{array}{l}\text { No significant enqiron- } \\
\text { mental welfare issues were } \\
\text { identified. }\end{array}$ & & \\
\hline Fusion & $\begin{array}{l}\text { No significant issues } \\
\text { were ident } i \doteqdot i e d \text { because } \\
\text { the technology is not } \\
\text { completely defined. }\end{array}$ & & \\
\hline
\end{tabular}


Table 5.4 Resources: Key Issues, Uncertainties, and Comparative Conclusions

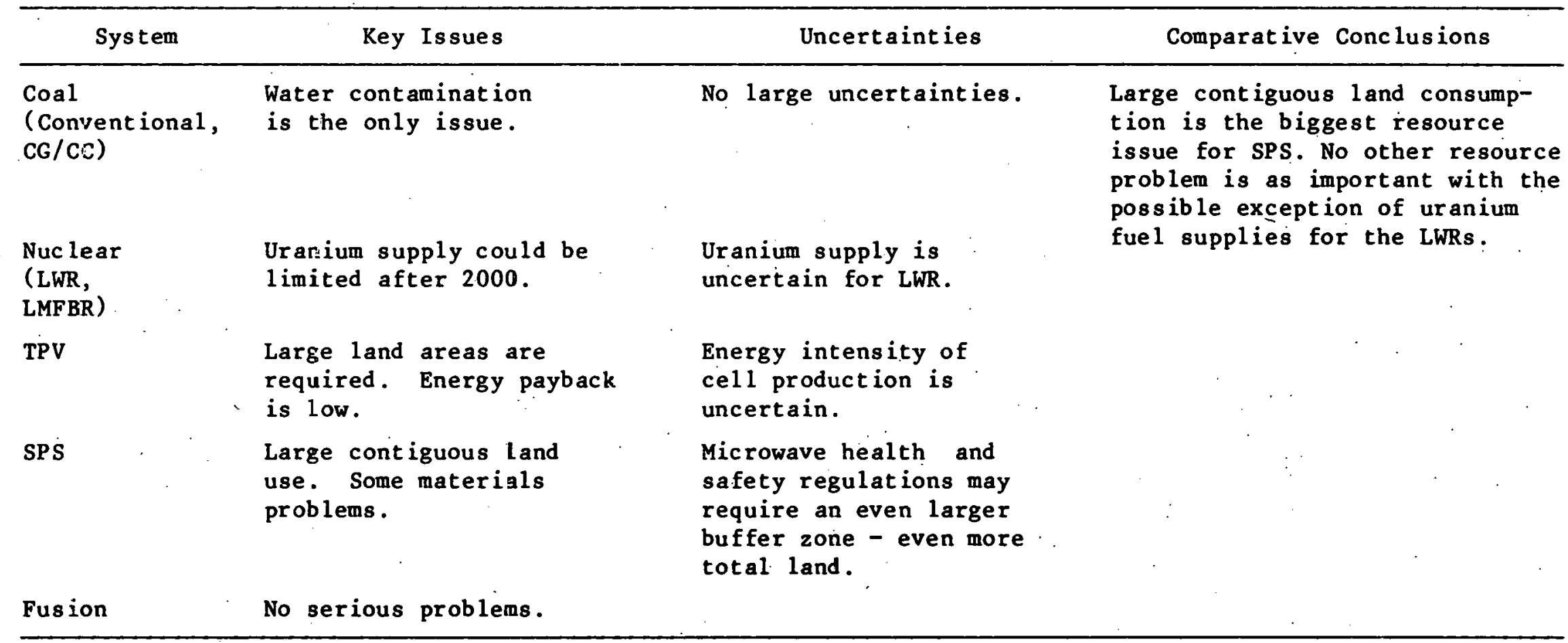


Table 5.5 Economic/Societal Issues: Key Issues, Uncertainties, and Comparative Conclusions

\begin{tabular}{|c|c|c|c|}
\hline System & Key Is sues & Uncertainties & Comparative Conclusions \\
\hline $\begin{array}{l}\text { Nuc lear } \\
\text { (LWR, } \\
\text { LMFBR) }\end{array}$ & $\begin{array}{l}\text { Possible opposition to } \\
\text { wide deployment of nuclear } \\
\text { technology by some sectors } \\
\text { of the public. }\end{array}$ & . & $\begin{array}{l}\text { 3iveness of the technology, would } \\
\text { mean that SPS could have the } \\
\text { largest effect on the GNP and the } \\
\text { economy. Regional impacts of } \\
\text {-mplementing nuclear technology }\end{array}$ \\
\hline TPV & $\begin{array}{l}\text { Regional implementation } \\
\text { expected. Large capital } \\
\text { requirements. }\end{array}$ & $\begin{array}{l}\text { Industrial infra- } \\
\text { structure not described. }\end{array}$ & $\begin{array}{l}\text { Ifission, fusion) are less signi- } \\
\text { cant than those of other tech- } \\
\text { nologies. }\end{array}$ \\
\hline SPS & $\begin{array}{l}\text { Capital cost and infra- } \\
\text { structure investments } \\
\text { could affect GNP. } \\
\text { Regional effects are } \\
\text { likely. Possible public } \\
\text { opposition. }\end{array}$ & $\therefore$ & \\
\hline Fusion & $\begin{array}{l}\text { No estimates of infra- } \\
\text { structure and } R \& D \text { costs. }\end{array}$ & & \\
\hline
\end{tabular}


Table 5.6 Institutional Issues: Key Issues, Uncertainties, and Comparative Conclusions

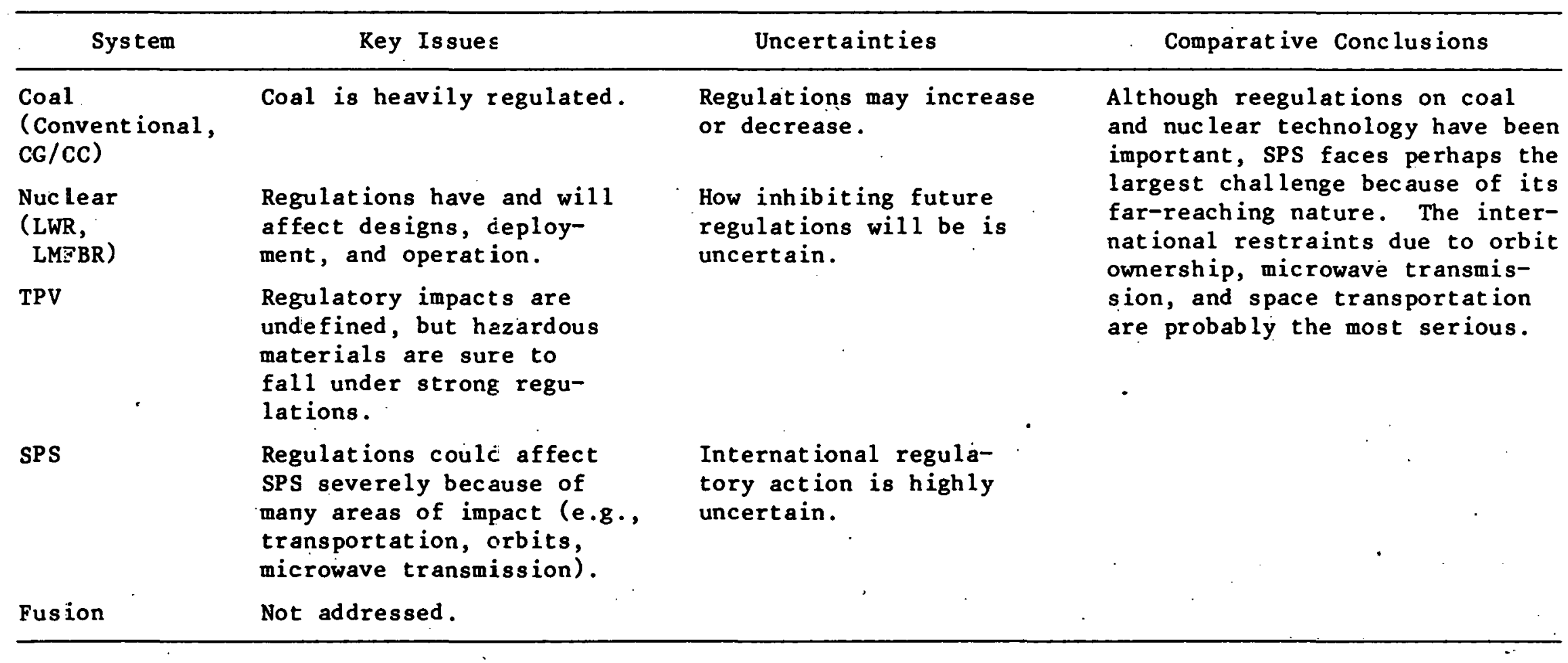


The cost ranges of all the advanced technologies (i.e., SPS, terrestrial photovoltaic, and fusion) appear to be approximately the same, but, given the large uncertainties and judgments about each of these technologies, no conclusion can be made regarding the viability of one relative to another. The cost drivers of each of these technologies have been defined, but it is difficult to come up with uncertainty bounds around each of the cost drivers. More detailed design and cost evaluation studies would be required on each of these advanced technologies to determine relative economic viability.

Health \& Safety. The satellite power system offers no overall health and safety advantages over the conventional technologies. The problems are more defined and the status of public knowledge is greater for the conventional technologies, but the problems that are still undefined for these technologies are no closer to solutions than those of the SPS, and uncertainty in such risks can only be quantified by long-term study. The problem of determining the risks associated with low-level human exposure to microwave radiation (specific to SPS) is similar to the problem of determining risk from low-level ionizing radiation (specific to nuclear) or air pollution (specific to coal). The difficult task in studying these areas is to develop impact analyses at low levels, and each will probably take years of careful research to determine the true impact. If the concern with health and safety con$t$ inues, the effect on SPS can be expected to be $s$ imilar to that on coal and nuclear technologies.

Terrestrial photovoltaics and fusion may offer fewer public health and safety problems and long-term undefined risks than do the conventional technologies and SPS. With the exception of the tritium problem for fusion, the risks now associated with these two technologies appear to be less than the risks from the low-level radiation or air pollution problems associated with the other technologies. Therefore, terrestrial photovoltaic and fusion may not be as restricted by hazards that cannot be quantified within the period of technology implementation.

Environmental Welfare. Each technology has a different set of environmental welfare problems. Among these, the climatological impacts of increased $\mathrm{CO}_{2}$ levels have the greatest catastrophic potential, but it must be pointed out that electricity production from coal causes only a small part of the $\mathrm{CO}_{2}$ problem. The microwave problems resulting from implementation of the SPS system will take many years, to solve, and the viability of a solution may not be known until after a system is built and operated.

Resources (Land, Materials, Energy, Water, Labor). The biggest issue in this area is the consumption of large contiguous land areas by the SPS and terrestrial photovoltaic systems. The terrestrial photovoltaic systems are designed in smaller capacity levels, i.e., $200 \mathrm{MW}$, so that large contiguous blocks of land would not be required for siting. However, the overall land use is approximately the same as that of the SPS. If the SPS is designed in smaller sizes (less than $5 \mathrm{GW}$ ), the need for large contiguous land areas may not be as severe a problem, but overall land consumption will probably be a continuing concern. 
Fuel supplies, particularly uranium, could be a problem after 2000 if increasing use of electricity continues in the next 20 years. If the demand for electricity continues to fall off as it has in the last several years, then the uranium supplies for use in LWRs could go on for many years beyond the time horizon of study (2000-2030). The introduction of the LMFBR would eliminate uranium resource concerns.

Terrestrial photovoltaic systems, particulary those using silicon cells, have a very poor energy payback because of the energy intensity of silicon cell production. If the energy requirements of silicon cell production are diminished, then energy payback does not appear to be a problem.

Economic/Societal Issues. The SPS, TPV, and fusion are different technologies than those currently producing electricity and will entail many new industries that will require large investments in infrastructure. These large investments, coupled with the capital intensiveness of the technology, could have the largest impact on the GNP compared to the other technologies. The infrastructure and R\&D costs for TPV and fusion have not been estimated; however, because the SPS would require many different types of systems (space transportation, space construction), many new types of jobs and training would be created to support it.

Nuclear and fusion technologies would not be as regionally biased as would the other technologies. Terrestrial photovoltaics would probably be the most regionally applied technology because its implementation is determined by climatological factors, and the proper climate is only available in certain areas of the country.

Institutional Issues. The environmental regulatory climate for coal and nuclear technology has increased substantially in the last 10 to 15 years. If this trend continues, the advanced technologies may also feel these institutional restraints at early stages of their development. SPS raises additional institutional questions because of its international nature. Institutional restraints concerning orbital ownership and microwave exposure standards pose the most serious institutional questions for the implementation of an SPS technology. As serious as the regulatory difficulties are within the United States, the international issues will most likely be even more difficult.

\subsection{ALTERNATIVE FUTURES CONCLUSIONS OF THE COMPARATIVE ASSESSMENT}

The energy supply/demand analyses that were part of this assessment produced several energy-demand and supply trajectories for the future. The two extremes of these scenarios are discussed here to form conclusions about the comparative viability of the SPS in an alternative futures framework. The other scenarios not discussed in this concluding section are intermediate cases and of fer no more perspective on SPS and the alternative technologies.

The two scenarios that were chosen were the unconstrained high energy demand scenario and the constrained intermediate demand scenario. These 
two scenarios are referred to as $\mathrm{UH}$ and $\mathrm{CI}$, respectively. The unconstrained high scenario ( $U H$ ) is a situation in which the cost of electrical energy from conventional sources does not rise at a rate much greater than inflation and therefore remains relatively cheap. The availability of cheap energy means that the demand for electrical energy from these sources will continue to rise. It also means that conservation and substitutes for these sources of energy would not penetrate to a great degree.

The other energy demand scenario (CI) is the constrained intermediate scenario. In this situation the electrical demand is low because of the increasing cost of energy due to regulatory constraints on the utilization of coal and nuclear energy. Fuel prices would rise, and conservation and other energy substitutes would diminish demand for electrical energy from these sources, thus lowering the overall demand for electrical energy.

Three different mixes of energy supply were examined for each of these scenarios (Table 5.7). Thooe mikes of eutryy supply were selected to illustrate differences in meeting these radically different demand scenarins.

Supply options 1 through 3 are evaluated for demand scenario UH for each of the comparative issues in Table 5.8. Supply options 4 through 6 are evaluated for demand scenario CI for each of the issue areas in Table 5.9.

Looking across the different supply options for energy demand UH, it appears that the conventional energy systems will bring about the lowest cost of energy for all cases if they remain relatively unconstrained. However, along with this low cost of energy, future health impacts and safety problems with coal would no doubt become more severe. In addition, since coal would be heavily used because of increased electrical production, it would be expected that the western states would continue their very rapid development. The utilization of the SPS, as described in supply option S2, would limit the production of energy from nuclear only to LWRs and then replace this with SPS. Since SPS can be expected to cost more than these unconstrained conventional technologies, the overall cost of energy. would rise. However, since the LMFBR would not be implemented, many of the health safeguard issues would not be of concern, but they would be replaced by the SPS health and safety issues. It is not expected that the $\mathrm{CO}_{2}$ problem would be lessened in the early post-2000 time frame, because the relative change in electrical energy production from coal could be small compared to the overall production of global $\mathrm{CO}_{2}$. In both supply options $\mathrm{S2}$ and $\mathrm{s} 3$, the introduction of a new technology (i.e., SPS or fusion) introduces new industries that would require large investments. In addition, the large coal boom that will exist and will last until fusion or SPS become available would most likely drop very rapidly and produce a boom/bust cycle.

Among the three supply options for the constrained intermediate demand case, supply option S4, the conventional one, would probably have the lowest energy cost. However, because all energy technology would probably be constrained, it is expected that all three of these cases would have higher energy costs than those described in demand scenario UH, unconstrained high. If the electrical energy growth is indeed constrained and substitution does occur in the form of other energy supply or conservation, then the conventional fuel resources (i.e., coal and uranium) will extend further into the $21 s t$ Century and therefore require very little in the form of other technologies for replacement. Supply scenarios s4-S6 replace each of these 
Table 5.7 Energy Supply Options

Supply Opt ion

S1 Conventional

S2 Conventional fuel utilization plus SPS

s3 Conventional fuel sources plus fusion

S4 This is the same as Supply Option 1 .

s5 Conventional systems plus SPS.

S6 Conventional systems plus fusion
Description

Conventional coal combustion and combined-cycle plants and nuclear LWRs with advancement to LMFBRs make up this supply option. Coal and uranium would be continually used in conventional sources until they are replaced by more improved systems, e.g., combined-cycle coal gasification and the LMFBR.

This supply option includes the use of coal, with nuclear only in the form of the LWR replaced by the SPS when fuel prices for uranium either rise too high or the resource is depleted.

This option utilizes coal with nuclear, in the form of both the LWR and LMFBR, and replaces these systems with fusion. If fusion is not available when the LWR fuels are running low, the LMFBR would be utilized until fusion technology is available.

Same as Supply Option 2 .

In this case since the energy demand is expected to be low, only nuclear LWRs would be used until fusion would be available. Since the energy demand is low, it is expected that the uranium fuel would last until fusion technology could be applied.

conventional technologies, coal and LWR, with the LMFBR or SPS or fusion. It would be very difficult to project the energy costs in the constrained, heavily environmentally regulated economy, to compare these latter supply options. However, it is expected that the availability of SPS or fusion wight bring down the cost of energy from depleted fuel sources because these resources would no longer be utilized. In all cases, for energy demand scenario $C I$, the requirement for an advanced technology is diminished for a couple of decades into the $21 \mathrm{st}$ Century; therefore, the decision time as to which advanced technology or technologies would replace conventional sources is delayed and would probably have very little effect on the overall future energy supply and demand. 
Table 5.8 Evaluation of Energy Supply Options S1-s3 for Demand Scenario UH - Unconstrained, High Demand

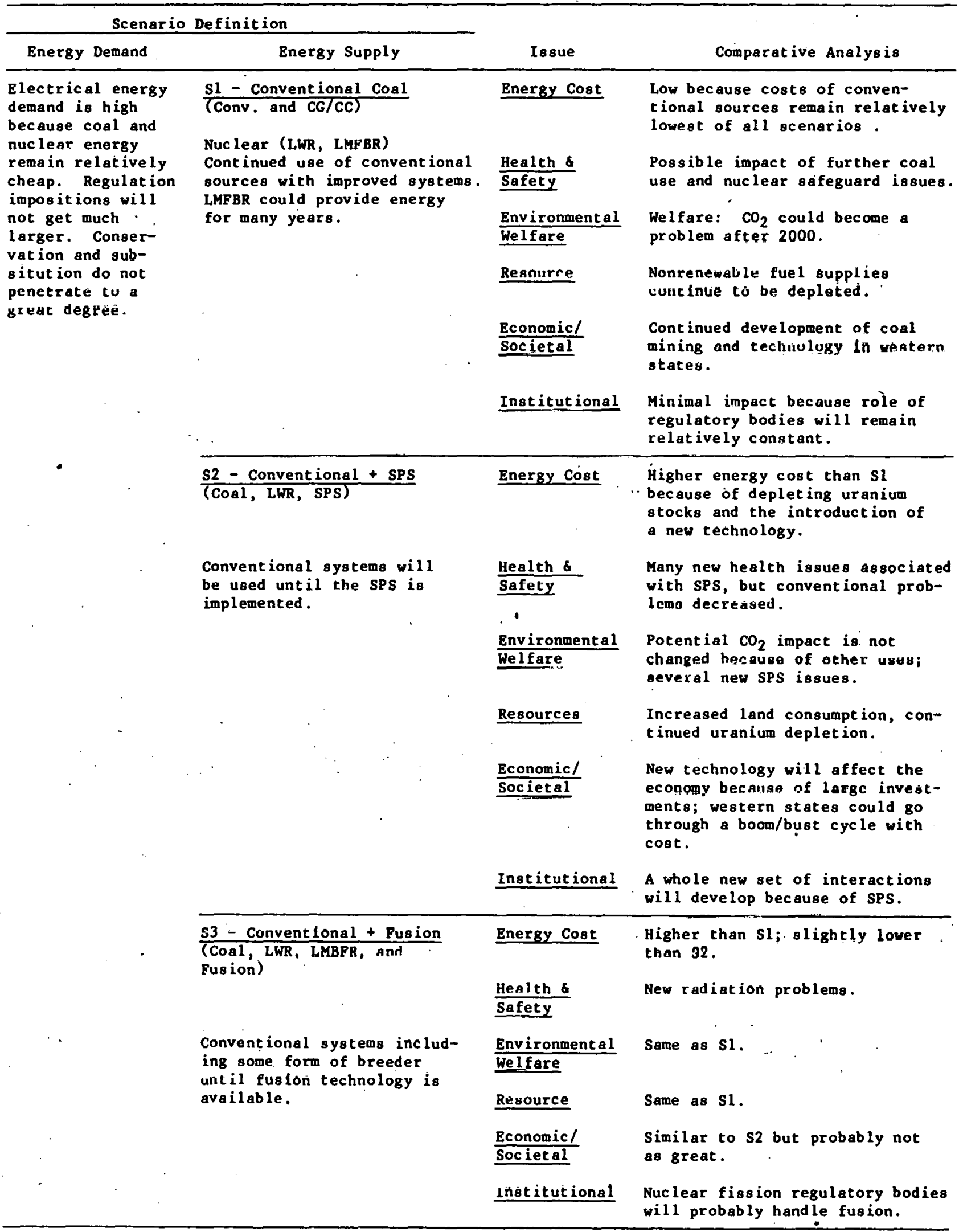


Table 5.9 Evaluation of Energy Supply Options S4-S6 for Demand Scenario CI - Constrained, Intermediate Demand

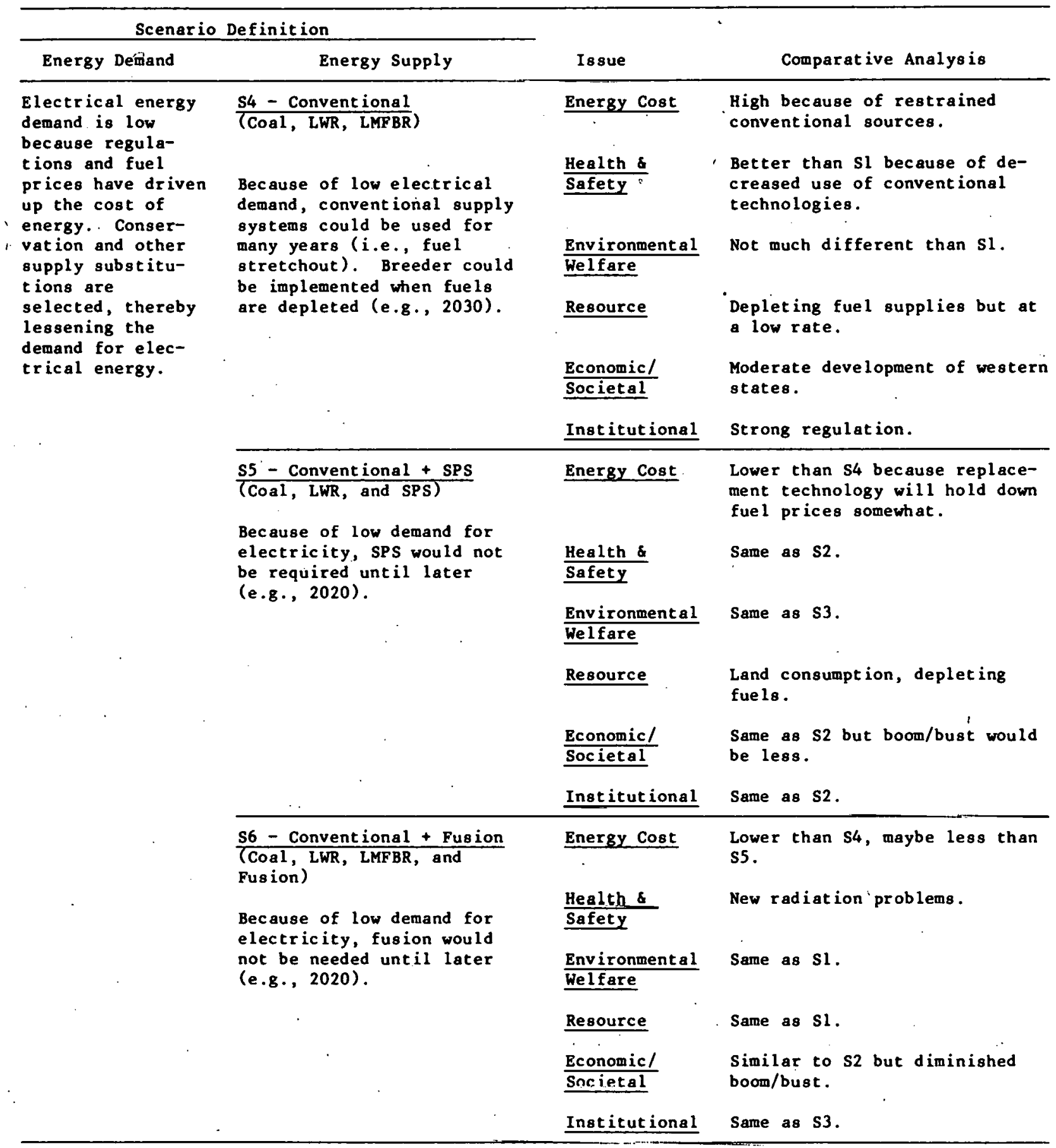




\subsection{CONCLUDING REMARKS}

Within the limits of present knowledge, it is expected that the cost of the SPS would be higher than that of the conventional technologies, its environmental problems different, and its resource consumption (in the form of land instead of fuels) no less important. However, this conclusion probably results in large part from the character of the SPS reference design. Conventional technology and ideas are incorporated into this reference design; they make it the most believable SPS concept but possibly not the most viable. A more advanced SPS concept might compare more favorably to the conventional technologies, but would be difficult to characterize. However, in order to go forward with such a large new venture as SPS, it is important that the payoffs be significant. Therefore a more advanced SPS concept might provide the margins of benefit that are needed to support such a large new technological venture. For example, the introduction of a different, more intense form of microwave transmission could reduce the land requirements, the microwave impacts, and the overall soot of the lechnology. Each one of these impact areas is a sensitive issue for the current SPS reference design. Therefore, it should be noted that the comparative assessment repored in this document considered only one concept for the SPS design, and that others, although much more advanced, may compare more favorably than the one chosen. 


\section{REFERENCES}

1. SPS Concept Development and Evaluation Program Reference System Report, U.S. Dept. of Energy and NASA, DOE/ER-0023 (Oct. 1978).

2. Wolsko, T., et al., A Preliminary Assessment of the Satellite Power System (SPS) and Six Other Energy Technologies, Argonne National Laboratory Report ANL/AA-20 (Apr. 1980).

3. Wolsko, T., et al., A Methodology for the Comparative Assessment of the Sateli ite Power System (SPS) and Alternative Technologies, U.S. Dept. of Energy Report DOE/ER-0051 (Jan. 1980).

4. TRW, Energy Systems Planning Division, Characterizations of Alternative Electric Generation Technologies for the SPS Comparative Assessment: Central-Station Technologies, Vols. 1 and 2, Argonne National Laboratory Report ANL/EES-TM-121 (Aug. 1980).

5. Satellite Power System and Alternative Technology Characterization, United Engineers and Constructors UE\&C-ANL-790831 (Aug. 1979).

6. Sansa, M., Selection of Alternative Central Station Technologies for the Satelitite Power System Comparative Assessment, U.S. Dept. of Energy Report DOE-ER-0052 (Apr. 1980).

7. Solar Power SatelZite System Definition Study, Volume I, Phase 1, Final Report, Boeing Aerospace Corporation D180-25037-1 (Feb. 1979).

8. Satelizte Power Systems (SPS) Concept Definition Study, (Exhibit C) Final Performance Review, Rockwe 11 International Corporation SSD79-0076 (Mar. 1979).

9. Marsh, W.D., Requirement Assessments of Photovoltaic Power Piants in Electric Utility Systems, Vols. 1-3, General Electric Company, EPRI Report ER-685 (June 1978).

10. Commercial Electric Power Cost Studies - Capital Cost: High and Low Sulfur Coal Plants - 1200 MWe, Vols. 1 and 2, United Engineers and Constructors for the U.S. Nuc lear Regulatory Commission and the U.S. Dept. of Energy, NUREG-0243, co0-2477-7 (June 1977).

11. Summary Report Sulfur Oxides Control Technology Series: Flue Gas Desulfurization Wellman-Lord Proces6, U.S. Enyironmental Protection Agency Report EPA 625/8-79-001 (Feb. 1979).

12. Brown, D.H., Conceptual Design and Implementation Assessment of a Utility Steam Plant with Conventional Furnace and Wet Lime Gas Scrubbers, Energy Conversion Alternatives Study (ECAS), General Electric Company for NASA, CR-1350 (Dec. 1976).

13. Utility Boiler Design/Cost Comparison: Fluidized Bed Combustion versus Flue-Gas Desulfurization, Tennessee Valley Authority for the USEPA, EPA 600/77-126 (Nov. 1977). 
14. Shah, R.P., Energy Conversion AZternatives Study (ECAS), General Electric Co. for NASA Lewis Research Center, NASA-CR 1349 (1978).

15. Grisso, J.R., Preliminary Design Study for an Integrated Coal Gasification Combined Cycle Power Plant, Ralph M. Parsons Co. for EPRI, AF-880 (1978).

16. Westinghouse Electric Company, Final Safety Analysis Report, NRC (1978) (as modified by. TRW).

17. Westinghouse Electric Company, Envirornental Report for Operating License, NRC.

18. Zaccari, D.R., and R.W. Hilles, Nuclear Plant Availability and Reliability, Electric Utility Engineering Conferences, Westinghouse Electric Company (1979).

19. Westinghouse Water Reactor Divisions, Summamy Description of Westinghouse PWR Nucloar Stoam Supply 3yslem.

20. Atomic Energy Commission, Environmental Survey of the Uranium Fuel Cycle, Wash-1248 (Apr. 1974).

21. Advanced Fuel Cycle and Reactor Concepts, Subgroup A: Once Through Fuel Cycles, INFCE Working Group 8 Proposed Draft Paper INFCE/WG8/USA/DOC 12 (May 31, 1978).

22. Final Report and Initial Update of the Energy Economic Data Base (EEDB) Program, United Engineers and Constructors for the U.S. Dept. of Energy, C00-4954-1 (Dec. 1979).

23. Envirormental Statement: Liquid Fast Breeder Reactor Program, Vols. 1-7, U.S. Atomic Energy Commission Report WASH-1535 (1974).

24. NUWMAK - A Tokamak Reactor Design Study, Nuc lear Engineering Department, University of Wisconsin, UWFDM-330 (Mar. 1979).

25. Solar Power Satellite System Definition, Executive Summary, Boeing Aerospace Corporation D180-25969-1 (June 1980).

26. Piland, R.O., Reference System Characterization and Cost Overview, DOE/ NASA Program Review (April 1980).

27. Wnnirnrk, G.R., Solar Powor fixtel.7.i.lus urul tho Evolutfon of Space Technology, presented at the 1980 Meeting and Technical Display of the American Institute of Aeronautics and Astronautics, Baltimore, Md. (May 1980).

28. Harron, R.J., and R.C. Wadle, SatelZite Power System Work Breakdown Structure and Cost Estimate, Unpublished information (Feb. 20, 1980).

29. Ayres, R., et al., Alternative Future Scenarios for the SPS Comparative Assessment, Argonne National Laboratory Report ANL/EES-TM-120 (Aug. 1980). 
30. Ridker, R., and W. Watson, To Choose a Ruture, Johns Hopkins Press for Resources for the Future, Inc. (in press).

31. Manne, A.S., ETA: A Model for Energy Technology Assessment, Bell J. Econ 7:379-406 (1976).

32. Nordhaus, W.D., The Allocation of Energy Resources, Brookings Papers Econ, Activity 3599570 (1973).

33. Hof fman, K., A United Framework for Energy System Planning, M. Sear1 Energy Modeling, Resources for the Future, Inc. (1973).

34. Cherniavsky, E.A., L.L. Huang, and H. Abilock, Dynomic Energy System Optimiaation Model (DESAM), Brookhaven National Laboratory, EPRI EA-1079 (May 1979).

35. Manne, A.S., ETA-MACRO, in C.J. Hitch (ed.), Modeling Energy Economy Interactions: Five Approaches, Resources for the Future, Inc. Research Paper R-5 (1977).

36. Hudson, E., and D.Jorgenson, U.S. Energy Policy and Economic Growth 1975-2000, Be11 J. Econ. Mgt. Sci. 5 (1974).

37. Federal Energy Administration, National Enengy Outlook, U.S. Government Printing Office, Washington, D.C. (Feb. 1976).

38. Cazalet, E.G., Generalized Equilibrium Modelling: The Methodology of the Gulf-SRI Model, Decision Focus, Inc., Palo Alto, Calif. (May 1979).

39. Almon, C. Jr., M.B. Buckler, L.M. Horowitz, and T.C. Reimbold, 1985: Interindustry Forecasts of the American Economy, Lexington Books, Lexington, Mass. (1974).

40. Schurr, S.H., et al., Energy in America's Puture, The Choices Before U8, Resources for the Future, Inc., Johns Hopkins University Press (July 1979).

41. Energy Information Administration, Anmial Report to Congres8, DOE/ELA0173, Vol. 3 (1978).

42. Research and Development Program Plan for 1979-1983, EPRI (July 1978).

43. Handy-Whitman Index of Public Utility Construction Costs, Whitman, Requardt and Associates, Publishers, Balt imore, Md. (1978).

44. Personal communications, Whitman, Requardt and Associates (1979).

45. Kraft, C.C., The Solar Power Satelzite Concept -- The Past Decade and the Next Decade, Paper \$79-0534, 15th Annual Meeting and Technical Display of the American Institute of Aeronautics and Astronautics, Washington, D.C. (Feb. 1979). 
46. Solar Power Satellite Concept Evaluation Activities Report: July 1976 to June 1977, National Aeronautics and Space Administration, Lyndon B. Johnson Space Center (July 1977).

47. Hazelrigg, G.A., Assessment of Economic Factors Affecting the Satellite Power System, Vol. I, System Cost Factors, p. 57, ECON, Inc. for NASA Report 非8-147-1 (Dec. 1978).

48. Glaser, P., Economic Envirormental Costs of Satellite Solar Power, Mechanical Engineering (Jan. 1978).

49. Technical Assessment Guide, EPRI, PS-1201 (July 1979).

50. Technology Assessment Guide, EPRI Special Report PS-86-SR (June 1978).

51. Habegger, L.J., J.R. Gasper, and C.D. Brown, Health and Safety: Preliminary Comparative Assessment of the Satellite Power System and Other Energy Alternatives, DOE/ER-0053 (Jan. 1980).

52. Samsa, M.E., Alternative Technologies - Cost and Performance Review, DOE/NASA SPS Program Review, Lincoln, Neb. (Apr. 1980).

53. Ritz, P.M., The Irqut-Output Structure of the U.S. Economy, 1972, U.S. Dept. of Commerce, Survey of Current Business, Vol. 59, No. 2 (Feb. 1979).

54. Occupational. Injuries and Illnesses in The United States by Industry, 1976, U.S. Dept. of Labor, Bureau of Labor Statistics, Bul1. 2019 (Apr. 1979).

55. Ketchan, N.H., and W. Norton, The Hazards to Health in the Hydrogeneration of Coal, III: The Industrial Hygiene Studies, Arch. Envr. Health, 1:194207 (1960).

56. An Assessment of National Consequences of Increased Coal Utilization, Executive Summary, U.S. Dept. of Energy Report TID-29425 (Vo1, 2) (Feb. 1979).

57. Comparative Risk-Cost-Benefit Study of Alternative Sources of Electrical Energy, Atomic Energy Commission Report WASH-1224 (1974).

38. The Effects on Populations of Exposure to Low Levels of Ionizing Radiation, Report of the Advisory Committee on Biological Effects of Ionfzing Radiation, Division of Medical Sciences, National Academy of Sciences, National Research Cuuncil (1972).

59. Energy and the Envirorment, Council on Environmental Quality (1973).

60. Cohen, B.L., Impact of Nuclear Industry on Human Health and Safety, Am. Scientist 64:550-559 (Sept. 1976).

61. Cohen, B.L., Conclusions of the BEIR and UNSCEAR Reports on Radiation Effects per Mar-Rem, Health Physics 30:351 (1976). 
62. The Hazards of Conventional Sources of Energy, Health and Safety Commission on the Hazards of Conventional Sources of Energy, London (Feb. 1978).

63. Envirormental Characteriaations for Energy Technologies and End Uses, Vol. 3, Characterization and Data in the Area of Nuclear and Coal Energy, U.S. Dept. of Energy (Nov. 1978).

64. Shipments of Nuclear Fuel and Waste, U.S. Dept: of Energy Report DOE/EV-0004/2, UC-71 (1978).

65. Cohen, B.L., A Catalog of Risks, Health Physics, 36:707-722 (1979).

66. AMA Council on Scientific Affairs, Health Evaluation of EnergyGenerating Sources: Council Report, JAMA, 240(20):2193-2195 (1978).

67. Study Group on Light Water Reactor Safety, American Physical Society, Review of Modern Physics, 47 (Suppl. 1) (1975).

68. Rochlin, G.I., Nuclear Waste Disposal: Two Social Criteria, Science 195: 23-32 (Jan. 7, 1977).

69. Lovins, A.B., Nuclear Weapons and Power Reactor Plutonium, Nature, 283: 817-823 (Feb. 1980).

70. Cochran, T.R., The Liquid Metal Fast Breeder Reactor, p. 171, Johns Hopkins University Press, Baltimore (1974).

71. Rich, V., Fire Threatened Fast Reactor Cooling System, Editorial, Nature, $283: 420$ (Jan. 1980).

72. Occupational Injuries and Illnesses in the United States by Industry, 1975, Bureau of Statistics, U.S. Dept. of Labor, Bulletin 1981 (1978).

73. Lee, D., Coal Worker Pneumoconiosio--State of Knowledge and Research Needs, J. Occupat. Med. 13:183-192 (1971).

74. Synopsis of the Work Proceedings, Spindletop International Conference on Coal Workers, Arch. Environ. Health 21:221 (1970).

75. Accident Bulletin No. 141, Federal Railroad Administration, U.S. Dept. of Transportation (1972).

76. Yearbook of Railroad Facts, Association of American Railroads (1973).

77. Buehring, W.A., A Model of Environmental Impacts from Electrical Generation in Wisconsin, Doctoral Thesis, U. of Wisconsin, Madison (1975).

78. Enviro Control, Inc., Recommended Health and Safety Guidelines for Coal Gasification Pilot Plants, Environmental Protection Agency Report EPA-600/7-78-007 (Jan. 1978).

79. Carcinogens Relating to Coal Conversion Processes, TRW Energy Systems Report FE-2213-1 (June 1976). 
80. Harper, W.C., Experimental Carcinogenic Studies of Hydrogenerated Coal Oils, Fischer-Tropsch Oil6, J. Indust. Med. Surg., pp. 459-462 (Oct. 1956).

81. Sikles, J.E., II, et al., Literature Survey of Emissions As8ociated. with Emerging Energy Technologies, U.S. Environmental Protection Agency Report EPA-600/7-77-104 (1977).

82. Hamersma, J.W., and S.R. Reynolds, Revisw of Process Measurements for Coal Gasification Proces6, TRW Doc. 24916-6018-RU-00 (1975).

83. Ca-A Cancer Journal for Clinicians, American Cancer Society, 26:1 (Jan.-Feb. 1976).

84. Particulate Polycyclic Orgnmic Mattor, National Academy of seiences (1.972).

85. Lundy, R.T., and D. Grahn, Predictions of the Effects of Energy Production on Human Heatth, Proceedings of the Annual Meeting of the American Stat istical Association, Chicago, I11. (1977).

86. Air/Water Polzution Report, Vol. 17, No. 37 (Sept. 11, 1978).

87. Chiu, S.Y., et al., The Water Quality Impacts of Increased Coal Utilization, Argonne National Laboratory Report ANL/EES-TM-74 (Apr. 1979).

88. McBride, J.P., et al., Radiological Inpact of Airborne Effluents of Coal-Fired and Nuclear Powsr Plants, Oak Ridge National Laboratory Report ORNL-5135 (1977).

89. Swanson, V.E., et al., Collection, Analysis, and Evaluation of Coal Samples in 1975, U.S. Dept. of the Interior, Geological Survey, Open-File Report 76-468 (1976).

90. Caputo, R., An Initial Comparative Assessment of Orbital and Terrestrial Central Power Systems, Jet Propulsion Laboratory Report 900-7800 (1977).

91. Gande1, M.G., et al., As8essment of Large Scale Photonol.taic Matorialo Production, Lockheed Missiles and Space Co. Report PB 272-064 (1968).

92. Commercialization ERD/EDP: Photovoltaics, U.S. Dept. of Energy (1978).

93. Poon, T.Y., et al., Preliminary Examination of Satellite Power Systom Oocupational Health Irqacts, Rev. A, Jet Propulsion Laboratory Report 900-820 (1979).

94. Preliminary Satellite Power System Impacts and Benefits Study, Jet Propulsion Laboratory (March 1978).

95. Preliminary Envirormental Assessment for the Satellite Power System, Revision 1, U.S. Dept. of Energy, DOE/ER-0036/2 (Jan. 1980). 
96. Stephens, J.B., and R.B. Stewart, Rocket Exhaust Effluent Modeling for Tropospheric Air Quality and Envirormental Assessments, National Aeronautics and Space Administration Report TR-R-473 (1977).

97. NASA Envirormental Impact Statement: Space Shuttle Program, National Aeronautics and Space Administration (July 1977).

98. Environmental Protection Agency, Interim Guidelines on Air Quiality Modele, Office of Air Quality Planning Report 1.2-080 (1977).

99. Code of Federal Regulations, 40CFR50.

100. Kortman, P.J., et al., SPS Comparative Assessment Technology Comparisons, TRW Energy, Systems Group (Dec. 1979).

101. Nuclear Power and the Envirorment, International Atomic Energy Agency, Vienna (1973).

102. Work Injury and Illness Rates, National Safety Council (1978).

103. Dingee, D.A., Fusion Power: Special Reports, Chem. Engineer. News, $19: 32-45$ (Apr. 2; 1979).

104. Strand, J.A., and T.M. Poston, Biological Effects of Activation Products and Other Chemicals Released from Fusion Power Plants, Battelle Northwest Laboratories Report BNWL-20-23 (1976).

105. Project Independence, Nuclear Energy, Task Force on Nuclear Energy, Federal Energy Administration, Atomic Energy Commission (1974).

106. Groth, D.H., et al., Carcinogencity of Beryllium Hydroxide and AZloys, Environmental Research $21: 63-84$ (1980).

107. Tritium in the Envirorment, NCRP Monograph 非 (1979).

108. Holdren, 'J.P., Envirormental Considerations of Fusion Power, presented at the Annual Meeting of AAAS (Jan. 1980).

109. Kulcenski, G.L., et al., Energy for the Long Run: Fission or Fusion? Am. Scientist 67:78-89 (1979).

110. Hafele, W., et al., Fusion and Fast Breeder Reactors, International Institute for Applied Systems Analysis, RR-77-8 (1977).

11. National Energy Transportation, Congressional Research Service Pub. 95-15, U.S. Senate (1977).

112. Post, R.F., and F.L. Ribe, Fusion Reactors as Future Energy Sources, Sc ience 186(4162): 397-407 (1974).

113. Capturing a Star; Controlzed Fusion Power, EPRI J. 2(10):2-15 (1977). 
114. Easlerty, C.E., ORNL Health Physics Annual Report, Oak Ridge National Laboratory Report ORNL-5171 (1976).

115. Reactor Safety Study: An Assessment of Accident Risks in U.S. Commercial Nuclear Power Plants, Nuclear Regulatory Commission Report WASH-1400 (1975).

116. Levine, E.P., et al., Comparative Assessment of Envirormental Welfare Effects of the Satelitite Power System and Other Energy Alternatives, U.S. Dept. of Energy Report DOE/ER-0055 (Apr. 1980).

117. Environmental Data for Energy Technology Policy Analysis, Vol. Z., MITRE Corp. for U.S. Dept. of Energy, HCP/EV-6119/1 (Jan. 1979).

118. Dvorak, A.J., et al., The Envirormental Effects of Using Coal for Generating Electricity. II.S. Nurlear Rogulatory Commission Report NUREG-ก25?. (June 1977).

119. Energy and Climate, National Academy of Sciences, National Research Council (May 1977).

120. Energy Alternatives: A Comparative Analysis, Science and Public Policy Program, Univ. of Oklahoma for the Council on Environmental Quality, Stock No. 041-011-00025-4, U.S. Government Printing Office (May 1975).

121. Annual Envirormental Analysis Report, MITRE Corp. (1977).

122. Szabo, M., Envirormental Assessment of Coal Transportation, U.S. Environmental Protection Agency Report EPA-600/7-78-081 (May 1978).

123. McBride, J., Radiological Impact of Airborne Effluents of Coal and Nuclear Plants, Science, 202(4372):1045-1050 (Dec. 8, 1978).

124. Activities, Effects and Impacts of the Coal Fuel Cycle for a 1,000 MWe Electric Power Generating Plant, Teknekron Resparrh, Inc., for U.S. Nuclear Regulatory Commission, NUREG/CR-1600 (Feb. 1980).

125. Principal Parameters Used in Source Term Caloulations, U.S. Atomic Energy Commission Directorate of Licensing.

126. Cheremisinoff, P.N., and A.C. Morresi, Envirormental Assessment and Impact Statement Handbook, Ann Arbor Science Press (1977).

127. Bailly Generating Station Nuclear 1. Environental Report, Northern Indiana Public Service Company (Jan. 1972).

128. Environent. Resources, Pollution, and Society, W.W. Murdock, ed., Sinauer Associates Inc., Stamford, Conn. (1975).

129. Draft Generic Envirormental Impact Statement on Uranium Milling, Vol. 1, U.S. Nuclear Regulatory Commission Report NUREG-0511 (Apr. 1979). 
130. Ransay, W., Urpaid Costs of Electrical Energy, Health and Envirormental Inpacts from Coal and Nuclear Power, Resources for the Future, Inc. (1979).

131. Boagart, S.L., ed.; Proceedings of the Second Fusion - Fission Energy Systems Review Meeting, (Vol. II), U.S. Dept. of Energy, Assistant Secretary for Energy Technology, Office of Fusion Energy, CoNF-771155 (July 1978).

132. Kneese, A.V., and B.T. Bower, Environmental Quality and Residual Management, Resources for the Future, Inc. (1979).

133. Final Envirormental Impact Statement, Waste Management Operations, Savannah River Plant, U.S. Energy Research and Development Administration Report ERDA-15़37 (1977).

134. Gandel, M., et al., Assessment of Large Scale Photovoltaic Materials Production, U.S. Environmental Protection Agency Report EPA-600/7-77-087 (Aug. 1977).

135. Envirormental Readiness Document: Photovoltaics Commercialization Phase III Planning, U.S. Dept. of Energy (Sept. 1978).

136. Herrera, G., Assessment of RD\&D Resources, Health and Envirormental Effects, O\&M Costs and Other Social Costs for Conventional and Terrestrial Solar Electric Plants, NASA/JPL International Report 900-782 (Jan. 1977).

137. Solar Program Assessment: Envirormental Factors - Photovoltaics, U.S. Energy Research and Development Administration Report ERDA 77-47-3 (March 1977).

138. Krupka, Milton C., Decentralized Solar Photovoltaic Energy Systems, Los Almos Laboratory for U.S. Dept. of Energy, LA-7866-TASE (June 1979).

139. Systems Descriptions and Engineering Costs for Solar - Related Teshnologies, MITRE/METREK MTR-7485 (June 1977).

140. Sears, D.R., et al., Environmental Impact Statement for a Hypothetical $1000 \mathrm{MW}(e)$ Photovoltaic Solar Electric Power Plant, U.S. Environmental Protection Agency Report EPA-600/7-77-085 (1977).

141. Preliminary Enviroronental Assessment for the Satellite Power System (SPS), Vol.. 2: Detailed Assessment, Revision 1, U.S. Dept. of Energy Report DOE/ER-0036/2 (Oct. 1978).

142. Livingston, F.R., Satellite Power System Envirormental Impacts, Preliminary Assessment, Rev. A, Jet Propulsion Laboratory Report 900-822 (May 1978).

143. Mendillo, M., G.S. Hawkins, and J.A. Klobuchar, A Large-Scale Hole in the Ionosphere Caused by the Launch of Skylab, Science, 187:343 (1975). 
144: Bloomquist, C., A. Davrio, and S. Shotland, Satellite Power Systems Preliminary Societal Assessment, PRC Energy Analysis for U.S. De'pt. of Energy (May 1979).

145. Powe11, J.R., ed., Proceedings of the Third Topical Meeting on the Technology of Controlled Nuclear Fusion, May 1978, Santa Fe, N.M., sponsored by ANS Trinity Section, ANS Division of Controlled Nuclear Fusion, DOE, Division of Magnetic Fusion Energy, and the Electric Power Institute.

146. Safety and Envirormental Aspects of Deuterium - Tritium Fusion Power Plants! Work Shop Summary, Seattle, Wash., U.S. Dept. of Energy, Assistant Secretary for Energy Technology (May 1978).

147. Envirormental Statement Tokamak Fusion Test Reactor Facilities, Princeton Plasma Physics Laboratory for U.S. Atomic Energy Commission (Jan. 1975).

148. Comptroller General, Report to the Congress of the United States, Fusion - A Possible Option for Solving Long Term Energy Problems, MED-79-27 (Sept. 1979).

149. Shank, K.E., T.W. Oakes, and C.E. Easterly, As8essment of Radiological Releases to the Envirormental From a Fusion Reactor Power Plant, Oak Ridge National Laboratory Report ORNL/TM-6368 (May 1978).

150. Bellis, R.J., and Z.A. Sabri, Fusion Power: Status and Options, Electric Power Research Institute Report EPRI ER-510-SR (1977).

151. Young, J.R., An Envirormental Analysis of Fusion Power to Determine Rezated $R$ and $D$ Needs, Battelle Northwest Laboratories Report BNWL 2010 (Nov. 1976).

152. Evaluation of Environmental Control Technologies for Magnetic Fields, U.S. Dept. nf Energy Report DOE/EV-0029 (1978).

153. Kellermeyer, D.A., Climate and Energy: A Comparative Assessment of the SPS and other Energy Alternative6, II.S. Dept. of Encrgy RepuiL DOL/ERUUSU (Jan. 1980).

154. Mitche11, J.M., A Reassessment of Atmospheric Pollution ae a Causi if Long-term Changes of Giobal Temperature, In S.F. Singer (ed.), The Changing Global Environment, D. Reidel, Publisher (1975).

155. Wang, w.t., et w1., Grosnhoube iffects Due to Man-Made Perturbations of Trace Gases, Science, 194:685-690 (1976).

156. Kramer, M.L., et al., Cooling Towers and the Envirorment, J. Air Poll. Contr. Asso., 25:582-584 (1976).

157. Ramsde11, J.V., et a1., Postulated Weather Modification Effects of Large Energy Releases, Battelle Pacific Northwest Laboratories Report BNWL-2162 (1977). 
158. Lee, J.L., D.M. Rote, and H.D. Orville, Workshop on Meteorological Effects of Satellite Power System Rectenna Operation, August 23-25, 1978, Chicago, I11., Bullet in of the American Meteorological Society, 60 (11) (Nov. 1979).

159. Final Envirormental Statement by the U.S. Nuclear Regulatory Commission for Black Fox Station, Units 1 and 2, proposed by Public Service Company of OkZahoma, NUREG-0176 (Feb. 1977).

160. Energy Conversion AZternatives Study (ECAS) General Electric Phase II Final Report: Volume II, Advanced Energy Conversion Systems: Conceptual Designs: Part 4, Summary of Results, NASA-CR 134949, (G.E. Report No. SRD-76-064-2) (Dec. 1976).

161. Evaluation of Phase 2 Conceptual Designs and Implementation Assessment Resulting from the Energy Conversion Alternatives Study (ECAS), NASA TM X-73515, NASA/Lewis Research Center (Apr. 1977).

162. Solar Power Satellite Baseline Review, NASA/MSFC and NASA/JSC, Washington, D.C. (June 5, 1979).

163. Brobst, D.A., and W.P. Pratt (eds.), United States Mineral Resources, U.S. Geological Survey Professional Paper No. 820, U.S. Government Printing office (1973).

164. Mineral Facts and Problems, Bureau of Mines, U.S. Dept. of the Interior (1976).

165. Office of Emergency Preparedness, List of Strategic and Critical Materials, Federal Register, Vol. 37, No. 39 (Feb. 26, 1972).

166. Kotin, A.D., Satellite Power System (SPS) Resource Requirements (Critical Materials, Energy, and Land), U.S. Dept. of Energy Report HCP/R-4024-02 (Oct. 1978).

167. Gallagher, J.M., et al., Resource Requirements, Impacts and Potential Constraints Associated with Various Energy Futures, Bechtel Corp. $\overrightarrow{\mathrm{PAE}}$ 3794-6 (March 1977).

168. Watts, R.L., et al., Some Potential Material Supply Constraints in the Deployment of Photovoltaic Solar Electric Systems: (A Preliminary Screening to Identify (ritical Materials), Battelle Pacific Northwest Laboratory, (Sept. 1978).

169. Cirillo, R.R., et al., Comparative Analysis of Net Energy Balance of Satellite Power Systems and Other Energy Systems, U.S. Dept. of Energy Report DOE/ER-0056 (Apr. 1980).

170. Herendeen, R.A., and C.W. Bullard III, Energy Costs of Goods and Services, 1963 and 1967, Center for Advanced Computation, Univ. of Illinois at Urbana-Champaign CAC Document No. 140 (Nov. 1974). 
171. Livingston, F.R., et al., Satellite Power System Preliminary Resource Assessment, Rev. A, Jet Propuls ion Laboratory Document No. 900-805 (Aug. 7, 1978).

172. Herendeen, R.A., T. Kary, and J. Rebitzer, Energy Analysis of. the Solar Power Satellite, Science, 205(4405):451-454 (Aug. 3,.1979).

173. Frabetti, A.J., Jr., et al., Application of Net Energy Analysis to Consumer Technologies, Development Sciences, Inc. Report DSI 047 (Dec. 22, 1976).

174. Bloomquist, C.E., A Survey of Satellite Power Stations, Planning Research Corporation Report DSE/2071-1 (Sept. 1976).

175. Keview Group on Design and Construction Project Leadtimes, Licensing, Debign, and Construction Problems: Priorities for Solution, 8, Atomic Industrial Forum, Inc. (Jan. 1978).

176. Breyer, S., Analyzing Regulatory Failure: Mismatches, Less Restrictive Alternatives, and Reform, Harvard Law Review, 92(3):549-609 (Jan. 1979).

177. Page, T., A Generic View of Toxic Chemicals and Similar Risks, Ecology Law Quarterly, 7(207) (1978).

178. Kemeny, J.G., et al., Report of the President's Commission on the Accident at Three Mile Island. The Need for Change: The Legacy of T.M.I., U.S. Government Printing Office (Oct. 31, 1979).

179. An Analysis of Federal Incentives Used to Stimulate Energy Production, Battelle Pacific Northwest Laboratory (Dec. 1978).

180. Special Analysis: Federal Funding for Activities Concernod with Coal Fi.ecal. Yeare 1870, 1980, National Coal Association (June 18, 1979).

181. Cost Impact Analysis of Selected Provisions of the Office of Surface Mining Permanent Regulatory Program, Consolidation Coal Company, Denver, Colo. (June 1979).

182. Cost of Goverrment Regulation Study for the Business Roundtable, Arthur Anderson \& Co., Washington, D.C. (March 1979).

183. United States General Accounting office, Nuclear Costs and Subsidise, Report by the Comptroller General of the United States, Washington, D.C. (June 13, 1979).

184. Price Anderson Act, P.L. 85-256, 71 Stat. 576 (Sept. 2, 1957).

185. Naisbitt, J., Satellite Power System (SPS): Centralization/ Decentralization, DOE/NASA Report HCP/R-4024-09 (Oct; 1978).

186. Political and Legal Implications of Developing and Operating a Satellite Power System, ECON, Inc. Report 77-195-1. (Aug. 15, 1977). 
195

187. Satellite Power System (SPS) International Agreements, U.S. Dept. of Energy Report HCP/R-4024-8 (Oct. 1978).

188. Satellite Power System (SPS) International Agreements, U.S. Dept. of Energy Report HCP/R-4024-12 (Oct. 1978).

189. Kotin, A.D., Satellite Power System (SPS): State and Local Regulations as Applied to Satellite Rower System Microwave Receiving Antenna Facilities, DOE/NASA Report HCP/R-4024-05 (Oct. 1978).

if U.S. GOVERNMENT PRINTING OFFICE: $1981-341 \cdot 060: 2004$ 
THIRD CLASS MAI

Official Business

Penalty for Private Use, $\$ 300$ 